\title{
Prenatal stress and the fetal gut
}

Citation for published version (APA):

Nikiforou, M. (2016). Prenatal stress and the fetal gut: potential interventions to prevent adverse outcomes. [Doctoral Thesis, Maastricht University]. CPI - Wöhrmann Print Service. https://doi.org/10.26481/dis.20161220mn

Document status and date:

Published: 01/01/2016

DOI:

10.26481/dis.20161220mn

Document Version:

Publisher's PDF, also known as Version of record

\section{Please check the document version of this publication:}

- A submitted manuscript is the version of the article upon submission and before peer-review. There can be important differences between the submitted version and the official published version of record.

People interested in the research are advised to contact the author for the final version of the publication, or visit the DOI to the publisher's website.

- The final author version and the galley proof are versions of the publication after peer review.

- The final published version features the final layout of the paper including the volume, issue and page numbers.

Link to publication

\footnotetext{
General rights rights.

- You may freely distribute the URL identifying the publication in the public portal. please follow below link for the End User Agreement:

www.umlib.nl/taverne-license

Take down policy

If you believe that this document breaches copyright please contact us at:

repository@maastrichtuniversity.nl

providing details and we will investigate your claim.
}

Copyright and moral rights for the publications made accessible in the public portal are retained by the authors and/or other copyright owners and it is a condition of accessing publications that users recognise and abide by the legal requirements associated with these

- Users may download and print one copy of any publication from the public portal for the purpose of private study or research.

- You may not further distribute the material or use it for any profit-making activity or commercial gain

If the publication is distributed under the terms of Article $25 \mathrm{fa}$ of the Dutch Copyright Act, indicated by the "Taverne" license above, 


\section{Prenatal stress and the fetal gut:}

\section{Potential interventions to prevent adverse outcomes}

Maria Nikiforou 


\section{Copyright @ Maria Nikiforou, Maastricht 2016.}

All rights reserved. No part of this book may be reproduced, stored in a retrieval system of any nature, or transmitted in any form or by any means without prior written permission of the copyright holder.

Cover Art:

Cover design:

Layout and figure design:

Printed by:

ISBN:
Annelie Solis (www.anneliesolis.com)

Dr. Konstantinos Markakis \& Maria Nikiforou

Maria Nikiforou

CPI Koninklijke Wöhrmann

978-94-6328-122-5 


\title{
Prenatal stress and the fetal gut:
}

\section{Potential interventions to prevent adverse}

\author{
outcomes
}

\section{Dissertation}

to obtain the degree of Doctor at Maastricht University, on the authority of the Rector Magnificus, Prof. Dr. Rianne M. Letschert in accordance with the decision of the Board of Deans, to be defended in public on Tuesday, December $20^{\text {th }} 2016$ at 10 o'clock by

\section{Maria Nikiforou}

Born on April 24 1985 in Athens, Greece 
Supervisors

Prof. Dr. Boris W. Kramer

Prof. Dr. Harry W. M. Steinbusch

\section{Co-supervisor}

Dr. Tim G.A.M. Wolfs

\section{Assessment Committee}

Prof. Dr. Marc H. V. de Baets (Chairman)

Prof. Dr. Paul H. M. Savelkoul

Prof. Dr. Marc E. A. Spaanderman

Prof. Dr. Mathias W. Hornef, RWTH Aachen

Prof. Dr. Aletta D. Kraneveld, Universiteit Utrecht 


\section{Table of Contents}

\section{Chapter 1}

General Introduction ................................................................................ 7

\section{Chapter 2}

Selective IL-1 $\alpha$ exposure to the fetal gut, lung and chorioamnion/skin causes intestinal inflammatory and developmental changes in fetal sheep

\section{Chapter 3}

Prophylactic interleukin-2 treatment prevents fetal gut inflammation and injury in an ovine model of chorioamnionitis

\section{Chapter 4}

Intra-amniotic Candida albicans infection induces mucosal injury and inflammation in the ovine fetal intestine

\section{Chapter 5}

Global hypoxia-ischemia induced inflammation and structural changes in the preterm ovine gut which were not ameliorated by mesenchymal stem cell treatment

\section{Chapter 6}

General Discussion

\section{Chapter 7}

Summary \& Samenvatting.

\section{Chapter 8}

Valorization

\section{Appendices}

List of Abbreviations ....................................................................................... 205

Acknowledgements ............................................................................... 213

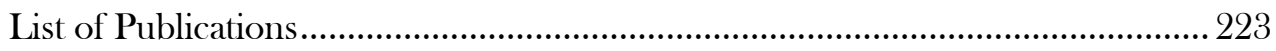

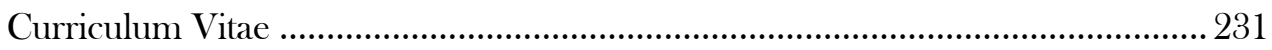





\section{Chapter 1}

\section{General Introduction}





\section{Preterm Birth}

Preterm birth is defined as delivery before 37 completed weeks of gestation and is the leading cause of neonatal morbidity and mortality (1). The World Health Organization (WHO) estimates that worldwide one in every 10 births are preterm accounting for approximately 15 million prematurely delivered babies each year (2). Over one million of these newborns will die shortly after birth due to complications of prematurity $(1,3)$. Many of the survivors will suffer from lifelong gastrointestinal and neurological sequelae such as altered intestinal motility, motor and learning disabilities (4). These detrimental outcomes are associated with a severe impact on emotional and financial status of patients, their families, caregivers and society (5).

Over the last decades, the incidence of preterm birth appears to have increased (6) and is accompanied by decreased mortality rates $(7,8)$. This decline in neonatal deaths is considered to be the result of new therapeutic interventions such as administration of maternal corticosteroids and postnatal surfactant replacement therapy that have been developed and implemented in the guidelines of clinical practice in the past decades (9-11). Pregnant women at high risk of preterm birth receive antenatal corticosteroids aiming at improving fetal lung maturation thereby decreasing the chances of developing respiratory distress syndrome (RDS) and related postnatal complications (11). Both maternal corticosteroids and surfactant replacement treatment have been associated with improved neonatal outcome such as reduced incidence of RDS, intraventricular haemorrhage, necrotizing enterocolitis (NEC) and infant's death $(11,12)$.

\section{Causes of Preterm Birth}

Preterm delivery can be classified in the following three categories with specific features: i) preterm labor with intact membranes ii) preterm premature rupture of the membranes (PPROM) and iii) induced preterm labor or the infant is delivered by caesarean section based on maternal or fetal indications. The first two categories are classified as spontaneous preterm birth whereas the third category is classified as 
indicated preterm birth (13). There are several pathological processes that can lead to spontaneous preterm labor including i) breakdown of maternal-fetal tolerance ii) uterine overdistension, iii) maternal stress iv) vascular disorders and v) intrauterine infection and/or inflammation $(14,15)$. In cases of a preterm labor due to maternal-fetal medical indication, fetal hypoxia-ischemia is the most common cause of premature delivery.

\section{Chorioamnionitis and perinatal asphyxia}

The increased risk of neonatal morbidity and mortality following preterm birth can be further aggravated by chorioamnionitis and perinatal asphyxia, which are independent risk factors for postnatal pathologies $(16,17)$. Chorioamnionitis is an infection related complication which involves pathogens or pathogen-related products. In contrast, perinatal asphyxia induces tissue hypoxia-ischemia to the fetus/neonate. Although the origin of the initial trigger differs, both pathologies share common inflammatory features which remain largely unexplored $(6,18,19)$. In the studies described in this thesis we aimed to understand the underlying inflammatory responses and developmental processes in the fetal gut associated with these two pathologies. In addition, we studied the potential of in utero therapeutic interventions to prevent intestinal injury.

\section{Chorioamnionitis}

Chorioamnionitis, defined as an inflammation of the chorion, amnion and the amniotic fluid, is one of the most frequent causes of preterm labor. One in every four premature infants is born by a mother diagnosed with intrauterine inflammation (14, 20). Chorioamnionitis is inversely correlated to gestational age with the highest incidence in the most immature infants (21). Approximately, $60 \%$ of preterm births below 25 weeks of gestation are associated with chorioamnionitis $(22,23)$.

A large proportion of chorioamnionitis cases remain clinically silent without distinct symptoms during pregnancy. In particular, chorioamnionitis is diagnosed by culture of the amniotic fluid, to identify possible microbial infection, and by histological 
examination of the placenta after birth which is considered as the "gold standard" for the diagnosis of intrauterine inflammation $(15,24)$. In severe cases of chorioamnionitis, the pregnant woman might develop the following clinical symptoms: fever, maternal tachycardia, increased plasma levels of C-reactive protein, uterine tenderness and malodorous vaginal discharge which is known as clinical chorioamnionitis (24, 25). In $30 \%$ of chorioamnionitis cases, bacteria are found in the fetal circulation leading to a fetal inflammatory response, which is classically referred to as "fetal inflammatory response syndrome" (FIRS). This response is characterized by systemic inflammation, funisitis, fetal vasculitis and elevated plasma concentration of pro-inflammatory cytokines such as interleukin (IL)-6, which is the hallmark of FIRS (26-29).

\section{Pathophysiology and treatment regimen of chorioamnionitis}

Chorioamnionitis is caused by microbial colonization of the uterine cavity. Microorganisms can invade the amniotic cavity by i) an ascending route from the vagina and cervix ii) haematogenous dissemination through the placenta iii) introduction during invasive procedures in regular prenatal examination and iv) retrograde spread through the fallopian tubes $(13,25)$. The ascending route is considered the most common pathway of infection since microbiomes isolated from the amniotic cavity constitute the commensal flora of the female genital tract (14). Chorioamnionitis is a multi-bacterial disease involving E.coli, Fusobacterium, Streptococcus, Bacteroides, Gardnerella spp, Ureaplasma spp (Ureaplasma urealyticum and Ureaplasma parvum) and Mycoplasma spp (Mycoplasma hominis), with the latter two being the most commonly identified (30-35). Although rare, evidence associates fungi and viruses in the pathogenesis of intra-uterine infection $(32,36-38)$. With an incidence range of 0 $5 \%$, Candida spp are one of the most frequently identified fungi in the amniotic fluid of pregnancies affected by chorioamnionitis (32, 39). Intra-amniotic (IA) Candida infection is associated with high morbidity and mortality rates (40-42).

Currently, upon diagnosis of clinical chorioamnionitis, immediate antibiotic administration to the mother, antipyretics and delivery of the fetus is recommended 
(16). Two retrospective studies have shown that this treatment management reduced maternal and neonatal complications after chorioamnionitis. Although there is a wide spectrum of antibiotics against bacteria available, there is lack of evidence to favor a specific antibiotic treatment over another. In addition, there is lack of a standardized treatment regime against viruses or Candida albicans (C.albicans)-mediated chorioamnionitis. The latter is highly susceptible to the anti-fungal drug fluconazole, which is well tolerated by the fetus after the first trimester and has been recently explored in two clinical cases (43). Nevertheless, there is limited clinical data to strongly support the efficacy of a specific antibiotic or anti-fungal treatment regimen in the course of chorioamnionitis (44), emphasizing the need to explore such a therapeutic strategy.

Experimental evidence indicates that the sequence of ascending microbial invasion of the amniotic cavity begins with infection of the choriodecidual or chorioamnion space by microorganism(s) from the lower genital tract (Figure 1, letter a). Subsequently, the organism gains access to the amniotic cavity and infects both the fetus and amniotic fluid (Figure 1, letter b). This infection precedes the wide spread of the microorganism into the choriodecidual space and the concomitant inflammatory response detected in the fetal membranes (Figure 1, letter c) (45, 46). Nevertheless, evidence has been provided that localized infection in the fetal membranes can trigger an inflammatory cascade in the amniotic fluid without an established IA infection (47). Once the microorganism is present in the choriodecidual membranes and amniotic cavity, microbial-related endotoxins and their products can be recognized by innate immune receptors including toll like receptors (TLRs) which are expressed by several cells such as leukocytes and epithelial cells (26). Such immune sensing ultimately results in production of cytokines, chemokines, interleukins such as IL-1, IL-6 and prostaglandins within the decidua and fetal membranes, progressing towards the process of labor $(14,19,48)$. Moreover, the microorganisms and their associated toxic and inflammatory components which are present in the contaminated amniotic fluid, can directly interact with the external fetal epithelial surfaces (such as the skin (49)) and with the internal surfaces by swallowing and breathing movements (Figure 1, letter d). 
In addition, inflammatory cell transfer from the infected/inflamed placenta (Figure 1, letter e) to the fetus is an alternative route of fetal exposure to inflammatory mediators. Accordingly, in utero microbial-induced inflammation can affect multiple fetal organs leading to postnatal adverse neonatal outcomes (Figure 1) (24, 26, 50).

\section{Consequences of Chorioamnionitis}

Chorioamnionitis is associated with severe developmental adverse outcomes not only during neonatal but also in early childhood $(51,52)$. Human and experimental data indicate that intra-uterine inflammation leads to heart dysfunction with babies displaying decreased mean and diastolic blood pressure (26). Heart malfunction is associated with reduced cerebral blood flow which might predispose the infant to develop adverse cerebral outcomes. Brain injury following chorioamnionitis has been documented in several studies which have shown that there is significant impairment of brain development and neuronal function leading to mental retardation, learning disability and cerebral palsy. In addition, chorioamnionitis can affect the fetal lung, the first organ which is essentially involved in the physiological transition of the fetus to extra uterine life. Studies have shown that fetuses exposed to inflammatory conditions in utero have increased risk of develop adverse pulmonary outcomes not only in early postnatal life but also in adulthood such as asthma $(26,53)$.

Among the most severe, life-threatening postnatal adverse effects of chorioamnionitis is NEC, which can develop irrespectively to fetal gestational age and antenatal corticosteroids treatment (54-56). NEC's clinical features can vary from mild/moderate symptoms such as feeding intolerance, vomiting and abdominal distention to severe symptoms such as sepsis, metabolic shock and apnea (57). Accordingly, NEC's mortality rate is $20-40 \%$ with survivors frequently suffering from long term negative sequelae (58). As chorioamnionitis alters the amniotic environment, the fetal gut becomes predisposed to develop NEC either by the presence of the actual microorganisms in the fetal intestines or by the immunological and structural changes that occur in the fetal gut following intrauterine inflammation (57). 


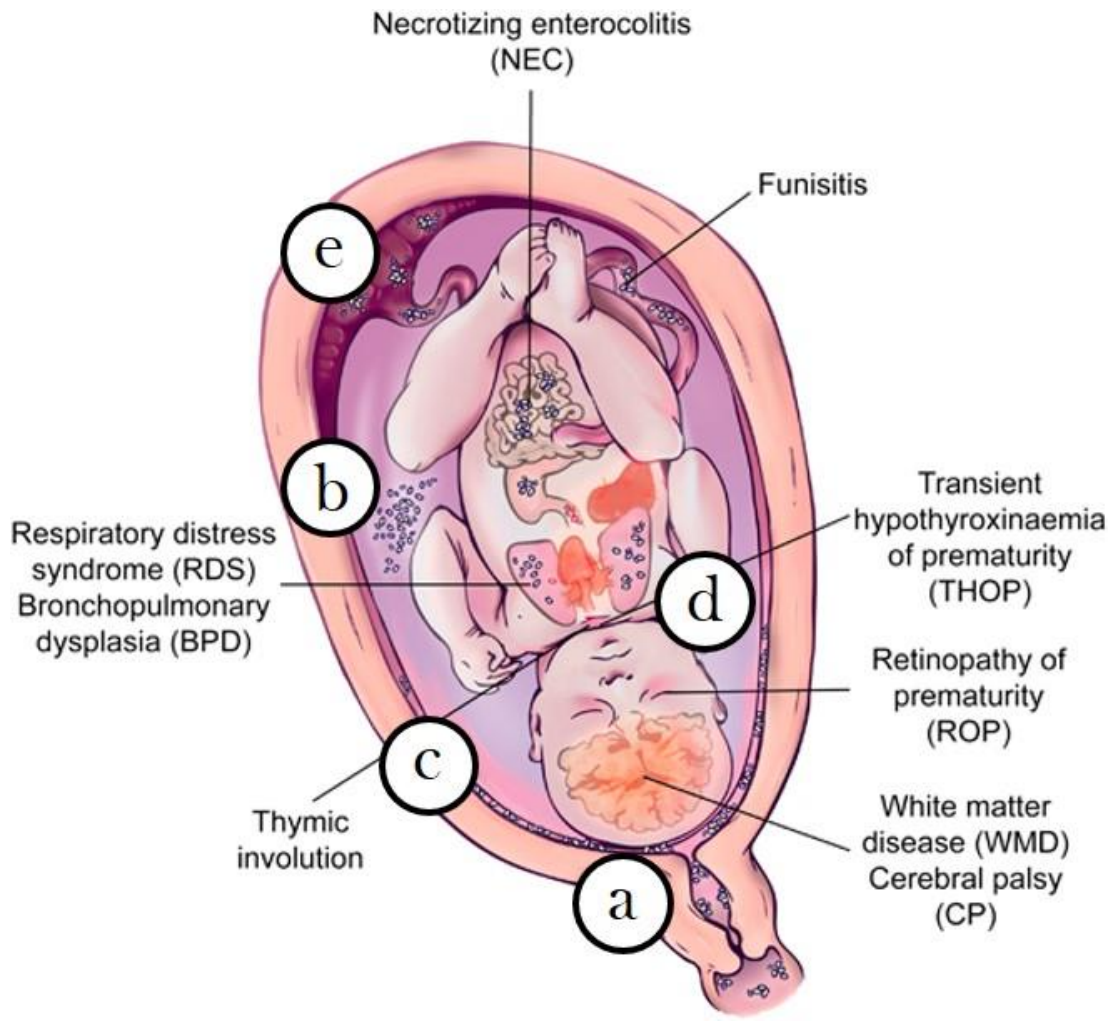

Figure 1. Chorioamnionitis affects multiple fetal organs and is associated with postnatal adverse outcomes. (a) Ascending microbial invasion from the lower genital tract to choriodecidual or chorioamnion space. (b) The organism gains access to the amniotic cavity. (c) The microorganism widely spreads into the choriodecidual space and provokes an inflammatory response in fetal membranes. (d) Pathogen and/or their associated toxic and inflammatory components can directly interact with the external and internal (swallowing and breathing movements) fetal epithelial surfaces. (e) Alternatively, the fetus is exposed to inflammatory mediators via inflammatory cell transfer from the infected/inflamed placenta. Adapted from Gantert et al. (24).

Although there is evidence that clearly links chorioamnionitis with postnatal adverse effects on several organs (such as the fetal lung, gut, brain, thymus, heart, liver, immune system, eyes etc.) (24), the exact mechanisms underlying this association warrant additional research. 


\section{Chorioamnionitis, FIRS and mucosal inflammatory responses}

To elucidate the fundamental mechanisms that may explain the impact of antenatal infection on fetal organ development, research has been conducted in animal models of chorioamnionitis (46). Studies have demonstrated that inflammatory responses following IA exposure to infection are fundamentally involved in adverse outcomes of the fetal organs. Experimentally, it has been shown that lung inflammation in fetal sheep is evident within a few hours after IA exposure to bacteria and/or inflammatory stimuli. In addition to pulmonary immune responses, chorioamnionitis resulted in structural changes of the fetal lung and FIRS, which were inhibited by blocking IL-1 signaling.

Another mucosal organ that is affected by chorioamnionitis is the fetal skin. Being the largest epithelial surface that is in direct contact with the contaminated and/or pro-inflammatory amniotic fluid, the fetal skin displays an inflammatory response already at 12 hours post IA exposure to LPS in fetal sheep that is driven by neutrophils, T cells and subsequent secretion of cytokines such as IL-1 $\beta$ and IL-6 (49). The fetal skin expresses TLRs which can sense components of the microbiomes that have invaded the amniotic cavity in the course of chorioamnionitis thereby activating the fetal immune system resulting in FIRS (46).

The mucosal surface of the fetal gut is also exposed to the contaminated amniotic fluid in the course of chorioamnionitis leading to an intestinal immune response which is evident as early as 2 days post IA exposure to inflammatory stimuli in fetal sheep. Experimental findings demonstrate that IA exposure to IL-1, LPS or Ureaplasma parvum can provoke an intestinal inflammatory response which is dominated by increased $\mathrm{CD}_{3}^{+}$and $\mathrm{CD} 4^{+} \mathrm{T}$ lymphocytes and myeloperoxidase (MPO) cells in conjunction with a storm of cytokines including IFN- $\gamma$, TNF- $\alpha$, IL-17, and IL-6 in the fetal ovine gut $(59,60)$. The influx of inflammatory cells was preceded by decreased frequencies of FoxP3 ${ }^{+}$(Treg) cells in the fetal gut which resulted in a disturbed intestinal regulatory/effector $\mathrm{T}$ (Treg/Teff) cell balance following chorioamnionitis (59). This chorioamnionitis-induced inflammatory response in the 
fetal gut was associated with loss of epithelial barrier integrity and impaired intestinal development by altering enterocytic proliferation, differentiation and maturation thereby causing severe villus atrophy, which was shown to be IL-1 dependent (61).

An intestinal Treg/Teff cell imbalance has also been found in samples from infants who developed NEC (62), which emphasizes the essential role of Treg cells in preserving intestinal immune homeostasis (63). Treg cells are identified as $\mathrm{CD} 4 \mathrm{CD} 25 \mathrm{FoxP}^{+} \mathrm{T}$ cells and are highly positive for $\mathrm{CD} 25$, which is the $\alpha$-chain of IL2 receptor. The development and function of these cells depends on the expression of FoxP3, which is a transcriptional regulatory factor and the most well characterized marker for Treg cells (64). CD4 CD25 FoxP3 ${ }^{+}$expressing Treg cells orchestrate the immune responses by generally suppressing uncontrolled immune responses and restricting unnecessary Teff cell expansion (65-67). Low numbers and/or impaired function of Treg cells are associated with several immune-mediated pathologies including infectious diseases, autoimmunity and inflammatory bowel disease (65). Treg cells can originate either from the thymus, known as natural occurring Treg cells, or from naive peripheral $\mathrm{CD} 4{ }^{+} \mathrm{T}$ cells that can differentiate into $\mathrm{CD} 4 \mathrm{CD} 25 \mathrm{FoxP} 3{ }^{+}$Treg cells when are stimulated with tumour growth factor (TGF)- $\beta$ and IL-2, known as inducible Treg cells $(64,68-70)$. Treg cells express all three chains of IL-2R complex (IL-2R $\alpha$ : CD25, IL-2R $\beta$ : CD122 and IL-2R $\gamma$ : CD132, or the $\gamma c$ common chain), enable them to create the high affinity IL-2 receptor (71). IL-2 is required for survival, expansion, activity and maintenance of Treg cells and IL-2 administration has been associated with attenuation of multiple immune-mediated diseases (71-73). Therefore, IL-2 is a potential tool to modulate immune responses by augmenting Treg cells which may have therapeutic value by suppressing Teff cell function and related inflammatory processes (74) in the context of chorioamnionitis.

\section{Perinatal asphyxia}

The second cause of fetal inflammation which is studied in this thesis is perinatal asphyxia. Perinatal asphyxia occurs around birth, with asphyxia (from the 
Greek word " $\alpha \sigma \varphi v \xi \xi^{\prime} \alpha$ ") referring to the absence of pulsation. Perinatal asphyxia is defined as a condition of impaired gas exchange that precedes or continues immediately at birth leading to progressive hypoxia (low oxygen concentration), hypercapnia (accumulation of carbon dioxide) and metabolic acidosis (75-78). Prolonged hypoxia results in tissue ischemia which is defined as inadequate blood supply to the fetal organs. Therefore, the term hypoxia-ischemia (HI) better describes the pathophysiology of asphyxia.

The incidence of perinatal asphyxia is estimated between 1 and 2 per 1000 births each year worldwide (79), with enormous variation in this prevalence depending on the geographic localization and socio-economic status of the corresponding region $(80,81)$. Globally the WHO estimates that each year around 9 million children (younger than 5 years old) die and approximately 4 million of them die during the neonatal period (82). Among these babies, perinatal asphyxia is responsible for $23 \%$ neonatal deaths accounting for around one million dead infants each year (82-84), and approximately an equal number of neonates who will survive and have high risk to develop severe lifelong motor and cognitive disabilities with subsequent socio-economic implications and impacts (79).

Fetal HI can be the result of i) pre-placental hypoxia, where both the mother and fetus are hypoxic ii) utero-placental hypoxia, where oxygen levels on the mother are normal but the utero-placental oxygenation is impaired and iii) post-placental hypoxia, where only the fetus is hypoxic (85). In case of pre-placental hypoxia, maternal heart disease and hypotension can lead to limited oxygen delivery to the fetus with concomitant adverse pregnancy outcomes. Conditions of fetal hypoxia are related to placental insufficiency causing intrauterine growth restriction (IUGR). In case of uteroplacental hypoxia, fetal hypoxia can be caused by abnormal placental implantation, preeclampsia or HELLP syndrome (Hemolysis, Elevated Liver enzymes, Low Platelet count) as well as by placenta abruption. Finally, in case of post-placental hypoxia, inadequate umbilical cord flow (due to umbilical cord prolapse or compression) and cardiac failure can lead to fetal HI $(75,85)$. 
There are several maternal and fetal risk factors responsible for perinatal asphyxia. Maternal characteristics such as civil status, maternal age (>40 years), overweight, and infertility treatment are associated with perinatal asphyxia $(86,87)$. In addition, prenatal viral infections, antepartum hemorrhage, placental malfunction, inadequate antenatal health care, poor nutrition during pregnancy and intrauterine growth restriction are correlated with higher incidence of asphyxia $(80,86,88)$. During parturition, the most frequent causes of perinatal asphyxia depend on risk factors associated with fetal condition and mode of delivery including prematurity, breech delivery, multiple births and umbilical cord complications (80, 86, 89, 90). Higher prevalence of perinatal asphyxia has been linked to insufficient medical care at births during night compared to daytime-associated substandard care (80).

\section{Consequences of perinatal asphyxia}

Perinatal asphyxia can have adverse effects on multiple fetal organs. During asphyxia, the blood flow is redistributed, with selective perfusion to essential organs such as the brain and heart at the expense of other "non-vital" organs such as the adrenals, muscles and the gut, a phenomenon known as "diving seal reflex" (91, 92). Although vascular resistance can be decreased (at minimum 50\%) to preserve cerebral blood flow with a minimal decrease in oxygen delivery, this compensatory mechanism will eventually fail (in case of prolonged asphyxia) resulting in brain injury (93). The fetal brain is the organ that is most severely affected by asphyxia leading to the development of hypoxic-ischemic encephalopathy (HIE) (94). Depending on the severity of asphyxia, 25-50\% preterm neonates with HIE develop cognitive and behavioral disorders and 5-10\% suffer from severe motor deficits (95-98). Severe damage to the central nervous system (CNS) in the majority of the cases is accompanied by hypoxic-ischemic injury in other organs whereas moderate injury to CNS involves fewer cases of peripheral organ damage (93). Acute kidney injury occurs in 30-56\% neonates with perinatal asphyxia leading to renal failure (99). Additional fetal organs that may be detrimentally affected by asphyxia include the lungs with high risk for 
persistent pulmonary hypertension of the newborn (PPHN) (100), the liver with higher prevalence of hepatic dysfunction (101), the heart with increased incidence of ventricular tachycardia (102) and myocardial infarction (103) and the gastrointestinal tract with an increased risk for NEC (91).

\section{Pathophysiology of hypoxic-ischemic injury}

The degree of cell dysfunction and damage depends on both the severity (magnitude) and the duration of HI (104). During HI, the cell adapts to anaerobic metabolism to maintain its needs for energy. During this process, excess production of hydrogen ions into the cell forces the $\mathrm{Na}^{+} / \mathrm{H}^{+}$channels to excrete hydrogen ions causing influx of sodium ions into the cell (104). These HI-induced cellular changes result in reduced intracellular $\mathrm{pH}$, depletion of ATP (adenosine triphosphate) with concomitant dysfunction of ATPases (i.e. sodium/potassium ATPase pump), reduced capacity to effectively discharge the $\mathrm{Ca}^{+*}$ and restricted ability of endoplasmic reticulum (ER) to recruit the calcium, thereby facilitating calcium accumulation in the cytosol. The subsequent opening of the mitochondrial permeability transition pore leads to defective ATP generation thereby further limiting ATP availability (104). These cellular alterations are followed by activation of $\mathrm{Ca}^{+*}$ dependent proteases and endonucleases which degrade intracellular proteins including cytoskeletal, ER and mitochondrial proteins leading to cell death. Upon cell injury, release of pro-inflammatory mediators in the microenvironment, known as damage-associated molecular patterns (DAMPs) such as DNA, heat shock and extracellular matrix proteins, are recognized by the innate immune system and provoke an inflammatory response by antigen presenting cells (APC) $(105,106)$. This inflammatory reaction is known as "sterile inflammation" since the inciting stimulus of immune activation does not involve pathogenic microorganisms. Inflammation is also triggered upon HI by induction of hypoxia inducible factor (HIF)dependent genes. HIF is activated when there is inadequate oxygen supply leading to transcription of HIF-associated inflammatory genes including those belonging to nuclear factor $\kappa \mathrm{B}(\mathrm{NF}-\mathrm{\kappa} \mathrm{B})$ and TLRs signaling pathways, which facilitate the induction 
of antimicrobial factors, phagocytosis, leukocyte recruitment and adaptive immune responses $(107,108)$.

The final outcome of tissue subjected to HI depends on two components that work synergistically in the induction of cellular injury: i) the damaging effects of the HI per se and ii) the injury induced by re-establishment of blood supply and subsequent oxygen levels in the hypoxic-ischemic tissue. This phenomenon is known as reperfusion injury and is considered to further exacerbate tissue damage (104). There are several factors responsible for tissue reperfusion injury including reactive oxygen species (ROS) that are generated once the blood flow is restored and oxygen has been reintroduced to the tissues, excess of calcium, secretion of cytokines and chemokines by the endothelium and tissue macrophages, activation and recruitment of neutrophils and innate and adaptive immune responses triggered by a plethora of DAMPs (109). Nevertheless, organ-specific characteristics define the magnitude, severity, sensibility and reversibility of organ injury $(104,110)$.

\section{Hypoxia-ischemia and adverse intestinal outcomes}

In the clinic, neonates with perinatal HI have decreased perfusion of the gastrointestinal tract and reduced intestinal motility which results in feeding intolerance. Infants who suffered from perinatal HI may develop GI bleeding, vomiting, diarrhea, and are associated with increased incidence of NEC (111). Experimentally, it has been shown that exposure of fetal sheep to global HI directed the distribution of blood flow away from the fetal intestine which resulted in persistent gastrointestinal hypoperfusion, as measured by the rate of blood flow in superior mesenteric artery (SMA) $(112,113)$. Nevertheless, the underlying mechanisms which could explain the impact of perinatal HI on fetal gut development remain largely unexplored.

Experimental evidence from models of transient SMA occlusion in adult rodents indicates that inflammation plays a crucial role in HI-induced intestinal injury. This HI-mediated inflammatory response is characterized by accumulation of inflammatory cells and leakage across epithelial and vascular barrier (114). In addition 
to immune activation, intestinal HI induced by SMA occlusion, resulted in muscle degeneration, neuronal damage and epithelial loss leading to impaired gut barrier integrity (115-120). A compromised mucosal barrier following intestinal HI can lead to translocation of bacteria to the systemic circulation and peripheral organs such as lymph nodes and spleen thereby increasing the risk for sepsis and multi-organ failure (115). Although these animal models provide insights into the pathological characteristics of HI-induced intestinal injury, they do not precisely recapitulate the clinical scenario of perinatal HI, where a global rather than a local HI event is responsible for the adverse effects on the fetal gut. Therefore, further research is needed to unravel the fundamental mechanisms which could elucidate the impact of global HI on fetal gut development.

\section{Treatment options for perinatal asphyxia}

Despite the severe adverse outcomes of perinatal HI on neonatal organ development, treatment options are limited for asphyxiated infants. Currently, the only therapeutic intervention for these neonates is hypothermia (121). Lowering body's temperature to $33.5^{\circ} \mathrm{C}$ is considered to reduce the metabolic activity and energy need of the fetal organs in conjunction with suppressed activity of reactive oxygen species, and inflammatory processes thereby protecting the fetal organs $(78,122,123)$. Although hypothermia has beneficial effects on neurodevelopment and gastrointestinal morbidity in cases of HI in term and late preterm infants $(111,124)$, it cannot be applied in early premature neonates (125), since they cannot tolerate the reduction in metabolic activity without adverse effects, which emphasizes the need for new therapeutic interventions for this vulnerable population.

In the past decade, stem cell therapy has been proposed as an innovative approach for HI-induced brain injury in neonates (126-128). Stem cell therapy might be especially beneficial for treating i) severe cases of perinatal asphyxia and ii) early preterm asphyxiated babies where the current therapeutic strategy is not applicable. Mesenchymal stem cells (MSCs) are usually isolated from bone marrow but they can also be harvested from umbilical cord and placenta $(129,130)$. MSCs have the ability 
to self-renew and differentiate in a plethora of cells of mesodermal origin such as connective stromal cell, cartilage, fat and bone cell but they can also differentiate into cells of ectodermal (epithelial cell and neuron) and endodermal (lung, gut epithelial and muscle cell) lineages (131). MSCs are a promising candidate for cell-based therapy since these cells have the capacity to migrate and differentiate in damaging areas and excrete paracrine molecules that facilitate repairing mechanisms and suppress inflammation (129). More precisely, MSCs can suppress both innate and adaptive immune responses, and stimulate the proliferation and differentiation of regulatory $\mathrm{T}$ cells, which are responsible for preserving immune homeostasis $(132,133)$. In addition, MSCs can protect the damaged tissue by secretion of growth factors (Vascular endothelial growth factor; VEGF, insulin-like growth factor - 1; IGF-1 and epidermal growth factor; EGF) and immune mediators such prostaglandin E2 (PGE2), TGF- $\beta$ and IL-10. As MSCs possess anti-inflammatory properties, they have been utilized for the treatment of inflammatory diseases in humans such as graft versus host disease and inflammatory bowel disease and in animal models of NEC and HI-induced intestinal injury (134-139).

\section{Translational animal models}

In the past years translational research has been proven fundamental to understand and unravel the pathophysiological mechanisms underlying chorioamnionitis and perinatal asphyxia on fetal organ development. These models enable investigators to expose fetuses to specific stimuli for a defined time, length and at a specified developmental stage during pregnancy. A plethora of different species have been used to investigate the impact of chorioamnionitis on fetal organ development including rats (140), mice (141), rabbits (142-144), guinea pigs (145, 146), rhesus macaques $(147,148)$ and sheep (149). Similarly, experimental models of perinatal asphyxia in mice (150), rats $(151,152)$, pigs $(75)$, non-human primates (153) and sheep $(97,154)$ have been developed to address the effects of perinatal asphyxia on fetal development. Although these models offer a tremendous opportunity to study the mechanisms involved in these pathologies, they do not always accurately simulate 
the human situation due to distinct developmental differences between humans and animals (155).

The development of the fetal rhesus macaques closely resembles human development (156). However, ethical and financial considerations restrict the use of non-human primate animal model. The use of fetal sheep as an animal model is widely accepted and most importantly, the developmental processes that occur in the ovine lungs, brain and intestine during gestation are highly similar to human situation (Figure 2) (157).

Intestinal crypt and villus formation of the human and ovine intestine occurs prenatally whereas in rodents, these anatomical structures develop almost near term in gestation or even postnatally (157). Furthermore, lung alveolarization and white matter maturation of the fetal brain in humans and sheep evolve prenatally whereas in rodents, these developmental components are established postnatally (157). In addition, the relative long gestational period in sheep (term at $\sim 147$ days) makes investigation of fetal pathologies at selected gestational/maturational stages and for longer periods of time feasible. Collectively, the ovine fetus is an attractive preclinical animal model to study the effects of chorioamnionitis and perinatal asphyxia on organ development. 
A intestinal villus formation

B intestinal crypt formation

$$
\text { C } \underset{\text { alveolarization }}{\text { lung }}
$$

D cerebral white
matter
myelination

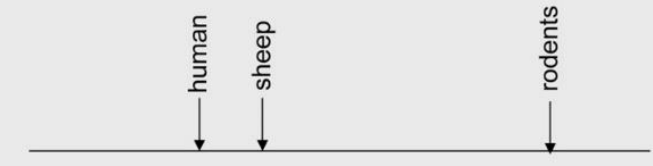

$0 \%$ $100 \%$

postnatal
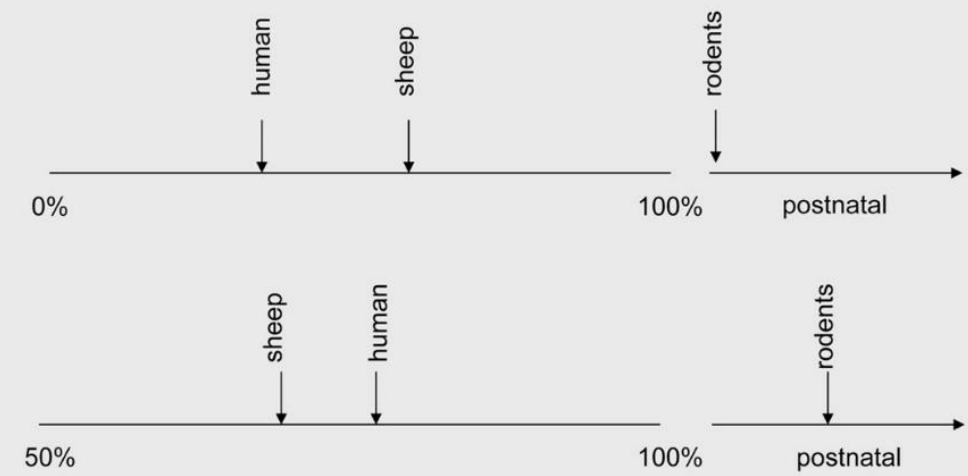

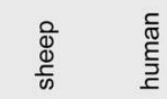

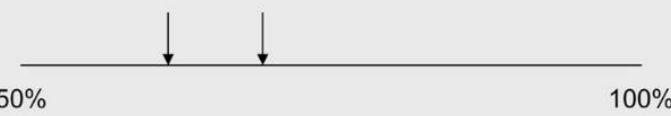

$100 \%$

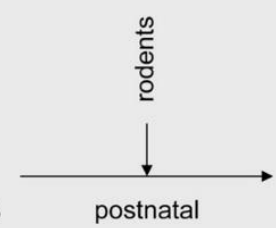

percent of completed gestation

Figure 2. Distinct developmental hallmarks in fetal gut (A, B), lung (C) and brain (D) during gestation in humans, sheep and rodents (157). 


\section{Outline of the thesis}

The aim of the current thesis was to provide insights in the intestinal pathological changes induced by chorioamnionitis and prenatal HI, and explore new therapeutic strategies to prevent adverse intestinal outcomes associated with these pathologies.

In our ovine chorioamnionitis model, we have shown that the adverse intestinal outcomes caused by chorioamnionitis were the combined result of local gut and pulmonary-driven systemic immune responses. In addition, IL-1 signaling appeared to be essential in antenatal inflammation as chorioamnionitis-induced gut inflammation and damage were largely prevented by blocking IL-1 signaling. Therefore in chapter 2 , we evaluated the effects of local (i.e. gut-derived) IL-1 $\alpha$ signaling or extraintestinal IL$1 \alpha$-driven immune responses (i.e. lung or chorioamnion/skin-derived) on intestinal outcomes in the course of experimental chorioamnionitis.

In the same translational model, chorioamnionitis-induced intestinal inflammation was characterized by depletion of Treg cells and accumulation of Teff cells, which decreased the Treg/Teff cell ratio (59). This Treg/Teff cell imbalance was accompanied by impaired barrier integrity and intestinal maturation. Therefore in chapter 3, our aim was to restore the Treg/Teff imbalance by prophylactic IL-2 treatment and to investigate whether this was sufficient to prevent chorioamnionitisinduced intestinal inflammation and mucosal injury.

Although chorioamnionitis is commonly caused by bacterial infection of the uterine cavity, fungi and especially C.albicans, is also associated with chorioamnionitis. Therefore in chapter 4, we used our ovine model of chorioamnionitis to assess whether IA exposure to C.albicans would induce fetal gut inflammation and mucosal injury. In addition, we tested whether fluconazole, the most frequently used anti-fungal drug, could attenuate the potential adverse intestinal effects caused by chorioamnionitis.

Although perinatal $\mathrm{HI}$ is associated with adverse postnatal intestinal outcomes, no antenatal studies have been conducted to investigate the underlying mechanisms by which global HI could provoke adverse effects on the fetal gut. Experimental evidence 
from adult animal models of locally-induced intestinal $\mathrm{HI}$ has shown that inflammation is essential in HI-induced injury of the gut. Importantly, MSC treatment prevented this HI-induced intestinal damage. Therefore in chapter 5, we used our preclinical animal model to investigate whether global HI induced inflammation, injury and developmental changes in the fetal gut and whether intravenous MSC administration ameliorated these HI-induced adverse intestinal effects.

In chapter 6, the major findings of this thesis in conjunction with potential implications for future research are discussed. 


\section{References}

1. Blencowe $\mathrm{H}$, Cousens $\mathrm{S}$. Addressing the challenge of neonatal mortality. Trop Med Int Health 2013;18:303-312.

2. Howson CP, Kinney MV, McDougall L, Lawn JE. Born too soon: preterm birth matters. Reprod Health 2013;10 Suppl 1:S1.

3. Blencowe H, Cousens S, Oestergaard MZ, Chou D, Moller AB, Narwal R, Adler A, Vera Garcia C, Rohde S, Say L, Lawn JE. National, regional, and worldwide estimates of preterm birth rates in the year 2010 with time trends since 1990 for selected countries: a systematic analysis and implications. Lancet 2012;379:2162-2172.

4. Lee AC, Kozuki N, Blencowe H, Vos T, Bahalim A, Darmstadt GL, Niermeyer S, Ellis M, Robertson NJ, Cousens S, Lawn JE. Intrapartum-related neonatal encephalopathy incidence and impairment at regional and global levels for 2010 with trends from 1990. Pediatr Res 2013;74 Suppl 1:50-72.

5. Hodek JM, von der Schulenburg JM, Mittendorf T. Measuring economic consequences of preterm birth - Methodological recommendations for the evaluation of personal burden on children and their caregivers. Health Econ Rev 2011;1:6.

6. McAdams RM, Juul SE. The role of cytokines and inflammatory cells in perinatal brain injury. Neurol Res Int 2012;2012:561494.

7. Costeloe KL, Hennessy EM, Haider S, Stacey F, Marlow N, Draper ES. Short term outcomes after extreme preterm birth in England: comparison of two birth cohorts in 1995 and 2006 (the EPICure studies). Bmj 2012;345:e7976.

8. Patel RM, Kandefer S, Walsh MC, Bell EF, Carlo WA, Laptook AR, Sanchez PJ, Shankaran S, Van Meurs KP, Ball MB, Hale EC, Newman NS, Das A, Higgins RD, Stoll BJ. Causes and timing of death in extremely premature infants from 2000 through 2011. N Engl J Med 2015;372:331-340.

9. Wapner RJ. Antenatal corticosteroids for periviable birth. Semin Perinatol 2013;37:410-413.

10. Tan MY, To M. Recent advances in the prevention and management of preterm birth. F1000Prime Rep 2015;7:40.

11. Greenough A, Ahmed N. Perinatal prevention of bronchopulmonary dysplasia. J Perinat Med 2013;41:119-126.

12. Walsh BK, Daigle B, DiBlasi RM, Restrepo RD. AARC Clinical Practice Guideline. Surfactant replacement therapy: 2013. Respir Care 2013;58:367-375.

13. Goldenberg RL, Culhane JF, Iams JD, Romero R. Epidemiology and causes of preterm birth. Lancet 2008;371:75-84.

14. Romero R, Dey SK, Fisher SJ. Preterm labor: one syndrome, many causes. Science 2014;345:760-765. 
15. Erdemir G, Kultursay N, Calkavur S, Zekioglu O, Koroglu OA, Cakmak B, Yalaz M, Akisu M, Sagol S. Histological chorioamnionitis: effects on premature delivery and neonatal prognosis. Pediatr Neonatol 2013;54:267-274.

16. Czikk MJ, McCarthy FP, Murphy KE. Chorioamnionitis: from pathogenesis to treatment. Clin Microbiol Infect 2011;17:1304-1311.

17. Aslam HM, Saleem S, Afzal R, Iqbal U, Saleem SM, Shaikh MW, Shahid N. "Risk factors of birth asphyxia". Ital J Pediatr 2014;40:94.

18. Okazaki K KT, Kusaka T, Kondo M, Kimura H Pathophysiological Roles of Cytokines in the Brain During Perinatal Asphyxia. Ann Pediatr Child Health 2015;3:1030.

19. Kemp MW. Preterm birth, intrauterine infection, and fetal inflammation. Front Immunol 2014;5:574.

20. Horvath B, Lakatos F, Toth C, Bodecs T, Bodis J. Silent chorioamnionitis and associated pregnancy outcomes: a review of clinical data gathered over a 16-year period. J Perinat Med 2014;42:441-447.

21. Lahra MM, Jeffery HE. A fetal response to chorioamnionitis is associated with early survival after preterm birth. Am J Obstet Gynecol 2004;190:147-151.

22. Goldenberg RL, Hauth JC, Andrews WW. Intrauterine infection and preterm delivery. N Engl J Med 2000;342:1500-1507.

23. Romero R, Espinoza J, Chaiworapongsa T, Kalache K. Infection and prematurity and the role of preventive strategies. Semin Neonatol 2002;7:259-274.

24. Gantert M, Been JV, Gavilanes AW, Garnier Y, Zimmermann LJ, Kramer BW. Chorioamnionitis: a multiorgan disease of the fetus? J Perinatol 2010;30 Suppl:S21-30.

25. Tita AT, Andrews WW. Diagnosis and management of clinical chorioamnionitis. Clin Perinatol 2010;37:339-354.

26. Galinsky R, Polglase GR, Hooper SB, Black MJ, Moss TJ. The consequences of chorioamnionitis: preterm birth and effects on development. J Pregnancy 2013;2013:412831.

27. Gotsch F, Romero R, Kusanovic JP, Mazaki-Tovi S, Pineles BL, Erez O, Espinoza J, Hassan SS. The fetal inflammatory response syndrome. Clin Obstet Gynecol 2007;50:652-683.

28. Madsen-Bouterse SA, Romero R, Tarca AL, Kusanovic JP, Espinoza J, Kim CJ, Kim JS, Edwin SS, Gomez R, Draghici S. The transcriptome of the fetal inflammatory response syndrome. Am J Reprod Immunol 2010;63:73-92.

29. Chiesa C, Pacifico L, Natale F, Hofer N, Osborn JF, Resch B. Fetal and early neonatal interleukin-6 response. Cytokine 2015;76:1-12. 
30. Kwak DW, Hwang HS, Kwon JY, Park YW, Kim YH. Co-infection with vaginal Ureaplasma urealyticum and Mycoplasma hominis increases adverse pregnancy outcomes in patients with preterm labor or preterm premature rupture of membranes. J Matern Fetal Neonatal Med 2014;27:333-337.

31. Romero R, Miranda J, Chaiworapongsa T, Chaemsaithong P, Gotsch F, Dong Z, Ahmed AI, Yoon BH, Hassan SS, Kim CJ, Korzeniewski SJ, Yeo L. A novel molecular microbiologic technique for the rapid diagnosis of microbial invasion of the amniotic cavity and intra-amniotic infection in preterm labor with intact membranes. Am J Reprod Immunol 2014;71:330-358.

32. Payne MS, Bayatibojakhi S. Exploring preterm birth as a polymicrobial disease: an overview of the uterine microbiome. Front Immunol 2014;5:595.

33. Martinez-Lopez DG, Funderburg NT, Cerissi A, Rifaie R, Aviles-Medina L, Llorens-Bonilla BJ, Sleasman J, Luciano AA. Lipopolysaccharide and soluble CD14 in cord blood plasma are associated with prematurity and chorioamnionitis. Pediatr Res 2014;75:67-74.

34. Ericson JE, Laughon MM. Chorioamnionitis: implications for the neonate. Clin Perinatol 2015;42:155-165, ix.

35. Musilova I, Pliskova L, Kutova R, Hornychova H, Jacobsson B, Kacerovsky M. Ureaplasma species and Mycoplasma hominis in cervical fluid of pregnancies complicated by preterm prelabor rupture of membranes. J Matern Fetal Neonatal Med 2015:1-7.

36. Vrachnis N, Vitoratos N, Iliodromiti Z, Sifakis S, Deligeoroglou E, Creatsas G. Intrauterine inflammation and preterm delivery. Ann N Y Acad Sci 2010;1205:118122.

37. DiGiulio DB, Romero R, Amogan HP, Kusanovic JP, Bik EM, Gotsch F, Kim CJ, Erez O, Edwin S, Relman DA. Microbial prevalence, diversity and abundance in amniotic fluid during preterm labor: a molecular and culture-based investigation. PLoS One 2008;3:e3056.

38. Ozer E, Unlu M, Ersen A, Gulekli B. Intrauterine fetal loss associated with Candida glabrata chorioamnionitis: report of two cases. Turk Patoloji Derg 2013;29:7779.

39. Combs CA, Gravett M, Garite TJ, Hickok DE, Lapidus J, Porreco R, Rael J, Grove T, Morgan TK, Clewell W, Miller H, Luthy D, Pereira L, Nageotte M, Robilio PA, Fortunato S, Simhan H, Baxter JK, Amon E, Franco A, Trofatter K, Heyborne K. Amniotic fluid infection, inflammation, and colonization in preterm labor with intact membranes. Am J Obstet Gynecol 2014;210:125 e121-125 e115.

40. Darmstadt GL, Dinulos JG, Miller Z. Congenital cutaneous candidiasis: clinical presentation, pathogenesis, and management guidelines. Pediatrics 2000;105:438-444. 
41. Meizoso T, Rivera T, Fernandez-Acenero MJ, Mestre MJ, Garrido M, Garaulet C. Intrauterine candidiasis: report of four cases. Arch Gynecol Obstet 2008;278:173-176.

42. Benjamin DK, Jr., Stoll BJ, Fanaroff AA, McDonald SA, Oh W, Higgins RD, Duara S, Poole K, Laptook A, Goldberg R. Neonatal candidiasis among extremely low birth weight infants: risk factors, mortality rates, and neurodevelopmental outcomes at 18 to 22 months. Pediatrics 2006;117:84-92.

43. Bean LM, Jackson JR, Dobak WJ, Beiswenger TR, Thorp JA. Intra-amniotic fluconazole therapy for Candida albicans intra-amniotic infection. Obstet Gynecol 2013;121:452-454.

44. Chapman E, Reveiz L, Illanes E, Bonfill Cosp X. Antibiotic regimens for management of intra-amniotic infection. Cochrane Database Syst Rev 2014;12:CD010976.

45. Kim MJ, Romero R, Gervasi MT, Kim JS, Yoo W, Lee DC, Mittal P, Erez O, Kusanovic JP, Hassan SS, Kim CJ. Widespread microbial invasion of the chorioamniotic membranes is a consequence and not a cause of intra-amniotic infection. Lab Invest 2009;89:924-936.

46. Kallapur SG, Presicce P, Rueda CM, Jobe AH, Chougnet CA. Fetal immune response to chorioamnionitis. Semin Reprod Med 2014;32:56-67.

47. Adams Waldorf KM, Gravett MG, McAdams RM, Paolella LJ, Gough GM, Carl DJ, Bansal A, Liggitt HD, Kapur RP, Reitz FB, Rubens CE. Choriodecidual group $\mathrm{B}$ streptococcal inoculation induces fetal lung injury without intra-amniotic infection and preterm labor in Macaca nemestrina. PLoS One 2011;6:e28972.

48. Burdet J, Rubio AP, Salazar AI, Ribeiro ML, Ibarra C, Franchi AM. Inflammation, infection and preterm birth. Curr Pharm Des 2014;20:4741-4748.

49. Zhang L, Saito M, Jobe A, Kallapur SG, Newnham JP, Cox T, Kramer B, Yang $\mathrm{H}$, Kemp MW. Intra-amniotic administration of $\mathrm{E}$ coli lipopolysaccharides causes sustained inflammation of the fetal skin in sheep. Reprod Sci 2012;19:1181-1189.

50. Elovitz MA, Mrinalini C. Animal models of preterm birth. Trends Endocrinol Metab 2004;15:479-487.

51. Getahun D, Strickland D, Zeiger RS, Fassett MJ, Chen W, Rhoads GG, Jacobsen SJ. Effect of chorioamnionitis on early childhood asthma. Arch Pediatr Adolesc Med 2010;164:187-192.

52. Kumar R, Yu Y, Story RE, Pongracic JA, Gupta R, Pearson C, Ortiz K, Bauchner HC, Wang X. Prematurity, chorioamnionitis, and the development of recurrent wheezing: a prospective birth cohort study. J Allergy Clin Immunol 2008;121:878-884 e876. 
53. Adams Waldorf KM, McAdams RM. Influence of infection during pregnancy on fetal development. Reproduction 2013;146:R151-162.

54. Been JV, Lievense S, Zimmermann LJ, Kramer BW, Wolfs TG. Chorioamnionitis as a risk factor for necrotizing enterocolitis: a systematic review and meta-analysis. J Pediatr 2013;162:236-242 e232.

55. Seliga-Siwecka JP, Kornacka MK. Neonatal outcome of preterm infants born to mothers with abnormal genital tract colonisation and chorioamnionitis: a cohort study. Early Hum Dev 2013;89:271-275.

56. Lau J, Magee F, Qiu Z, Hoube J, Von Dadelszen P, Lee SK. Chorioamnionitis with a fetal inflammatory response is associated with higher neonatal mortality, morbidity, and resource use than chorioamnionitis displaying a maternal inflammatory response only. Am J Obstet Gynecol 2005;193:708-713.

57. Coggins SA, Wynn JL, Weitkamp JH. Infectious causes of necrotizing enterocolitis. Clin Perinatol 2015;42:133-154, ix.

58. Sharma R, Hudak ML. A clinical perspective of necrotizing enterocolitis: past, present, and future. Clin Perinatol 2013;40:27-51.

59. Wolfs TG, Kallapur SG, Polglase GR, Pillow JJ, Nitsos I, Newnham JP, Chougnet CA, Kroon E, Spierings J, Willems CH, Jobe AH, Kramer BW. IL-1alpha mediated chorioamnionitis induces depletion of $\mathrm{FoxP} 3+$ cells and ileal inflammation in the ovine fetal gut. PLoS One 2011;6:e18355.

60. Wolfs TG, Buurman WA, Zoer B, Moonen RM, Derikx JP, Thuijls G, Villamor E, Gantert M, Garnier Y, Zimmermann LJ, Kramer BW. Endotoxin induced chorioamnionitis prevents intestinal development during gestation in fetal sheep. PLoS One 2009; 4:e5837.

61. Wolfs TG, Kallapur SG, Knox CL, Thuijls G, Nitsos I, Polglase GR, Collins JJ, Kroon E, Spierings J, Shroyer NF, Newnham JP, Jobe AH, Kramer BW. Antenatal ureaplasma infection impairs development of the fetal ovine gut in an IL-1-dependent manner. Mucosal Immunol 2013;6:547-556.

62. Weitkamp JH, Koyama T, Rock MT, Correa H, Goettel JA, Matta P, OswaldRichter K, Rosen MJ, Engelhardt BG, Moore DJ, Polk DB. Necrotising enterocolitis is characterised by disrupted immune regulation and diminished mucosal regulatory (FOXP3)/effector (CD4, CD8) T cell ratios. Gut 2013;62:73-82.

63. Izcue A, Coombes JL, Powrie F. Regulatory T cells suppress systemic and mucosal immune activation to control intestinal inflammation. Immunol Rev 2006;212:256-271.

64. Liao W, Lin JX, Leonard WJ. Interleukin-2 at the crossroads of effector responses, tolerance, and immunotherapy. Immunity 2013;38:13-25. 
65. Sakaguchi S, Yamaguchi T, Nomura T, Ono M. Regulatory T cells and immune tolerance. Cell 2008;133:775-787.

66. Yamaguchi T, Wing JB, Sakaguchi S. Two modes of immune suppression by Foxp3(+) regulatory $\mathrm{T}$ cells under inflammatory or non-inflammatory conditions. Semin Immunol 2011;23:424-430.

67. Sakaguchi S, Miyara M, Costantino CM, Hafler DA. FOXP3+ regulatory T cells in the human immune system. Nat Rev Immunol 2010;10:490-500.

68. Malek TR. The biology of interleukin-2. Annu Rev Immunol 2008;26:453479 .

69. Cesana GC, DeRaffele G, Cohen S, Moroziewicz D, Mitcham J, Stoutenburg J, Cheung K, Hesdorffer C, Kim-Schulze S, Kaufman HL. Characterization of $\mathrm{CD} 4+\mathrm{CD} 25+$ regulatory $\mathrm{T}$ cells in patients treated with high-dose interleukin-2 for metastatic melanoma or renal cell carcinoma. J Clin Oncol 2006;24:1169-1177.

70. Gaffen SL, Liu KD. Overview of interleukin-2 function, production and clinical applications. Cytokine 2004;28:109-123.

71. Shevach EM. Application of IL-2 therapy to target T regulatory cell function. Trends Immunol 2012;33:626-632.

72. Matsuoka K, Koreth J, Kim HT, Bascug G, McDonough S, Kawano Y, Murase K, Cutler C, Ho VT, Alyea EP, Armand P, Blazar BR, Antin JH, Soiffer RJ, Ritz J. Low-dose interleukin-2 therapy restores regulatory $\mathrm{T}$ cell homeostasis in patients with chronic graft-versus-host disease. Sci Transl Med 2013;5:179ra143.

73. Boyman O, Sprent J. The role of interleukin-2 during homeostasis and activation of the immune system. Nat Rev Immunol 2012;12:180-190.

74. Sakaguchi S, Wing K, Onishi Y, Prieto-Martin P, Yamaguchi T. Regulatory T cells: how do they suppress immune responses? Int Immunol 2009;21:1105-1111.

75. Alonso-Spilsbury M, Mota-Rojas D, Villanueva-Garcia D, Martinez-Burnes J, Orozco H, Ramirez-Necoechea R, Mayagoitia AL, Trujillo ME. Perinatal asphyxia pathophysiology in pig and human: a review. Anim Reprod Sci 2005;90:1-30.

76. Berglund S, Norman M, Grunewald C, Pettersson H, Cnattingius S. Neonatal resuscitation after severe asphyxia--a critical evaluation of 177 Swedish cases. Acta Paediatr 2008;97:714-719.

77. Halloran DR, McClure E, Chakraborty H, Chomba E, Wright LL, Carlo WA. Birth asphyxia survivors in a developing country. J Perinatol 2009;29:243-249.

78. Pfister RH, Soll RF. Hypothermia for the treatment of infants with hypoxicischemic encephalopathy. J Perinatol 2010;30 Suppl:S82-87.

79. Heringhaus A, Blom MD, Wigert H. Becoming a parent to a child with birth asphyxia-From a traumatic delivery to living with the experience at home. Int J Qual Stud Health Well-being 2013;8:1-13. 
80. Golubnitschaja O, Yeghiazaryan K, Cebioglu M, Morelli M, Herrera-Marschitz M. Birth asphyxia as the major complication in newborns: moving towards improved individual outcomes by prediction, targeted prevention and tailored medical care. Epma J 2011;2:197-210.

81. Graham EM, Ruis KA, Hartman AL, Northington FJ, Fox HE. A systematic review of the role of intrapartum hypoxia-ischemia in the causation of neonatal encephalopathy. Am J Obstet Gynecol 2008;199:587-595.

82. Black RE, Cousens S, Johnson HL, Lawn JE, Rudan I, Bassani DG, Jha P, Campbell H, Walker CF, Cibulskis R, Eisele T, Liu L, Mathers C. Global, regional, and national causes of child mortality in 2008: a systematic analysis. Lancet 2010;375:1969-1987.

83. Lawn JE, Kerber K, Enweronu-Laryea C, Cousens S. 3.6 million neonatal deaths--what is progressing and what is not? Semin Perinatol 2010;34:371-386.

84. S Dongol JS, S Shrestha, A Shakya. Clinical Profile of Birth Asphyxia in Dhulikhel Hospital: A Retrospective Study. NEPAS 2010;30:141-146.

85. Hutter D, Kingdom J, Jaeggi E. Causes and mechanisms of intrauterine hypoxia and its impact on the fetal cardiovascular system: a review. Int J Pediatr 2010;2010:401323.

86. Berglund S, Grunewald C, Pettersson H, Cnattingius S. Risk factors for asphyxia associated with substandard care during labor. Acta Obstet Gynecol Scand 2010;89:39-48.

87. Milsom I, Ladfors L, Thiringer K, Niklasson A, Odeback A, Thornberg E. Influence of maternal, obstetric and fetal risk factors on the prevalence of birth asphyxia at term in a Swedish urban population. Acta Obstet Gynecol Scand 2002;81:909-917.

88. Majeed R, Memon Y, Majeed F, Shaikh NP, Rajar UD. Risk factors of birth asphyxia. J Ayub Med Coll Abbottabad 2007;19:67-71.

89. Nauman Kiyani A, Khushdil A, Ehsan A. Perinatal Factors Leading to Birth Asphyxia among Term Newborns in a Tertiary Care Hospital. Iran J Pediatr 2014;24:637-642.

90. Lee AC, Mullany LC, Tielsch JM, Katz J, Khatry SK, LeClerq SC, Adhikari RK, Shrestha SR, Darmstadt GL. Risk factors for neonatal mortality due to birth asphyxia in southern Nepal: a prospective, community-based cohort study. Pediatrics 2008;121:e1381-1390.

91. Young CM, Kingma SD, Neu J. Ischemia-reperfusion and neonatal intestinal injury. J Pediatr 2011;158:e25-28.

92. Chhavi N, Zutshi K, Singh NK, Awasthi A, Goel A. Serum liver enzyme pattern in birth asphyxia associated liver injury. Pediatr Gastroenterol Hepatol Nutr 2014;17:162-169. 
93. Perlman JM. Interruption of placental blood flow during labor: potential systemic and cerebral organ consequences. J Pediatr 2011;158:e1-4.

94. van Handel M, Swaab H, de Vries LS, Jongmans MJ. Long-term cognitive and behavioral consequences of neonatal encephalopathy following perinatal asphyxia: a review. Eur J Pediatr 2007;166:645-654.

95. Volpe JJ. Brain injury in premature infants: a complex amalgam of destructive and developmental disturbances. Lancet Neurol 2009;8:110-124.

96. Volpe JJ. The encephalopathy of prematurity--brain injury and impaired brain development inextricably intertwined. Semin Pediatr Neurol 2009;16:167-178.

97. Jellema RK, Lima Passos V, Zwanenburg A, Ophelders DR, De Munter S, Vanderlocht J, Germeraad WT, Kuypers E, Collins JJ, Cleutjens JP, Jennekens W, Gavilanes AW, Seehase M, Vles HJ, Steinbusch H, Andriessen P, Wolfs TG, Kramer BW. Cerebral inflammation and mobilization of the peripheral immune system following global hypoxia-ischemia in preterm sheep. J Neuroinflammation 2013;10:13. 98. Armstrong-Wells J, Bernard TJ, Boada R, Manco-Johnson M. Neurocognitive outcomes following neonatal encephalopathy. NeuroRehabilitation 2010;26:27-33.

99. Durkan AM, Alexander RT. Acute kidney injury post neonatal asphyxia. J Pediatr 2011;158:e29-33.

100. Lapointe A, Barrington KJ. Pulmonary hypertension and the asphyxiated newborn. J Pediatr 2011;158:e19-24.

101. Choudhary M, Sharma D, Dabi D, Lamba M, Pandita A, Shastri S. Hepatic dysfunction in asphyxiated neonates: prospective case-controlled study. Clin Med Insights Pediatr 2015;9:1-6.

102. Nirupam N, Nangia S, Saili A. Ventricular tachycardia due to perinatal asphyxia. Indian Pediatr 2014;51:227-228.

103. Dattilo G, Tulino V, Tulino D, Lamari A, Falanga G, Marte F, Patane S. Perinatal asphyxia and cardiac abnormalities. Int J Cardiol 2011;147:e39-40.

104. Kalogeris T, Baines CP, Krenz M, Korthuis RJ. Cell biology of ischemia/reperfusion injury. Int Rev Cell Mol Biol 2012;298:229-317.

105. Rock KL, Latz E, Ontiveros F, Kono H. The sterile inflammatory response. Annu Rev Immunol 2010;28:321-342.

106. Kono H, Onda A, Yanagida T. Molecular determinants of sterile inflammation. Curr Opin Immunol 2014;26:147-156.

107. Eltzschig HK, Carmeliet P. Hypoxia and inflammation. N Engl J Med 2011;364:656-665.

108. Eltzschig HK, Bratton DL, Colgan SP. Targeting hypoxia signalling for the treatment of ischaemic and inflammatory diseases. Nat Rev Drug Discov 2014;13:852869. 
109. Shen H, Kreisel D, Goldstein DR. Processes of sterile inflammation. J Immunol 2013;191:2857-2863.

110. Collard CD, Gelman S. Pathophysiology, clinical manifestations, and prevention of ischemia-reperfusion injury. Anesthesiology 2001;94:1133-1138.

111. Thornton KM, Dai H, Septer S, Petrikin JE. Effects of whole body therapeutic hypothermia on gastrointestinal morbidity and feeding tolerance in infants with hypoxic ischemic encephalopathy. Int J Pediatr 2014;2014:643689.

112. Bennet L, Quaedackers JS, Gunn AJ, Rossenrode S, Heineman E. The effect of asphyxia on superior mesenteric artery blood flow in the premature sheep fetus. J Pediatr Surg 2000;35:34-40.

113. Quaedackers JS, Roelfsema V, Heineman E, Gunn AJ, Bennet L. The role of the sympathetic nervous system in postasphyxial intestinal hypoperfusion in the preterm sheep fetus. J Physiol 2004;557:1033-1044.

114. Grenz A, Clambey E, Eltzschig HK. Hypoxia signaling during intestinal ischemia and inflammation. Curr Opin Crit Care 2012;18:178-185.

115. Ozban M, Aydin C, Cevahir N, Yenisey C, Birsen O, Gumrukcu G, Aydin B, Berber I. The effect of melatonin on bacterial translocation following ischemia/reperfusion injury in a rat model of superior mesenteric artery occlusion. BMC Surg 2015;15:18.

116. Gan X, Xing D, Su G, Li S, Luo C, Irwin MG, Xia Z, Li H, Hei Z. Propofol Attenuates Small Intestinal Ischemia Reperfusion Injury through Inhibiting NADPH Oxidase Mediated Mast Cell Activation. Oxid Med Cell Longev 2015;2015:167014.

117. Hale Sayan-Ozacmaka VHO, , Inci Turana, Figen Barutb, Volkan Hancic. Pretreatment with remifentanil protects against the reduced-intestinal contractility related to the ischemia and reperfusion injury in rat. Rev Bras Anestesio 2014;http://dx.doi.org/10.1016/j.bjane.2013.09.007

118. Evennett N, Cerigioni E, Hall NJ, Pierro A, Eaton S. Smooth muscle actin as a novel serologic marker of severe intestinal damage in rat intestinal ischemiareperfusion and human necrotising enterocolitis. J Surg Res 2014;191:323-330.

119. Sise MJ. Acute mesenteric ischemia. Surg Clin North Am 2014;94:165-181.

120. Gonzalez LM, Moeser AJ, Blikslager AT. Animal models of ischemiareperfusion-induced intestinal injury: progress and promise for translational research. Am J Physiol Gastrointest Liver Physiol 2015;308:G63-75.

121. Drury PP, Gunn ER, Bennet L, Gunn AJ. Mechanisms of hypothermic neuroprotection. Clin Perinatol 2014;41:161-175.

122. Wassink G, Gunn ER, Drury PP, Bennet L, Gunn AJ. The mechanisms and treatment of asphyxial encephalopathy. Front Neurosci 2014;8:40. 
123. Drury PP, Bennet L, Gunn AJ. Mechanisms of hypothermic neuroprotection. Semin Fetal Neonatal Med 2010;15:287-292.

124. Jacobs SE, Berg M, Hunt R, Tarnow-Mordi WO, Inder TE, Davis PG. Cooling for newborns with hypoxic ischaemic encephalopathy. Cochrane Database Syst Rev 2013;1:CD003311.

125. Thoresen M. Who should we cool after perinatal asphyxia? Semin Fetal Neonatal Med 2015;20:66-71.

126. Bennet L, Tan S, Van den Heuij L, Derrick M, Groenendaal F, van Bel F, Juul S, Back SA, Northington F, Robertson NJ, Mallard C, Gunn AJ. Cell therapy for neonatal hypoxia-ischemia and cerebral palsy. Ann Neurol 2012;71:589-600.

127. Titomanlio L, Kavelaars A, Dalous J, Mani S, El Ghouzzi V, Heijnen C, Baud $\mathrm{O}$, Gressens P. Stem cell therapy for neonatal brain injury: perspectives and challenges. Ann Neurol 2011;70:698-712.

128. Gortner L, Felderhoff-Muser U, Monz D, Bieback K, Kluter H, Jellema R, Kramer BW, Keller M, Reiss I, Horn PA, Giebel B. Regenerative therapies in neonatology: clinical perspectives. Klin Padiatr 2012;224:233-240.

129. Manieri NA, Stappenbeck TS. Mesenchymal stem cell therapy of intestinal disease: are their effects systemic or localized? Curr Opin Gastroenterol 2011;27:119124 .

130. Portmann-Lanz CB, Schoeberlein A, Huber A, Sager R, Malek A, Holzgreve W, Surbek DV. Placental mesenchymal stem cells as potential autologous graft for preand perinatal neuroregeneration. Am J Obstet Gynecol 2006;194:664-673.

131. Uccelli A, Moretta L, Pistoia V. Mesenchymal stem cells in health and disease. Nat Rev Immunol 2008;8:726-736.

132. Qinjun Zhaoa HR, Zhongchao Han. Mesenchymal stem cells: Immunomodulatory capability and clinical potential in immune diseases Journal of Cellular Immunotherapy 2015;http://dx.doi.org/10.1016/j.jocit.2014.12.001

133. Luz-Crawford P, Kurte M, Bravo-Alegria J, Contreras R, Nova-Lamperti E, Tejedor G, Noel D, Jorgensen C, Figueroa F, Djouad F, Carrion F. Mesenchymal stem cells generate a CD4+CD25+Foxp3+ regulatory $\mathrm{T}$ cell population during the differentiation process of Th1 and Th17 cells. Stem Cell Res Ther 2013;4:65.

134. Newman RE, Yoo D, LeRoux MA, Danilkovitch-Miagkova A. Treatment of inflammatory diseases with mesenchymal stem cells. Inflamm Allergy Drug Targets 2009;8:110-123.

135. Jiang H, Qu L, Li Y, Gu L, Shi Y, Zhang J, Zhu W, Li J. Bone marrow mesenchymal stem cells reduce intestinal ischemia/reperfusion injuries in rats. J Surg Res 2011;168:127-134. 
136. Jiang H, Qu L, Dou R, Lu L, Bian S, Zhu W. Potential role of mesenchymal stem cells in alleviating intestinal ischemia/reperfusion impairment. PLoS One 2013;8:e74468.

137. Tayman C, Uckan D, Kilic E, Ulus AT, Tonbul A, Murat Hirfanoglu I, Helvacioglu F, Haltas H, Koseoglu B, Tatli MM. Mesenchymal stem cell therapy in necrotizing enterocolitis: a rat study. Pediatr Res 2011;70:489-494.

138. Nagaishi K, Arimura Y, Fujimiya M. Stem cell therapy for inflammatory bowel disease. J Gastroenterol 2015;50:280-286.

139. Ringden O, Keating A. Mesenchymal stromal cells as treatment for chronic GVHD. Bone Marrow Transplant 2011;46:163-164.

140. Dell'Ovo V, Rosenzweig J, Burd I, Merabova N, Darbinian N, Goetzl L. An animal model for chorioamnionitis at term. Am J Obstet Gynecol 2015;213:387 e381387 e310.

141. Burd I, Brown A, Gonzalez JM, Chai J, Elovitz MA. A mouse model of term chorioamnionitis: unraveling causes of adverse neurological outcomes. Reprod Sci 2011;18:900-907.

142. Yoon BH, Kim CJ, Romero R, Jun JK, Park KH, Choi ST, Chi JG. Experimentally induced intrauterine infection causes fetal brain white matter lesions in rabbits. Am J Obstet Gynecol 1997;177:797-802.

143. Debillon T, Gras-Leguen C, Verielle V, Winer N, Caillon J, Roze JC, Gressens $\mathrm{P}$. Intrauterine infection induces programmed cell death in rabbit periventricular white matter. Pediatr Res 2000;47:736-742.

144. Launay E, Joram N, Jacqueline C, Miegeville AF, Caillon J, Potel G, Roze JC, Gras-Le Guen C. Efficacy of ciprofloxacin in an experimental model of Escherichia coli chorioamnionitis in rabbits. Antimicrob Agents Chemother 2009;53:1624-1627.

145. Wang B, Navath RS, Menjoge AR, Balakrishnan B, Bellair R, Dai H, Romero R, Kannan S, Kannan RM. Inhibition of bacterial growth and intramniotic infection in a guinea pig model of chorioamnionitis using PAMAM dendrimers. Int J Pharm 2010;395:298-308.

146. Patrick LA, Gaudet LM, Farley AE, Rossiter JP, Tomalty LL, Smith GN. Development of a guinea pig model of chorioamnionitis and fetal brain injury. Am J Obstet Gynecol 2004;191:1205-1211.

147. Kallapur SG, Presicce P, Senthamaraikannan P, Alvarez M, Tarantal AF, Miller LM, Jobe AH, Chougnet CA. Intra-amniotic IL-1 beta induces fetal inflammation in rhesus monkeys and alters the regulatory $\mathrm{T}$ cell/IL-17 balance. J Immunol 2013;191:1102-1109.

148. Presicce P, Senthamaraikannan P, Alvarez M, Rueda CM, Cappelletti M, Miller LA, Jobe AH, Chougnet CA, Kallapur SG. Neutrophil recruitment and 
activation in decidua with intra-amniotic IL-1beta in the preterm rhesus macaque. Biol Reprod 2015;92:56.

149. Kramer BW. Chorioamnionitis - new ideas from experimental models. Neonatology 2011;99:320-325.

150. Fleiss B, Coleman HA, Castillo-Melendez M, Ireland Z, Walker DW, Parkington HC. Effects of birth asphyxia on neonatal hippocampal structure and function in the spiny mouse. Int J Dev Neurosci 2011;29:757-766.

151. Vlassaks E, Nikiforou M, Strackx E, Hutten M, Bekers O, Gazzolo D, Li Volti G, Martinez-Martinez P, Kramer BW, Gavilanes AW. Acute and chronic immunomodulatory changes in rat liver after fetal and perinatal asphyxia. J Dev Orig Health Dis 2014;5:98-108.

152. Herrera-Marschitz M, Neira-Pena T, Rojas-Mancilla E, Espina-Marchant P, Esmar D, Perez R, Munoz V, Gutierrez-Hernandez M, Rivera B, Simola N, Bustamante D, Morales P, Gebicke-Haerter PJ. Perinatal asphyxia: CNS development and deficits with delayed onset. Front Neurosci 2014;8:47.

153. Jacobson Misbe EN, Richards TL, McPherson RJ, Burbacher TM, Juul SE. Perinatal asphyxia in a nonhuman primate model. Dev Neurosci 2011;33:210-221.

154. Koome ME, Davidson JO, Drury PP, Mathai S, Booth LC, Gunn AJ, Bennet L. Antenatal dexamethasone after asphyxia increases neural injury in preterm fetal sheep. PLoS One 2013;8:e77480.

155. Puiman P, Stoll B. Animal models to study neonatal nutrition in humans. Curr Opin Clin Nutr Metab Care 2008;11:601-606.

156. Makori N, Tarantal AF, Lu FX, Rourke T, Marthas ML, McChesney MB, Hendrickx AG, Miller CJ. Functional and morphological development of lymphoid tissues and immune regulatory and effector function in rhesus monkeys: cytokinesecreting cells, immunoglobulin-secreting cells, and CD5(+) B-1 cells appear early in fetal development. Clin Diagn Lab Immunol 2003;10:140-153.

157. Wolfs TG, Jellema RK, Turrisi G, Becucci E, Buonocore G, Kramer BW. Inflammation-induced immune suppression of the fetus: a potential link between chorioamnionitis and postnatal early onset sepsis. J Matern Fetal Neonatal Med 2012;25 Suppl 1:8-11. 
General Introduction 



\title{
Chapter 2
}

\section{Selective IL $-1 \alpha$ exposure to the fetal gut, lung and chorioamnion/skin causes intestinal inflammatory and developmental changes in fetal sheep.}

\author{
Maria Nikiforou, Matthew W. Kemp, Rick H. van Gorp, Masatoshi Saito, John P. \\ Newnham, Niki L. Reynaert, Leon E.W. Janssen, Alan H. Jobe, Suhas G. Kallapur, \\ Boris W. Kramer and Tim G.A.M. Wolfs
}

Lab Invest. 2016 Jan;96(1):69-80 


\section{Abstract}

Chorioamnionitis, caused by intra-amniotic exposure to bacteria and their toxic components, is associated with fetal gut inflammation and mucosal injury. In a translational ovine model, we have shown that these adverse intestinal outcomes to chorioamnionitis were the combined result of local gut and pulmonary driven systemic immune responses. Chorioamnionitis-induced gut inflammation and injury was largely prevented by inhibiting interleukin (IL)-1 signaling. Therefore, we investigated whether local (gut-derived) IL-1 $\alpha$ signaling or systemic IL-1 $\alpha$-driven immune responses (lung or chorioamnion/skin-derived), were sufficient for intestinal inflammation and mucosal injury in the course of chorioamnionitis.

Fetal surgery was performed in sheep to isolate the lung, gastrointestinal tract and chorioamnion/skin and IL-1 $\alpha$ or saline was given into the trachea, stomach or amniotic cavity 1 or 6 days prior to preterm delivery.

Selective IL-1 $\alpha$ exposure to the lung, gut or chorioamnion/skin increased the $\mathrm{CD} 3^{+}$cell numbers in the fetal gut. Direct IL-1 $\alpha$ exposure to the gut impaired intestinal zonula occludens protein-1 expression, induced villus atrophy, changed the expression pattern of intestinal fatty acid binding protein (I-FABP) along the villus and increased the CD68, IL-1 and TNF- $\alpha$ mRNA levels in the fetal ileum. With lung or chorioamnion/skin exposure to IL-1 $\alpha$, intestinal inflammation was associated with increased numbers of blood leukocytes without induction of intestinal injury or immaturity.

We concluded that local IL-1 $\alpha$ signaling was required for intestinal inflammation, disturbed gut maturation and mucosal injury in the context of chorioamnionitis. 


\section{Introduction}

Intrauterine infection is the most frequent cause of preterm birth (1) before 28 weeks of gestation (2). Chorioamnionitis, which is commonly caused by intrauterine bacterial infection, is defined as an inflammation of the fetal membranes, amniotic fluid and placenta (3-5). Bacterial infection of the amniotic cavity results in direct exposure of the lung (by fetal breathing), gastrointestinal tract (by swallowing), skin and chorioamnion to bacteria and their inflammatory components in the contaminated amniotic fluid. The fetal inflammatory response to chorioamnionitis is associated with multi-organ dysfunction $(6,7)$ which increase the incidence of periventricular leukomalacia (8), bronchopulmonary dysplasia (9) and necrotizing enterocolitis (NEC) $(10,11)$.

We have used a translational ovine model of chorioamnionitis to investigate the impact of intrauterine inflammation on fetal organs. Using this model we have shown that intra-amniotic (IA) delivery of E.coli lipopolysaccharide (LPS) resulted in an acute inflammatory response in the chorioamnion and increased influx of inflammatory cells in the respiratory tract within 5 hours (hrs) $(12,13)$. These immune alterations were rapidly followed by systemic inflammation at the same time point and fetal skin inflammation $12 \mathrm{hrs}$ post LPS exposure $(13,14)$. The first signs of intestinal inflammation were detected 2 days after IA delivery of LPS, and this inflammatory response resulted from direct LPS exposure to the gut and pulmonary-induced systemic inflammation (15). Importantly, inhibition of IL-1 signaling with an IL-1 receptor antagonist in our chorioamnionitis model largely prevented fetal organ inflammation and its negative sequelae $(16,17)$. IL-1 signaling is central to antenatal inflammation in multiple animal models (18-20) and IA IL-1 $\alpha$ administration in fetal sheep caused inflammation in the chorioamnion with injury to the respiratory and gastrointestinal tract (21-23). However, it remains unstudied whether local (i.e. gut-derived) IL-1 $\alpha$ signaling or systemic IL-1 $\alpha$-driven immune activation (i.e. lung or chorioamnion/skinderived) is causally involved in intestinal inflammation and mucosal injury from chorioamnionitis. 
To answer this question, we surgically isolated the lung, gastrointestinal tract and chorioamnion/skin in fetal sheep for selective IL-1 $\alpha$ exposure 1 or 6 days prior to preterm delivery. We evaluated the systemic and intestinal immune responses of IL-1 $\alpha$ exposure to the different isolated fetal compartments.

\section{Materials and Methods}

\section{Animals}

All experiments were approved by the Animal Ethics Committee of the University of Western Australia (Perth, WA, Australia) and the Children's Hospital Medical Center (Cincinnati, Ohio, USA).

\section{Experimental procedures and design}

Experimental procedures were performed as previously described (15). Fetal sheep were randomized to experimental groups as defined in Table 1. Fetal surgery was performed at 116 or 121 days of gestational age (GA) (term $\sim 150$ days). Fetuses received either IL-1 $\alpha$ (Protein express, Cincinnati, OH, USA) or saline (Control) at 118 or 123 days GA via a 24 hrs osmotic pump. We used the following doses: $10 \mu \mathrm{g}$ of IL$1 \alpha$ for intra-tracheal infusion, $50 \mu \mathrm{g}$ of IL-1 $\alpha$ for gastrointestinal infusion and $100 \mu \mathrm{g}$ of IL-1 $\alpha$ for intra-amniotic (IA) infusion. A dose of $100 \mu \mathrm{g}$ IL-1 $\alpha$ into the amniotic cavity induces chorioamnionitis and inflammation in the lung and gut with concomitant developmental changes $(21,22)$. Intra-tracheal infusion of IL-1 $\alpha(10 \mu \mathrm{g})$ causes pulmonary inflammation and maturation (24). Since the swallowing volume rate of fetus is about $50 \%$ of the total amniotic volume over $24 \mathrm{hrs}$ (25), a dose of $50 \mu \mathrm{g}$ of IL-1 $\alpha$ was infused to the GI tract. Fetal sheep were surgically delivered at 124 days of gestation and were euthanized with an intravenous bolus of pentobarbitone $(100 \mathrm{mg} / \mathrm{kg}) 1$ or 6 days after IL- $1 \alpha$ or saline infusion.

Isolation of the fetal organs was performed as previously (15). Briefly, fetal lung isolation: a catheter was connected to an osmotic pump to administer IL-1 $\alpha$ or saline for controls. The trachea and esophagus were ligated to prevent contact with the 
amniotic fluid; isolation of the fetal gastrointestinal tract: a catheter was placed via the esophagus into the stomach and an osmotic pump was used to administer IL-1 $\alpha$ or saline for controls. The esophagus was ligated in order to avoid IL-1 $\alpha$ reaching the amniotic fluid; isolation of the fetal snout: selective exposure of IL-1 $\alpha$ in the skin and chorioamnion was achieved by occlusion of the snout with a surgical glove. An osmotic pump was sutured to the fetal skin and delivered IL-1 $\alpha$ or saline for controls.

\section{Cell count measurement in Cord Blood}

Differential cell counts in cord blood were performed by Coulter counter (VetPath Laboratory Services, Ascot, WA, Australia).

Table 1. Summary of experimental groups with fetal compartments exposed to IL-1 $\alpha$ or saline.

\begin{tabular}{lccccc}
\hline & & 1 Day exposure & & 6 Days exposure \\
\cline { 3 - 6 } Procedure & Site of exposure & $\boldsymbol{n}$ & Abbreviation & $\boldsymbol{n}$ & Abbreviation \\
\hline $\begin{array}{l}\text { Lung isolation } \\
\text { tracheal infusion of IL-1 } \alpha\end{array}$ & Lung & 7 & $1 \mathrm{~d}$ lung IL-1 $\alpha$ & 8 & $6 \mathrm{~d}$ lung IL-1 $\alpha$ \\
\hline $\begin{array}{l}\text { Gut isolation } \\
\text { stomach infusion of IL-1 } \alpha\end{array}$ & Gut & 5 & $1 \mathrm{~d}$ gut IL-1 $\alpha$ & 6 & $6 \mathrm{~d}$ gut IL-1 $\alpha$ \\
\hline $\begin{array}{l}\text { Snout occlusion } \\
\text { IA infusion of IL-1 } \alpha\end{array}$ & Amniotic cavity, skin & 5 & $1 \mathrm{~d}$ Ocln IL-1 $\alpha$ & 4 & $6 \mathrm{~d}$ Ocln IL-1 $\alpha$ \\
\hline $\begin{array}{l}\text { Combined controls } \\
\text { infusion of saline }\end{array}$ & $\begin{array}{c}\text { Lung or gut or } \\
\text { chorioamnion/skin }\end{array}$ & 4 & Control & 5 & Control
\end{tabular}

IA: intra-amniotic; IL: interleukin; Ocln: snout occlusion; n: number of animals; * combined control group of all saline treated animals.

\section{Antibodies}

The following antibodies were used: rabbit antibody against human cluster of differentiation 3 (CD3; 1:1000) and myeloperoxidase (MPO; 1:500) both from Dako (Glostrup, Denmark); intestinal fatty acid-binding protein (I-FABP; 1:3000) from Hycultbiotech (Uden, the Netherlands); rabbit antibody against mouse Zonula 
occludens protein 1 (ZO-1, 1:100) from Invitrogen (San Francisco, CA); monoclonal mouse antibody against human FoxP3 (1:250) from Bioscience (San Diego, CA); mouse anti-human Ki-67 (1:100) from DAKO (Glostrup, Denmark) and rabbit antihuman Caspase-3 (1:1000) from Cell Signaling Technology (Danvers, MA). As secondary antibodies, Texas Red conjugated goat anti-rabbit (1:100) from Southern Biotechnology (Birmingham, AL); biotin conjugated swine anti-rabbit (1:200) or goat anti-mouse (1:200) from Dako and peroxidase conjugated goat anti-rabbit (1:200) from Jackson (West Grove, PA) were used. All antibodies were diluted in $0.1 \%$ bovine serum albumin in phosphate buffered saline.

\section{Immunohistochemistry}

Formalin-fixed terminal ileum was embedded in paraffin and sectioned to 4 $\mu \mathrm{m}$. Inflammatory cells were identified by immunohistochemical staining for Tlymphocytes (CD3), forkhead box P3 (FoxP3) and myeloperoxidase (MPO) synthesized mainly by neutrophils. Maturation of fetal intestine was assessed by immunohistochemical staining for intestinal fatty acid binding protein (I-FABP). Proliferating and apoptotic cells were identified by Ki-67 and Caspase-3 staining respectively. Endogenous peroxidase activity was blocked with either $0.3 \% \mathrm{H}_{2} \mathrm{O}_{2}$ diluted in TBS (MPO), PBS (CD3, FoxP3, Ki-67 and Caspase-3) or methanol (I-FABP). Nonspecific binding was blocked with normal goat serum (MPO; 10\% and FoxP3; 20\%, Ki67; 5\%) and bovine serum albumin (CD3; 5\% and I-FABP; 5\%) for either 30 minutes (MPO, CD3 and FoxP3) or 1 hour (I-FABP and Ki-67) at room temperature and the sections were incubated with the primary antibody as appropriate. After washing, sections were incubated with the selected secondary-conjugated antibody. CD3, FoxP3, Ki-67 and Caspase-3 antibodies were recognized with streptavidin-biotin method (Dakocytomation) and antibodies against MPO and I-FABP were recognized with a peroxidase-conjugated secondary antibody. Substrate staining for MPO and I-FABP was performed with 3-amino-9-ethylcarbazole (AEC, Sigma); haematoxyline was used as counterstain for nuclei. Immunoreactivity for CD3, FoxP3, Ki-67 and Caspase-3 was 
detected by using nickel-DAB. Except for I-FABP, the positive stained cells were counted in three high power fields. The average number of positive cells per high power field per animal is given. Maturity of the fetal intestine was evaluated based on the size of vacuoles and the localization of I-FABP.

\section{Immunofluorescence}

Tight junction morphology was evaluated by immunofluorescence staining against Zonula Occludens 1 (ZO-1) as previously described (15). Briefly, ileal cryosections $(4 \mu \mathrm{m})$ were incubated with anti-ZO-1 followed by Texas Red conjugated goatanti-rabbit as a secondary antibody and 4',6'-diamino-2-phenyl indole (DAPI) as a stain for the nuclei. The distribution of ZO-1 was examined in 400X magnification using an AxioCam MRc5 camera (ZEISS, Jena, Germany) mounted on an ECLIPSE E800 fluorescence microscope (Nikon, Amsterdam, the Netherlands).

\section{RNA isolation and qPCR}

Total RNA was extracted from ileum tissue using Trizol Reagent (Invitrogen, Breda, the Netherlands), according to manufacturer's guidelines. DNA contamination was removed by using RQ1 DNase kit (Promega, Madison, WI) following the manufacturer's instructions. The digestion of genomic DNA was confirmed by polymerase chain reaction (PCR) using ovine $\beta$-actin (forward sequence 5'CAGCACAGGCCTCTCGCCTTC-3'; reverse sequence: 5'CTGGGTCATCTTCTCACGGTTGG-3’). Reverse transcription was performed by using M-MLV Reverse transcriptase (Invitrogen, Bleiswijk, the Netherlands) according to supplier's recommendations, using oligo DT primers. 10ng of cDNA was amplified with LightCycler 480 SYBR Green I Master (Roche Applied Science, Almere, the Netherlands). qPCR was performed using the Light Cycler 480 (Roche) with primers designed on ovine specific sequences (Table 2). Melt-curve analysis was performed

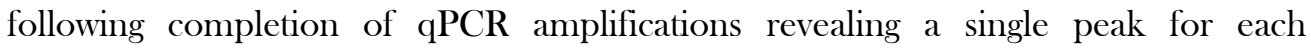
investigated amplicon, confirming the detection of a specific product. The results were 
Table 2. Primers used for qPCR.

\begin{tabular}{ccc}
\hline Primer & $\boldsymbol{F}_{\boldsymbol{W}}$ sequence (5'-3') & $\boldsymbol{R} \boldsymbol{R}$ sequence (5'-3') \\
\hline ovRPS15 & CGAGATGGTGGGCAGCAT & GCTTGATTTCCACCTGGTTGA \\
\hline TNF- $\alpha$ & GCCGGAATACCTGGACTATGC & CAGGGCGATGATCCCAAAGTAG \\
\hline IL-6 & ACATCGTCGACAAAATCTCTGCAA & GCCAGTGTCTCCTTGCTGTTT \\
\hline IL-17 & TGTGAGGGTCAACCTGAACAT & TGATAATCGGTGGGCCTTCTG \\
\hline IL-1 & AGAATGAGCTGTTATTTGAGGTTGATG & GTGAGAAATCTGCAGCTGGATGT \\
\hline IFN- $\gamma$ & TCAAGCAAGACATGTTTCAGAAGTTCT & CCGGAATTTGAATCAGCCTTTTGAA \\
\hline CD68 & AGGCAGTGCAGTGGACATTC & CAAGGTGTAAAGCTGGTGAAAC \\
\hline IL-4 & TGCCTGTAGCAGACGTCTTTG & GCCCTGCAGAAGGTTTCCT \\
\hline IL-10 & CATGGGCCTGACATCAAGGA & CGGAGGGTCTTCAGCTTCTC \\
\hline
\end{tabular}

Fw: forward, IFN: interferon, IL: interleukin, qPCR: quantitative real time polymerase chain reaction, Rv: reverse.

normalized to ovine $40 \mathrm{~S}$ ribosomal protein S15 (ovRPS15) and mean fold changes in mRNA expression relative to control are presented.

\section{Statistical Analysis}

Data are presented as mean \pm standard deviation (SD). Statistical analysis was performed using GraphPad Prism software (version v5.0; GraphPad Software Inc.) by using a non-parametric Kruskal Wallis tst followed by Dunn’s post-hoc test. Differences were considered statistically significant at $\mathrm{p}<0.05$.

\section{Results}

Inflammatory cells in the fetal ileum after selective exposure of lung, gut or chorioamnion/skin to IL-1 $\alpha$.

We evaluated the accumulation of inflammatory cells in the gut after IL-1 $\alpha$ exposure to the lung, gut or chorioamnion/skin by immunohistochemistry. Direct IL$1 \alpha$ exposure to the gut resulted in increased numbers of $\mathrm{CD}^{+}$cells in the fetal ileum when compared to control animals at 1 day post IL-1 $\alpha$ infusion. CD $3{ }^{+}$cells in the fetal ileum remained unchanged at 1 day post IL-1 $\alpha$ exposure to the lung or chorioamnion/skin when compared to controls (Figure 1). At 6 days, IL-1 $\alpha$ increased the numbers of $\mathrm{CD}^{+}$cells in the fetal ileum in all experimental groups when compared 
to controls (Figure 1A-E).

In contrast, the number of immunosuppressive regulatory $\mathrm{T}$ (Treg) cells (26), expressing the transcription factor FoxP3 (27), remained unchanged in the fetal gut at 1 or 6 days after IL-1 $\alpha$ infusion in any fetal compartment when compared to controls (Figure 2A). Similarly, the number of $\mathrm{MPO}^{+}$cells in the fetal intestine was comparable to control animals after 1 or 6 days of IL-1 $\alpha$ exposure to any fetal compartment (Figure 2B).

Intestinal mRNA levels of CD68, a marker for activated macrophages, were analyzed by qPCR. At 1 day after IL- $1 \alpha$ infusion in all compartments, CD68 mRNA levels remained unaltered in the fetal ileum when compared to controls (Figure 2C). At 6 days, IL-1 $\alpha$ infusion to the lung did not change the mRNA levels of CD68 in the fetal gut compared to controls whereas the mRNA levels of CD68 were increased when the gut or chorioamnion/skin were exposed to IL-1 $\alpha$ (Figure 2C).

Cytokine mRNA levels in the fetal gut after IL-1 $\alpha$ exposure in the different fetal compartments.

In order to further characterize the intestinal inflammatory responses following selective exposure of IL-1 $\alpha$ to the lung, gut and chorioamnion/skin, mRNA levels of pro- and anti-inflammatory cytokines were evaluated by qPCR. Ileal mRNA levels of IFN- $\gamma$, TNF- $\alpha$, IL-1, IL-17, IL-4, IL-10 and IL-6 remained unaltered at 1 day after any of the IL-1 $\alpha$ exposures (Figure 3). Compared to controls, gut mRNA levels of TNF- $\alpha$ and IL-1 were significantly increased at 6 days after IL-1 $\alpha$ exposure to GI tract (Figure $3 \mathrm{~B}$ and C) whereas these cytokines remained unaltered when the lung or chorioamnion/skin were exposed to IL-1 $\alpha$ (Figure 3B and C).

The intestinal mRNA levels of IL-10 were increased 6 days after IL-1 $\alpha$ exposure to the chorioamnion/skin (Figure 3F) whereas no differences were observed in the rest of the groups when compared to controls (Figure 3F). The gut mRNA levels of IFN- $\gamma$, IL-17, IL-4 and IL-6 remained unaltered 6 days post IL- $1 \alpha$ infusion to any fetal compartment (Figure 3A, D, E and G). 

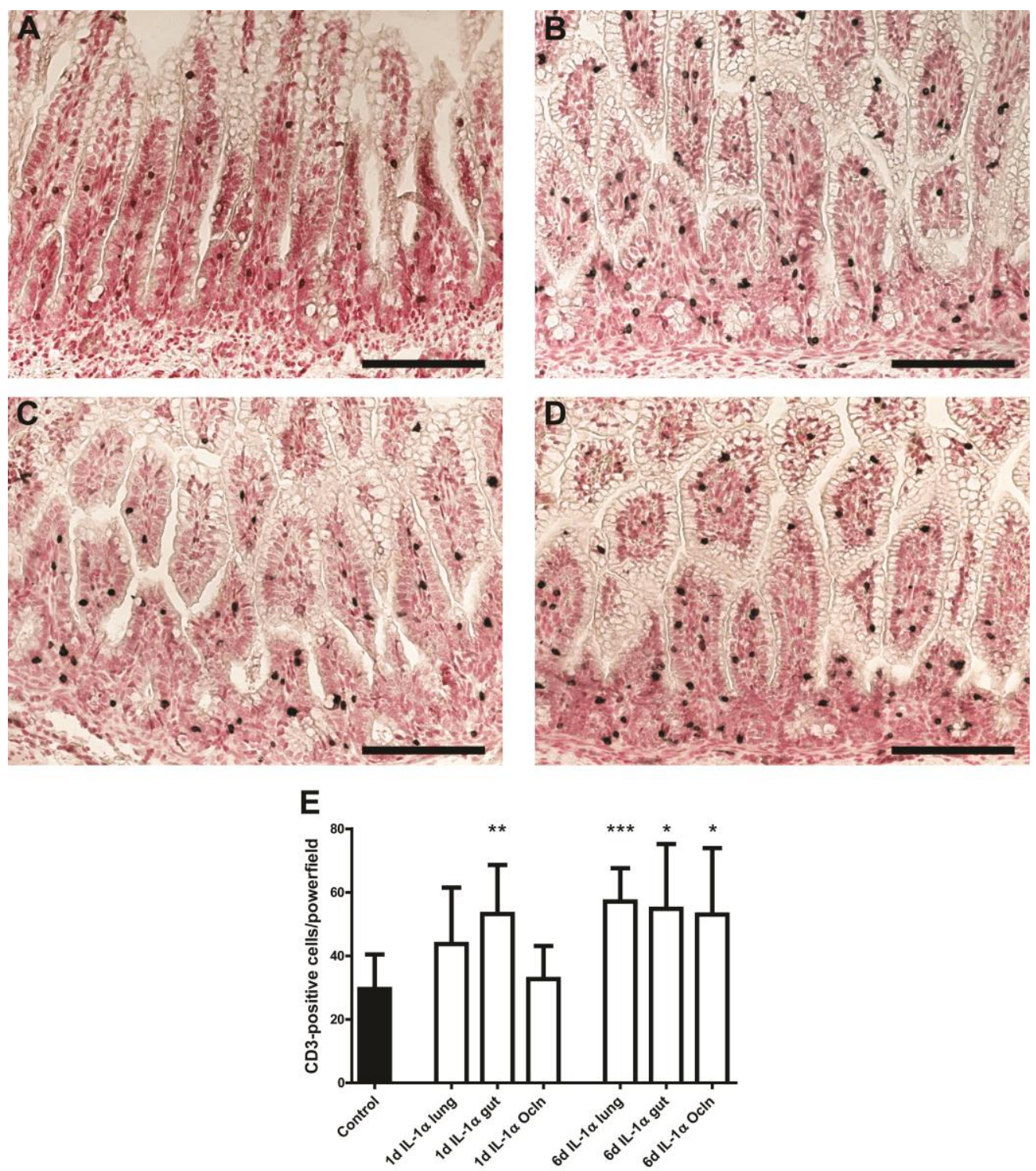

Figure 1. Number of T lymphocytes in the in the fetal intestine. Representative sections of fetal ileum were stained by immunohistochemistry for $\mathrm{CD}^{+}$cells of Control (A), $6 \mathrm{~d}$ IL- $1 \alpha$ lung (B), $6 \mathrm{~d}$ IL-1 $\alpha$ gut (C) and $6 \mathrm{~d}$ IL-1 $\alpha$ Ocln (D) animals. For each experimental group, CD3 positive expressing cells were counted and the mean cell counts per high power field per animal is given (E). Scale bar: 100 $\mu \mathrm{m}$. Data are presented as mean \pm SD. ${ }^{*} \mathrm{p}<0.05,{ }^{* *} \mathrm{p}<0.01$ and ${ }^{* * *} \mathrm{p}<0.001$ compared to control. CD3: cluster of differentiation 3, IL-1 $\alpha$ : interleukin-1 alpha. 
A

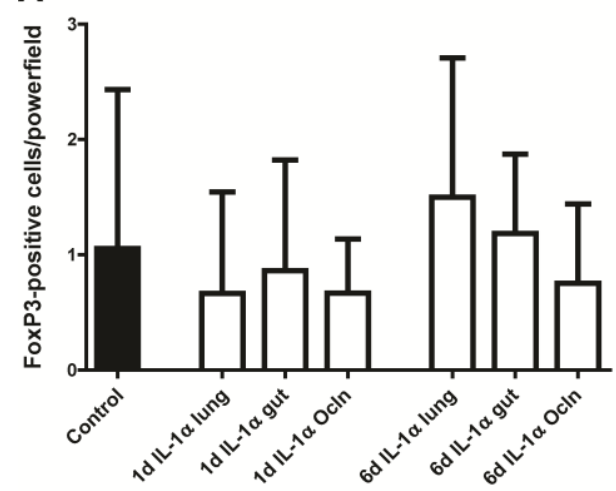

C

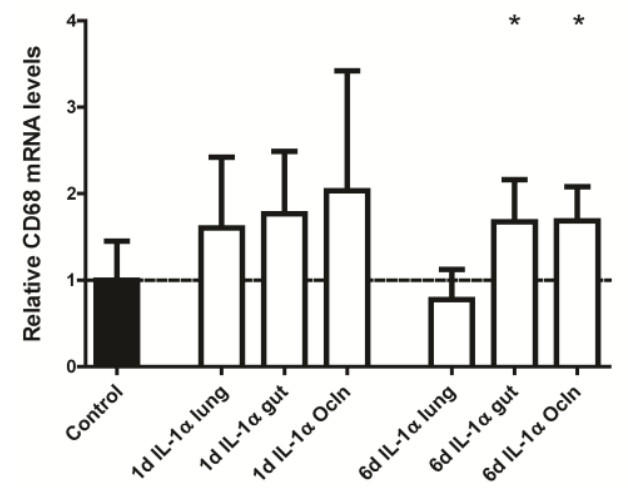

B

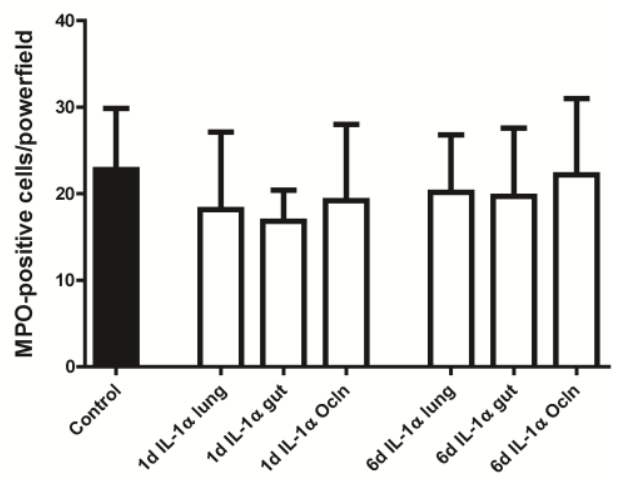

Figure 2. Number of inflammatory cells in the fetal ileum. For each experimental group, positive expressing cells of FoxP3 ${ }^{+}(\mathrm{A})$ and $\mathrm{MPO}^{+}(\mathrm{B})$ were counted and the mean cell counts per high power field per animal is given. The mRNA levels of CD68 (C) were evaluated by qPCR and the values were normalized to ovRPS15 rRNA levels. Data are presented as mean \pm SD. ${ }^{*} \mathrm{p}<0.05$ compared to control. CD68: cluster of differentiation 68, FoxP3: forkhead box P3, IL-1 $\alpha$ : interleukin-1 alpha, MPO: myeloperoxidase, qPCR: quantitative real time polymerase chain reaction. 

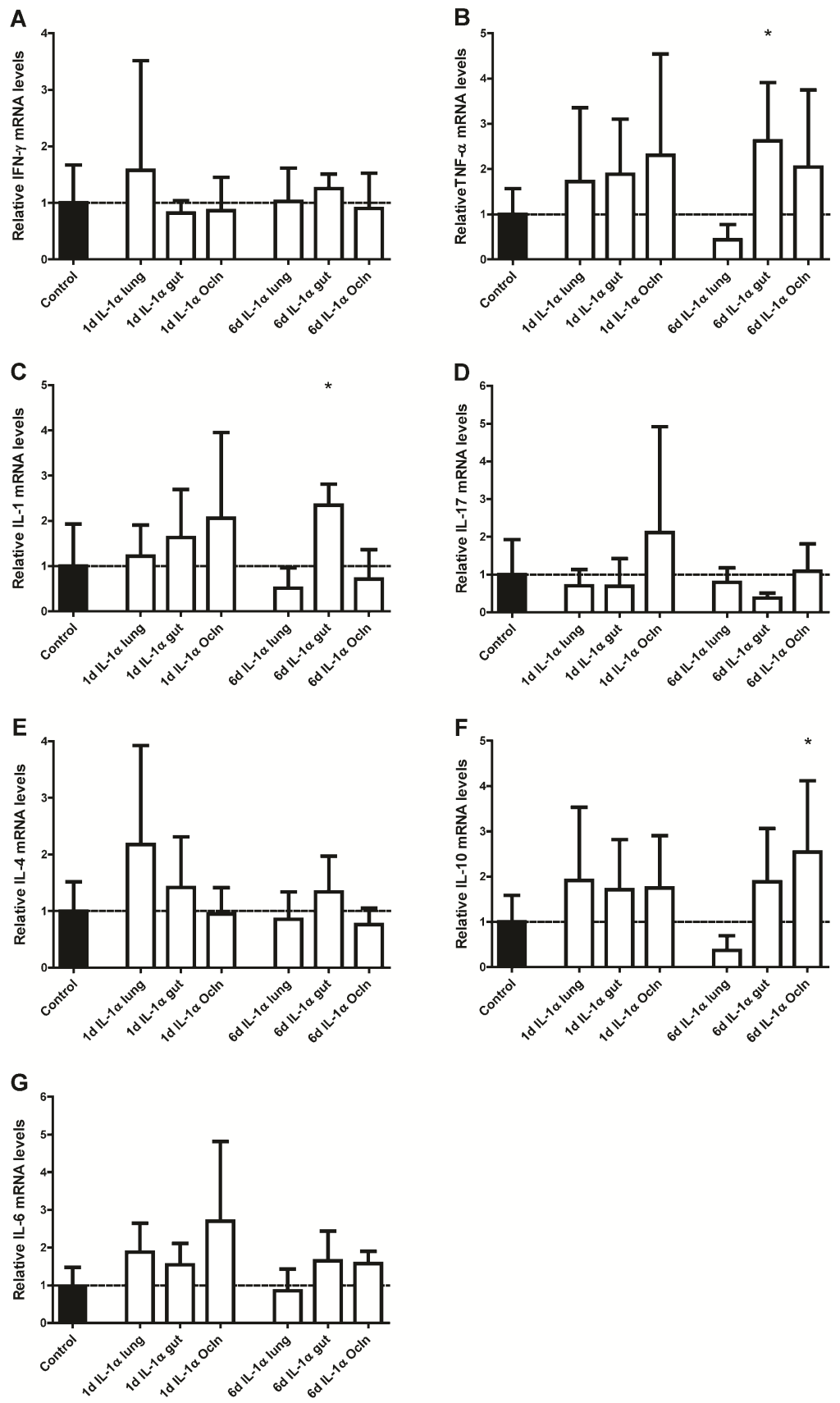

Figure 3. Cytokine mRNA levels in fetal ileum of animals exposed to IL-1 $\alpha$. The inflammatory cytokines: IFN- $\gamma$ (A), TNF- $\alpha$ (B), IL-1 (C), IL-17 (D), IL-4 (E), IL-10 (F) and IL-6 (G) were assessed by qPCR and the values for each cytokine were normalized to ovRPS15 rRNA levels. Data are 
presented as mean \pm SD. * $p<0.05$ compared to control. IL-: interleukin, IFN- $\gamma$ : interferon-gamma, qPCR: quantitative real time polymerase chain reaction.

\section{Gut injury and morphological changes after selective IL-1 $\alpha$ exposure to the gut, lung or chorioamnion/skin.}

We first evaluated whether selective IL-1 $\alpha$ exposure to different epithelial surfaces resulted in morphological changes in the fetal intestine by histochemical H\&E staining. No clear signs of intestinal epithelial injury were observed at 1 or 6 days after IL-1 $\alpha$ infusion to any fetal compartment (data not shown). This finding was also confirmed by immunohistochemical analysis of I-FABP, a protein that is expressed by intestinal epithelial cells and is released upon epithelial injury $(28,29)$.

We then assessed whether selective IL-1 $\alpha$ exposure to different fetal compartments resulted in impaired gut development. Maturation of the fetal gut was assessed by immunohistochemical staining of I-FABP (30) and by the size of vacuoles in the intestinal epithelium. In control animals (Figure 4A), I-FABP expression was detected along the villus, which is characteristic for animals of this gestational age (17). In contrast, 6 days after IL-1 $\alpha$ exposure to the gut, I-FABP expression was primarily localized in the crypts (Figure 4B) and large vacuoles were detected in the fetal intestine when compared to controls, indicative of intestinal prematurity (Figure 4B). No significant changes were observed between control, IL-1 $\alpha$ lung and IL-1 $\alpha$ chorioamnion/skin exposed animals (data not shown). Finally, direct IL-1 $\alpha$ exposure to the gut resulted in significant shortening of the villus length at 6 days when compared to controls whereas no changes were observed in villus length 1 or 6 days post IL-1 $\alpha$ exposure to the lung and chorioamnion/skin (Figure 4C).

To gain insight into the mechanism of the observed decreased villus length and the immature intestinal phenotype at 6 days after IL-1 $\alpha$ exposure to the gut, we performed an immunohistochemical staining for the proliferation marker Ki-67 and apoptotic marker Caspase-3. No differences were detected in the number of Ki-67 

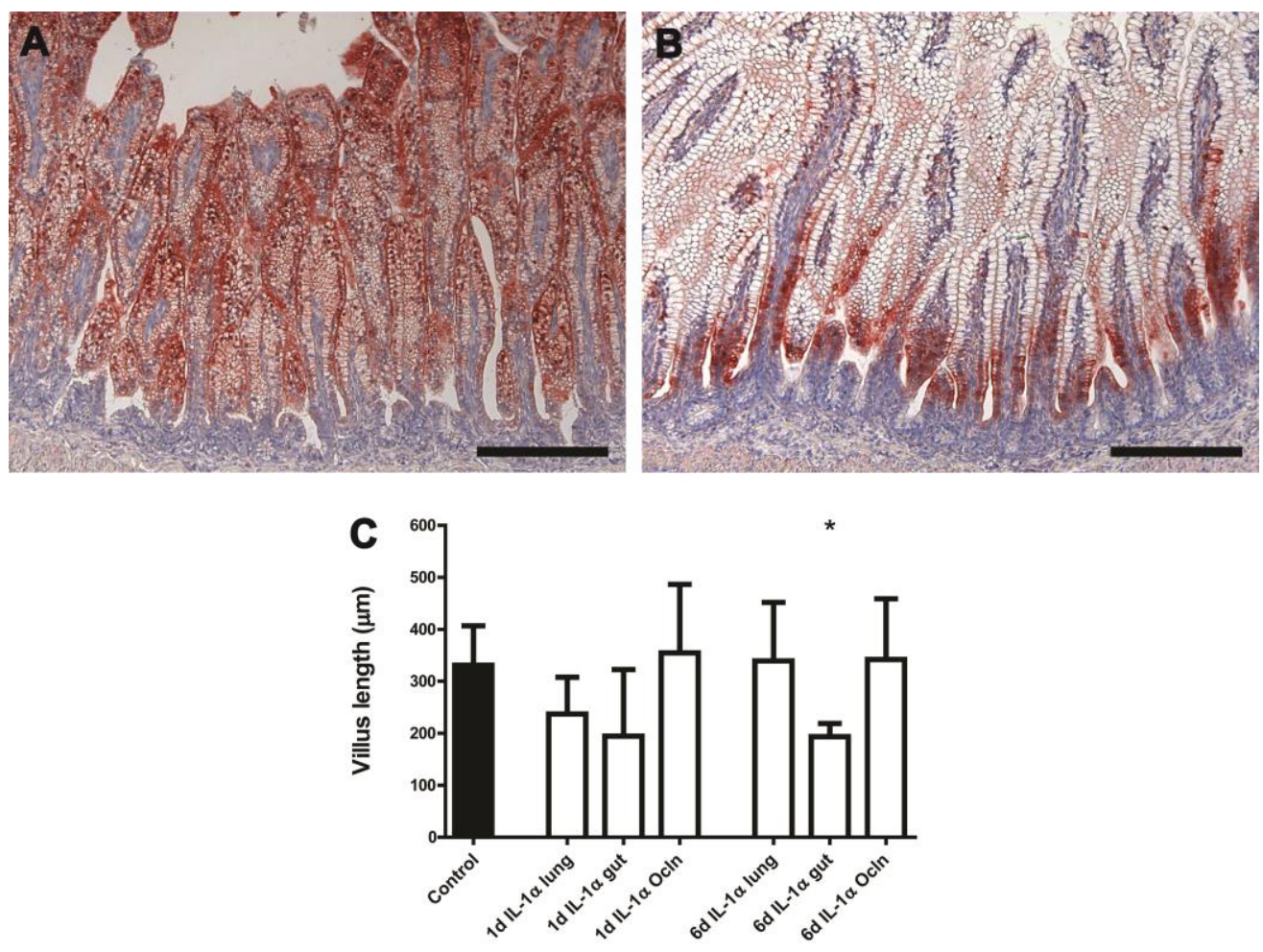

Figure 4. Maturation of the fetal intestine was evaluated by morphological changes determined by staining for I-FABP. In control animals, the expression of I-FABP was localized across the villi (A). In contrast, IL-1 $\alpha$ exposure to the gut resulted in I-FABP expression in the lower villi and revealed enlarged vacuoles along the epithelium at 6 days post infusion (B), a characteristic of immaturity. The villus length was significantly decreased 6 days after direct IL-1 $\alpha$ exposure to the gut compared to controls (C). Scale bar: $200 \mu \mathrm{m}$. Data are presented as mean \pm SD. ${ }^{*} \mathrm{p}<0.05$ compared to control. IL-1 $\alpha$ : interleukin-1 alpha, I-FABP: intestinal-fatty acid binding protein.

(Figure 5) and Caspase-3 (data not shown) positive cells in the intestinal mucosa between control, IL-1 $\alpha$ lung, IL-1 $\alpha$ gut and IL-1 $\alpha$ chorioamnion/skin exposed animals.

The integrity of tight junctions was evaluated by immunofluorescence staining of ZO-1, an important tight junctional protein in epithelial cells involved in paracellular permeability (31). In premature control animals, the distribution of ZO-1 was fragmented (Figure 6A) and this ZO-1 localization in the fetal gut was further disturbed after selective intestinal IL-1 $\alpha$ exposure (Figure 6C and F) with more severe fragmenta- 

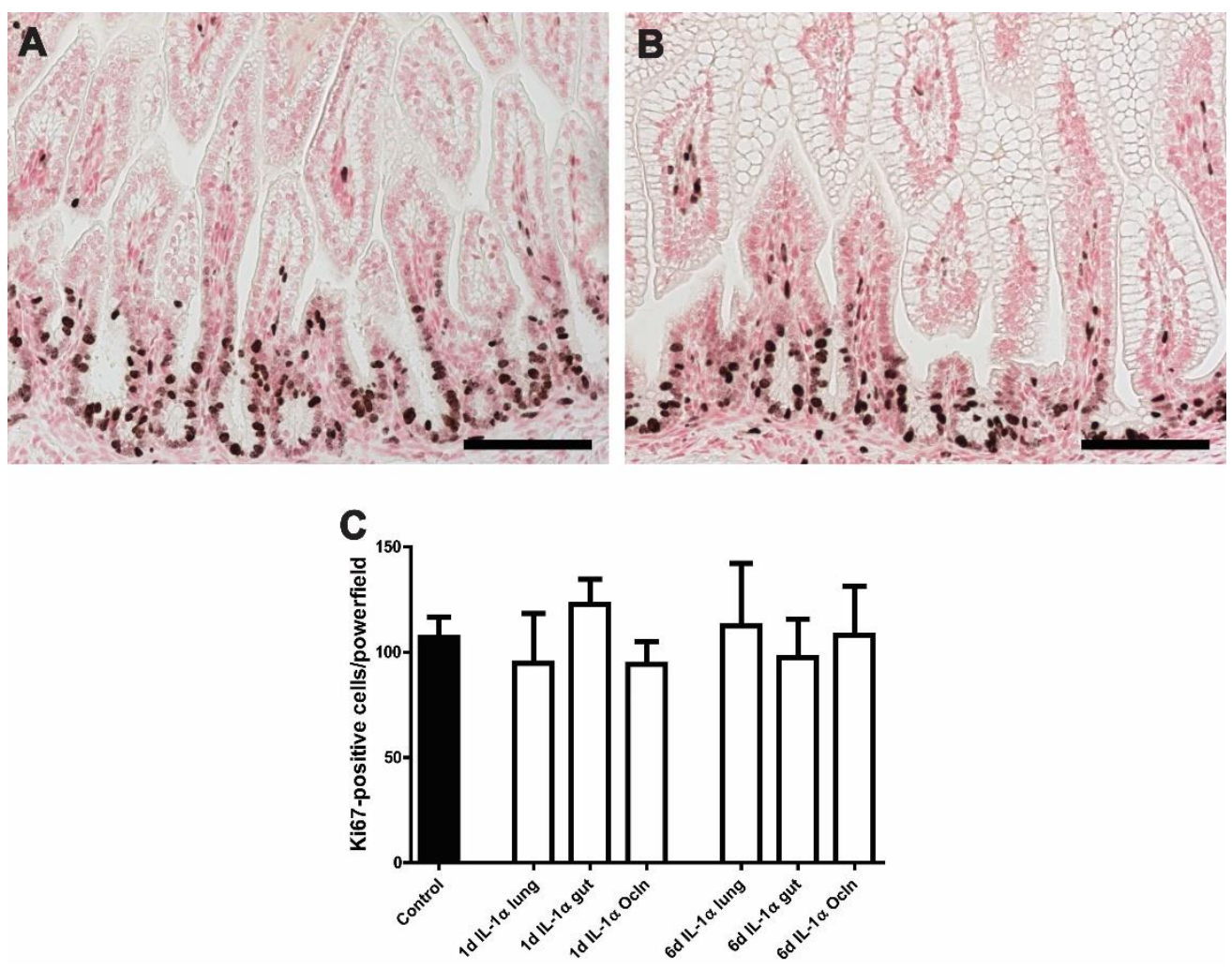

Figure 5. Distribution of $\mathrm{Ki}-67$ positive cells in the fetal ileum of animals exposed to IL- $1 \alpha$. Representative intestinal sections of Control (A) and 6d IL-1 $\alpha$ gut (B) were stained by immunohistochemistry for Ki-67 positive cells. No differences were observed between control and IL-1 $\alpha$ lung, gut and chorioamnion/skin exposed animals (C). For each experimental group, Ki-67 positive expressing cells were counted and the mean cell counts per high power field per animal is given (C). Scale bar: $100 \mu \mathrm{m}$. Data are presented as mean \pm SD. IL-1 $\alpha$ : interleukin-1 alpha.

tion at 1 day post IL- $1 \alpha$ infusion to the GI tract (Figure $6 \mathrm{C}$ ). The ZO-1 distribution pattern in the rest investigated groups was similar to control animals (Figure 6). 
Chapter 2
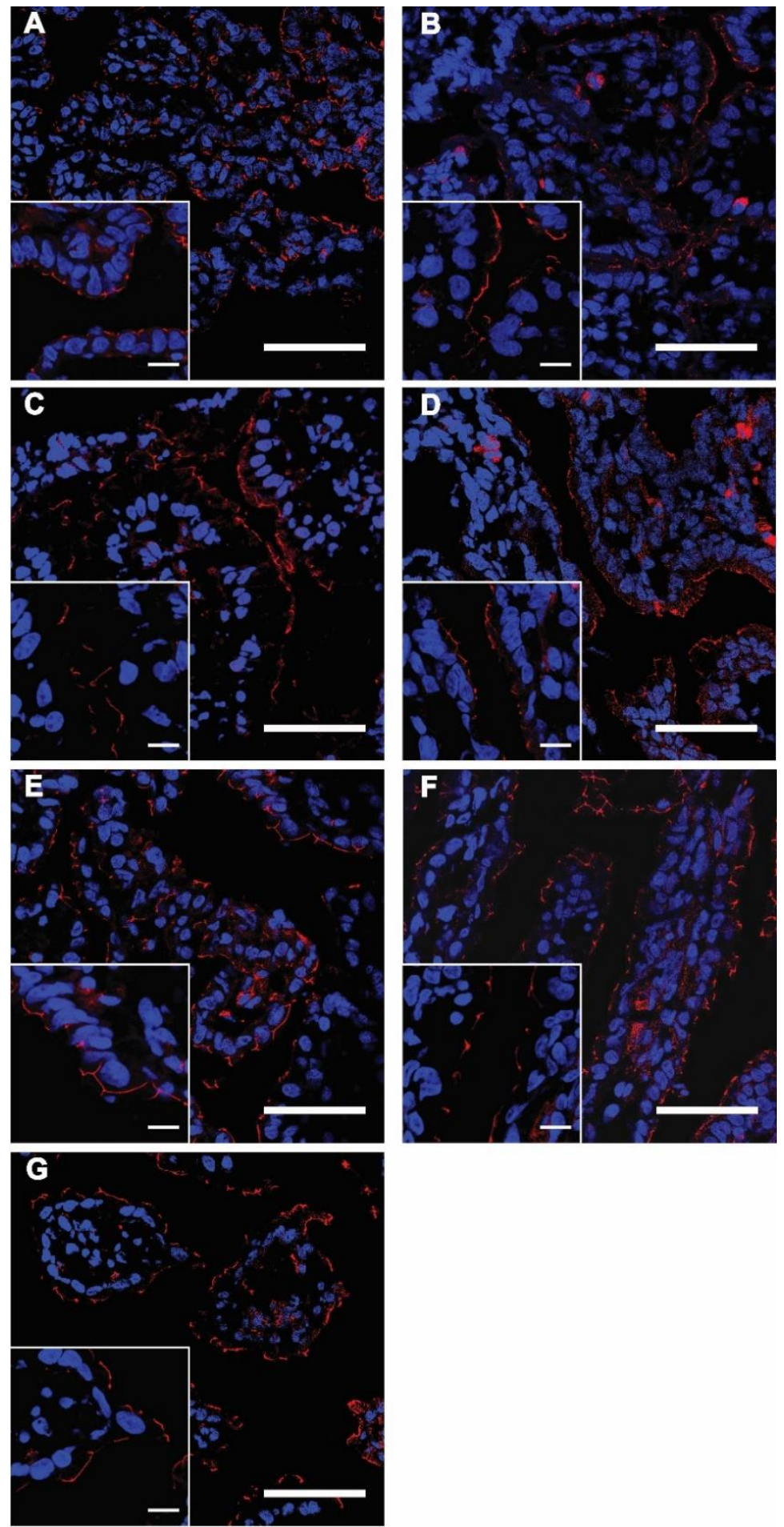
Figure 6. Distribution of Zonula occludens (ZO)-1 in the fetal ileum of animals exposed to IL-1 $\alpha$. Control animals had a moderate fragmentation of ZO-1 expression along the epithelium (A). This fragmentation was further disturbed after selective IL-1 $\alpha$ exposure to the gut $(\mathrm{C}$ and $\mathrm{F}$ ) with more severe ZO-1 fragmentation at 1 day post IL-1 $\alpha$ infusion to the GI tract (C). The distribution of ZO-1 in (B) $1 \mathrm{~d}$ IL-1 $\alpha$ lung, (D) $1 \mathrm{~d}$ IL-1 $\alpha$ Ocln, (E) $6 \mathrm{~d}$ IL-1 $\alpha$ lung and (G) $6 \mathrm{~d}$ IL-1 $\alpha$ Ocln animals was similar to the control (A). Scale bar $50 \mu \mathrm{m}$. Scale bar in insets $10 \mu \mathrm{m}$. IL-1 $\alpha$ : interleukin-1 alpha.

\section{Systemic immune activation following IL-1 $\alpha$ exposure to the lung, gut or chorioamnion/skin.}

We examined whether 6 days after selective IL-1 $\alpha$ exposure to the lung, gut or chorioamnion/skin resulted in systemic inflammation. The number of white blood cells, monocytes, lymphocytes and neutrophils was increased in cord blood after 6 days of IL-1 $\alpha$ exposure to the lung (Figure 7). Increased number of white blood cells, monocytes and neutrophils was also observed in cord blood 6 days after IL-1 $\alpha$ exposure to the chorioamnion/skin whereas the number of lymphocytes was similar to control animals (Figure 7C). The cell counts of white blood cells, monocytes, lymphocytes and neutrophils in cord blood after 6 days of IL-1 $\alpha$ exposure to the gut were not different when compared to controls. 
A

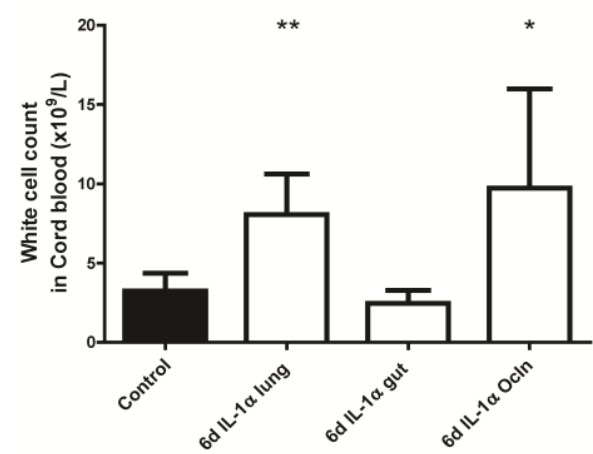

C

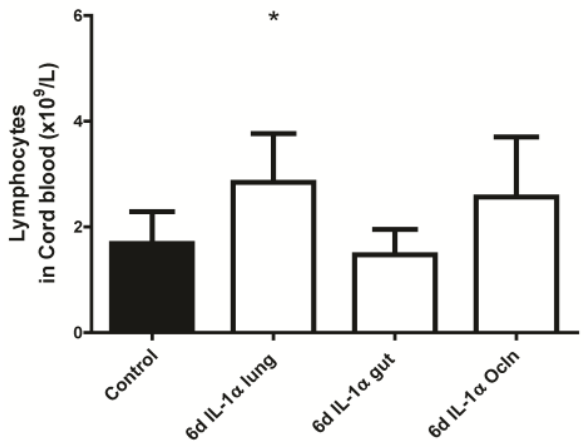

B

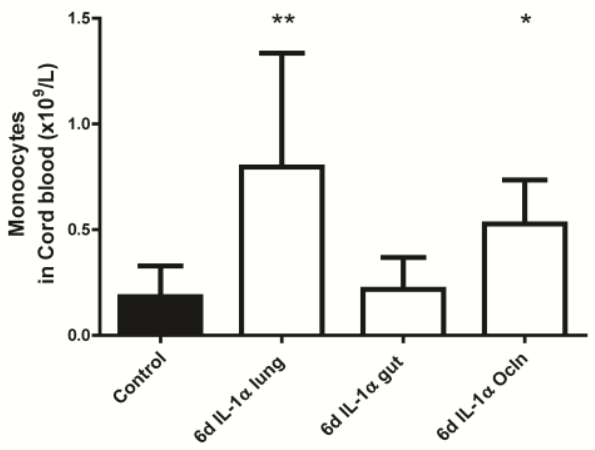

D

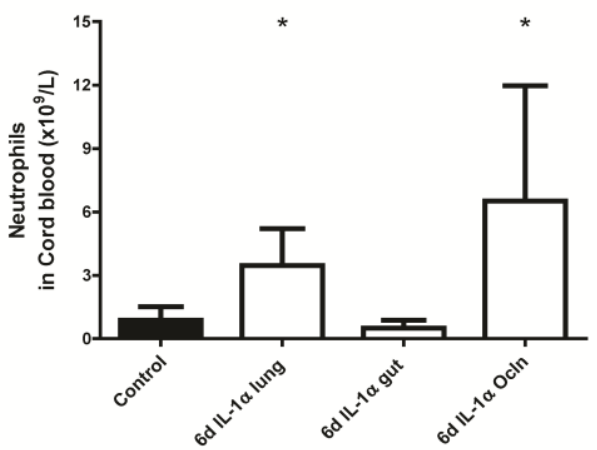

Figure 7. Differential cord blood counts of white blood cells (A), monocytes (B), lymphocytes (C) and neutrophils (D). Data are presented as mean \pm SD. ${ }^{*} \mathrm{p}<0.05$ and ${ }^{*} \mathrm{p}<0.01$ compared to control. IL-1 $\alpha$ : interleukin-1 alpha. 


\section{Discussion}

We previously demonstrated that inhibition of IL-1 signaling in the course of Ureaplasma (UP)-induced chorioamnionitis substantially prevented inflammation, disturbed maturation and injury of the fetal intestine (17). In the present study, we evaluated the impact of IL-1 $\alpha$ signaling on intestinal inflammation and injury when different epithelial organs were selectively exposed to IL-1 $\alpha$. Our findings indicate that the adverse outcomes of the fetal gut in the course of chorioamnionitis are the combined result of selective IL- $1 \alpha$-driven signaling of the lung, gut and chorioamnion/skin. Interestingly, intestinal inflammatory responses were distinct following different sites of IL-1 $\alpha$ exposure and gut injury and immaturity were only induced upon direct contact of IL-1 $\alpha$ to the gastrointestinal mucosa.

At day 1 after IL-1 $\alpha$ infusion into the GI tract, intestinal inflammation was characterized by infiltration of $\mathrm{T}$ cells and subsequent tight junctional loss. The current findings confirm and explain our earlier observations, showing that local exposure of the intestinal epithelium to LPS induces lymphocyte influx and impaired gut integrity (15). In line with these data, in vitro experiments with intestinal epithelial cells have shown that IL-1 supplementation in the culture system increased the permeability of tight junctions (32, 33). These findings indicate that increased intestinal IL-1 $\alpha$ levels directly interact with the intestinal epithelial cells and/or resident immune cells to induce adverse intestinal outcomes as seen in the fetal intestine in the course of chorioamnionitis.

At 6 days, intestinal inflammation appears to be dependent on the route of IL$1 \alpha$ exposure. In particular, $6 \mathrm{~d}$ after direct IL-1 $\alpha$ to the GI tract, intestinal immune activation was characterized by increased TNF- $\alpha$ and IL-1 mRNA levels and moderate signs of tight junctional loss. These current findings provide a mechanistic explanation for previous findings showing that direct gut exposure to LPS induced the expression of these pro-inflammatory cytokines in the fetal ileum and this increase was associated with intestinal injury (15). 
Intestinal inflammation was associated with an immature intestinal phenotype 6 days post IL- $1 \alpha$ exposure to the GI tract as the villi were shortened, formed by enterocytes with enlarged vacuoles and I-FABP expression was restricted to the basis of the villi, a characteristic pattern found in the extreme premature gut (30). Interestingly, these morphological changes were not associated with altered number of Ki-67 or Caspase-3 positive cells in the intestinal mucosa at 6 days after IL-1 $\alpha$ exposure to the fetal gut. Therefore, diminished differentiation, rather than altered cell proliferation and/or cell death, appears to be responsible for the observed immature intestinal phenotype at 6 days after IL-1 $\alpha$ exposure to the gut. Underdevelopment of the fetal intestine was shown to be impaired in an IL-1 dependent manner in the context of chorioamnionitis (17). Therefore, these results indicate that disturbed maturation of the intestinal epithelium during antenatal inflammation is the result of direct IL-1 $\alpha$ effects to the GI mucosa. Alternatively, increased vacuolization and shortened villi at 6 days after IL-1 $\alpha$ exposure to the fetal gut could also be interpreted as indicators of mucosal injury. However, at this stage increased vacuolization and villus atrophy was not associated with increased apoptosis, shedding of epithelial cells and accumulation of cellular debris in the lumen. Therefore, the shortening of the villi might originate from inflammation-induced smooth muscle reactivity and/or inflammation-driven changes of the subepithelial architecture of myofibroblasts within the villus compartment (34).

Systemic inflammation was associated with intestinal inflammation 6 days after IL-1 $\alpha$ exposure to the chorioamnion/skin. This finding is in contrast with previous reports demonstrating that LPS exposure to the chorioamnion/skin provoked a systemic response without inducing intestinal immune activation (15, 35). This discrepancy could be explained by the relative low number of circulating monocytes when compared to LPS (35) after IL-1 $\alpha$ infusion into the snout occluded animals which was paralleled by increased CD68 (macrophages) mRNA levels in the fetal gut, indicating influx and/or differentiation of monocytes from the periphery. It is tempting to speculate that intestinal macrophages in the GI tract following IL-1 $\alpha$ exposure to the chorioamnion/skin might be responsible for the accumulation of $\mathrm{T}$ cells in the fetal gut 
(36). This intestinal immune response at 6 days after IL-1 $\alpha$ administration to the chorioamnion/skin appeared to have an anti-inflammatory character as upregulated mRNA levels of IL-10, a cytokine which plays central role in maintaining gut wall integrity $(37,38)$, were detected and associated with absence of epithelial damage in the fetal ileum.

The intestinal immune response 6 days after IL- $1 \alpha$ intra-tracheal infusion was characterized by marginal inflammatory changes in the fetal gut with no signs of mucosal injury. In contrast, we have shown that intra-tracheal LPS delivery results in intestinal inflammation and mucosal damage (15). These findings imply that induction of intestinal epithelial damage after pulmonary mediated (systemic) immune activation are largely IL-1 independent.

Although the mechanisms by which the fetal intestine responses to indirect IL$1 \alpha$ exposure to the lung or chorioamnion/skin remain to be elucidated, the current study provides evidence that direct IL-1 $\alpha$ exposure to these epithelial organs (i.e. lung and chorioamnion/skin) can trigger gut inflammatory processes in the course of chorioamnionitis. Since not only the gut but also the lung and chorioamnion/skin seem to play a role in IL- $1 \alpha$-mediated inflammatory changes of the fetal gut during chorioamnionitis, future therapeutic interventions may need to focus on targeting both IL-1 $\alpha$ local and systemically mediated immune responses during antenatal inflammation.

In conclusion, we have shown that IL-1 $\alpha$ signaling in different fetal compartments contributes to the induction of intestinal inflammation in the course of chorioamnionitis. Importantly, altered gut development and mucosal injury required direct contact of IL-1 $\alpha$ to GI epithelium which emphasized the crucial role of local IL$1 \alpha$-driven intestinal inflammatory processes in the context of chorioamnionitis. 


\section{References}

1. Goldenberg RL, Culhane JF, Iams JD, Romero R. Epidemiology and causes of preterm birth. Lancet 2008;371:75-84.

2. Kemp MW. Preterm birth, intrauterine infection, and fetal inflammation. Front Immunol 2014;5:574.

3. Ericson JE, Laughon MM. Chorioamnionitis: implications for the neonate. Clin Perinatol 2015;42:155-165, ix.

4. Galinsky R, Polglase GR, Hooper SB, Black MJ, Moss TJ. The consequences of chorioamnionitis: preterm birth and effects on development. J Pregnancy 2013;2013:412831.

5. Romero R, Miranda J, Kusanovic JP, Chaiworapongsa T, Chaemsaithong P, Martinez A, Gotsch F, Dong Z, Ahmed AI, Shaman M, Lannaman K, Yoon BH, Hassan SS, Kim CJ, Korzeniewski SJ, Yeo L, Kim YM. Clinical chorioamnionitis at term I: microbiology of the amniotic cavity using cultivation and molecular techniques. J Perinat Med 2015;43:19-36.

6. Gantert M, Been JV, Gavilanes AW, Garnier Y, Zimmermann LJ, Kramer BW. Chorioamnionitis: a multiorgan disease of the fetus? J Perinatol 2010;30 Suppl:S21-30.

7. Kallapur SG, Presicce P, Rueda CM, Jobe AH, Chougnet CA. Fetal immune response to chorioamnionitis. Semin Reprod Med 2014;32:56-67.

8. Denzler A, Burkhardt T, Natalucci G, Zimmermann R. Latency after preterm prelabor rupture of the membranes: increased risk for periventricular leukomalacia. J Pregnancy 2014;2014:874984.

9. Paul DA, Zook K, Mackley A, Locke RG. Reduced mortality and increased BPD with histological chorioamnionitis and leukocytosis in very-low-birth-weight infants. J Perinatol 2010;30:58-62.

10. Been JV, Lievense S, Zimmermann LJ, Kramer BW, Wolfs TG. Chorioamnionitis as a risk factor for necrotizing enterocolitis: a systematic review and meta-analysis. J Pediatr 2013;162:236-242 e232.

11. Coggins SA, Wynn JL, Weitkamp JH. Infectious Causes of Necrotizing Enterocolitis. Clin Perinatol 2015;42:133-154.

12. Kallapur SG, Willet KE, Jobe AH, Ikegami M, Bachurski CJ. Intra-amniotic endotoxin: chorioamnionitis precedes lung maturation in preterm lambs. Am J Physiol Lung Cell Mol Physiol 2001;280:L527-536.

13. Kramer BW, Moss TJ, Willet KE, Newnham JP, Sly PD, Kallapur SG, Ikegami M, Jobe AH. Dose and time response after intraamniotic endotoxin in preterm lambs. Am J Respir Crit Care Med 2001;164:982-988. 
14. Zhang L, Saito M, Jobe A, Kallapur SG, Newnham JP, Cox T, Kramer B, Yang H, Kemp MW. Intra-amniotic administration of $\mathbf{E}$ coli lipopolysaccharides causes sustained inflammation of the fetal skin in sheep. Reprod Sci 2012;19:1181-1189.

15. Wolfs TG, Kramer BW, Thuijls G, Kemp MW, Saito M, Willems MG, Senthamarai-Kannan P, Newnham JP, Jobe AH, Kallapur SG. Chorioamnionitisinduced fetal gut injury is mediated by direct gut exposure of inflammatory mediators or by lung inflammation. Am J Physiol Gastrointest Liver Physiol 2014;306:G382-393. 16. Kallapur SG, Nitsos I, Moss TJ, Polglase GR, Pillow JJ, Cheah FC, Kramer BW, Newnham JP, Ikegami M, Jobe AH. IL-1 mediates pulmonary and systemic inflammatory responses to chorioamnionitis induced by lipopolysaccharide. Am J Respir Crit Care Med 2009;179:955-961.

17. Wolfs TG, Kallapur SG, Knox CL, Thuijls G, Nitsos I, Polglase GR, Collins JJ, Kroon E, Spierings J, Shroyer NF, Newnham JP, Jobe AH, Kramer BW. Antenatal ureaplasma infection impairs development of the fetal ovine gut in an IL-1-dependent manner. Mucosal Immunol. 2013;6:547-556.

18. Vadillo-Ortega F, Sadowsky DW, Haluska GJ, Hernandez-Guerrero C, Guevara-Silva R, Gravett MG, Novy MJ. Identification of matrix metalloproteinase-9 in amniotic fluid and amniochorion in spontaneous labor and after experimental intrauterine infection or interleukin-1 beta infusion in pregnant rhesus monkeys. Am J Obstet Gynecol 2002;186:128-138.

19. Bry K, Lappalainen U, Hallman M. Intraamniotic interleukin-1 accelerates surfactant protein synthesis in fetal rabbits and improves lung stability after premature birth. J Clin Invest 1997;99:2992-2999.

20. Adams Waldorf KM, Rubens CE, Gravett MG. Use of nonhuman primate models to investigate mechanisms of infection-associated preterm birth. Bjog 2011;118:136-144.

21. Wolfs TG, Kallapur SG, Polglase GR, Pillow JJ, Nitsos I, Newnham JP, Chougnet CA, Kroon E, Spierings J, Willems CH, Jobe AH, Kramer BW. IL-1alpha mediated chorioamnionitis induces depletion of FoxP3+ cells and ileal inflammation in the ovine fetal gut. PLoS One 2011;6:e18355.

22. Kallapur SG, Kramer BW, Nitsos I, Pillow JJ, Collins JJ, Polglase GR, Newnham JP, Jobe AH. Pulmonary and systemic inflammatory responses to intraamniotic IL-1alpha in fetal sheep. Am J Physiol Lung Cell Mol Physiol 2011;301:L285295.

23. Berry CA, Nitsos I, Hillman NH, Pillow JJ, Polglase GR, Kramer BW, Kemp MW, Newnham JP, Jobe AH, Kallapur SG. Interleukin-1 in lipopolysaccharide induced chorioamnionitis in the fetal sheep. Reprod Sci 2011;18:1092-1102. 
24. Sosenko IR, Kallapur SG, Nitsos I, Moss TJ, Newnham JP, Ikegami M, Jobe AH. IL-1 alpha causes lung inflammation and maturation by direct effects on preterm fetal lamb lungs. Pediatr Res 2006;60:294-298.

25. Nijland MJ, Day L, Ross MG. Ovine fetal swallowing: expression of preterm neurobehavioral rhythms. J Matern Fetal Med 2001;10:251-257.

26. Renz H, Brandtzaeg P, Hornef M. The impact of perinatal immune development on mucosal homeostasis and chronic inflammation. Nat Rev Immunol 2012;12:9-23.

27. Rocchi MS, Wattegedera SR, Frew D, Entrican G, Huntley JF, McNeilly TN. Identification of CD4+CD25 high Foxp3+ $\mathrm{T}$ cells in ovine peripheral blood. Vet Immunol Immunopathol 2011;144:172-177.

28. Grootjans J, Thuijls G, Verdam F, Derikx JP, Lenaerts K, Buurman WA. Noninvasive assessment of barrier integrity and function of the human gut. World $\mathbf{J}$ Gastrointest Surg 2010;2:61-69.

29. Khadaroo RG, Fortis S, Salim SY, Streutker C, Churchill TA, Zhang H. IFABP as biomarker for the early diagnosis of acute mesenteric ischemia and resultant lung injury. PLoS One 2014;9:e115242.

30. Reisinger KW, Elst M, Derikx JP, Nikkels PG, de Vries B, Adriaanse MP, Jellema RK, Kramer BW, Wolfs TG. Intestinal fatty acid-binding protein: a possible marker for gut maturation. Pediatr Res 2014;76:261-268.

31. Gumber S, Nusrat A, Villinger F. Immunohistological characterization of intercellular junction proteins in rhesus macaque intestine. Exp Toxicol Pathol 2014;66:437-444.

32. Capaldo CT, Nusrat A. Cytokine regulation of tight junctions. Biochim Biophys Acta 2009;1788:864-871.

33. Lie PP, Cheng CY, Mruk DD. The biology of interleukin-1: emerging concepts in the regulation of the actin cytoskeleton and cell junction dynamics. Cell Mol Life Sci 2012;69:487-500.

34. Boshuizen JA, Reimerink JH, Korteland-van Male AM, van Ham VJ, Koopmans MP, Buller HA, Dekker J, Einerhand AW. Changes in small intestinal homeostasis, morphology, and gene expression during rotavirus infection of infant mice. J Virol 2003;77:13005-13016.

35. Kemp MW, Kannan PS, Saito M, Newnham JP, Cox T, Jobe AH, Kramer BW, Kallapur SG. Selective exposure of the fetal lung and skin/amnion (but not gastrointestinal tract) to LPS elicits acute systemic inflammation in fetal sheep. PLoS One 2013;8:e63355.

36. Pabst O, Bernhardt G. The puzzle of intestinal lamina propria dendritic cells and macrophages. Eur J Immunol 2010;40:2107-2111. 
37. Emami CN, Chokshi N, Wang J, Hunter C, Guner Y, Goth K, Wang L, Grishin A, Ford HR. Role of interleukin-10 in the pathogenesis of necrotizing enterocolitis. Am J Surg 2012;203:428-435.

38. Olszak T, Neves JF, Dowds CM, Baker K, Glickman J, Davidson NO, Lin CS, Jobin C, Brand S, Sotlar K, Wada K, Katayama K, Nakajima A, Mizuguchi H, Kawasaki K, Nagata K, Muller W, Snapper SB, Schreiber S, Kaser A, Zeissig S, Blumberg RS. Protective mucosal immunity mediated by epithelial CD1d and IL-10. Nature 2014;509:497-502. 



\section{Chapter 3}

\section{Prophylactic interleukin-2 treatment prevents fetal gut inflammation and injury in an ovine model of chorioamnionitis.}

Maria Nikiforou', Joris Vanderlocht', Claire A. Chougnet, Reint K. Jellema, Daan R.M.G. Ophelders, Mandy Joosten, Nico Kloosterboer, Birgit L.M.G. SendenGijsbers, Wilfred T.V. Germeraad, Boris W. Kramer and Tim G.A.M. Wolfs

Inflamm Bowel Dis 2015; 21(9):2026-38

reproduced with permission from Wolters Kluwer Health 


\section{Abstract}

Background Chorioamnionitis results from an infection of the fetal membranes and is associated with fetal adverse outcomes, notably in the intestine. Using a translational ovine model, we showed that intra-amniotic exposure to inflammatory stimuli decreased the regulatory/effector $\mathrm{T}$ (Treg/Teff) cell balance in the gut, which was accompanied by intestinal inflammation and mucosal injury. We thus aimed to augment the Treg/Teff cell ratio in the fetal gut by prophylactic IL-2 treatment, and evaluate whether it is sufficient to prevent chorioamnionitis-induced intestinal inflammation and mucosal injury.

Methods Fetal sheep (122 days of gestation) were intra-amniotically exposed to lipopolysaccharide for 2 or 7 days, with or without prophylactic IL-2 treatment (4 d). We evaluated the infiltration of inflammatory cells in the ileum and mesenteric lymph nodes. Cytokine gene expression was analyzed in fetal ileum and the inflammatory changes were correlated with gut wall integrity.

Results IL-2 administration preferentially increased intestinal Treg cells and thus the Treg/Teff cell ratio. Prophylactic IL-2 treatment reduced the lipopolysaccharideinduced influx of neutrophils and $\mathrm{CD}^{+} \mathrm{T}$ cells and decreased the messenger RNA levels of proinflammatory cytokines including IL-6 and IL-17 in the fetal ileum. Importantly, prophylactic IL-2 treatment prevented mucosal damage without inducing fetal adverse treatment outcomes.

Conclusions Our data show that prophylactic IL-2 treatment prevents fetal intestinal inflammation and mucosal injury in the context of experimental chorioamnionitis. Modulation of the Treg/Teff cell balance may contribute to the protective effects of IL2. 


\section{Introduction}

Preterm birth complications are the leading cause of morbidity and mortality accounting for $35 \%$ of neonatal deaths globally (1). The most important risk factor of preterm labor is chorioamnionitis, an inflammation/infection of the chorion and amnion, which can be caused by a plethora of pathogens or pathogen related products including lipopolysaccharide (LPS) from E.coli and Ureaplasma spp. (2-4). Chorioamnionitis affects multiple organs of the fetus $(5,6)$, and is associated with adverse clinical outcomes of the intestines including necrotizing enterocolitis (NEC) (7), which is the most severe gastrointestinal pathology affecting preterm infants $(8,9)$. To gain mechanistic insight into the underlying causes of the observed correlation between chorioamnionitis and intestinal pathologies, a translational ovine chorioamnionitis model was previously developed (10). This animal model is relevant to human pathology, since the developmental biology and physiology of the fetal lamb closely resemble those in humans (11). In addition, this model allows us to perform complex fetal surgery. Using this translational model, we have shown that intra-amniotic (IA) exposure to LPS, IL-1 $\alpha$, or Ureaplasma provokes an intestinal inflammation in fetal sheep, characterized by increased influx of neutrophils and effector T cells (Teff) with concomitant mucosal injury and disturbed ileal maturation $(10,12,13)$. This inflammatory reaction was preceded by depletion of regulatory $\mathrm{T}$ cells (Treg) which decreased the Treg/Teff cell balance (12). Importantly, this feature reproduces what has recently been found in neonates suffering from NEC and the loss of intestinal Treg cells is now considered to play an essential role in NEC pathology (14).

Treg cells that are characterized by expression of CD4, CD25hi and the transcription factor FoxP3 are critical for immune homeostasis in different organs including the intestinal tract (15). Disruption of Treg cell development and/or function is causally linked with pathologies including infectious diseases, autoimmunity and inflammatory bowel disease (16). Treg cell development, expansion, activity and survival depend on $\gamma_{c}$ cytokines, most notably IL-2 $(17,18)$, and IL-2 administration is associated with beneficial effects in controlling autoimmune and inflammatory diseases 
$(17,19)$.

We therefore hypothesized that prophylactic administration of IL-2 would preferentially expand Treg cells and augment the Treg/Teff cell ratio in the fetal gut thereby preventing chorioamnionitis-induced intestinal inflammation and mucosal injury. We first performed a pilot study and determined that a clinically relevant intravenous dose of IL-2 (20) increased the absolute number of Treg cells in the gastrointestinal tract of fetal lambs. Because previous experiments from our group did not reveal dose-dependent inflammatory changes in the amniotic cavity and fetal lung when we tested the effect of 1, 4 or $10 \mathrm{mg}$ LPS (21), a dose of $5 \mathrm{mg}$ LPS was given IA. As the presence of LPS in cord plasma was recently associated with chorioamnionitis and prematurity (2), IA delivery of LPS was used to model the fetal inflammatory response to bacteria. For this purpose, LPS was administered IA 2 or 7 days before preterm delivery in the presence or absence of IL-2 (the experimental design is presented in Materials and Methods). The immuno-modulatory effects of IL-2 treatment were studied by evaluating the $\mathrm{T}$ cell influx in the fetal mesenteric lymph node (MLN) and intestine, and by analyzing the peripheral $\mathrm{T}$ cell response. In addition, the cytokine profile and gut wall integrity of the fetal ileum were analyzed.

\section{Materials and Methods}

\section{Animals}

The Animal Ethics Board of Maastricht University, the Netherlands, approved all experiments according to Dutch governmental regulations.

\section{Experimental procedures and design}

Fetuses of time-mated Texel ewes were instrumented at 114 days of gestational age (GA) as previously described with slight modifications (22). Ewes were anesthetized by induction of thiopental $(15 \mathrm{mg} / \mathrm{kg})$ intravenously. During surgery, general anesthesia was maintained by $1 \%$ to $2 \%$ isoflurane and followed by remifentanil $\left(0.75 \mu \mathrm{g} \mathrm{kg} \mathrm{min}^{-1}\right.$ ) intravenously for analgesia. A catheter was introduced to the maternal saphenous vein to obtain blood samples and administer prophylactic antibiotics during four days of 
recovery after surgery. Fetuses were exposed by median laparotomy and two 3.5 French umbilical vessel catheters (Covidien, Mansfield, MA, USA) were placed in the femoral artery and vein. An amniotic catheter was introduced to obtain access to the amniotic cavity and to record amniotic pressure. Finally, catheters were exteriorized through the flank of the ewe and were continuously flushed (except from the amniotic catheter) with heparinized saline $(25 \mathrm{IU} / \mathrm{mL}, 0.2 \mathrm{~mL} / \mathrm{h})$. After surgery, animals were housed in a confined space to allow recovery. Ewes had ad libitum access to water and food and their welfare was daily evaluated by certified personnel.

\section{In vivo evaluation of intravenous IL-2 administration}

Fetuses were instrumented at 114 days of GA. After four days of recovery (118 days of GA), fetuses were randomly assigned to either receive IL-2 (proleukin human IL-2; Novartis Pharma B.V, Arnhem, The Netherlands) through a venous catheter for four consecutive days (122 days of GA) or heparinized saline (25 IU/mL, $0.2 \mathrm{~mL} / \mathrm{h}$ ). Because we have shown in earlier in vitro experiments that ovine splenocytes respond in a similar range to human recombinant IL-2 as human splenocytes (22), a clinically relevant pharmacological dose of 250,000 IU/kg/day (20) was used. On day 122 of GA, ewes and fetuses were sacrificed by intravenous overdose of sodiumthiopental $20 \%$ (Euthanal 20\%) and MLN was collected for analysis.

\section{Chorioamnionitis model}

Fetuses were instrumented and after four days of recovery, animals were randomly assigned to receive heparinized saline $(25 \mathrm{IU} / \mathrm{mL}, 0.2 \mathrm{~mL} / \mathrm{h})$ or IL-2 $(250,000$ $\mathrm{IU} / \mathrm{kg} /$ day) through a venous catheter for 4 consecutive days (122 days of GA). On day 122 of GA, ewes were assigned to receive a single IA dose of LPS (5 mg, Sigma) or equivalent volume of saline. Thereafter, ewes and fetuses were housed for two $(2 \mathrm{~d}$ exposure) or seven days (7 d exposure) and killed at 124 or 129 days of GA (term at 147 days), respectively (Fig. 1). These gestational ages of the fetal lambs are approximately comparable to $27-28$ weeks of gestation in humans, simulating a premature delivery. 


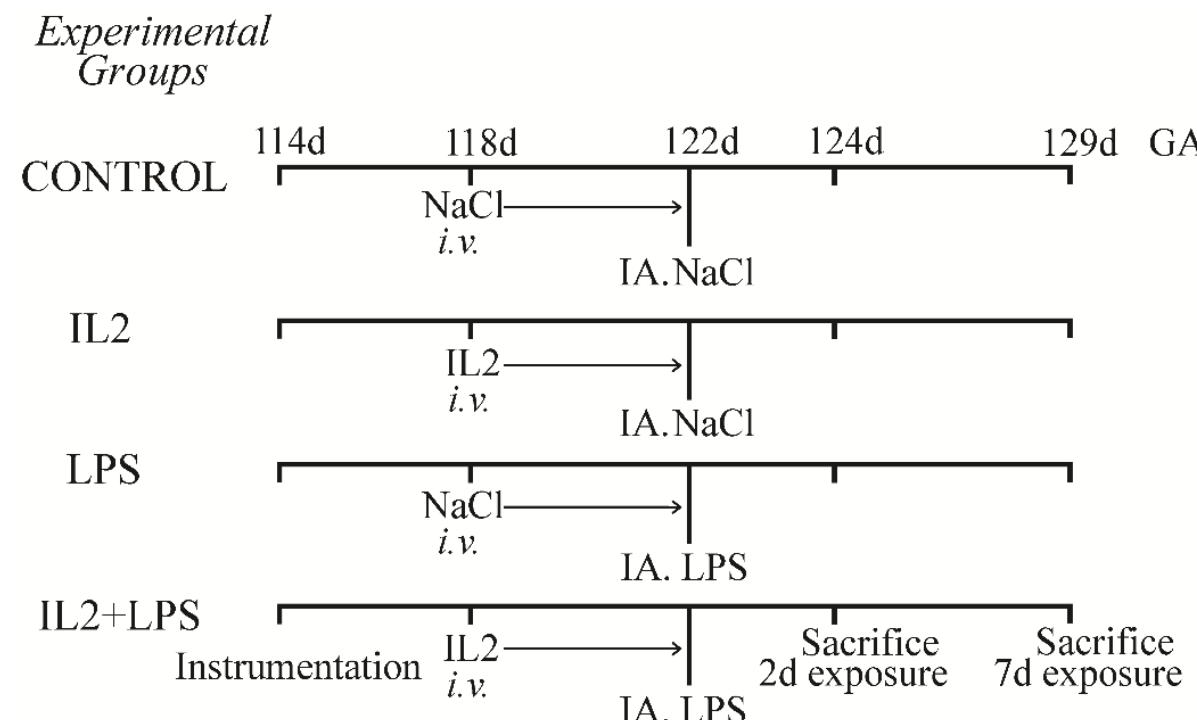

Figure 1. Experimental design of animals that were exposed to LPS for 2 or 7 days with or without prophylactic IL-2 treatment (250,000 IU/kg/day). d: days, GA: gestational age, IA: intra-amniotic, IL: interleukin, i.v.: intravenous, LPS: lipopolysaccharide.

\section{Antibodies}

The following antibodies were used: rabbit antibody against human CD3, MPO from Dakocytomation (Glostrup, Denmark) and intestinal fatty acid binding protein (IFABP) from Hycultbiotech (Uden, the Netherlands); rabbit antibody against mouse Zonula occludens protein 1 (ZO-1) from Invitrogen (San Francisco, CA); monoclonal mouse antibody against human FoxP3 from Bioscience (San Diego, CA). As secondary antibodies, Texas Red conjugated goat-anti-rabbit from Southern Biotechnology (Birmingham, AL); biotin conjugated swine-anti-rabbit or goat-anti-mouse from Dakocytomation and peroxidase conjugated goat-anti-rabbit from Jackson (West Grove, PA) were used. For flow cytometry, mouse antibodies against sheep CD4 (CD4AlexaFluor 647, clone 44.38), CD25 (CD25-FITC, clone 9.14), CD45 (CD45-biotin, clone 1.11.32), all from AbDSerotec (Düsseldorf, Germany) and rat anti-mouse/rat FoxP3 from eBioscience (FoxP3-PE, clone FJK-16s, San Diego, CA) were used. For 
labeling of CD $45^{\dagger}$ cells, streptavidin Horizon V450 from BD Bioscience (Bleiswijk, the Netherlands) was used.

\section{Immunohistochemistry}

Fetal fixed ileum and MLN were embedded in paraffin and $4 \mu \mathrm{m}$ sections were prepared. Morphological changes were assessed following a hematoxylin and eosin staining (H\&E). Inflammatory cell infiltration and mucosal injury were evaluated by immunohistochemical staining for T-lymphocytes (CD3), FoxP3, myeloperoxidase (MPO) and I-FABP. Endogenous peroxidase activity was blocked with $0.3 \% \mathrm{H}_{2} \mathrm{O}_{2}$ diluted in tris-buffered saline (MPO), phosphate-buffered saline (CD3, FoxP3) or methanol (I-FABP). Nonspecific binding was blocked with normal goat serum (MPO, FoxP3) or bovine serum albumin (CD3, I-FABP) for 30 minutes (MPO, CD3 and FoxP3) or $1 \mathrm{~h}$ (I-FABP). Thereafter, sections were incubated with the primary antibody of interest for $1 \mathrm{~h}$ (MPO) at room temperature or overnight at $4{ }^{\circ} \mathrm{C}(\mathrm{CD} 3, \mathrm{FoxP} 3$ and I-FABP). Sections were incubated with a secondary biotin (CD3, FoxP3) or peroxidase (MPO, I-FABP)-conjugated antibody. Substrate staining for MPO and I-FABP was performed with 3-amino-9-ethylcarbazole (AEC, Sigma); nuclei were counterstained with hematoxylin. CD3 and FoxP3 reactivity were detected by using nickel-DAB. Positive stained cells were counted per high power field (200x). I-FABP-expressing cells were counted in the upper one-third of the villi tips. The average number of positive cells per high power field per animal is given. To avoid bias, appropriate sections (corresponding to animals of each experimental group) received an encryption number before counting and were scored by three independent investigators who were blinded to the treatment arm.

\section{Immunofluorescence}

Fetal ileum was embedded in Optimal Cutting Temperature (OCT) compound and $4 \mu \mathrm{m}$ sections were cut. Tight junction morphology was evaluated by immunofluorescence staining against ZO-1 as previously described (10). Briefly, after 
blocking the non-specific binding, ileal sections were incubated with primary antibody ZO-1 for 1 hour followed by incubation with a secondary Texas Red-conjugated antibody. Nuclei were stained with 4',6'-diamino-2-phenyl indole (DAPI). The distribution of ZO-1 was examined by using the Metasystem Image Pro System (black and white charge-couple device camera; Metasystems, Sandhausen, Germany) mounted on a Leica DM-RE fluorescence microscope (Leica, Wetzler, Germany).

\section{RNA Extraction and Quantitative Real-Time PCR (qPCR)}

The messenger RNA (mRNA) expression of cytokines was measured by quantitative real-time PCR (qPCR) as previously described with slight modifications (23). Briefly, total RNA was isolated from ileum by Trizol/chloroform extraction. Reverse transcription was performed by using RevertAid First Strand cDNA Synthesis Kit (Roche-Applied, Mannheim, Germany). Quantitative real-time PCR was performed with the LightCycler 480 SYBR Green I Master mix (Roche Applied Science, Almere, the Netherlands) in a LightCycler 480 with specific ovine primers (Table 1). Quantitative real-time PCR results were normalized to the housekeeping gene ovine $40 \mathrm{~S}$ ribosomal protein S15 (ovRPS15), and mean fold changes in mRNA levels are presented relative to control.

\section{Sample processing for Flow Cytometry}

After death, single-cell suspensions of spleen and MLN were obtained by dissociation in gentle MACS C-tubes from Miltenyi (Leiden, the Netherlands) filled with Gibco Iscove's Modified Dulbecco's Medium from Life Technologies (Bleiswijk, the Netherlands) using the gentleMACS Dissociator from Miltenyi (Leiden, the Netherlands). Cell suspensions were passed through a 70- $\mu \mathrm{m}$ cell strainer from BD Biosciences (Erembodegem-Aalst, Belgium) and stored in freezing medium (Iscove's Modified Dulbecco's Medium, 10\% heat-inactivated FCS, 10\% DMSO) in liquid nitrogen. 
Table 1. Oligonucleotide Primers Used for

Quantitative Real-time Polymerase Chain Reaction

\begin{tabular}{ll}
\hline Primer & \multicolumn{1}{c}{ Sequence (5'-3') } \\
\hline ovRPS15 Fw & CGAGATGGTGGGCAGCAT \\
ovRPS15 Rv & GCTTGATTTCCACCTGGTTGA \\
IL-1 Fw & AGAATGAGCTGTTATTTGAGGTTGATG \\
IL-1 Rv & GTGAGAAATCTGCAGCTGGATGT \\
TNF- $\alpha$ Fw & GCCGGAATACCTGGACTATGC \\
TNF- $\alpha$ Rv & CAGGGCGATGATCCCAAAGTAG \\
IL-6 Fw & ACATCGTCGACAAAATCTCTGCAA \\
IL-6 Rv & CGGAGTGTCTCCTTGCTGTTT \\
IL-10 Fw & CATGGGCCTGACATCAAGGA \\
IL-10 Rv & CGGAGGGTCTTCAGCTTCTC \\
IL-17 Fw & TGTGAGGGTCAACCTGAACAT \\
IL-17 Rv & TGATAATCGGTGGGCCTTCTG \\
IL-8 Fw & GTTCCAAGCTGGCTGTTGCT \\
IL-8 Rv & GTGGAAAGGTGTGGAATGTGTTT \\
IFN- $\gamma$ Fw & TCAAGCAAGACATGTTTCAGAAGTTCT \\
IFN- $\gamma$ Rv & CCGGAATTTGAATCAGCCTTTTGAA \\
IL-4 Fw & TGCCTGTAGCAGACGTCTTTG \\
IL-4 Fw & GCCCTGCAGAAGGTTTCCT \\
\hline
\end{tabular}

Fw: forward, IFN: interferon, IL: interleukin, Rv: reverse.

\section{Flow cytometry analysis}

Single-cell suspensions of MLN and spleen were stained for detection of CD45, CD4 $4^{*}, \mathrm{CD} 25^{+}$and Treg (identified as CD4CD25hiFoxP3) cells according to manufacturer's protocol. Stained cells were acquired on a FACS Canto II (BD) Biosciences) flow cytometer equipped with FACS Diva software (version 6.1.2; BD Biosciences). 


\section{Statistics}

Statistical analysis was performed with GraphPad Prism software (version v5.0; GraphPad Software Inc.). Data were analyzed by using a nonparametric Kruskal Wallis test, followed by Dunn's post-hoc test. Significance was established at p<0.05.

\section{Results}

\section{Preferential Treg cell expansion by IL-2 treatment.}

To evaluate whether IL-2 administration induced preferential Treg cell expansion in the gastrointestinal tract of the fetus, we performed flow cytometric analysis on MLN directly after IL-2 treatment, being immediately at the end of four days of continuous intravenous IL-2 infusion. Intravenous IL-2 administration induced preferential Treg cell (identified as CD $4{ }^{+} \mathrm{CD} 25$ hiFoxP $3^{+} \mathrm{T}$ cells) accumulation in MLN compared with control (Control 7.4\% vs. IL-2 15.0\% Treg cells in CD4+ cells) (Figs. 2A, B). The increased number of Treg cells in the MLN was accompanied by increased expression of FoxP3 per cell (a transcription factor predominantly expressed by Treg cells (24) but also by a small fraction of activated effector $\mathrm{T}$ cells), as evaluated by fluorescence intensity (MFI) of FoxP3 in the Treg cell population (FoxP3 MFI of 2.066 vs 2.752 in control and IL-2-treated animals, respectively, data not shown). In addition, Treg cells were localized in MLN by immunohistochemistry staining for FoxP3. Consistent with the flow cytometric analysis, increased Treg cell numbers were shown directly after IL-2 treatment and these cells were located in the paracortex, where stimulated T lymphocytes proliferate (data not shown). 
A.
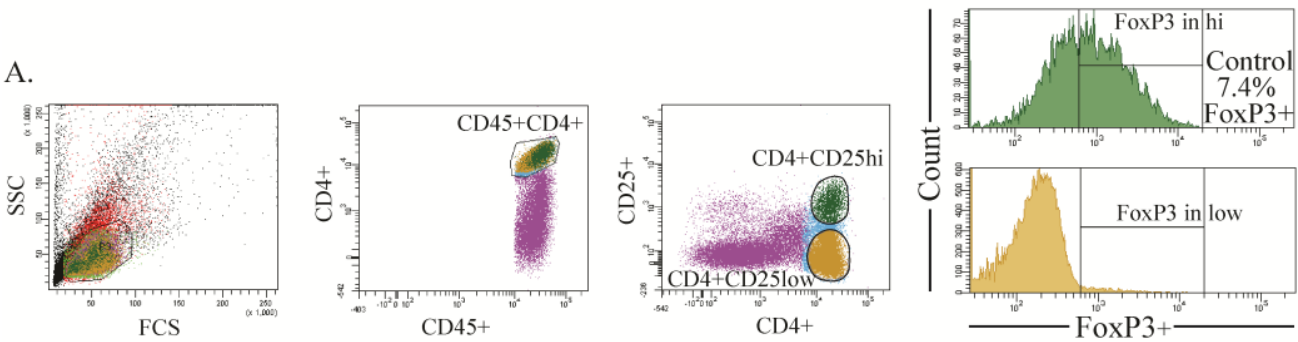

B.
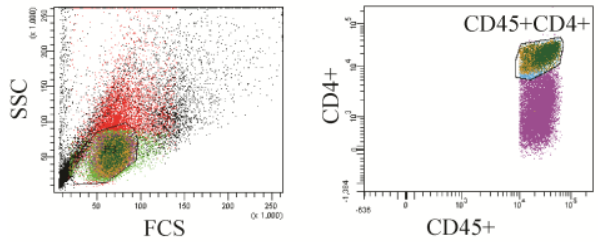

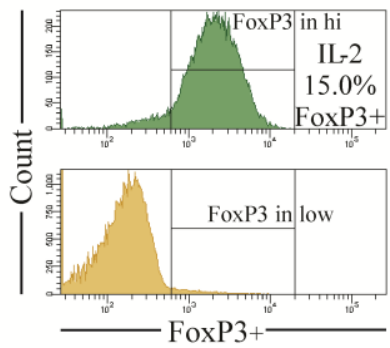

Figure 2. Preferential expansion of Treg cells (CD4CD25hiFoxP3+) by IL-2 in MLN directly after the end of IL-2 treatment. A gate was set on lymphocytes in forward and side scatter, in which the $\mathrm{CD} 45^{+} \mathrm{CD} 4^{+} \mathrm{T}$ cells were gated. From this population the $\mathrm{CD} 4 \mathrm{CD} 25^{+}$double positive cells with high and low expression of CD25 were selected. In these two populations, the expression of FoxP3 was analyzed in histograms. Gating strategy and FoxP3 content (histograms) of 7.4\% CD4 CD25hiFoxP3 in $\mathrm{CD} 4{ }^{+}$cells in control animals (A). Gating strategy and Foxp3 content of $15.0 \%$ CD4 CD25hiFoxP3 in CD4 $4^{+}$cells in IL-2-treated animals (B). Gating for FoxP3 was based on the expression of FoxP3 in CD45 CD4: cells in MLN (data not shown). FSC: forward scatter, SSC: side scatter.

The absolute increase of Treg cell numbers in the MLN, which occurred within 4 days of IL-2 administration, returned to baseline levels within 2 days after ending IL2 treatment, as shown by FACS analysis (Supplementary fig. 1) and immunohistochemistry (data not shown). 


\section{Prophylactic IL-2 treatment in the course of chorioamnionitis}

\section{Inflammatory cell influx in fetal intestine}

Next, the pharmacological effects of prophylactic IL-2 administration were evaluated in our chorioamnionitis model. We first examined whether IL-2 treatment caused accumulation of Treg cells in the fetal gut by immunohistochemistry staining of FoxP3. Intravenous IL-2 administration significantly increased the number of FoxP3 ${ }^{+} \mathrm{T}$ cells in the fetal gut when compared to control animals at 2 and 7 days post IL-2 treatment (Fig. 3). In contrast, the number of FoxP3 ${ }^{+} \mathrm{T}$ cells of animals which were exposed to LPS or IL-2 + LPS for 2 or 7 days, were not significantly different when compared to controls (Figs. 3C, D).

LPS exposure for 2 or 7 days significantly increased $\mathrm{CD}^{+} \mathrm{T}$ cell numbers in the fetal intestine when compared with controls, as evaluated by immunohistochemistry (Figs. 4A-D). The increased influx of $\mathrm{CD}^{3} \mathrm{~T}$ cells after IA LPS exposure was prevented by prophylactic IL-2 administration (Figs. 4A-D). Numbers of CD $3+\mathrm{T}$ cells significantly increased 2 days after IL-2 administration compared with controls (Fig. 4C).

We next evaluated the proportions of FoxP3 $3^{+}$cells relative to total $\mathrm{CD}^{3} \mathrm{~T}$ cells in the fetal intestine. Relative to controls, 2 days of LPS exposure resulted in a significant decrease of the FoxP3/CD3 ratio (Fig. 4E), and this reduction was prevented by prophylactic IL-2 treatment (Fig. 4E). The ratio of FoxP3 to CD3 was significantly increased 2 days after IL-2 administration. In the 7-day group, a significant increase of the FoxP3/CD3 ratio was detected in the IL-2-treated animals when compared with control or LPS-exposed animals (Fig. 4F). 


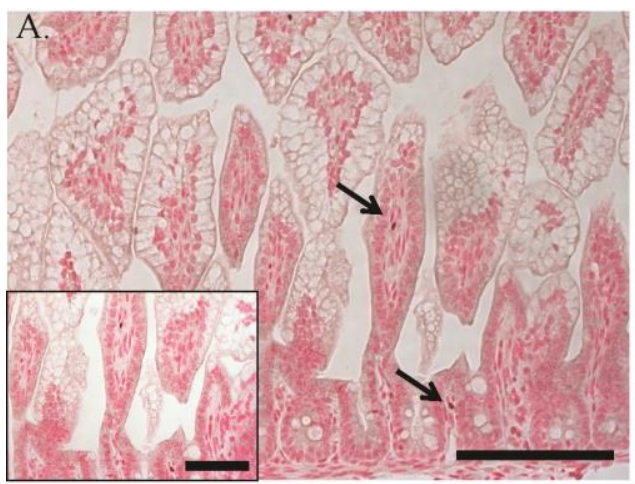

C.

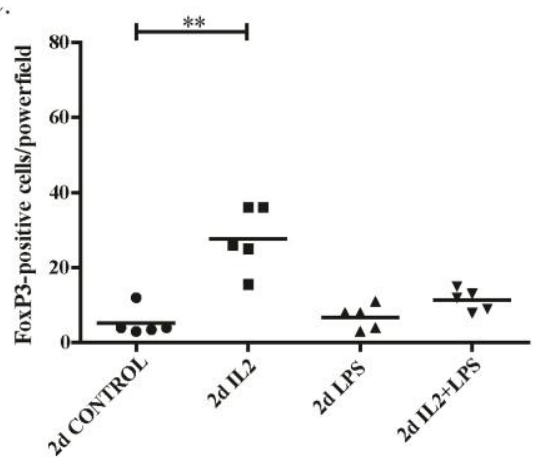

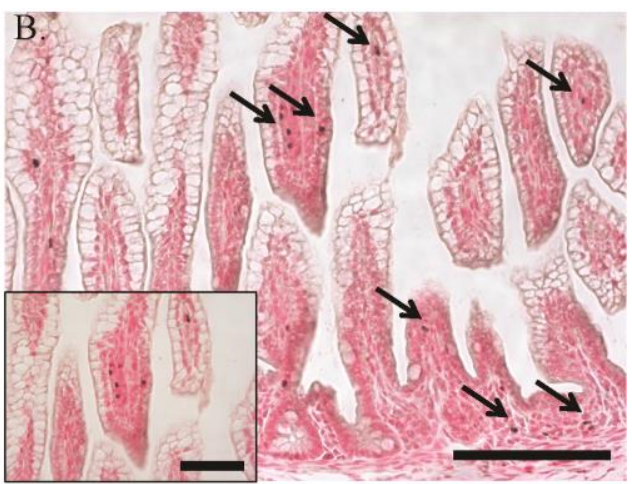

D.

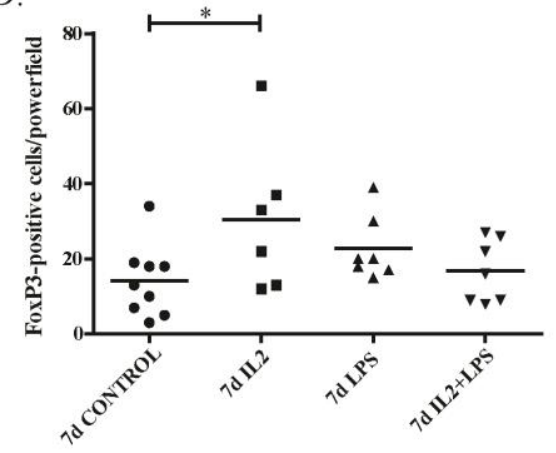

Figure 3. Increased FoxP3 $3^{+}$cells in the fetal ileum 2 and 7 days after IL-2 treatment. Representative sections of fetal ileum were stained by immunohistochemistry for FoxP3 of (A) 2 day-control and (B) 2 day-IL-2-treated animals. For each experimental group, positive expressing cells of (C) 2 day-FoxP3 and (D) 7 day-FoxP3 $3^{+}$cells were counted, and the mean cell counts per high power field per animal is given. The scale bar in (A and B) represents $100 \mu \mathrm{m}$. The scale bar in insets represents 50 $\mu \mathrm{m}$. Original magnification X200. For inset, X400 magnification was used. ${ }^{*} \mathrm{p}<0.05$ and ${ }^{*}{ }^{*} \mathrm{p}<0.01$. LPS: lipopolysaccharide.

Importantly, LPS exposure for 2 or 7 days significantly increased the number of $\mathrm{MPO}^{+}$cells (mainly neutrophils(25)) compared with controls whereas this increase was significantly prevented in 2 days LPS-exposed animals that were pretreated with IL2 (Fig. 4G). Significantly increased numbers of $\mathrm{MPO}^{+}$cells were also observed in IL-2treated animals when compared with controls (Fig. 4G). 


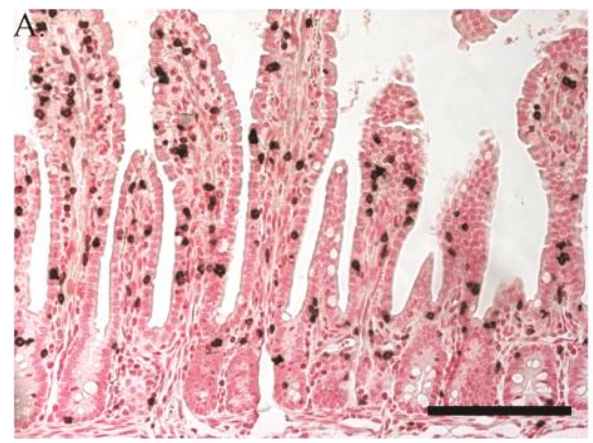

C.

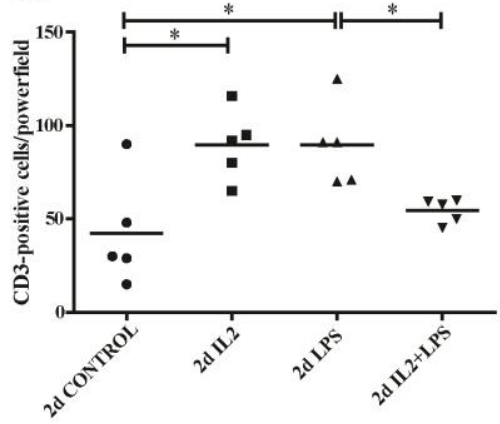

E.

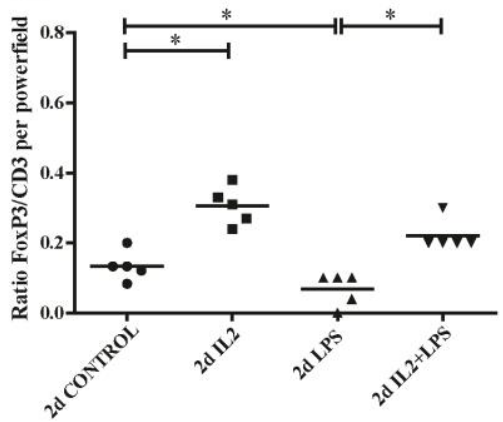

G.

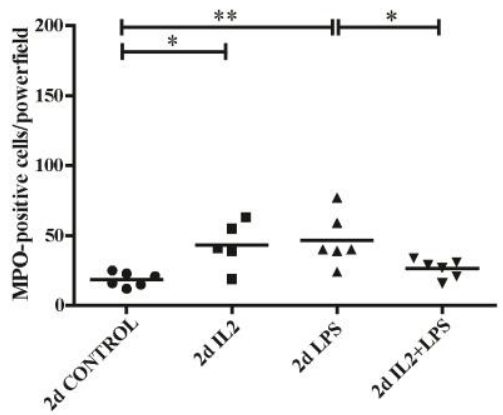

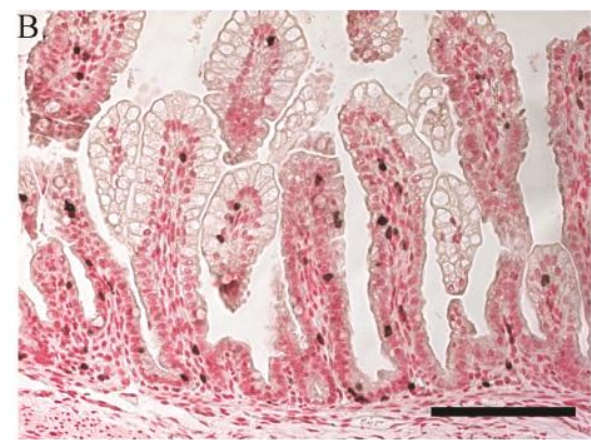

D.

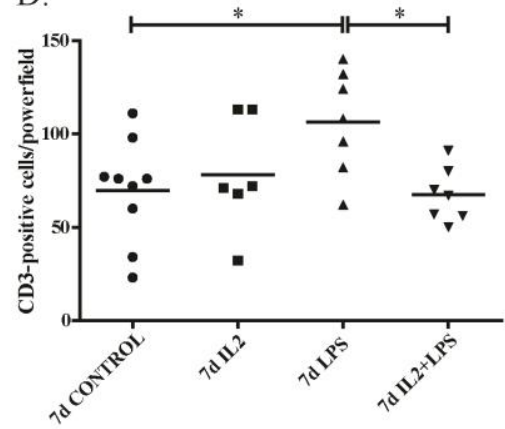

F.

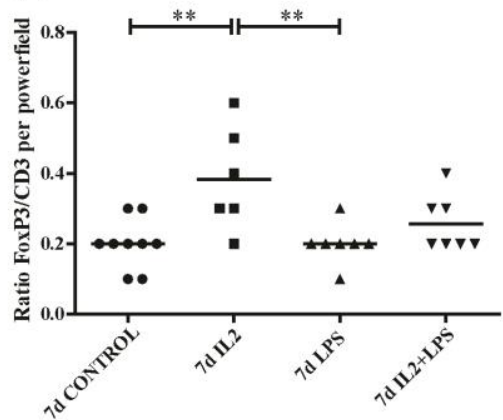

$\mathrm{H}$.

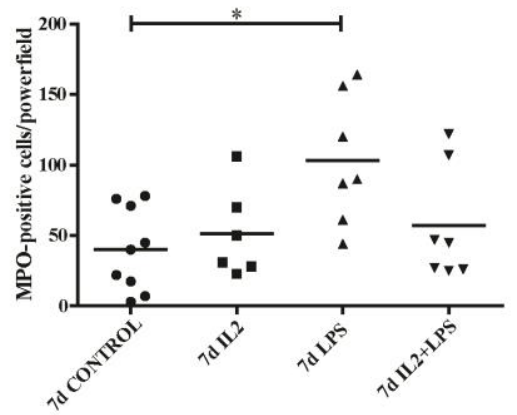


Figure 4. Number of infiltrating inflammatory cells in the fetal ileum assessed by immunohistochemistry. Representative sections stained for $\mathrm{CD}^{+}$of (A) 2-day LPS and (B) 2-day IL2+LPS-treated animals. For each experimental group, positive expressing cells of (C) 2-day CD3, (D) 7-day CD3 $3^{+}$, (E) 2-day FoxP3\% $/ \mathrm{CD}^{+}$, (F) 7-day FoxP3 $/ \mathrm{CD}^{+}$, (G) 2-day MPO ${ }^{+}$, and (H) 7-day $\mathrm{MPO}^{+}$were counted, and the mean cell counts per high power field per animal is given. The scale bar in (A and B) represents $100 \mu \mathrm{m}$. Original magnification X200. ${ }^{*} \mathrm{p}<0.05$ and ${ }^{*}{ }^{*} \mathrm{p}<0.01$. LPS: lipopolysaccharide, MPO: myeloperoxidase.

\section{Cytokine mRNA levels}

To evaluate whether the influx of inflammatory cells in the gut by IL-2 treatment was associated with changes in the intestinal cytokine profile, we assessed the mRNA levels of inflammatory proteins in the fetal intestine. LPS exposure for 2 days significantly increased the mRNA levels of IL-17 when compared with controls (Fig. 5A). The increased IL-17 mRNA levels were significantly inhibited by IL-2 treatment prior to 2 days LPS exposure (Fig. 5A). IL-17 mRNA expression was not detectable in animals exposed for 7 days (data not shown).

IL-2 treatment before LPS exposure significantly decreased the gut mRNA levels of TNF- $\alpha$ and IL-1, at 2 days after IA LPS administration compared with controls (Figs. 5C, H). At day 2, the intestinal IFN- $\gamma$ mRNA levels were 3-fold higher in the IL$2+$ LPS group than in the control or LPS groups (Fig. 5G). Compared with control animals, intestinal IL-1 mRNA levels were significantly reduced at 2 days after IL-2 administration (Fig. 5H).

IL-6 mRNA levels in 7-day LPS exposed animals were significantly elevated compared with those of controls, and this increase was prevented by prophylactic IL-2 treatment (Fig. 6B). Significantly, increased mRNA levels of IL-1, IL-4, IL-10, IL-8 and IFN- $\gamma$ were observed 7 days after IL-2 administration (Figs. 6A, D-G). 
A.

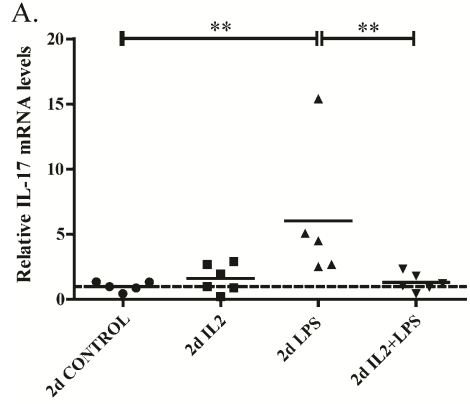

C.

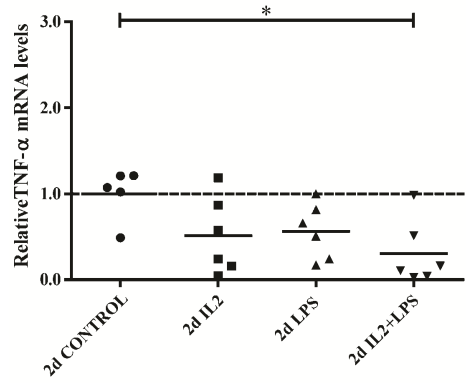

E.
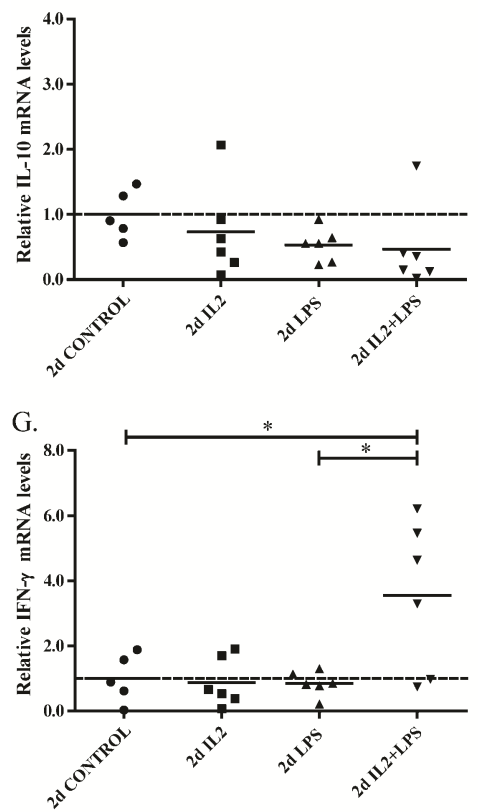

B.

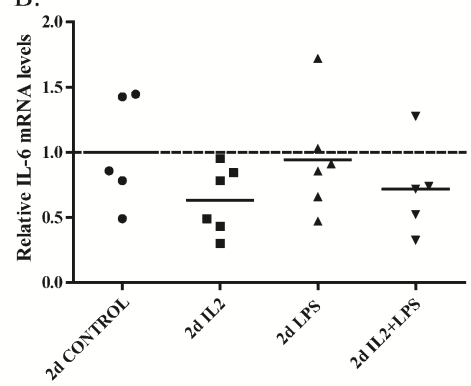

D.

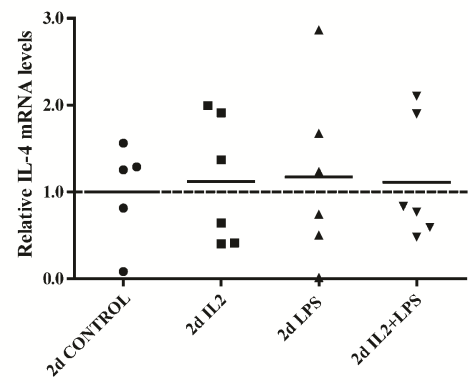

F.
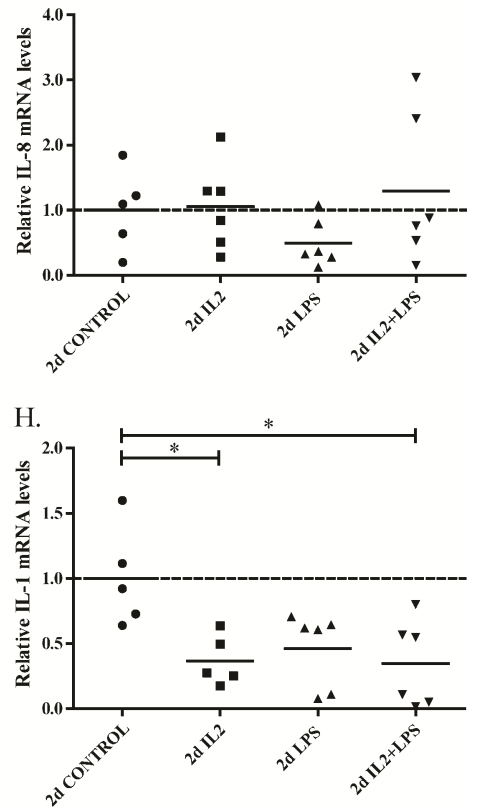

Figure 5. Cytokine mRNA levels in terminal ileum of animals exposed for 2 days. The inflammatory cytokines: (A) IL-17, (B) IL-6, (C) TNF- $\alpha$, (D) IL-4, (E) IL-10, (F) IL-8, (G) IFN- $\gamma$, and (H) IL-1 were assessed by quantitative real-time PCR (qPCR). ${ }^{*} \mathrm{p}<0.05$ and ${ }^{*}$ p $<0.01$. d: days, LPS: lipopolysaccharide. 
A.

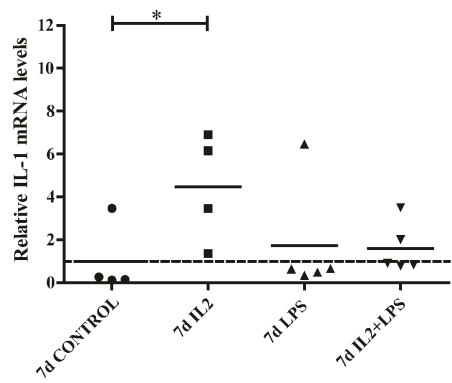

C.

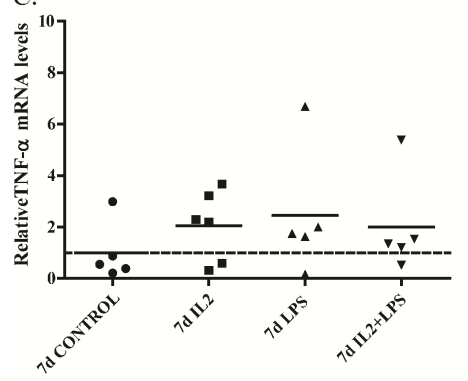

E.

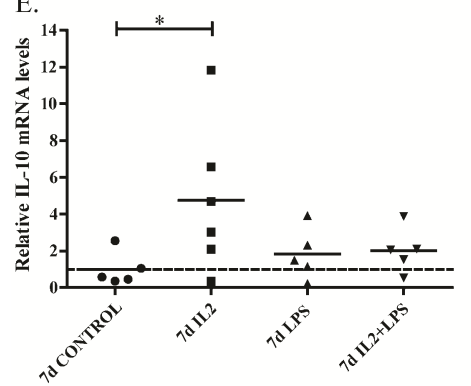

G.

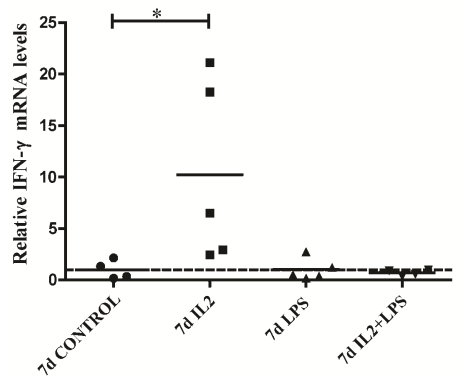

B.
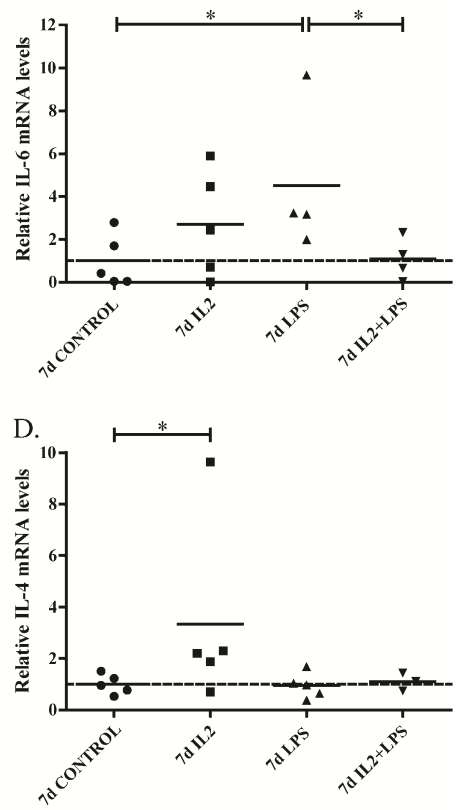

F.

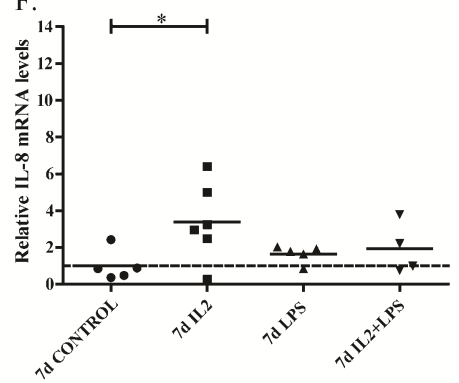

Figure 6. Cytokine mRNA levels in terminal ileum of animals exposed for 7 days. The inflammatory cytokines: (A) IL-1 (B) IL-6 (C) TNF- $\alpha$ (D) IL-4 (E) IL-10 (F) IL-8 and (G) IFN- $\gamma$ were assessed by quantitative real-time PCR (qPCR). ${ }^{*} \mathrm{p}<0.05$. d: days, LPS: lipopolysaccharide. 


\section{Intestinal damage}

First, H\&E staining was performed to evaluate morphological changes. Clear signs of intestinal epithelial injury were observed at 7 days post LPS exposure (data not shown) which was confirmed an extended by immunohistochemical analysis for IFABP, a small protein that is present in the cytosol of enterocytes and is released upon epithelial injury. In control animals, I-FABP was located along the villus (Fig. 7A), a staining pattern characteristic for this gestational age (13). In contrast, IA LPS exposure resulted at 7 days in severe morphological epithelial damage in the tips of many villi as indicated by the reduced numbers of I-FABP-expressing cells lining the tips of the villi (Fig. 7E) and accumulation of luminal debris (Figs. 7C, E). This severe mucosal injury in LPS-exposed animals was prevented by prophylactic IL-2 treatment (Figs. 7D, E).

Finally, we assessed the expression pattern of the tight junction protein ZO-1, a protein involved in the regulation of intestinal paracellular barrier sealing. In control animals, the distribution of ZO-1 was fragmented (Fig. 8A), and this characteristic pattern at this GA (10) remained unchanged 7 days after IL-2 exposure (Fig. 8B). After 7 days of LPS exposure, ZO-1 expression was further fragmented compared with control animals (Fig. 8C). IL-2 treatment before LPS exposure completely prevented this pronounced ZO-1 fragmentation (Fig. 8D). 

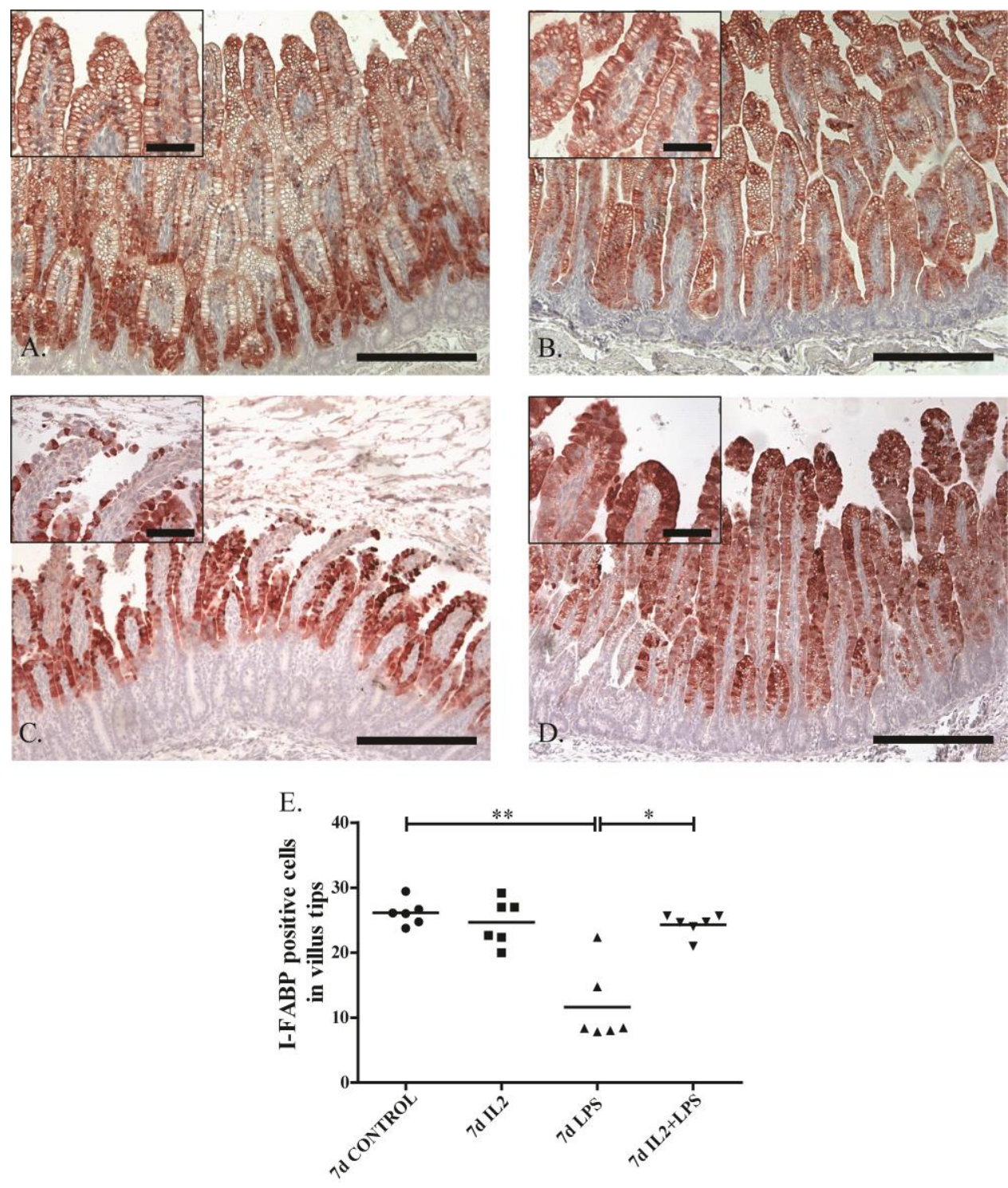

Figure 7. Immunolocalization of I-FABP and cell counts of I-FABP-expressing cells in the fetal terminal ileum of 7 days exposed animals. I-FABP is expressed in enterocytes along the villus in control animals (A). IL-2 administration did not affect the constitutive I-FABP distribution (B). Animals exposed to LPS for 7 days presented with damaged enterocytes and I-FABP release (C). IL2 administration before 7 days of LPS exposure prevented epithelial injury and concomitant I-FABP leakage (D). For each experimental group, the I-FABP expressing cells in the upper one-third of the villi tips were counted, and the mean cell counts per high power field per animal is given (E). The scale bar in panels represents $200 \mu \mathrm{m}$. The scale bar in insets represents $50 \mu \mathrm{m}$. Original magnification X100x. For inset, X400 magnification was used. ${ }^{*} \mathrm{p}<0.05$ and ${ }^{*}{ }^{*} \mathrm{p}<0.01$. LPS: lipopolysaccharide. 

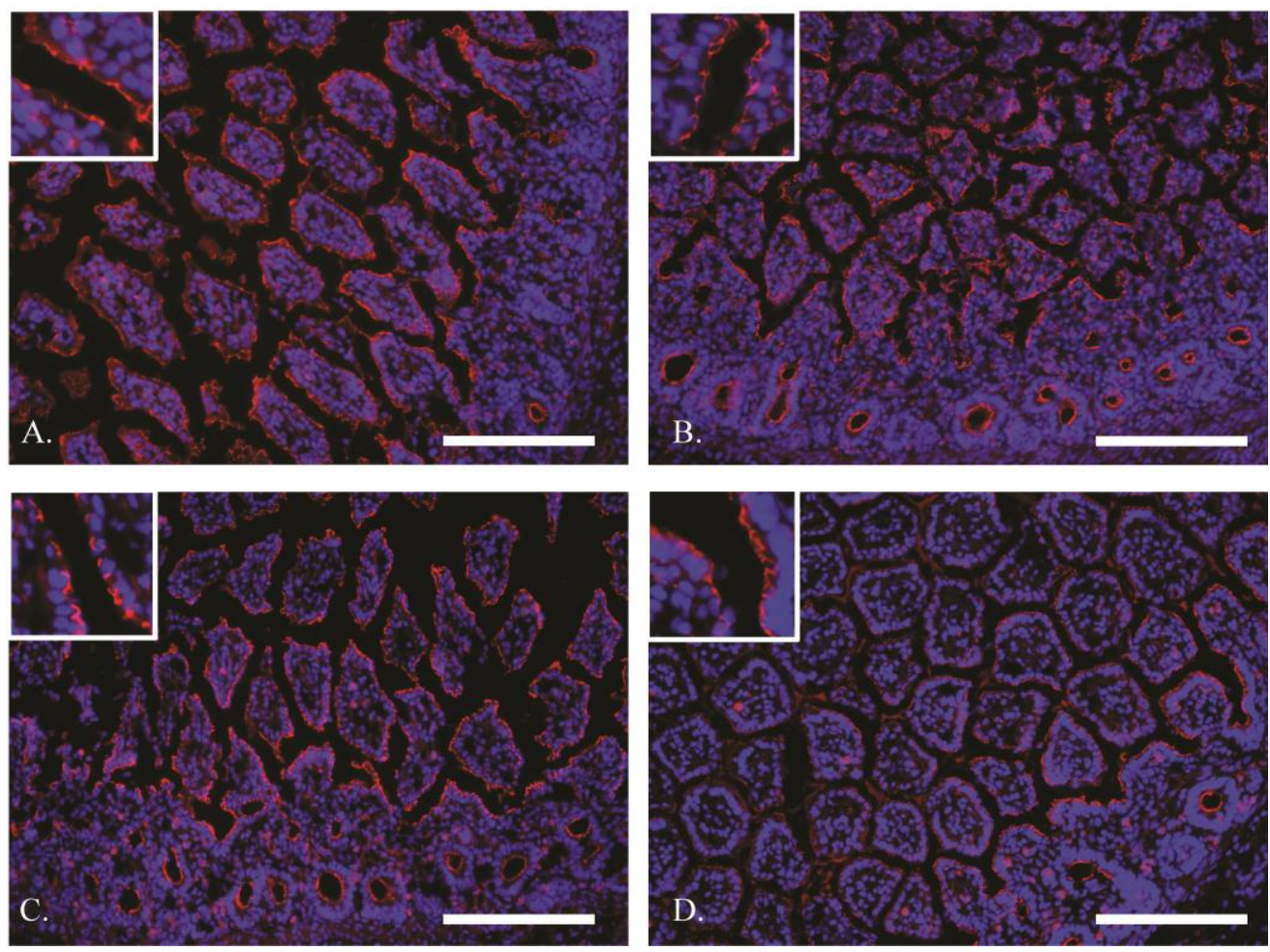

Figure 8. Distribution of ZO-1 in the fetal terminal ileum of animals exposed for 7 days. Control animals appeared with fragmented ZO-1 expression along the epithelium, a characteristic pattern of this GA (A). IL-2 treatment did not influence the expression of ZO-1 (B). LPS exposure for 7 days revealed further fragmentation of ZO-1 compared with controls (C). IL-2 pretreatment restored the disturbed fragmentation of ZO-1 presenting similar to control appearance indicative of solid barrier integrity (D). For each experimental group, 6 animals were evaluated. The scale bar in panels represents $100 \mu \mathrm{m}$. Original magnification X200. For inset, X1000 magnification was used. LPS: lipopolysaccharide. 


\section{Discussion}

In this study, we show in a preclinical model that prophylactic intravenous IL2 treatment can protect the fetal gut against inflammation and mucosal injury in the course of chorioamnionitis. The protective effects of IL-2 treatment in the LPS-exposed animals could be explained by different mechanisms that appear to be time-dependent.

In the early phase (2 d) after IL-2 administration, increased intestinal Treg cell numbers were observed and the FoxP3/CD3 ratio was maintained in IL-2 + LPS animals, compared with LPS animals. We therefore speculate that this early change in Treg cell homeostasis due to IL-2 treatment might prevent the LPS-induced influx of effector CD $3{ }^{+}$cells $(18,26)$, which we have previously described. In addition, IL-2 administration alone induced $\mathrm{CD}^{+}$cells in the fetal gut at this stage. This could be explained by the fact that not only Treg cells but also activated conventional $\mathrm{CD} 4^{+}$and CD8 ${ }^{+} \mathrm{T}$ cells can co-express all 3 subunits of IL-2 receptor (CD25, CD122 and $\gamma_{c}$ ), which are necessary to generate the high affinity IL-2 receptor (27). However, consistent with previous studies administering IL-2 in humans or other species (20, 28), we found that IL-2 appears to have a preferential effect on Treg cells as the FoxP3/CD3 ratio was significantly increased in animals that received IL-2.

Various mechanisms are orchestrated by Treg cells to control Teff cells including cell-cell contact-dependent suppression, induction of Teff cell death, and secretion of suppressive cytokines such as IL-10 (29). However, because gut IL-10 mRNA levels remained unaltered at 2 days post IL-2 administration, this latter mode of suppression seems unlikely in this early phase. Of note, Treg cells were able to suppress pulmonary inflammation independently of IL-10 secretion, in a murine model of influenza infection (30). Consistent with this proposed mechanism, modulation of the Treg/Teff cell balance by induction of Treg cells in the immature intestine following adoptive transfer, oral Lactobacillus reuteri administration or dietary GD3 ganglioside supplementation has been shown to be protective in different rodent models of NEC (31-34). Importantly, priming for postnatal complications including NEC can already be initiated during pregnancy $(35,36)$. 
Alternatively and non-exclusively, prophylactic IL-2 treatment might protect the fetal gut against inflammation at this stage by preventing IL-17 induction $(37,38)$. This hypothesis is supported by decreased gut mRNA levels of IL-17 after 2 days of prophylactic IL-2 treatment. Of note, experiments in a rhesus macaque model of chorioamnionitis revealed that IA exposure to inflammatory cytokines rapidly changed the Treg/Th17 balance (39). Moreover, a reduced influx of neutrophils was found in IL-2-pretreated animals, which was associated with reduced gut IL-17 mRNA levels, a cytokine involved in neutrophil recruitment (40).

During the later phase $(7 \mathrm{~d})$, normalization of the Treg/Teff ratio was detected in LPS-exposed animals including those that had received prophylactic IL-2 treatment. However, we observed decreased numbers of $\mathrm{CD} 3^{+} \mathrm{T}$ cells at day 7 and no signs of intestinal inflammation (cytokines) and epithelial injury in animals that were pretreated with IL-2 before IA LPS exposure. Thus, our data suggest that IL-2 created early on an anti-inflammatory environment. The observed effects of prophylactic IL-2 treatment on the fetal gut in our model could be, at least in part, explained by inhibition of IL-6 because IL-6 is causally linked with epithelial tight junctional loss and mucosal injury (41). In support of this theory, elevated IL-6 levels are found in gastric aspirates of neonates diagnosed with intrauterine infection at birth (42) and NEC infants (43). It is also possible that other mechanisms than an effect on Treg cells contributed to the preventive effect of IL-2 treatment. One could be a direct role of IL-2 on intestinal epithelial cells because IL-2 promotes epithelial restitution and cell proliferation, thereby preserving epithelial integrity (44). Importantly, IL-2 expression in the intestine starts early through gestation, irrespective of inflammation, and remains constitutively expressed during pregnancy. This indicates that IL-2 plays a role during intestinal development (45). Second, anti-inflammatory (IL-4 and IL-10) cytokines, which were also induced in the fetal ileum might contribute to the preventive effect of IL-2. However, IL-2 treatment also resulted in enhanced pro-inflammatory cytokine mRNA levels. Collectively, our data nevertheless suggest that the anti-inflammatory arm of the immune response prevailed since no signs of mucosal damage were observed. 
The significant increase of $\mathrm{MPO}^{+}$and $\mathrm{CD}^{+}$cells in the fetal ileum after an established IA LPS dose was not reflected by increased mRNA changes on cytokine level with the exception of IL-6 and IL-17. This remarkable finding is consistent with earlier observations showing a similar increase of neutrophils and $\mathrm{T}$ lymphocytes in the absence of robust alterations on cytokine level (46). In this latter study (46) in which animals were sacrificed at different time points after IA LPS exposure, increased TNF$\alpha$ mRNA levels were detected, whereas no increase of IL-6 and IL-17 mRNA was observed. This indicates that estimating cytokine changes on mRNA level appear to be time dependent. Measuring cytokine levels in serum and intestine on protein level would therefore be very helpful to further clarify this aspect and important to understand the observed cytokine mRNA changes in the current study. Moreover, inclusion of additional time points would provide more insight in the cytokine changes over time. Unfortunately, because of the intended study design as a proof of concept and the inherent limitations of our model including a lack of reagents, a low litter size, and high costs, these cytokine changes cannot be studied in detail at present. However, our ovine translational preclinical animal model was deliberately chosen for the current proof of concept study because the anatomic and functional properties of the ovine fetal intestine are comparable to the human infant. Importantly, large animals such as sheep allow us to perform complicated surgical interventions or manipulations, which would be impossible to conduct in mice or rodents. Taken together, our model provides a suitable clinical platform for the administration of drugs in reliable doses that potentially could be used in humans.

In this study, we were not able to elucidate the origin of the early increased numbers of Treg cells in the fetal gut after IL-2 administration. This important aspect needs to be established in future studies. However, several mechanisms could be involved. Most notably, Treg cells might originate from the periphery or result from local expansion in the gut (47). In particular, intravenous IL-2 treatment could preferentially mobilize Treg cells from the circulation to migrate towards the gut. This is supported by the fact that cord blood Treg cells abundantly express the gut homing 
receptor $\alpha 4 \beta 7$ and migrate towards the gut-associated chemokine CCL25 in vitro (48). IL-2 treatment could also result in activation and migration of Treg cells from the spleen towards other organs including the gut. However, the frequency of Treg cells in the spleen remained unaltered 2 days after IL-2 treatment (Supplementary fig. 2), which does not support this hypothesis. Nevertheless, we cannot exclude this possibility as activation and migration of Treg cells might have occurred before day 2, our first analyzed time point. Furthermore, Treg cells in the gut might also originate from the MLN, as gut-associated lymphoid tissues are considered to be a crucial source of inducible Treg generation in the gut (49). This scenario is supported by the accumulation of Treg cells in the MLN as seen directly after 4 days of IL-2 administration. Alternatively, increased intestinal Treg numbers could result from local expansion of Treg cells or from differentiation of resident-naïve CD4 T cells (49) under the influence of IL-2.

Our study is a proof of principle that IL-2, a drug that is already in clinical use, has the potential to be used as a prophylactic therapeutic approach for the adverse intestinal outcomes following antenatal inflammation. In this study, IL-2 treatment was not associated with adverse outcomes of the fetus, such as immunosuppression, activation of effector $\mathrm{T}$ cells, brain inflammation (data not shown), and vascular leak syndrome (indicated by the absence of pulmonary edema and hypotension; data not shown). Based on this promising clinical potential of IL-2 in the fetal gut, future studies will be conducted to investigate whether IL-2 can be used not only as a preventive strategy but also after the establishment of intrauterine inflammation. More generally, our study supports the concept that boosting fetal Treg cell frequency could be beneficial in the case of chorioamnionitis-associated prematurity. The development of therapeutic strategies inducing Treg cell expansion and controlling Th17 cells is a vibrant area of research to treat auto-immune disorders, and novel compounds, safe to be administered to humans, will likely become available, and our animal model will be adequate to test their efficacy at preventing severe inflammation-induced gut damage. 


\section{References}

1. Blencowe $\mathrm{H}$, Cousens $\mathrm{S}$. Addressing the challenge of neonatal mortality. Trop Med Int Health 2013;18:303-312.

2. Martinez-Lopez DG, Funderburg NT, Cerissi A, Rifaie R, Aviles-Medina L, Llorens-Bonilla BJ, Sleasman J, Luciano AA. Lipopolysaccharide and soluble CD14 in cord blood plasma are associated with prematurity and chorioamnionitis. Pediatr. Res. 2014;75:67-74.

3. Viscardi RM. Ureaplasma species: role in neonatal morbidities and outcomes. Arch. Dis. Child Fetal Neonatal Ed. 2014;99:F87-92.

4. Romero R, Espinoza J, Goncalves LF, Kusanovic JP, Friel L, Hassan S. The role of inflammation and infection in preterm birth. Semin. Reprod. Med. 2007;25:2139.

5. Gantert M, Been JV, Gavilanes AW, Garnier Y, Zimmermann LJ, Kramer BW. Chorioamnionitis: a multiorgan disease of the fetus? J Perinatol 2010;30 Suppl:S21-30.

6. Bastek JA, Weber AL, McShea MA, Ryan ME, Elovitz MA. Prenatal inflammation is associated with adverse neonatal outcomes. Am. J. Obstet. Gynecol. 2014;210:450 e451-410.

7. Been JV, Lievense S, Zimmermann LJ, Kramer BW, Wolfs TG. Chorioamnionitis as a risk factor for necrotizing enterocolitis: a systematic review and meta-analysis. J Pediatr 2013;162:236-242 e232.

8. Neu J, Walker WA. Necrotizing enterocolitis. N. Engl. J. Med. 2011;364:255264.

9. Gordon PV, Swanson JR. Necrotizing enterocolitis is one disease with many origins and potential means of prevention. Pathophysiology. 2014;21:13-19.

10. Wolfs TG, Buurman WA, Zoer B, Moonen RM, Derikx JP, Thuijls G, Villamor E, Gantert M, Garnier Y, Zimmermann LJ, Kramer BW. Endotoxin induced chorioamnionitis prevents intestinal development during gestation in fetal sheep. PLoS One 2009;4:e5837.

11. Wolfs TG, Jellema RK, Turrisi G, Becucci E, Buonocore G, Kramer BW. Inflammation-induced immune suppression of the fetus: a potential link between chorioamnionitis and postnatal early onset sepsis. J. Matern. Fetal Neonatal Med. 2012;25 Suppl 1:8-11.

12. Wolfs TG, Kallapur SG, Polglase GR, Pillow JJ, Nitsos I, Newnham JP, Chougnet CA, Kroon E, Spierings J, Willems CH, Jobe AH, Kramer BW. IL-1alpha mediated chorioamnionitis induces depletion of $\mathrm{FoxP} 3+$ cells and ileal inflammation in the ovine fetal gut. PLoS One 2011;6:e18355. 
13. Wolfs TG, Kallapur SG, Knox CL, Thuijls G, Nitsos I, Polglase GR, Collins JJ, Kroon E, Spierings J, Shroyer NF, Newnham JP, Jobe AH, Kramer BW. Antenatal ureaplasma infection impairs development of the fetal ovine gut in an IL-1-dependent manner. Mucosal Immunol. 2013;6:547-556.

14. Weitkamp JH, Koyama T, Rock MT, Correa H, Goettel JA, Matta P, OswaldRichter K, Rosen MJ, Engelhardt BG, Moore DJ, Polk DB. Necrotising enterocolitis is characterised by disrupted immune regulation and diminished mucosal regulatory (FOXP3)/effector (CD4, CD8) T cell ratios. Gut. 2013;62:73-82.

15. van Wijk F, Cheroutre H. Mucosal $\mathrm{T}$ cells in gut homeostasis and inflammation. Expert Rev. Clin. Immunol. 2010;6:559-566.

16. Sakaguchi S, Yamaguchi T, Nomura T, Ono M. Regulatory T cells and immune tolerance. Cell. 2008;133:775-787.

17. Shevach EM. Application of IL-2 therapy to target T regulatory cell function. Trends Immunol. 2012;33:626-632.

18. Brandenburg S, Takahashi T, de la Rosa M, Janke M, Karsten G, Muzzulini T, Orinska Z, Bulfone-Paus S, Scheffold A. IL-2 induces in vivo suppression by CD4(+)CD25(+)Foxp3(+) regulatory T cells. Eur. J. Immunol. 2008;38:1643-1653.

19. Matsuoka K, Koreth J, Kim HT, Bascug G, McDonough S, Kawano Y, Murase K, Cutler C, Ho VT, Alyea EP, Armand P, Blazar BR, Antin JH, Soiffer RJ, Ritz J. Low-dose interleukin-2 therapy restores regulatory $\mathrm{T}$ cell homeostasis in patients with chronic graft-versus-host disease. Sci. Transl. Med. 2013;5:179ra143.

20. Zhang H, Chua KS, Guimond M, Kapoor V, Brown MV, Fleisher TA, Long LM, Bernstein D, Hill BJ, Douek DC, Berzofsky JA, Carter CS, Read EJ, Helman LJ, Mackall CL. Lymphopenia and interleukin-2 therapy alter homeostasis of CD4+CD25+ regulatory T cells. Nat. Med. 2005;11:1238-1243.

21. Kramer BW, Moss TJ, Willet KE, Newnham JP, Sly PD, Kallapur SG, Ikegami M, Jobe AH. Dose and time response after intraamniotic endotoxin in preterm lambs. Am. J. Respir. Crit. Care Med. 2001;164:982-988.

22. Jellema RK, Wolfs TG, Lima Passos V, Zwanenburg A, Ophelders DR, Kuypers E, Hopman AH, Dudink J, Steinbusch HW, Andriessen P, Germeraad WT, Vanderlocht J, Kramer BW. Mesenchymal stem cells induce T-cell tolerance and protect the preterm brain after global hypoxia-ischemia. PLoS One. 2013;8:e73031.

23. Kuypers E, Collins JJ, Jellema RK, Wolfs TG, Kemp MW, Nitsos I, Pillow JJ, Polglase GR, Newnham JP, Germeraad WT, Kallapur SG, Jobe AH, Kramer BW. Ovine fetal thymus response to lipopolysaccharide-induced chorioamnionitis and antenatal corticosteroids. PLoS One. 2012;7:e38257. 
24. Rocchi MS, Wattegedera SR, Frew D, Entrican G, Huntley JF, McNeilly TN. Identification of CD4+CD25 high Foxp3+ $\mathrm{T}$ cells in ovine peripheral blood. Vet Immunol Immunopathol 2011;144:172-177.

25. Klebanoff SJ. Myeloperoxidase: friend and foe. J. Leukoc. Biol. 2005;77:598625 .

26. Vignali DA, Collison LW, Workman CJ. How regulatory T cells work. Nat. Rev. Immunol. 2008;8:523-532.

27. Malek TR. The biology of interleukin-2. Annu. Rev. Immunol. 2008;26:453479 .

28. Bell CJ, Sun Y, Nowak UM, Clark J, Howlett S, Pekalski ML, Yang X, Ast O, Waldhauer I, Freimoser-Grundschober A, Moessner E, Umana P, Klein C, Hosse RJ, Wicker LS, Peterson LB. Sustained in vivo signaling by long-lived IL-2 induces prolonged increases of regulatory T cells. J. Autoimmun. 2015;56:66-80.

29. Miyara M, Sakaguchi S. Natural regulatory T cells: mechanisms of suppression. Trends Mol. Med. 2007;13:108-116.

30. Moser EK, Hufford MM, Braciale TJ. Late engagement of CD86 after influenza virus clearance promotes recovery in a FoxP3+ regulatory $\mathrm{T}$ cell dependent manner. PLoS Pathog. 2014;10:e1004315.

31. Dingle BM, Liu Y, Fatheree NY, Min J, Rhoads JM, Tran DQ. FoxP3(+) regulatory $\mathrm{T}$ cells attenuate experimental necrotizing enterocolitis. PLoS One. 2013;8:e82963.

32. Liu Y, Fatheree NY, Dingle BM, Tran DQ, Rhoads JM. Lactobacillus reuteri DSM 17938 changes the frequency of Foxp3+ regulatory T cells in the intestine and mesenteric lymph node in experimental necrotizing enterocolitis. PLoS One. 2013;8:e56547.

33. Liu Y, Tran DQ, Fatheree NY, Marc Rhoads J. Lactobacillus reuteri DSM 17938 differentially modulates effector memory T cells and Foxp3+ regulatory T cells in a mouse model of necrotizing enterocolitis. Am. J. Physiol. Gastrointest. Liver Physiol. 2014;307:G177-186.

34. Xu J, Anderson V, Schwarz SM. Dietary GD3 ganglioside reduces the incidence and severity of necrotizing enterocolitis by sustaining regulatory immune responses. J. Pediatr. Gastroenterol. Nutr. 2013;57:550-556.

35. Giannone PJ, Nankervis CA, Richter JM, Schanbacher BL, Reber KM. Prenatal lipopolysaccharide increases postnatal intestinal injury in a rat model of necrotizing enterocolitis. J. Pediatr. Gastroenterol. Nutr. 2009;48:276-282.

36. Okogbule-Wonodi AC, Gross GW, Sun CC, Agthe AG, Xiao L, Waites KB, Viscardi RM. Necrotizing enterocolitis is associated with ureaplasma colonization in preterm infants. Pediatr. Res. 2011;69:442-447. 
37. Zheng SG, Wang J, Horwitz DA. Cutting edge: Foxp3+CD4+CD25+ regulatory $\mathrm{T}$ cells induced by IL-2 and TGF-beta are resistant to Th17 conversion by IL-6. J. Immunol. 2008;180:7112-7116.

38. Liao W, Lin JX, Wang L, Li P, Leonard WJ. Modulation of cytokine receptors by IL-2 broadly regulates differentiation into helper $\mathrm{T}$ cell lineages. Nat. Immunol. 2011;12:551-559.

39. Kallapur SG, Presicce P, Senthamaraikannan P, Alvarez M, Tarantal AF, Miller LM, Jobe AH, Chougnet CA. Intra-amniotic IL-1 beta induces fetal inflammation in rhesus monkeys and alters the regulatory $\mathrm{T}$ cell/IL-17 balance. J. Immunol. 2013;191:1102-1109.

40. Annunziato F, Romagnani C, Romagnani S. The 3 major types of innate and adaptive cell-mediated effector immunity. J. Allergy Clin. Immunol. 2015;135:626-635. 41. Al-Sadi R, Ye D, Boivin M, Guo S, Hashimi M, Ereifej L, Ma TY. Interleukin6 modulation of intestinal epithelial tight junction permeability is mediated by JNK pathway activation of claudin-2 gene. PLoS One. 2014;9:e85345.

42. Kim YD, Hyun WY, Cha HJ. Funisitis and raised interleukin 6 concentrations in gastric aspirates at birth. Arch. Dis. Child Fetal Neonatal Ed. 2005;90:F349-350.

43. Maheshwari A, Schelonka RL, Dimmitt RA, Carlo WA, Munoz-Hernandez B, Das A, McDonald SA, Thorsen P, Skogstrand K, Hougaard DM, Higgins RD. Cytokines associated with necrotizing enterocolitis in extremely-low-birth-weight infants. Pediatr. Res. 2014;76:100-108.

44. Dignass AU, Podolsky DK. Interleukin 2 modulates intestinal epithelial cell function in vitro. Exp. Cell. Res. 1996;225:422-429.

45. Yang-Snyder JA, Rothenberg EV. Spontaneous expression of interleukin-2 in vivo in specific tissues of young mice. Dev. Immunol. 1998;5:223-245.

46. Wolfs TG, Kramer BW, Thuijls G, Kemp MW, Saito M, Willems MG, Senthamarai-Kannan P, Newnham JP, Jobe AH, Kallapur SG. Chorioamnionitisinduced fetal gut injury is mediated by direct gut exposure of inflammatory mediators or by lung inflammation. Am J Physiol Gastrointest Liver Physiol 2014;306:G382-393. 47. Pabst O. Trafficking of regulatory T cells in the intestinal immune system. Int. Immunol. 2013;25:139-143.

48. Grindebacke H, Stenstad H, Quiding-Jarbrink M, Waldenstrom J, Adlerberth I, Wold AE, Rudin A. Dynamic development of homing receptor expression and memory cell differentiation of infant $\mathrm{CD} 4+\mathrm{CD} 25$ high regulatory T cells. J. Immunol. 2009;183:4360-4370.

49. Pabst O, Bernhardt G. On the road to tolerance--generation and migration of gut regulatory T cells. Eur. J. Immuno. 2013;43:1422-1425. 


\section{Supplementary Material}
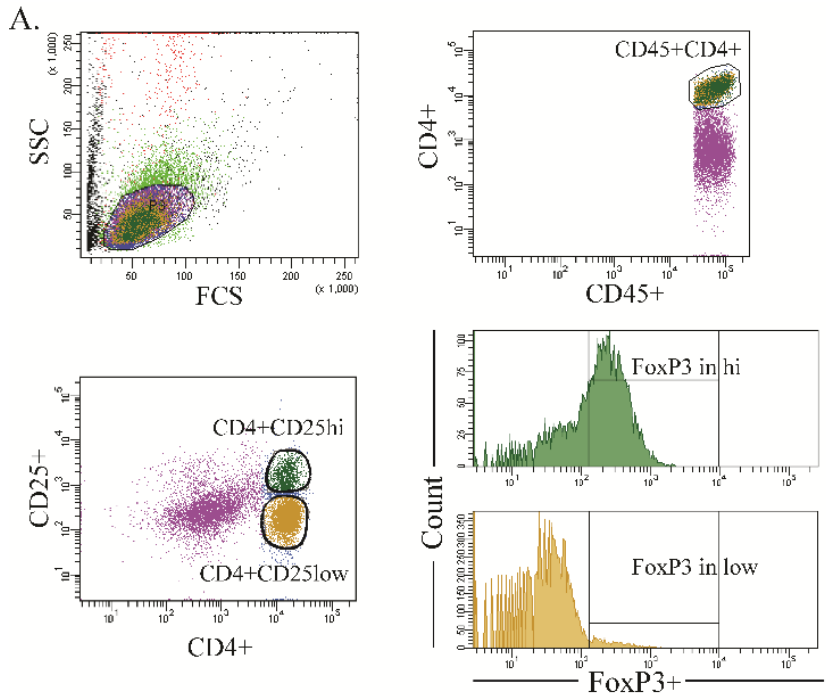

B.

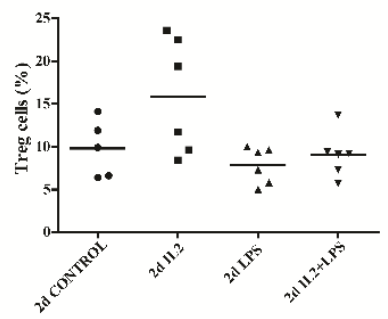

C.

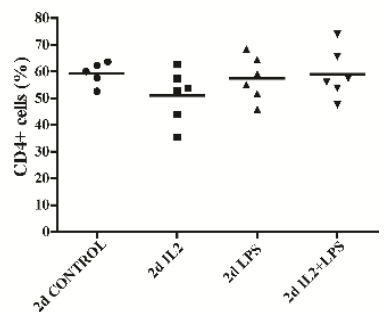

Supplementary figure 1 . T cell subsets in the fetal mesenteric lymph nodes (MLN) of 2 days exposed animals. Representative dot plots illustrating gating strategy and analysis of MLN by flow cytometry. The cells of interest were identified by forward and side scatter (A). The $\mathrm{CD} 45^{+} \mathrm{CD} 4{ }^{+}$cells were gated and from this population the CD4 CD25 double positive cells with high and low expression of CD25 were selected. In these two populations, the expression of FoxP3 was analyzed in histograms. The CD4 CD25hiFoxP3 ${ }^{+}$cells were identified and considered as Treg cells (A). Gating for FoxP3 was based on the expression of $\mathrm{FoxP}^{+}$in $\mathrm{CD} 45 \mathrm{CD} 4$ double positive cells in MLN (data not shown). Mean cell percentages (\%) of Treg in $\mathrm{CD} 4^{+}$(B) and (\%) of $\mathrm{CD} 4^{+}$in $\mathrm{CD} 45^{+}$(C) $\mathrm{T}$ cells of each experimental group are presented. FSC: forward scatter, SSC: side scatter, d: days, LPS: lipopolysaccharide, Treg: regulatory $\mathrm{T}$ cell. 
A.
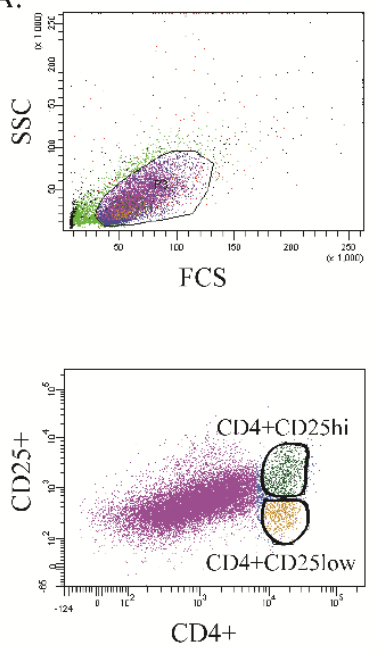
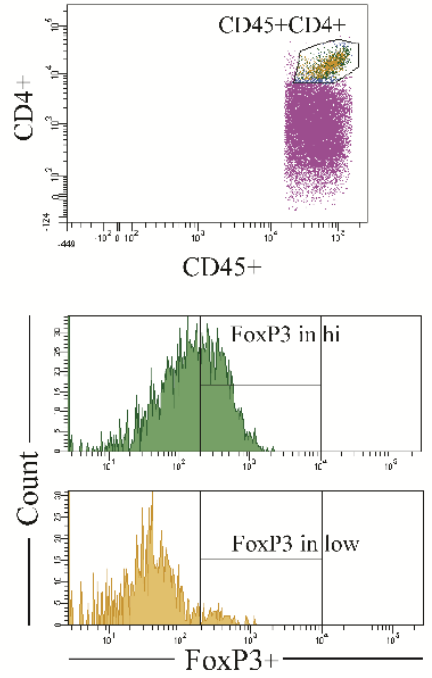

B.

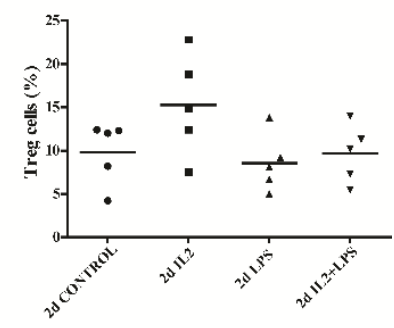

C.

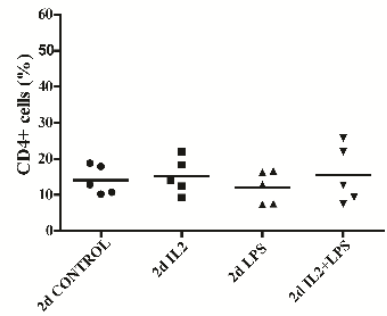

Supplementary figure 2. T cell subsets in the fetal spleen of 2 days exposed animals. Representative dot plots illustrating gating strategy and analysis of splenocytes by flow cytometry. The cells of interest were identified by forward and side scatter (A). The CD 45 CD $4^{+}$splenocytes were gated and from this population the CD $4 \mathrm{CD} 25^{+}$double positive cells with high and low expression of CD25 were selected. In these two populations, the expression of FoxP3 was analyzed in histograms. The CD4 ${ }^{+}$D25hiFoxP3 ${ }^{+}$cells were identified and considered as Treg cells (A). Gating for FoxP3 was based on the expression of $\mathrm{FoxP}^{+}$in $\mathrm{CD} 45 \mathrm{CD} 4$ splenocytes (data not shown). Mean splenic percentages (\%) of Treg in CD $4^{+}(\mathrm{B})$ and $(\%)$ of $\mathrm{CD} 4^{+}$in CD45 (C) $\mathrm{T}$ cells of each experimental group are presented. FSC: forward scatter, SSC: side scatter, d: days, LPS: lipopolysaccharide, Treg: regulatory $\mathrm{T}$ cell. 
Prophylactic IL-2 prevents fetal gut inflammation 



\section{Chapter 4}

\section{Intra-amniotic Candida albicans infection induces mucosal}

injury and inflammation in the ovine fetal intestine.

Maria Nikiforou, Esmee M.R. Jacobs, Matthew W. Kemp, Mathias W. Hornef, Matthew S. Payne, Masatoshi Saito, John P. Newnham, Leon E.W. Janssen, Alan H. Jobe, Suhas G. Kallapur, Boris W. Kramer and Tim G.A.M. Wolfs

Sci Rep. 2016 Jul 14;6:29806 


\section{Abstract}

Chorioamnionitis is caused by intrauterine infection with microorganisms including Candida albicans (C.albicans). Chorioamnionitis is associated with postnatal intestinal pathologies including necrotizing enterocolitis. The underlying mechanisms by which intra-amniotic C.albicans infection adversely affects the fetal gut remain unknown. Therefore, we assessed whether intra-amniotic C.albicans infection would cause intestinal inflammation and mucosal injury in an ovine model. Additionally, we tested whether treatment with the fungistatic fluconazole ameliorated the adverse intestinal outcome of intra-amniotic C.albicans infection.

Pregnant sheep received intra-amniotic injections with $10^{7}$ colony-forming units C.albicans or saline at 3 or 5 days before preterm delivery at 122 days of gestation. Fetuses were given intra-amniotic and intra-peritoneal fluconazole treatments 2 days after intra-amniotic administration of C.albicans.

Intra-amniotic C.albicans caused intestinal colonization and invasive growth within the fetal gut with mucosal injury and intestinal inflammation, characterized by increased CD3+ lymphocytes, MPO' cells and elevated TNF- $\alpha$ and IL-17 mRNA levels. Fluconazole treatment in utero decreased intestinal C.albicans colonization, mucosal injury but failed to attenuate intestinal inflammation.

Intra-amniotic Calbicans caused intestinal infection, injury and inflammation. Fluconazole treatment decreased mucosal injury but failed to ameliorate Calbicansmediated mucosal inflammation emphasizing the need to optimize the applied antifungal therapeutic strategy. 


\section{Introduction}

Preterm birth, which frequently results from intrauterine infection, represents a major cause of neonatal morbidity and mortality (1). Chorioamnionitis, defined as inflammation of the chorioamniotic membranes and amniotic fluid (2), is commonly caused by ascending infection into the uterine cavity $(3,4)$. While numerous different bacterial species have been cultured from the amniotic fluid of affected human fetuses, Ureaplasma (UP), Fusobacterium and Mycoplasma are the most commonly isolated microorganisms $(2,5,6)$. Microbial growth within the amniotic cavity exposes the fetus to bacterial toxins and inflammatory mediators that cause a fetal inflammatory response syndrome (FIRS) that is associated with postnatal adverse outcomes in multiple fetal organs including the gastrointestinal tract (7). Preterm infants exposed to chorioamnionitis present in the clinic with a wide spectrum of adverse intestinal consequences ranging from poor nutritional uptake and subsequent postnatal growth deficits (8) to severe, life-threatening gastrointestinal complications such as necrotizing enterocolitis (NEC) $(9,10)$.

Emerging evidence from recent studies supports an association between fungi (in particular yeasts such as Candida spp.) and chorioamnionitis (11-13). Although Candida albicans (C.albicans) can be a commensal organism in the female genital tract, chorioamnionitis with $C$ albicans can cause fetal death or fetal candidiasis with systemic manifestations including sepsis (14-16). Treatment of Calbicans infection during pregnancy has been challenging (17). Although fluconazole, the most commonly used anti-fungal agent, has been associated with teratogenicity when administered at high doses orally, during the first trimester of pregnancy (18), clinical cases of C.albicansmediated chorioamnionitis at later stages of gestation were successfully treated with oral and intra-amniotic (IA) fluconazole in the absence of reported adverse effects (15).

We have previously used a translational ovine chorioamnionitis model and have shown that IA exposure to lipopolysaccharide (LPS), UP or inflammatory mediators induces intestinal inflammation and mucosal injury (19-21). Amniotic fluid infection with C.albicans can result in a reservoir of this organism in the fetal bowel 
where potentially may induce gastrointestinal pathologies. However, the underlying mechanisms by which intrauterine infection with Calbicans may result in adverse intestinal effects remain substantially unexplored. Therefore, we utilized our chorioamnionitis model to assess whether IA C.albicans infection caused intestinal colonization, local invasive growth and mucosal intestinal inflammatory responses associated with tissue damage to the fetal gut. Additionally, we tested whether IA and intra-peritoneal fluconazole treatment would ameliorate the adverse effects of C.albicans-mediated chorioamnionitis on the fetal ovine gut.

\section{Materials and Methods}

\section{Animals}

All animal experiments were approved by the Animal Ethics Committee of the University of Western Australia (Perth, WA, Australia) and the Children's Hospital Medical Center (Cincinnati, Ohio, USA). All experimental methods were performed in accordance with the approved guidelines and regulations.

\section{Experimental design}

All experimental procedures were performed as previously described (22). Date-mated Merino sheep (Ovis aries) were randomly assigned to either 1) a control group ( $(\mathrm{n}=6)$, which received an IA injection of saline, 2) an antifungal group ( $\mathrm{n}=3)$, which received fluconazole treatment only, 3) a 3d Calbicans group $(\mathrm{n}=7)$, which received an IA injection of $10^{7}$ colony-forming units (CFU) of C.albicans (all $C$. albicans inoculums prepared in sterile saline) 3 days before preterm delivery and IA injection of saline 1 day before delivery, 4) a 3d Calbicans and $1 \mathrm{~d}$ fluconazole group $(\mathrm{n}=6)$, which received an IA injection of $10^{7}$ CFU C.albicans 3 days before preterm delivery and fluconazole treatment 1 day before delivery or 5) a $5 \mathrm{~d}$ C.albicans and $3 \mathrm{~d}$ fluconazole group $(\mathrm{n}=5)$, which received an IA injection of $10^{7} \mathrm{CFU}$ Calbicans 5 days before delivery and fluconazole treatment 3 days before delivery (Figure 1). Since an IA exposure to C.albicans for 5 days was previously shown to result in fetal mortality, our 
experimental setting does not contain a group of animals only exposed to C.albicans for 5 days (22). A dose of $15 \mathrm{mg}$ fluconazole was injected into the amniotic cavity and 15 $\mathrm{mg}$ was given by intra-peritoneal injection to the fetus. This route of administration was chosen because of the long half-life of fluconazole and its direct availability to the fetus through swallowing of the amniotic fluid. All injections were performed under ultrasound guidance. All fetuses were delivered surgically at 122 days ( \pm 1 day) of gestation (term at $\sim$ 147-150 days) simulating a preterm human delivery of approximately 32-34 weeks of gestation.

Fetuses and ewes were euthanized with an intravenous bolus of pentobarbital $(100 \mathrm{mg} / \mathrm{kg})$. Fetal terminal ileum was immediately collected, frozen in liquid nitrogen and stored in -80. In addition, fetal terminal ileum was placed in cassettes and immerged in formalin for immunohistochemical stainings.

\section{Antibodies}

The following antibodies were used. Polyclonal rabbit antibody against human CD3 (catalog reference A0452, 1:1000); rabbit antibody against human myeloperoxidase (MPO, catalog reference A0398, 1:500) both from Dako, (Glostrup, Denmark). As secondary antibodies, biotin conjugated swine anti-rabbit (catalog reference E0353, 1:200) from Dako and peroxidase conjugated goat anti-rabbit (catalog reference 111-035-045, 1:200) from Jackson (West Grove, PA) were used.

\section{Blood cultures}

C.albicans in blood cultures was detected as described previously (22). Briefly, fetal blood was inoculated into culture vials and incubated at $37^{\circ} \mathrm{C}$ for 72 hours. Every day, $1 \mathrm{ml}$ sample was removed and subcultured on sheep blood agar at $37^{\circ} \mathrm{C}$ for 48 hours. C.albicans colonial morphology was confirmed by growth on Brilliance Candida Agar (Oxoid, Adelaide, Australia) as previously reported (22). 


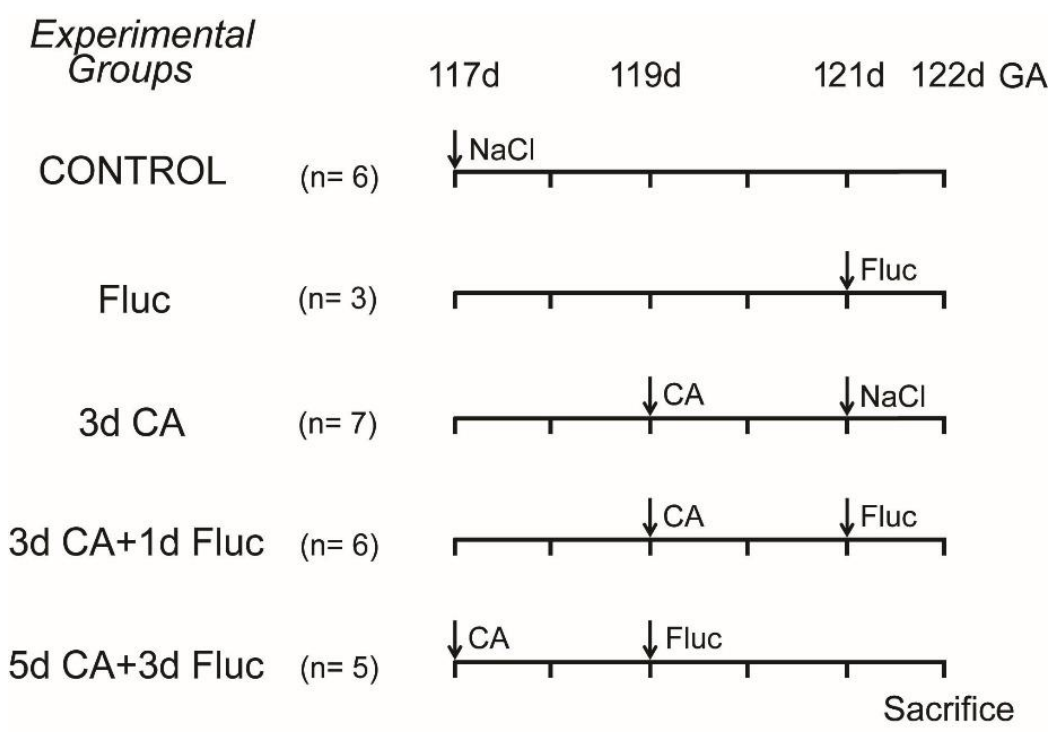

Figure 1: Experimental design. Fetal sheep were given intra-amniotic (IA) C.albicans or saline at 3 or 5 days before preterm delivery at 122 days of gestation. IA and intra-peritoneal fluconazole treatment was administered to the fetus 2 days after Calbicans infection. CA: C.albicans, d: day(s), Fluc: Fluconazole, GA: gestational age, n: number.

\section{Immunohistochemistry}

Formalin-fixed paraffin-embedded fetal terminal ileum was cut in $4 \mu \mathrm{m}$ thick sections. Morphology was evaluated using hematoxylin-and-eosin (H\&E)-staining and fungi were visualized with periodic acid Schiff (PAS) staining. Immunohistochemistry was performed as previously described (23). After blocking the endogenous peroxidase activity and non-specific binding, sections were incubated with anti-MPO or anti-CD3 antibodies for either 1 hour or overnight, respectively. Thereafter, sections were washed and incubated with a secondary biotin (CD3) or peroxidase (MPO) conjugated antibody. Substrate staining for MPO was performed with 3-amino-9-ethylcarbazole (AEC) from Invitrogen, (Bleiswijk, the Netherlands). CD3 immunoreactivity was detected by using nickel-DAB from Dako, (Glostrup, Denmark). Nuclei were counterstained with either Nuclear Fast Red (CD3) or hematoxylin (MPO). CD3 and MPO expressing cells were counted per high power field (Magnification x 200) and the 
average number of positive cells in 5 high power fields of terminal ileum per animal is presented. Assessment of the sections was performed as previously described (23). Briefly, the high power field was defined under the microscope, a picture was captured and subsequently cell counting was performed using Image $\mathbf{J}$.

\section{Quantitative Real Time PCR (qPCR)}

The mRNA expression level of cytokines was measured by qPCR as previously described (24). Total RNA was isolated from $50 \mathrm{mg}$ freshly frozen ileal tissue by Trizol/chloroform extraction using the SV Total RNA Isolation System (Promega, Madison, WI, USA) according to manufacturer's guidelines. The samples were treated with RQ1 DNase (Promega, Madison, WI, USA) to eliminate genomic DNA contamination. The extracted RNA was tested for the presence of genomic DNA using ovine specific actin primers by PCR (Westburg Thermocycler, Leusden, the Netherlands) and analyzed with agarose gel electrophoresis. Briefly, PCR amplification was performed with DNA Taq Polymerase (Promega) at $95^{\circ} \mathrm{C}$ for 5 minutes, followed by 34 cycles at $95{ }^{\circ} \mathrm{C}$ for 30 seconds, $52{ }^{\circ} \mathrm{C}$ for 45 seconds and $72{ }^{\circ} \mathrm{C}$ for 30 seconds. The quality of PCR products was tested in a $1.2 \%$ agarose gel. Reverse transcription was performed with M-MLV Reverse transcriptase from Invitrogen, (Bleiswijk, the Netherlands) according to manufacturer's guidelines using oligo(dT) primers. qPCR was performed with the SensiMix SYBR \& Fluorescein Kit from GC Biotech B.V. (Alphen aan de Den Rijn, the Netherlands) using a LightCycler 480 from Roche Applied Science, (Almere, the Netherlands) according to manufacturer's instructions. The PCR reactions were run with 10 ng of cDNA, in duplicates using the appropriate primers to specifically amplify the ovine gene transcript (Supplementary table 1). Based on previous reports $(25,26)$, expression stability and expression level (Cq value $\sim 20)$ of S15 across several ovine tissues (including the gut) which were tested in our laboratory, we concluded that S15 can serve as a good reference gene. The efficiency of the primers was tested by dilution experiments. The results were normalized to the 
S15 ribosomal protein (ovRPS15) as a housekeeping gene (with a $\mathrm{Cq}$ value of 20), and the mean fold change in mRNA levels relative to the control are presented.

\section{Enzyme-Linked Immunosorbent Assay (ELISA)}

To quantify the degree of infection-induced damage to the intestinal epithelium, the concentration of intestinal fatty acid-binding protein (I-FABP) was measured in fetal plasma samples by ELISA as previously described (27). Briefly, an Elisa plate was coated with $3 \mu \mathrm{g} /$ well of anti-human I-FABP monoclonal antibody for 24 hours. A dilution series of a known concentration of human recombinant I-FABP protein was used for a standard curve. Plasma samples were diluted two times and were incubated with biotin-conjugated polyclonal anti-human I-FABP antibody, followed by incubation with streptavidin peroxidase. After incubation with the substrate, the reaction in the samples was terminated by adding $1 \mathrm{M}$ of $\mathrm{H}_{2} \mathrm{SO}_{4}$ and the optical density was measured at $450 \mathrm{~nm}$ in a Thermo Electron Type 1500 Multiskan Spectrum Microplate Reader.

\section{Statistical Analysis}

Statistical analysis was performed using GraphPad Prism software (version v5.0; GraphPad Software Inc., La Jolla, CA, USA). Comparisons between groups were evaluated by non-parametric Kruskal Wallis tests followed by Dunn's multiple comparisons tests. Differences between groups in the detection of Calbicans in fetal blood and gut were analyzed by Fisher's Exact Test. Data are presented as mean \pm standard deviation (SD). Differences were considered statistically significant at $\mathrm{p}<0.05$.

\section{Results}

\section{Systemic effects of IA C.albicans administration}

Blood cultures for C.albicans and plasma levels of IL-6 as shown previously $(22,28)$ are depicted in table 1. 


\section{C.albicans in the fetal intestine}

We evaluated whether Calbicans could be detected in the fetal gut tissue by histochemical PAS staining. C.albicans was found in fetal gut tissue in 6/7 (86\%) animals that were exposed to C.albicans for 3 days. In contrast, C.albicans was detected only in 2/6 (33\%) animals that were exposed to Calbicans for 3 days and were treated with fluconazole for 1 day and in 1/5 (20\%) animals that were exposed to C.albicans for 5 days and were treated with fluconazole for 3 days (Table 1).

Table 1: Detection of Calbicans in fetal blood and gut tissue, and IL-6 plasma levels.

\begin{tabular}{|c|c|c|c|c|c|}
\hline & Control & Fluconazole & 3d C.albicans & $\begin{array}{c}\text { 3d C.albicans } \\
+1 \mathrm{~d} \text { Fluc }\end{array}$ & $\begin{array}{c}\text { 5d C.albicans } \\
+3 \mathrm{~d} \text { Fluc }\end{array}$ \\
\hline $\begin{array}{l}\text { Positive } \\
\text { Calbicans } \\
\text { blood } \\
\text { culture }\end{array}$ & $\begin{array}{l}0 / 6 \\
(0 \%)\end{array}$ & 0/3 (0\%) & $\begin{array}{c}5 / 7(71 \%){ }^{*} \\
\text { OR: } 28.6 \\
95 \% \text { CI } \\
(1.12-731.54)\end{array}$ & $\begin{array}{c}5 / 6(83 \%){ }^{*} \\
\text { OR: } 47.67 \\
95 \% \text { CI } \\
(1.6-1422.69)\end{array}$ & $3 / 5(60 \%)$ \\
\hline $\begin{array}{l}\text { Positive PAS } \\
\text { staining for } \\
\text { Candida } \\
\text { in the gut }\end{array}$ & $\begin{array}{c}0 / 6 \\
(0 \%)\end{array}$ & 0/3 (0\%) & $\begin{array}{c}6 / 7(86 \%)^{* *} \\
\text { OR: } 56.33 \\
95 \% \text { CI } \\
(1.92-1655)\end{array}$ & $2 / 6(33 \%)$ & $\begin{array}{c}1 / 5(20 \%)^{8} \\
\text { OR: } 0.033 \\
95 \% \text { CI } \\
(0.001-0.68)\end{array}$ \\
\hline IL-6 (ng/mL) & N.D. & N.D. & $40 \pm 45^{*, *}$ & N.D. & $19 \pm 29$ \\
\hline
\end{tabular}

For the detection of C.albicans in blood cultures and gut, the results were analyzed by Fisher's Exact Test. Data are presented as positive/total number of animals. For IL-6 results, differences between groups were analyzed by non-parametric Kruskal Wallis tests followed by Dunn's multiple comparisons test. Data are presented as mean \pm SD. ${ }^{*} \mathrm{p}<0.05$ and ${ }^{*}{ }^{*} \mathrm{p}<0.01$ compared to control. \# p $<0.05$ compared to $3 \mathrm{~d}$ C.albicans $+1 \mathrm{~d}$ Fluc group and ${ }^{8} \mathrm{p}<0.05$ compared to $3 \mathrm{~d}$ C.albicans. CI: confidence interval, Fluc: fluconazole, IL: interleukin, n: number, N.D.: not detectable, OR: odds ratio, PAS: Periodic acid-Schiff.

Importantly, Calbicans had generated hyphae and invasive growth of C.albicans hyphae were found within the intestinal villi (Figure 2A) and in the lamina propria (Figure 2B), and particularly in close proximity to or inside Peyer's patches (PP) (Figure 2C and D). C.albicans was not detected in control animals or animals that had only received fluconazole. 

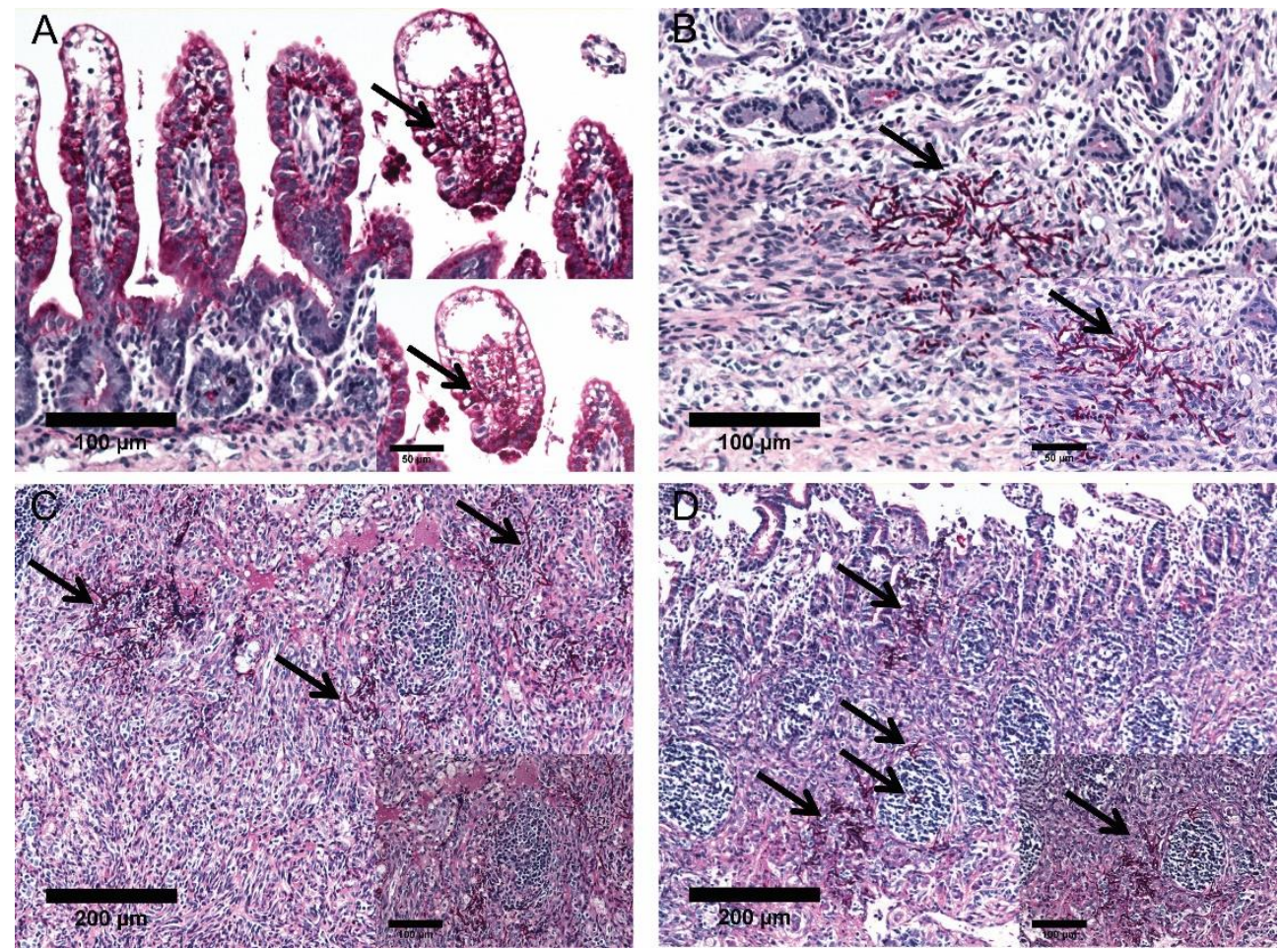

Figure 2: Detection of C.albicans hyphae in the fetal gut tissue. Hyphae of C.albicans were detected in the fetal gut at 3 days after IA exposure to Calbicans. Hyphae were found in intestinal villi (A), lamina propria (B), adjacent to (C) and inside mucosal Peyer's patches (D) 3 days after IA exposure to C.albicans.

\section{C.albicans caused gut epithelial injury}

Subsequently, we evaluated whether C.albicans exposure caused intestinal epithelial damage by measuring plasma I-FABP, an enterocyte-specific cytosolic protein that is released upon injury $(29,30)$. Significantly increased $(p<0.05)$ concentration of IFABP was detected in plasma samples of animals that were infected with C.albicans for 3 days when compared to controls (Figure 3). The elevated I-FABP levels were significantly prevented at 1 day after fluconazole treatment (Figure 3). I-FABP levels were not changed in the fluconazole only group and $5 \mathrm{~d}$ C.albicans plus $3 \mathrm{~d}$ fluconazole treatment group when compared to control. 


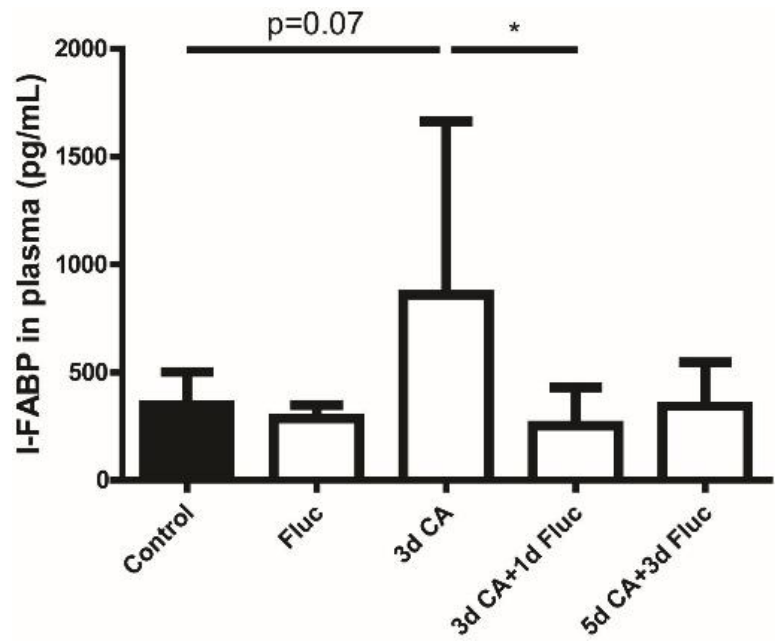

Figure 3: Concentration of I-FABP $(\mathrm{pg} / \mathrm{mL})$ in fetal plasma. Intra-amniotic C.albicans exposure for 3 days increased the I-FABP levels in the fetal plasma. I-FABP levels were decreased in animals that were treated with fluconazole for 1 day after IA exposure to C.albicans. Data are presented as mean \pm SD. ${ }^{*} \mathrm{p}<0.05$.

\section{C.albicans induced infiltration of inflammatory cells in the fetal gut}

We next assessed the accumulation of $\mathrm{MPO}^{+}$and $\mathrm{CD} 3^{+}$immune cells in the fetal gut by immunohistochemistry. Significantly increased $(p<0.05)$ numbers of MPO cells were found in animals exposed to Calbicans for 3 days as well as in animals that were exposed to Calbicans for 5 days followed by fluconazole for 3 days when compared with controls (Figure 4). Similarly, significantly increased $(\mathrm{p}<0.05)$ numbers of $\mathrm{CD}^{+} \mathrm{T}$ cells were detected in the fetal gut of animals that were exposed to C.albicans for 3 days when compared with controls (Figure 5). Fluconazole treatment after C.albicans exposure did not prevent the accumulation of $\mathrm{CD}^{+}$lymphocytes in the fetal gut (Figure 5C). 

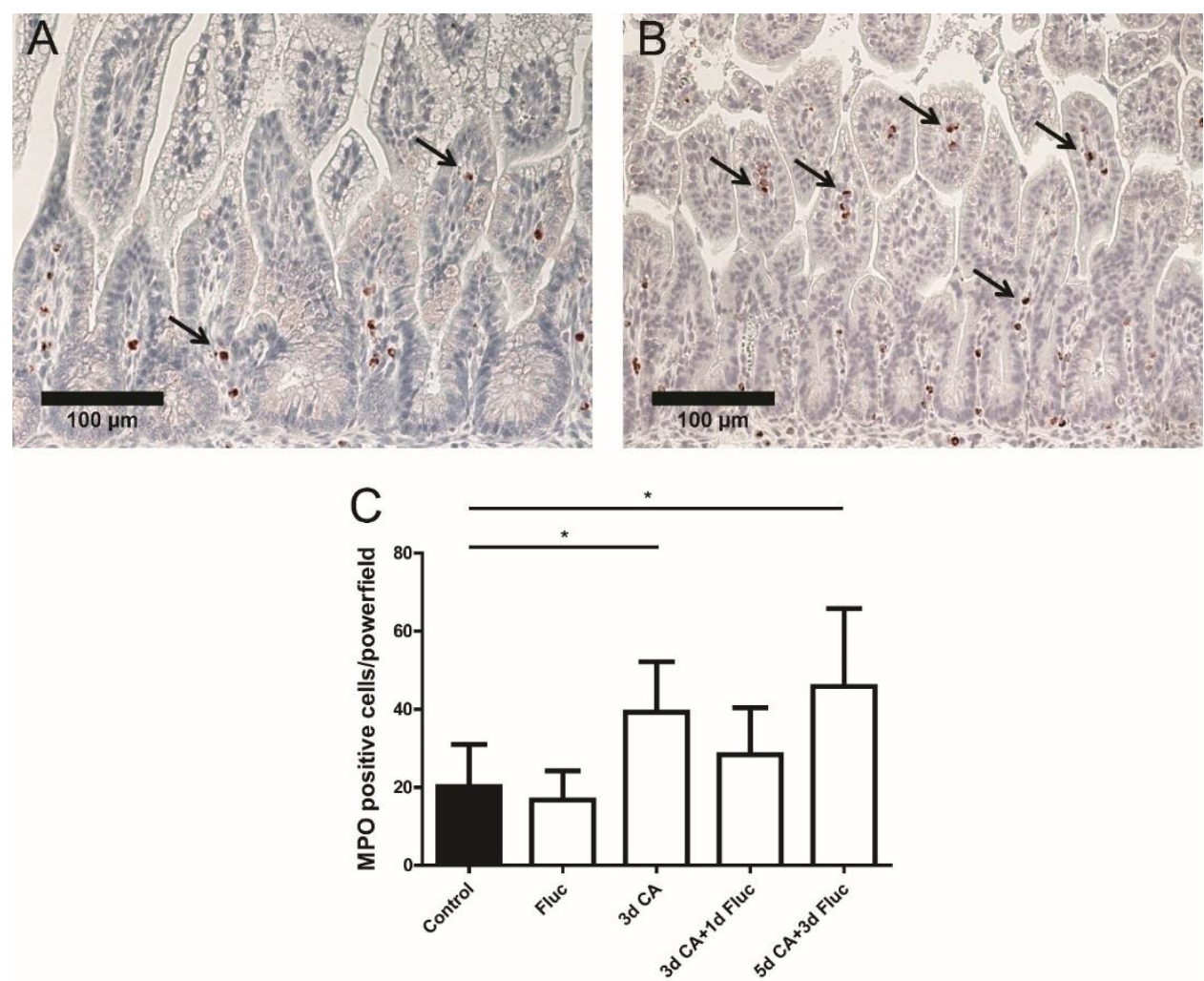

Figure 4: Number of $\mathrm{MPO}^{+}$cells in the fetal ileum. For each experimental group, intestinal sections of (A) control and animals that were exposed to Calbicans for 3 days (B) were stained by immunohistochemistry for MPO. For each experimental group, positive expressing cells of MPO (arrow) were counted and the mean cell counts per high power field per animal is indicated (C). Data are presented as mean \pm SD. ${ }^{*} \mathrm{p}<0.05$. MPO: myeloperoxidase. 

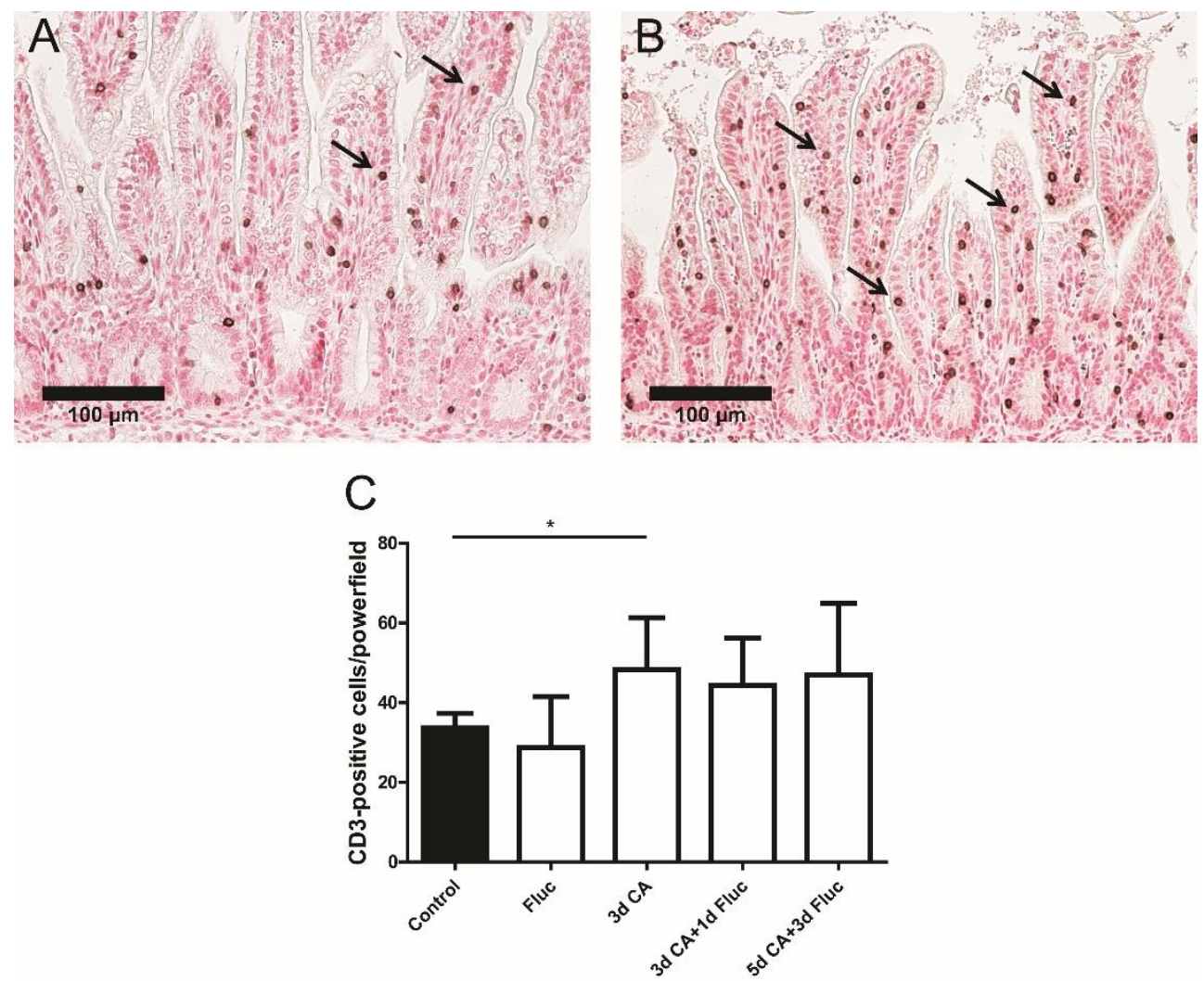

Figure 5: Number of $\mathrm{CD}^{+}$cells in the fetal ileum. For each experimental group, intestinal sections of (A) control and animals that were exposed to Calbicans for 3 days (B) were stained by immunohistochemistry for CD3. For each experimental group, positive expressing cells of CD3 (arrow) were counted and the mean cell counts per high power field per animal is indicated (C). Data are presented as mean \pm SD. ${ }^{*} \mathrm{p}<0.05$. CD: cluster of differentiation.

\section{C.albicans increased gut mRNA levels of pro-inflammatory cytokines}

We further characterized the inflammatory response by evaluating mRNA levels of pro- and anti-inflammatory cytokines in total gut tissue specimens. C.albicans exposure for 3 days significantly increased the intestinal mRNA levels of TNF- $\alpha$ and IL-17 ( $<<0.05$ for both) when compared to controls (Figure 6A and B). The elevated TNF- $\alpha$ and IL-17 mRNA levels were not decreased at 1 day after fluconazole treatment. No changes were found in the mRNA levels of animals that were exposed to C.albicans 
A

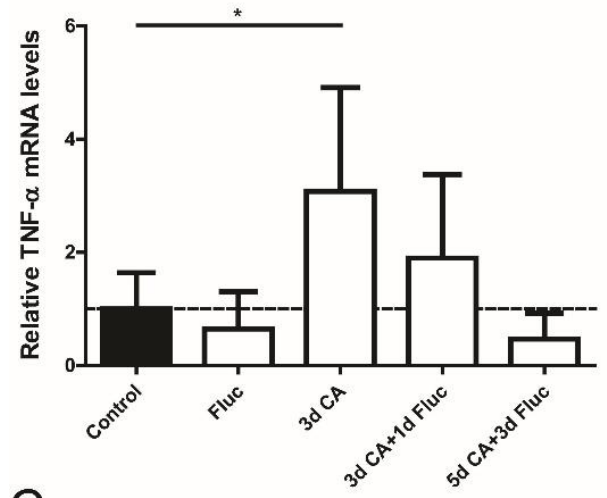

C

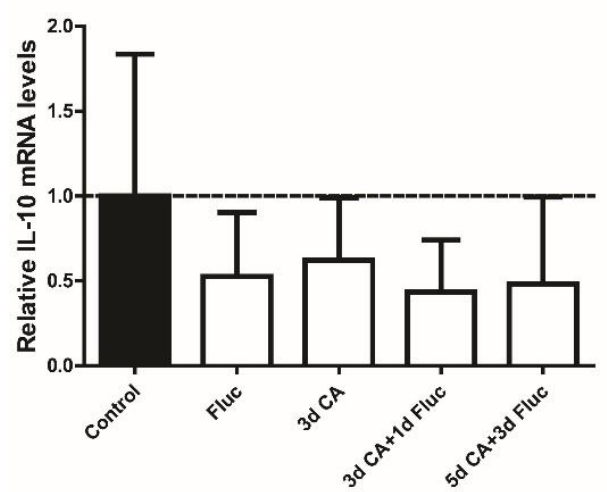

B

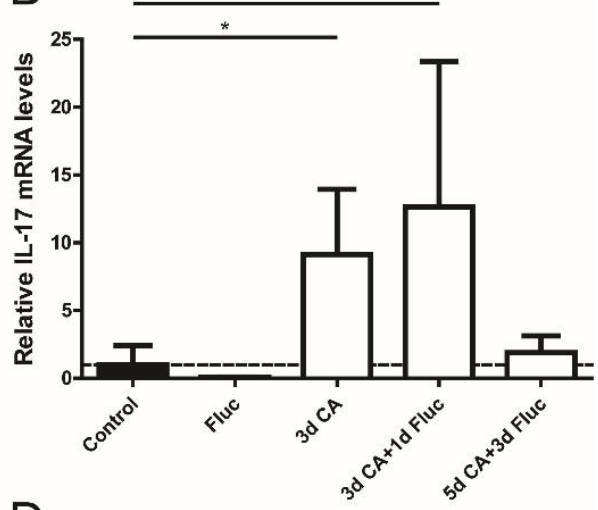

D

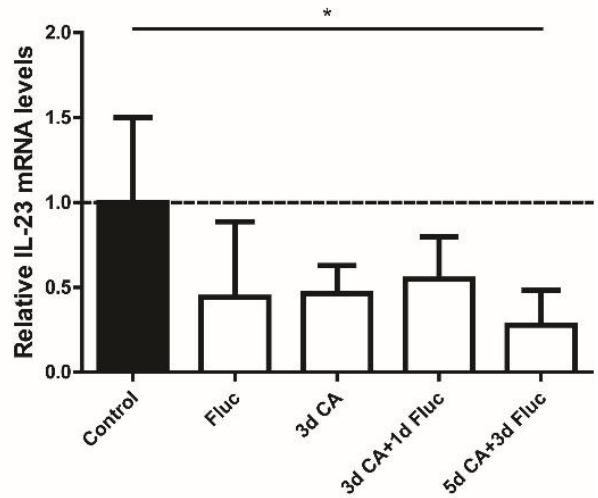

Figure 6: Cytokine mRNA levels in total fetal ileal tissue. The inflammatory cytokines TNF- $\alpha$ (A), IL-17 (B), IL-10 (C) and IL-23 (D) were assessed by qPCR and the values for each cytokine were normalized to ovRPS15 rRNA. Data are presented as mean \pm SD. * $\mathrm{p}<0.05$. IL: interleukin, TNF$\alpha$ : tumor necrosis- $\alpha$, qPCR: quantitative real time polymerase chain reaction.

for 5 days and treated with fluconazole when compared with controls. Intereukin-10 is known to be produced by the host upon infection with C.albicans hyphae and increased levels of IL-10 have been associated with increased susceptibility to candidiasis (31). The mRNA levels of IL-10 remained unaltered after IA exposure to C.albicans with or without fluconazole treatment when compared with controls (Figure 6C). The intestinal mRNA levels of IL-23 were significantly decreased in animals that were exposed to IA 
C.albicans infection for 5 days and treated with fluconazole compared to controls (Figure 6D). No changes were detected in gut IL-23 mRNA of the remaining groups.

\section{Discussion}

We have shown that IA exposure of fetal lambs to C.albicans resulted in an invasive Calbicans infection of the fetal gut tissue associated with epithelial injury and the induction of mucosal inflammation. At this stage, the described intestinal changes were accompanied by fungal translocation and systemic spread of $C$.albicans associated with systemic inflammation. Fluconazole treatment prevented systemic inflammation and Calbicans colonization of the fetal gut in the majority of Calbicans exposed animals. In addition, administration of fluconazole decreased epithelial injury of the fetal gut without inhibiting intestinal inflammation.

Growth of C.albicans in its hyphal form in the gut tissue strongly suggests that the detected mucosal injury is a direct consequence of Calbicans infection and translocation through the intestinal epithelial barrier. Invasion of enterocytes is mediated by active penetration of C.albicans in which, the hyphal form of C.albicans was previously shown to be necessary for the invasive process and the concomitant epithelial injury (32). Hyphae of C.albicans were also in close proximity to PP. Recent in vitro experiments have shown that in addition to active penetration of enterocytes, C.albicans can translocate the intestinal epithelium via endocytosis by microfold (M) cells. M cells are located at the follicle-associated epithelium (FAE) of the PP (33). The identification of C.albicans hyphae both within intestinal villi and in close proximity to PP suggests that both routes of intestinal translocation might have contributed to the disease observed after IA administration of C.albicans.

Epithelial damage as indicated by increased circulatory I-FABP levels following C.albicans exposure is an absolute requirement for Candida dissemination to the bloodstream $(34,35)$. Consistently, intestinal colonization and the associated mucosal injury at 3 days after C.albicans infection resulted in candidemia. The gastrointestinal tract is considered to be the most frequently organ that is involved in systemic 
dissemination (36) and systemic candidiasis is a major contributor to neonatal sepsis (37). In addition to translocation through the intestinal barrier, C.albicans might have breached the mucosa in other mucosal organs exposed to amniotic fluid (38).

Mucosal invasion of Calbicans in the fetal gut by 3 days after infection was associated with infiltration of immune cells and was paralleled by elevated intestinal levels of TNF- $\alpha$ and IL-17. Increased levels of these cytokines were measured in gastrointestinal and oral mucosal surfaces of mice colonized by C.albicans (39-42). Importantly, induction of TNF- $\alpha$ and IL-17 after Calbicans infection has been previously reported to stimulate the recruitment of neutrophils at the site of infection (43) as detected in our chorioamnionitis model. Neutrophils are believed to be fundamental in the process of phagocytosis against mucosal and disseminated C.albicans infection (43). Additionally, IL-17 is considered to be essential in mucosal immunity against Calbicans infection, as increased levels of IL-17 promote inflammation and disease progression (44). Th17 cells (a hallmark of IL-17 production) are commonly involved in host defense against Calbicans in epithelial and mucosal surfaces as they express chemokine receptors which locate them in epithelial and mucosal regions (45). Evaluating the expression of Th17-specific surface markers would be crucial to identify and important to unravel the precise defense mechanism of fetal intestinal Th17 cells against IA C.albicans infection. In addition, establishing the role of intestinal macrophages (a predominant source of TNF- $\alpha$ ) against $C$ albicans infection would provide more insight in the process of phagocytosis and the interplay between innate and adaptive immune responses.

Unfortunately, considering the current study design and the intrinsic limitations of our model such as the lack of ovine specific reagents, these intestinal immunological responses against IA Calbicans infection cannot be studied in detail at this stage. Nevertheless, this animal model was used as the development of the fetal ovine intestine during gestation is similar to human and this large animal model allow us to administer therapeutics, in doses which could potentially be used in humans. Therefore, this model is an appropriate preclinical model to investigate gut complications after C.albicans- 
mediated chorioamnionitis and test the therapeutic potential of IA fluconazole treatment during gestation.

In the same animals, we have previously shown that fluconazole treatment administered 2 days after IA administration of C.albicans, temporally prevented systemic inflammation and reduced fetal mortality $(22,28)$. In the present study, fluconazole treatment initiated 2 days after Calbicans infection decreased Calbicans colonization and epithelial injury of the fetal gut. Remarkably, although circulatory IL6 levels returned to baseline levels after fluconazole treatment, C.albicans infection persisted in the bloodstream of these animals. Since fluconazole treatment after C.albicans infection transiently prevented chorioamnion and lung inflammatory changes (22), we speculated that the decreased IL-6 levels in the fetal plasma following fluconazole treatment were mediated by the lung and/or chorioamnion (46). Nevertheless, the exact cause of systemic inflammation induced by IA C.albicans administration requires further investigation.

The reduction of intestinal C.albicans colonization in fluconazole treated animals was not associated with reduced intestinal inflammation. Fluconazole inhibits fungal growth by compromising its cell wall integrity $(47,48)$, which maintains inflammation. In fact the treatment-induced fungal cell destruction might temporarily increase the concentration of immunostimulatory molecules. On the other side, the ongoing inflammatory response is considered essential to eradicate the fungus $(49,50)$.

We have previously shown that fluconazole treatment after C.albicans infection was inadequate to eliminate C.albicans from the amniotic fluid. Moreover, the inflammatory response in several fetal organs was only temporarily decreased following anti-fungal treatment (22). These previous results combined with current data indicate that future research is warranted to explore the efficacy of alternative timing, dosing and frequency of fluconazole treatment in the context of intrauterine C.albicans infection.

In conclusion, we have shown that IA exposure of fetal lambs to C.albicans resulted in gut colonization, mucosal translocation, tissue injury and inflammation. These adverse intestinal consequences are associated with C.albicans translocation to 
the bloodstream with signs of systemic inflammation which was previously shown (22, 28). Although we did not assess the postnatal consequences of these findings, gut inflammation and tissue injury in conjunction with systemic inflammation are all pathological features, which are associated with neonatal gastrointestinal pathologies. In line, we have previously reported that chorioamnionitis with a fetal systemic inflammatory response, is strongly associated with NEC (51). In addition, a single fluconazole treatment prevented systemic inflammation and decreased intestinal injury whereas mucosal inflammation and dissemination of C.albicans in the bloodstream remained unaffected. Consequently, future studies should focus on optimizing a fluconazole-based therapeutic strategy to completely protect the fetal gut in the context of C.albicans-mediated chorioamnionitis. 


\section{References}

1. Blencowe H, Cousens S. Addressing the challenge of neonatal mortality. Trop. Med. Int. Health. 2013;18:303-312.

2. Galinsky R, Polglase GR, Hooper SB, Black MJ, Moss TJ. The consequences of chorioamnionitis: preterm birth and effects on development. J. Pregnancy. 2013;2013:412831.

3. Goldenberg RL, Culhane JF, Iams JD, Romero R. Epidemiology and causes of preterm birth. Lancet. 2008;371:75-84.

4. Goldenberg RL, Hauth JC, Andrews WW. Intrauterine infection and preterm delivery. N. Engl.J. Med. 2000;342:1500-1507.

5. Czikk MJ, McCarthy FP, Murphy KE. Chorioamnionitis: from pathogenesis to treatment. Clin. Microbiol. Infect. 2011;17:1304-1311.

6. Viscardi RM. Ureaplasma species: role in neonatal morbidities and outcomes. Arch. Dis. Child. Fetal Neonatal Ed. 2014;99:F87-92.

7. Gantert M, et al. Chorioamnionitis: a multiorgan disease of the fetus? J. Perinatol. 2010;30 Suppl:S21-30.

8. Mestan $\mathrm{K}$, et al. Placental inflammatory response is associated with poor neonatal growth: preterm birth cohort study. Pediatrics. 2010;125:e891-898.

9. Been JV, Lievense S, Zimmermann LJ, Kramer BW, Wolfs TG. Chorioamnionitis as a risk factor for necrotizing enterocolitis: a systematic review and meta-analysis. J. Pediatr. 2013;162:236-242 e232.

10. Coggins SA, Wynn JL, Weitkamp JH. Infectious causes of necrotizing enterocolitis. Clin. Perinatol. 2015;42:133-154, ix.

11. Iwatani $S$, et al. Neonatal leukemoid reaction associated with Candida albicans chorioamnionitis. Pediatr. Int. 2014;56:277-279.

12. Combs CA, et al. Amniotic fluid infection, inflammation, and colonization in preterm labor with intact membranes. Am.J. Obstet. Gynecol. 2014;210:125 e121-125 e115.

13. Jackel D, Lai K. Candida glabrata sepsis associated with chorioamnionitis in an in vitro fertilization pregnancy: case report and review. Clin. Infect. Dis. 2013;56:555558.

14. Meizoso T, et al. Intrauterine candidiasis: report of four cases. Arch. Gynecol. Obstet. 2008;278:173-176.

15. Bean LM, Jackson JR, Dobak WJ, Beiswenger TR, Thorp JA. Intra-amniotic fluconazole therapy for Candida albicans intra-amniotic infection. Obstet Gynecol. 2013;121:452-454. 
16. Payne MS, Bayatibojakhi S. Exploring preterm birth as a polymicrobial disease: an overview of the uterine microbiome. Front. Immunol. 2014;5:595.

17. Pilmis B, et al. Antifungal drugs during pregnancy: an updated review. $J$. Antimicrob. Chemother. 2015;70:14-22.

18. Molgaard-Nielsen D, Pasternak B, Hviid A. Use of oral fluconazole during pregnancy and the risk of birth defects. N. Engl. J. Med. 2013;369:830-839.

19. Wolfs TG, et al. Endotoxin induced chorioamnionitis prevents intestinal development during gestation in fetal sheep. PLoS One. 2009;4:e5837.

20. Wolfs TG, et al. Antenatal ureaplasma infection impairs development of the fetal ovine gut in an IL-1-dependent manner. Mucosal Immunol. 2013;6:547-556.

21. Wolfs TG, et al. IL-1alpha mediated chorioamnionitis induces depletion of FoxP3+ cells and ileal inflammation in the ovine fetal gut. PLoS One. 2011;6:e18355.

22. Maneenil G, et al. Fluconazole treatment of intrauterine Candida albicans infection in fetal sheep. Pediatr. Res. 2015;77:740-748.

23. Nikiforou M, et al. Prophylactic Interleukin-2 Treatment Prevents Fetal Gut Inflammation and Injury in an Ovine Model of Chorioamnionitis. Inflamm. Bowel. Dis. 2015;21:2026-2038.

24. Nikiforou M, et al. Selective IL-1 $\alpha$ exposure to the fetal gut, lung, and chorioamnion/skin causes intestinal inflammatory and developmental changes in fetal sheep. Lab. Invest. 2015

25. Yuan M, et al. Selection and evaluation of potential reference genes for gene expression analysis in the brown planthopper, Nilaparvata lugens (Hemiptera: Delphacidae) using reverse-transcription quantitative PCR. PLoS One. 2014;9:e86503. 26. Bionaz M, Loor JJ. Identification of reference genes for quantitative real-time PCR in the bovine mammary gland during the lactation cycle. Physiol Genomics. 2007;29:312-319.

27. Wolfs TG, et al. Chorioamnionitis-induced fetal gut injury is mediated by direct gut exposure of inflammatory mediators or by lung inflammation. Am. J. Physiol. Gastrointest. Liver. Physiol. 2014;306:G382-393.

28. Ophelders DR, et al. Neuroinflammation and structural injury of the fetal ovine brain following intra-amniotic Candida albicans exposure. $J$ Neuroinflammation. 2016;13:29.

29. Vermeulen Windsant IC, et al. Circulating intestinal fatty acid-binding protein as an early marker of intestinal necrosis after aortic surgery: a prospective observational cohort study. Ann. Surg. 2012;255:796-803.

30. Reisinger KW, et al. Noninvasive measurement of intestinal epithelial damage at time of refeeding can predict clinical outcome after necrotizing enterocolitis. Pediatr. Res. 2013;73:209-213. 
31. van der Graaf CA, Netea MG, Verschueren I, van der Meer JW, Kullberg BJ. Differential cytokine production and Toll-like receptor signaling pathways by Candida albicans blastoconidia and hyphae. Infect Immun. 2005;73:7458-7464.

32. Naglik JR, Moyes DL, Wachtler B, Hube B. Candida albicans interactions with epithelial cells and mucosal immunity. Microbes Infect. 2011;13:963-976.

33. Albac S, et al. Candida albicans is able to use $\mathbf{M}$ cells as a portal of entry across the intestinal barrier in vitro. Cell Microbiol. 2015

34. Koh AY, Kohler JR, Coggshall KT, Van Rooijen N, Pier GB. Mucosal damage and neutropenia are required for Candida albicans dissemination. PLoS Pathog. 2008;4:e35.

35. Yan L, Yang C, TangJ. Disruption of the intestinal mucosal barrier in Candida albicans infections. Microbiol. Res. 2013;168:389-395.

36. Romeo MG, et al. Role of probiotics in the prevention of the enteric colonization by Candida in preterm newborns: incidence of late-onset sepsis and neurological outcome. J Perinatol. 2011;31:63-69.

37. Parra-Herran CE, Pelaez L, Sola JE, Urbiztondo AK, Rodriguez MM. Intestinal candidiasis: an uncommon cause of necrotizing enterocolitis (NEC) in neonates. Fetal Pediatr. Pathol. 2010;29:172-180.

38. Payne MS, et al. Intrauterine Candida albicans infection elicits severe inflammation in fetal sheep. Pediatr. Res. 2014;75:716-722.

39. Kumamoto CA. Inflammation and gastrointestinal Candida colonization. Curr. Opin. Microbiol. 2011;14:386-391.

40. Hernandez-Santos N, et al. Th17 cells confer long-term adaptive immunity to oral mucosal Candida albicans infections. Mucosal Immunol. 2013;6:900-910.

41. Gladiator A, Wangler N, Trautwein-Weidner K, LeibundGut-Landmann S. Cutting edge: IL-17-secreting innate lymphoid cells are essential for host defense against fungal infection. J. Immunol. 2013;190:521-525.

42. Jawhara $\mathrm{S}$, et al. Colonization of mice by Candida albicans is promoted by chemically induced colitis and augments inflammatory responses through galectin-3. J. Infect. Dis. 2008;197:972-980.

43. Cheng SC, Joosten LA, Kullberg BJ, Netea MG. Interplay between Candida albicans and the mammalian innate host defense. Infect Immun. 2012;80:1304-1313.

44. Conti HR, Gaffen SL. Host responses to Candida albicans: Th17 cells and mucosal candidiasis. Microbes Infect. 2010;12:518-527.

45. Conti HR, Gaffen SL. Host responses to Candida albicans: Th17 cells and mucosal candidiasis. Microbes Infect. 2010;12:518-527. 
46. Kemp MW, et al. Selective exposure of the fetal lung and skin/amnion (but not gastro-intestinal tract) to LPS elicits acute systemic inflammation in fetal sheep. PLoS One. 2013;8:e63355.

47. Sorgo AG, et al. Effects of fluconazole on the secretome, the wall proteome, and wall integrity of the clinical fungus Candida albicans. Eukaryot. Cell. 2011;10:10711081 .

48. Kabir MA, Ahmad Z. Candida infections and their prevention. ISRN. Prev. Med. 2013;2013:763628.

49. Garcha UK, Brummer E, Stevens DA. Synergy of fluconazole with human monocytes or monocyte-derived macrophages for killing of Candida species. J. Infect. Dis. 1995;172:1620-1623.

50. Hazen KC, Mandell G, Coleman E, Wu G. Influence of fluconazole at subinhibitory concentrations on cell surface hydrophobicity and phagocytosis of Candida albicans. FEMS. Microbiol. Lett. 2000;183:89-94.

51. Been JV, Lievense S, Zimmermann LJ, Kramer BW, Wolfs TG. Chorioamnionitis as a risk factor for necrotizing enterocolitis: a systematic review and meta-analysis. J Pediatr. 2013;162:236-242 e232. 


\section{Supplementary Material}

Supplementary Table 1: Primers used for qPCR.

\begin{tabular}{ccc}
\hline Primer & $\boldsymbol{F}_{\boldsymbol{W}}$ sequence (5'-3') & $\boldsymbol{R} \boldsymbol{R}$ sequence (5'-3') \\
\hline ovRPS15 & CGAGATGGTGGGCAGCAT & GCTTGATTTCCACCTGGTTGA \\
\hline TNF- $\alpha$ & GCCGGAATACCTGGACTATGC & CAGGGCGATGATCCCAAAGTAG \\
\hline IL-17 & TGTGAGGGTCAACCTGAACAT & TGATAATCGGTGGGCCTTCTG \\
\hline IL-23 & GGGAAGTGGACAGAGGTTCC & CTGCCTCTCCAATCTGGCTG \\
\hline IL-10 & CATGGGCCTGACATCAAGGA & CGGAGGGTCTTCAGCTTCTC \\
\hline
\end{tabular}

Fw: forward, IL: interleukin, qPCR: quantitative real time polymerase chain reaction, Rv: reverse. 



\title{
Chapter 5
}

\section{Global hypoxia-ischemia induced inflammation and structural changes in the preterm ovine gut which were not ameliorated by mesenchymal stem cell treatment.}

\author{
Maria Nikiforou, Carolin Willburger, Anja E. de Jong, Nico Kloosterboer, Reint K. \\ Jellema, Daan R.M.G. Ophelders, Harry W.M. Steinbusch, Boris W. Kramer and \\ Tim G.A.M. Wolfs
}

Mol Med. 2016 Apr 14;22 


\begin{abstract}
Perinatal asphyxia, a condition of impaired gas exchange during birth, leads to fetal hypoxia-ischemia (HI) and is associated with postnatal adverse outcomes including intestinal dysmotility and necrotizing enterocolitis (NEC). Evidence from adult animal models of transient, locally-induced intestinal HI has shown that inflammation is essential in HI-induced injury of the gut. Importantly, mesenchymal stem cell (MSC) treatment prevented this HI-induced intestinal damage. We therefore assessed whether fetal global HI induced inflammation, injury and developmental changes in the gut and whether intravenous MSC administration ameliorated these HI-induced adverse intestinal effects.
\end{abstract}

In a preclinical ovine model, fetuses were subjected to umbilical cord occlusion (UCO), with or without MSC treatment, and euthanized 7 days after UCO. Global HI increased the number of myeloperoxidase positive cells in the mucosa, upregulated mRNA levels of interleukin (IL)-1 $\beta$ and IL-17 in gut tissue and caused T-cell invasion in the intestinal muscle layer. Intestinal inflammation following global HI was associated with increased $\mathrm{Ki} 67^{+}$cells in the muscularis and subsequent muscle hyperplasia. Global HI caused distortion of glial fibrillary acidic protein immunoreactivity in the enteric glial cells and increased synaptophysin and serotonin expression in the myenteric ganglia. Intravenous MSC treatment did not ameliorate these HI-induced adverse intestinal events.

Global HI resulted in intestinal inflammation and enteric nervous system abnormalities which are clinically associated with postnatal complications including feeding intolerance, altered gastrointestinal transit and NEC. The intestinal histopathological changes were not prevented by intravenous MSC treatment directly after HI, indicating that alternative treatment regimens for cell-based therapies should be explored. 


\section{Introduction}

Perinatal asphyxia is defined as a condition of impaired gas exchange during birth which leads to fetal hypoxia-ischemia (HI) and metabolic acidosis (1, 2). Perinatal asphyxia is one of the most frequent causes of perinatal morbidity accounting for approximately $23 \%$ of neonatal deaths worldwide $(3,4)$. Fetuses that suffered from HI are at high risk to develop multi-organ dysfunction $(5,6)$ including the gut. HI-induced gut injury may result in adverse clinical outcomes such as feeding intolerance, altered intestinal motility (7) and necrotizing enterocolitis (NEC), the most serious lifethreatening gastrointestinal disease in neonates $(8,9)$.

Numerous studies have recently demonstrated that the inflammatory processes which followed intestinal HI played a key role in the pathophysiology of HI-induced gut injury (10-12). This evidence is primarily based on experiments in adult rodent models of transient superior mesenteric artery occlusion showing that intestinal HI induces gut inflammation with concomitant epithelial lining loss, gut barrier dysfunction, morphological and functional changes in the muscle layers and enteric nervous system (12-19). Although these studies provide insights into the mechanisms of HI-induced adverse intestinal outcomes, they represent the clinical scenario of locally induced intestinal HI in adults whereas global HI, which occurs during perinatal asphyxia, leads to $\mathrm{HI}$ in multiple organs.

The systemic administration of mesenchymal stem cells (MSCs) has been tested as an innovative therapeutic approach to modulate inflammation in a plethora of immune-mediated diseases (20). In particular, intravenous infusion of MSCs was proven successful to protect the gut against inflammatory bowel diseases $(21,22)$ and experimental NEC (23), two gastrointestinal pathologies that share some mutual features with the HI-induced injury of the adult intestine. We recently assessed the therapeutic potential of intravenous MSC administration in a preclinical model of global $\mathrm{HI}$ in the preterm ovine fetus in which, fetal global $\mathrm{HI}$ induced a systemic inflammatory response that was associated with structural and functional impairment of the fetal brain (24). These adverse effects of global HI on the fetal brain were substantially prevented 
by intravenous administration of MSCs, which are known to possess immunomodulatory, regenerative and reparative properties (25-27).

The aim of the current study was therefore twofold: first to assess whether fetal global HI resulted in inflammatory and/or structural changes of the intestine. For this purpose, preterm fetal sheep were exposed to 25 minutes of transient umbilical cord occlusion (UCO) in utero. Secondly, we investigated whether intravenous administration of MSCs in this ovine model would ameliorate the global HI-induced adverse effects of the fetal intestine. To test our hypothesis, a clinically relevant intravenous dose of MSCs (28-30) was administered 1 hour (h) after UCO. We assessed the fetal ovine gut at 7 days after $\mathrm{UCO}$ with respect to mucosal inflammation and injury, muscle abnormalities and changes in the enteric nervous system as these pathophysiological characteristics contribute to feeding intolerance, altered gastrointestinal transit and NEC (31).

\section{Materials and Methods}

\section{Animals}

All experiments were approved by the Animal Ethics Committee of Maastricht University, the Netherlands according to Dutch governmental regulations.

\section{Experimental procedures}

Fetuses of time-mated Texel ewes were instrumented at $101 \pm 0.9($ mean \pm SD) days of gestation as previously described (24). The ewe was anesthetized and a catheter was placed in the maternal saphenous vein for pre- and postoperative administration of antibiotics and blood sampling. The fetus was exposed by a midline incision and catheters were placed in the femoral artery and brachial vein. In addition, electrodes were placed for electroencephalography (EEG) and electrocardiography (ECG) recordings and an inflatable umbilical vascular occluder was placed around the umbilical cord to induce a hypoxic-ischemic insult. Finally, a catheter was placed in the amniotic cavity for amniotic fluid pressure measurements. The EEG, ECG and 
amniotic fluid pressure measurements have been previously reported by Jellema et al. (32). All fetal catheters were exteriorized through a trocar hole in the flank of the ewe.

\section{Hypoxia-ischemia and MSC administration}

The experimental design of the study is depicted in figure 1. The fetal sheep was used as validated animal model to study the effects of fetal HI on organ development (33). In addition, fetal instrumentation in utero enables us to test potential therapeutics to prevent organ damage after global HI (34-36). Fetal instrumentation was followed by a recovery period of four days as previously described (24). On day $105 \pm$ 0.9 (mean $\pm \mathrm{SD}$ ) of gestation (term approximately at 147 days), fetuses were randomly assigned to an experimental group. The fetuses assigned to the HI group underwent 25 minutes of umbilical cord occlusion (UCO) to induce global HI, whereas the fetuses belonging to sham-UCO were not occluded. Occlusion of the umbilical cord was confirmed by heart rate and arterial blood pressure recordings in conjunction with fetal blood gas analysis demonstrating bradycardia, hypotension, acidemia, hypoxia and hypercapnia as previously reported (24). In order to induce an acute, sub-lethal asphyctic insult at this gestational age (0.7 of gestation), a 25 minutes UCO was applied as previously reported (37). In addition, transient clamping of the umbilical cord for 25 minutes at this gestational age has been previously reported to result in fetal HI and cerebral and gastrointestinal hypoperfusion in ovine fetuses (37-40). One hour after the end of UCO (HI group, $\mathrm{n}=6$ ) or sham-UCO (Control group, $\mathrm{n}=8$ ), MSCs ( $\mathrm{HI}+\mathrm{MSC}$ group, $\mathrm{n}=7$ ) or saline were given intravenously to the fetus. The sham-UCO group received either saline (Control group) or MSCs (MSC group, $n=7$ ). MSCs were prepared at a dose of $3.5 \times 10^{6}$ MSCs (approximately $2.0 \times 10^{6} / \mathrm{kg}$ ) based on clinical trials of focal ischemia (28) and patients with inflammatory bowel disease (29, 30). MSCs were given intravenously and were not associated with any signs of immunological rejection as previously described (32). At 113 days of gestation, (7 days after the induction of UCO), both the ewes and fetuses were euthanized by pentobarbital (200 $\mathrm{mg} / \mathrm{kg}$ ). The rationale to euthanize the animals 7 days after $\mathrm{UCO}$ was based on the 
current feeding guidelines in the clinic which indicate that enteral feeding is initiated approximately at 7 days after birth and it is gradually advanced in asphyxiated newborns. Therefore, in order to explore the underlying histopathological changes of the fetal gut after global HI which might explain the clinical experience where the asphyxiated babies are not able to tolerate full enteral feeds at approximately one week of age, we chose to sacrifice our animals exactly the moment that the enteral feeding would gradually start in the clinic. The survival rate in this model was $90 \%$ and deceased animals were not included in the analyses. Importantly, autopsy of the dead animals revealed that fetal death was caused by technical reasons (e.g. arterial catheter not in situ resulting in exsanguination and subsequent fetal death, occluder obstructing the umbilical cord without inflation) and was unrelated to MSC treatment.

In the current study, the gestational age of the fetal sheep is equivalent to a human premature baby of approximately 28-32 weeks of gestation $(37,41)$. Terminal ileum was examined as this region of the intestine is primarily affected in cases of perinatal asphyxia and NEC $(42,43)$.

\section{Preparation of mesenchymal stem cells}

Human bone marrow-derived mesenchymal stem cells (Merck Millipore, Billerica MA, USA) were isolated and prepared as previously described (32). Briefly, MSCs were isolated from a male donor, expanded, frozen and stored in liquid nitrogen. The MSCs were characterized by identifying cell surface molecules by flow cytometry analysis as previously described (32). MSCs were suspended in PBS one hour before administration. 


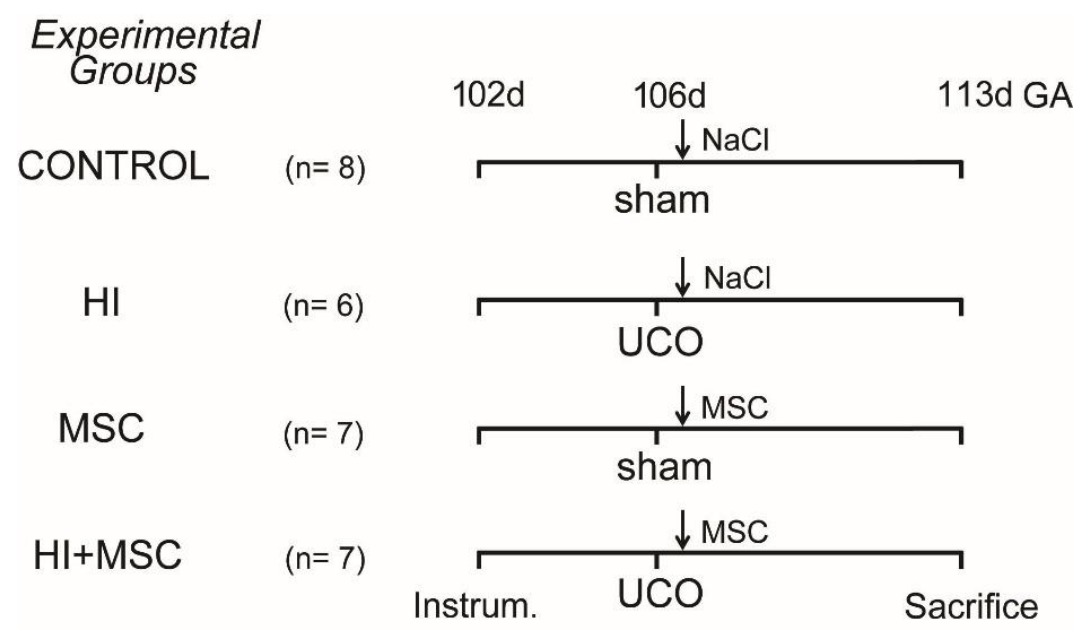

Figure 1: Experimental design of the study. Fetuses were instrumented at gestational age (GA) of 102 days. Four days after instrumentation (106 GA), umbilical cord occlusion (UCO) or sham was performed for 25 minutes followed by intravenous administration of either mesenchymal stem cells (MSCs) or saline $(0.9 \% \mathrm{NaCl}) 1$ hour after the end of UCO. The fetuses were sacrificed 7 days after UCO or sham at 113 days of gestation. d: days, GA: gestational age, HI: hypoxia-ischemia, Instrum.: instrumentation, MSC: mesenchymal stem cell, n: number, UCO: umbilical cord occlusion.

\section{Antibodies}

The following antibodies were used in this study: rabbit antibody against human CD3 and MPO (Dako, Glostrup, Denmark) for identification of T cells and neutrophils; mouse anti-SMA22 (Generous gift of Dr. Olde Damink, Department of Surgery, Maastricht University, the Netherlands) for characterization of smooth muscle actin present in circular and longitudinal muscle layers; mouse anti-human Ki67 (DAKO, Glostrup, Denmark) for detection of proliferating cells; mouse antisynaptophysin (Millipore, Billerica, MA, USA) for detection of presynaptic vesicle; monoclonal mouse anti-NeuN (Millipore, Billerica, MA, USA) for detection of postmitotic neurons; polyclonal rabbit anti-5-HT (5-hydroxytryptamine) custom made from the department of Neuroscience (Maastricht University, Maastricht, the Netherlands) for identification of serotonin expressing cells and polyclonal rabbit anti-glial fibrillary acid protein (GFAP) (DAKO, Glostrup, Denmark) for identification of enteric glial 
cells (44). Intestinal integrity was examined by staining for the tight junctional protein Zonula Occludens protein 1 (ZO-1) (Invitrogen, Bleiswijk, the Netherlands). For general morphological evaluation in the fetal intestine, a hematoxylin and eosin $(\mathrm{H} \& \mathrm{E})$ staining was performed.

As secondary antibodies, Texas Red conjugated goat anti-rabbit from Southern Biotechnology (Birmingham, AL, USA); biotin conjugated swine anti-rabbit or goat anti-mouse from Dakocytomation and peroxidase conjugated goat anti-rabbit from Jackson ImmunoResearch Laboratories (West Grove, PA, USA) or goat anti-mouse from DAKO (Glostrup, Denmark) were used.

\section{Immunohistochemistry}

Formalin-fixed terminal ileum was embedded in paraffin and $4 \mu \mathrm{m}$ sections were cut. After deparaffinization and rehydration, endogenous peroxidase activity was blocked with either $0.3 \% \mathrm{H}_{2} \mathrm{O}_{2}$ diluted in TBS (MPO) or PBS (CD3, NeuN, 5-HT, synaptophysin) or methanol (SMA22, Ki67). Non-specific binding was blocked with normal goat serum (MPO, Ki67, NeuN, synaptophysin) or bovine serum albumin (CD3, SMA22, 5-HT) for 30 minutes at room temperature. Thereafter, sections were incubated with the primary antibody of interest and subsequently were incubated with the selected secondary-conjugated antibody. CD3, Ki67, synaptophysin, SMA22 and 5HT antibodies were recognized with the streptavidin-biotin method (Dakocytomation) and antibodies against MPO and NeuN were detected by using a peroxidase-conjugated secondary antibody. Substrate staining for MPO and SMA22 was performed with 3amino-9-ethylcarbazole (AEC, Sigma); haematoxylin (MPO and SMA22) and nuclear fast red (CD3, Ki67, NeuN, synaptophysin and 5-HT) were used as counterstain for nuclei respectively. Immunoreactivity for CD3, Ki67, NeuN, synaptophysin and 5-HT was detected by using nickel-DAB. 


\section{Quantification of immunohistochemical stainings}

Pictures were taken with a light microscope (Leica Microsystems CTG, type DFC295, Germany) using the Leica QWin Pro version 3.4.0 software (Leica Microsystems) or with the Olympus Research System Microscope AX70 Brightfield (Olympus Corporation, Tokyo, Japan) using the CellProfiler software (Broad Institute, Cambridge, MA, USA) as appropriate. The positive stained cells were counted in five high power fields. The average number of positive cells per high power field per animal is given. Quantification was performed as previously described (45). In brief, the high power field was defined using the microscope, a picture was taken and the cells were counted immediately after taking the picture on the computer screen by using Image J. To verify accurate cell counting, the high power field was still defined under the microscope during counting on the computer screen. Only after finishing the counting per picture, the next high power field was defined. For the CD3 and MPO quantification, the total number of $\mathrm{CD}^{+}$cells was counted in the mucosa and the MPO cells were also counted in the upper two third of the villi. The thickness of the muscle layers was measured by using a marker for smooth muscle actin (SMA22). The proliferation rate (\%) in the muscle layers was determined by counting the Ki67 cells (positive) and Ki67 (negative) cells in a determined area and the percentage of (Ki67 cells/ total cells) was calculated and expressed per $1000 \mu \mathrm{m}^{2}$. The number of nuclei and the hypertrophy index in the muscles were calculated as previously (46). Briefly, the total number of nuclei in muscles was calculated by counting the number of nuclei in muscle layers in determined area and multiplied by the surface area $\left(\mu \mathrm{m}^{2}\right)$ occupied by each muscle layer per power field and the mean total cell counts is presented. The hypertrophy index was calculated by dividing the total number of nuclei by the muscle surface $\left(\mu \mathrm{m}^{2}\right)$ and is expressed per $1000 \mu \mathrm{m}^{2}$. The number of neuronal nuclei (NeuN cells) was counted in the ganglia of myenteric plexus. In addition, the area fraction (\%) of synaptophysin and 5-HT (serotonin) were determined in ganglia of myenteric plexus (47). 5-HT cells were also counted in the mucosa, as 5-HT is expressed by 
enterochromaffin cells (48). Stainings were evaluated by three independent observers who were blinded to the experimental groups.

\section{Immunofluorescence}

Fetal ileum embedded in optimal cutting temperature (O.C.T) solution was cut at a thickness of $4 \mu \mathrm{m}$ for immunofluorescence staining of GFAP and ZO-1 as reported previously (49). After fixation (15 minutes in $4 \%$ paraformaldehyde), the sections were incubated with $5 \%$ normal goat serum in 1\% tween-20 (GFAP) or 10\% normal goat serum (ZO-1) for 15 minutes to block the non-specific binding and thereafter sections were incubated overnight with GFAP or ZO-1 as a primary antibody. The next day, sections were washed and then incubated with Texas Red conjugated secondary antibody. After 1 hour of incubation, nuclei were stained with 4',6'-diamino-2-phenyl indole (DAPI) for 2 minutes. Finally, sections were mounted with fluorescent mounting solution. The immunoreactivity of GFAP was evaluated by a Leica DMI 4000 inverted fluorescence microscope (Leica, Wetzler, Germany) using the LAS AF software. The ZO-1 stained tight junctions were evaluated by using an AxioCam MRc5 camera (ZEISS, Jena, Germany) mounted on an ECLIPSE E800 fluorescence microscope (Nikon, Amsterdam, the Netherlands).

\section{RNA isolation and quantitative real-time PCR}

The mRNA levels of cytokines were measured by quantitative real-time PCR (qPCR) as described previously (45). RNA was extracted from ileum by Trizol/chloroform method. Reverse transcription was achieved by using M-MLV Reverse transcriptase (Invitrogen, Bleiswijk, the Netherlands) according to supplier's guidelines. The qPCR reaction was performed with the LightCycler 480 SensiMix SYBR master mix (GC biotech B.V., Alphen aan den Rijn, the Netherlands) in a LightCycler 480 with specific ovine primers (Supplementary table 1). The results were normalized to the housekeeping gene ovine $40 \mathrm{~S}$ ribosomal protein S15 (ovRPS15), and mean fold changes relative to control levels are presented. 


\section{Statistical Analysis}

Data are presented as mean \pm SEM. Statistical analysis was performed using GraphPad Prim software (version v5.0; GraphPad Software Inc.) by using a nonparametric Kruskal Wallis test followed by Dunn's post-hoc test. Non-parametric analysis was used based on the following criteria: 1) low number of animals per group and 2) visual inspection of our data in histograms which indicated that our results did not follow a Gaussian distribution. Only differences which were considered statistically significant at $\mathrm{p}<0.05$ are indicated in the figures.

\section{Results}

\section{Fetal $\mathrm{HI}$ induced intestinal inflammation}

We assessed the inflammatory response in the fetal gut 7 days after UCO by immunohistochemical staining for CD3 and MPO, which are markers for T lymphocytes and neutrophils, respectively. Total number of $\mathrm{MPO}^{+}$cells in the intestinal mucosa did not differ between the groups (data not shown). However, fetal HI resulted in increased numbers of $\mathrm{MPO}^{+}$cells in the upper part of the intestinal villi 7 days after UCO when compared to control animals (Figure 2). Similarly, when animals treated with MSCs after UCO, elevated numbers of $\mathrm{MPO}^{+}$cells were found in the villus tips when compared to control and MSC treated animals (Figure 2C).

The number of $\mathrm{CD}^{+}$cells in the intestinal mucosa remained unaltered in all experimental groups when compared to control animals at 7 days after UCO (Figure 3C). However, fetal $\mathrm{HI}$ resulted in significant $\mathrm{CD}^{+}$cell influx in the circular muscle at 7 days after UCO when compared to control which was not prevented by MSC treatment (Figure 3A, B and D). Importantly, the significant increase of $\mathrm{CD}^{+}{ }^{+}$cells in the circular muscle of the $\mathrm{HI}+\mathrm{MSC}$ group was maintained, even in the absence of the highest value within this $\mathrm{HI}+\mathrm{MSC}$ group (Figure 3D). 

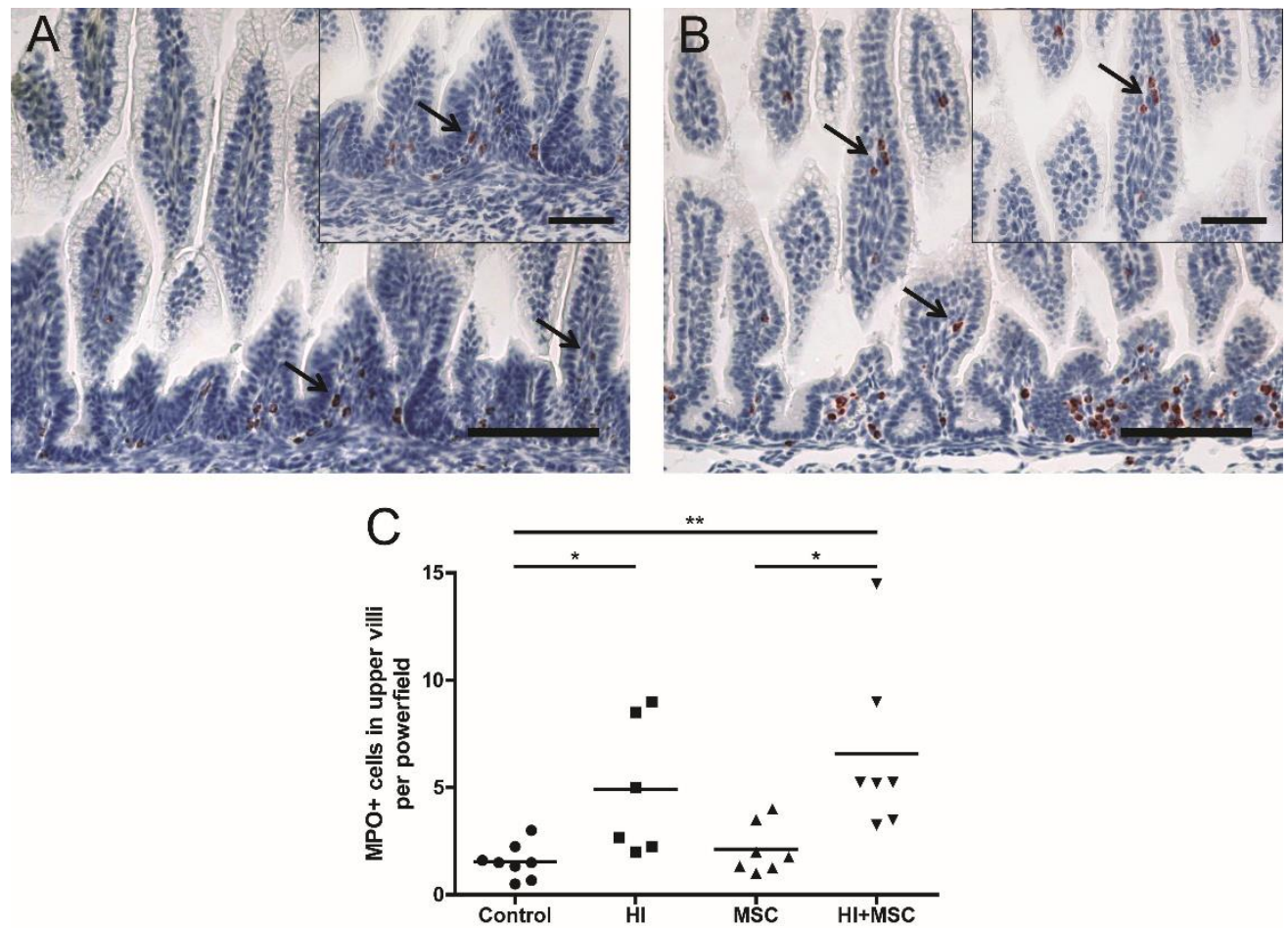

Figure 2: Increased number of $\mathrm{MPO}^{+}$cells in the upper part of the villi at 7 days after $\mathrm{HI}$. Representative intestinal sections of (A) control and (B) HI animals were stained by immunohistochemistry for MPO. For each experimental group, positive expressing cells of MPO (arrows) in the upper part of the villi were counted and the mean cell counts per power field per animal are given $(\mathrm{C})$. The scale bar in panels $\mathrm{A}$ and B represents $100 \mu \mathrm{m}$. The scale bar in insets represents $50 \mu \mathrm{m} .{ }^{*} \mathrm{p}<0.05$ and ${ }^{*}{ }^{*} \mathrm{p}<0.01$.

We further characterize the intestinal inflammatory response by measuring mRNA levels of IL-1 $\beta$ and IL-17, two pro-inflammatory cytokines with mitogenic capacities that are upregulated following HI $(12,50)$. Fetal HI, with or without MSC treatment, increased the intestinal mRNA levels of IL-1 $\beta$ when compared to control (Figure 4A). Similarly, increased mRNA levels of IL-17 were detected in the fetal gut after HI when compared to control. No significant changes were found in IL-17 mRNA levels of the remaining groups (Figure 4B). 

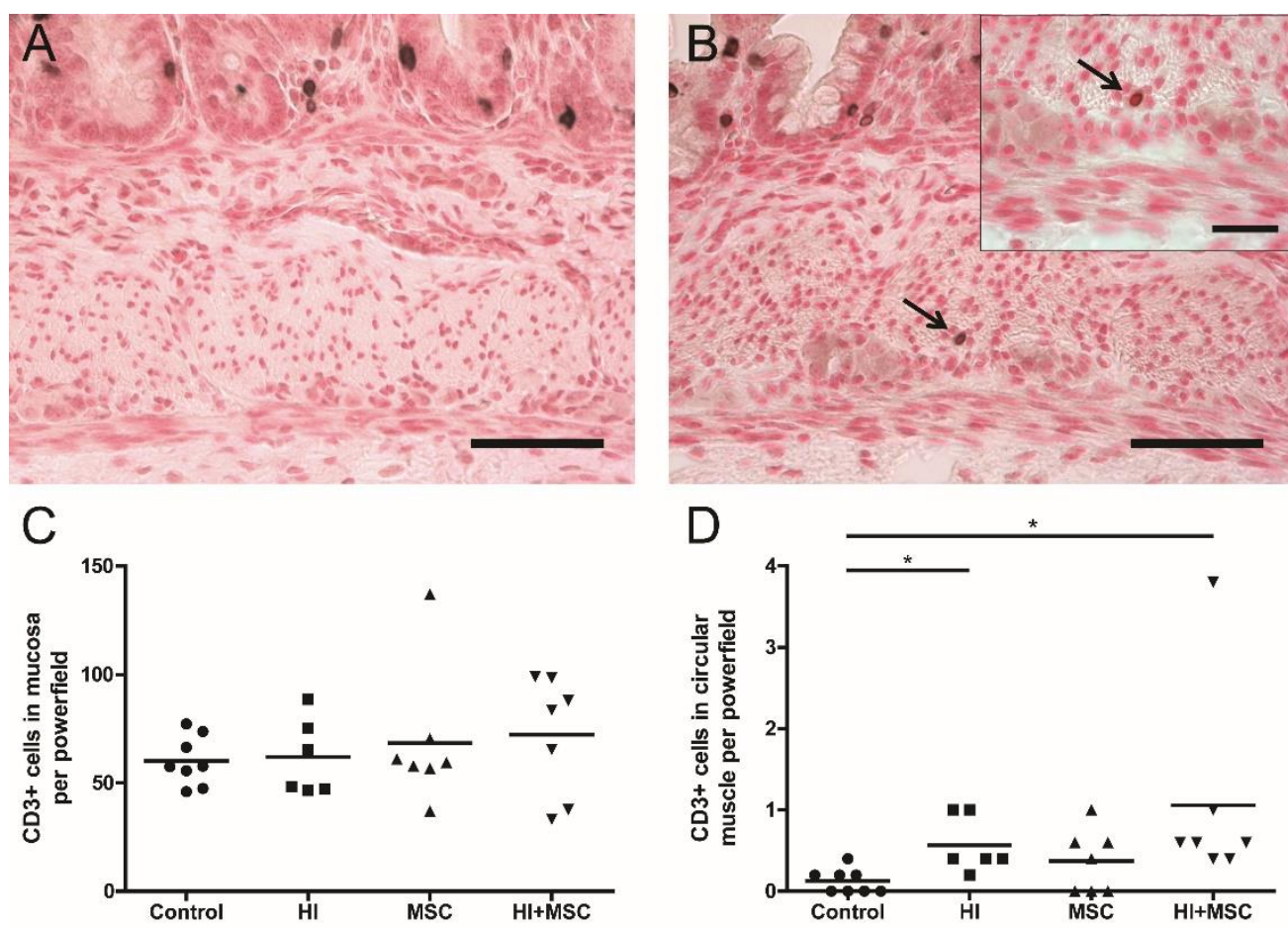

Figure 3: Invasion of $\mathrm{CD}^{+}$cells in the circular muscle layer 7 days after HI. Representative intestinal sections of (A) control and (B) HI animals were stained by immunohistochemistry for CD3. For each experimental group, positive expressing cells of CD3 (arrow) in the mucosa (C) and circular muscle layer (D) were counted and the mean cell counts per power field per animal are given. The scale bar in panels A and B represents $50 \mu \mathrm{m}$. The scale bar in insets represents $20 \mu \mathrm{m}$. ${ }^{*} \mathrm{p}<0.05$.

\section{Morphological changes of the fetal intestine after global HI}

We performed an H\&E staining to assess morphological changes in the fetal ileum at 7 days after fetal HI. No clear signs of epithelial injury were seen between the experimental groups (Supplementary figure 1). Consistently, with the exception of one HI animal, no signs of tight junctional loss were found, as evaluated by immunofluorescence staining of ZO-1 (data not shown). In addition, H\&E staining revealed variation in the thickness of both the circular and longitudinal muscle layers between the groups (Supplementary figure 1). 

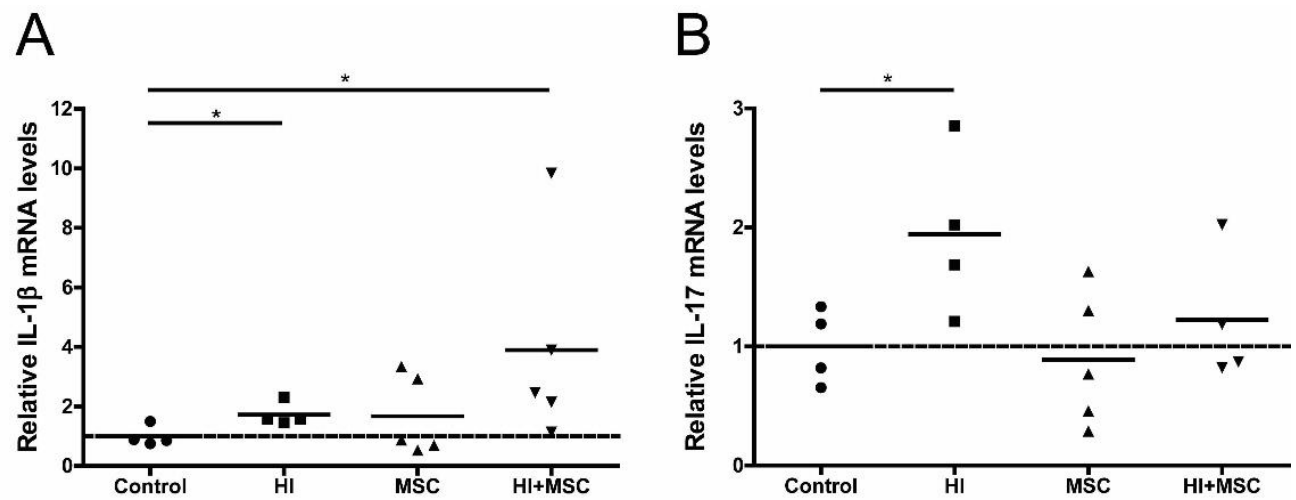

Figure 4: Increased mRNA levels of inflammatory cytokines in the fetal intestinal tissue 7 days after global HI. The inflammatory cytokines (A) IL-1 $\beta$ and (B) IL-17 were assessed by quantitative realtime PCR. * $\mathrm{p}<0.05$.

\section{Fetal HI induced intestinal muscle thickness}

Since the H\&E staining revealed variation in the muscle layers between the experimental groups, we evaluated the effects of fetal $\mathrm{HI}$ in the circular and longitudinal muscle layer by immunohistochemical staining for SMA22, a marker for smooth muscle actin (51). At 7 days after UCO, increased muscle thickness was observed in circular and longitudinal muscle layers when compared to control animals (Figure 5AD). The increased thickness of both muscle layers at 7 days after HI was not prevented in animals that were treated with MSCs after UCO when compared with control (Figure $5 \mathrm{C}$ and $\mathrm{D})$.

To evaluate whether the increased thickening of the muscle layers was associated with increased cell proliferation, we stained the circular and longitudinal muscle layer for Ki67 as a marker for proliferation. Compared to control animals, the proliferation rate in the circular and longitudinal muscle layers was increased at 7 days after UCO (Figure 6A-D). The increased proliferation rate of cells in the circular and longitudinal muscle layers of animals subjected to HI was not affected by MSC treatment (Figure 6C and D). 

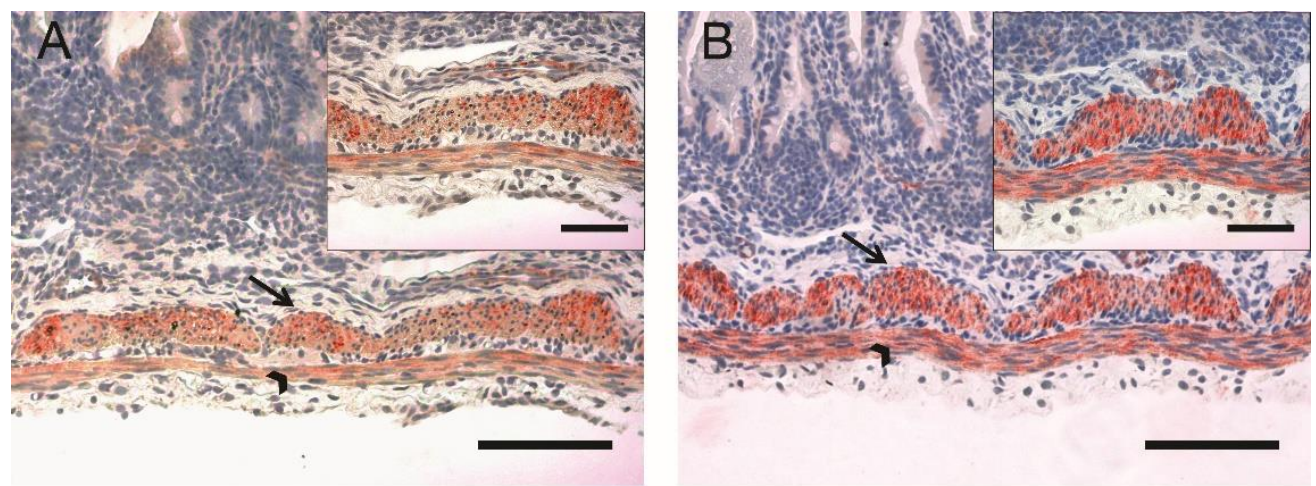

C
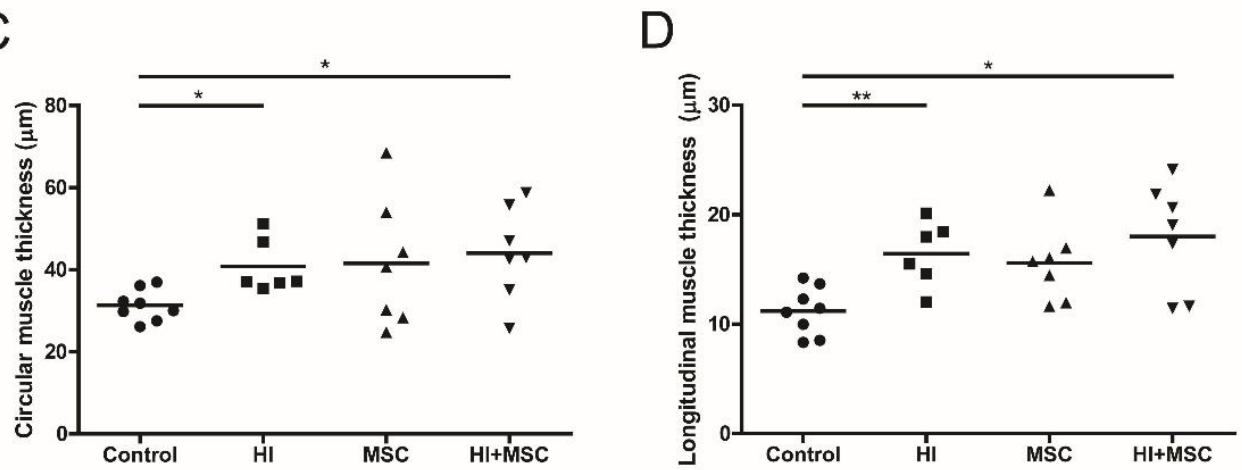

Figure 5: Increased thickness of the longitudinal and circular muscle layer 7 days after HI. Representative intestinal sections of (A) control and (B) HI animals were stained by immunohistochemistry for SMA22 (red). For each experimental group, muscle thickness in (C) circular (arrow) and (D) longitudinal (arrow head) muscle layer was measured and the mean thickness per power field per animal is given. The scale bar in panels A and B represents $100 \mu \mathrm{m}$. The scale bar in insets represents $50 \mu \mathrm{m} .{ }^{*} \mathrm{p}<0.05$ and ${ }^{* *} \mathrm{p}<0.01$.

To determine whether hyperplasia (increased cells numbers) or hypertrophy (increased cell size) was responsible for the increased thickness of the circular and longitudinal muscle layer, we assessed the number of cells within the muscle layers. Fetal HI, with or without MSC treatment, increased the numbers of cells in both longitudinal and circular muscle layer compared to controls (Figure $6 \mathbf{E}$ and F). In contrast, no differences were found in the hypertrophy index between the groups in both muscle layers (data not shown). 

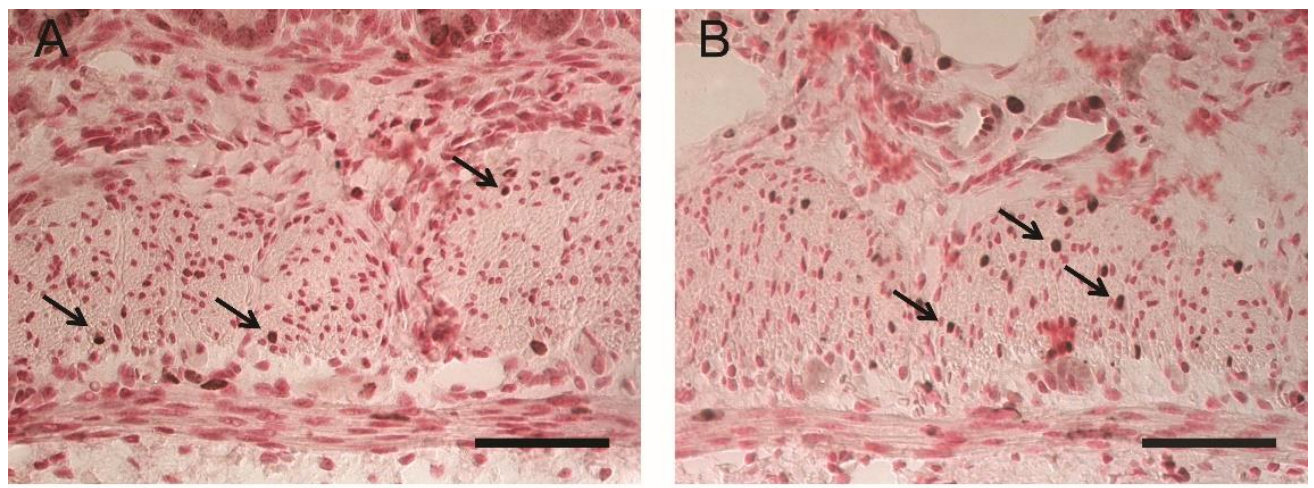

C

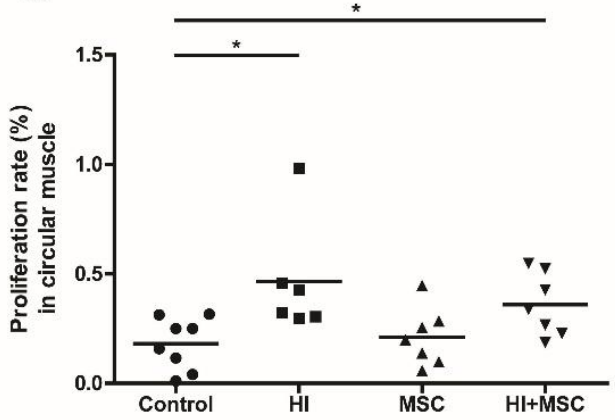

$\mathrm{D}$

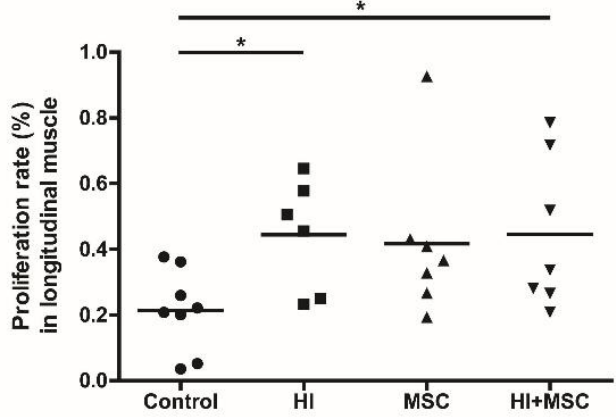

$E$

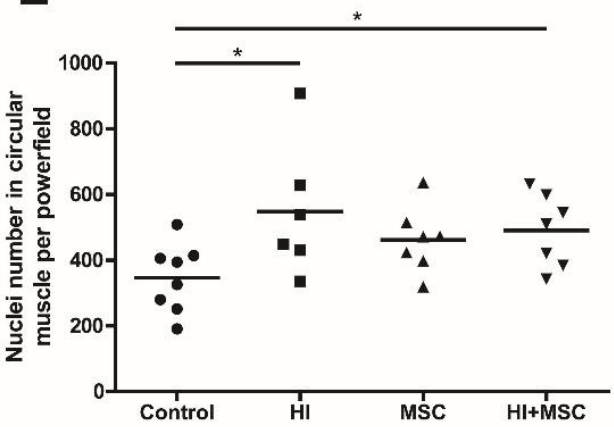

$\mathrm{F}$

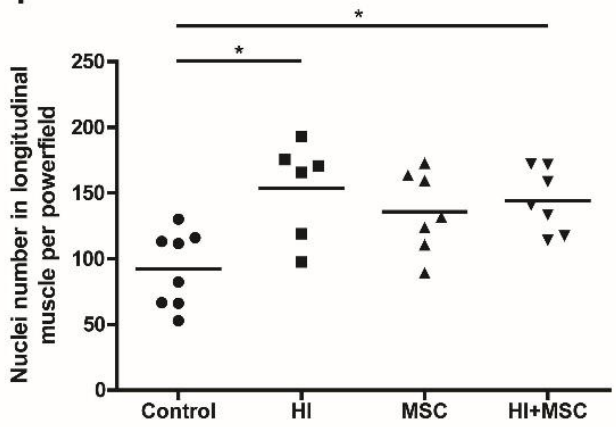

Figure 6: Increased proliferation rate and number of nuclei in muscle layers 7 days after HI. Representative intestinal sections of (A) control and (B) HI animals were stained by immunohistochemistry for Ki67. For each experimental group, proliferation rate in (C) circular and (D) longitudinal and nuclei numbers in (E) circular and (F) longitudinal muscle layer were counted and the mean cell counts per power field per animal are given. The proliferation rate (\%) is expressed per $1000 \mathrm{~mm}^{2}$. The arrows indicate Ki67 cells within the muscle layers. The scale bar in panels A and B represents $50 \mu \mathrm{m}$. * $\mathrm{p}<0.05$. 


\section{Fetal $\mathrm{HI}$ induced changes in the fetal enteric nervous system (ENS)}

We investigated the impact of global HI in the ganglia of myenteric plexus which are involved in the regulation of intestinal motility (52). We first counted the number of $\mathrm{NeuN}^{+}$cells (neurons) in the myenteric plexus by immunohistochemistry. The number of NeuN ${ }^{+}$cells in the myenteric ganglia remained at baseline levels in all investigated groups (Figure 7A-C). We then examined whether fetal HI induced structural changes in the enteric glial cells by immunofluorescent staining for glial fibrillary acidic protein (GFAP). The myenteric ganglia of control animals appeared with normal GFAP immunoreactivity where the perinuclear rim and glial processes were evident (Figure 8A). In contrast, animals that were subjected to UCO appeared with distorted GFAP immunoreactivity where glial processes were absent and GFAP globules were displayed (Figure 8B). The distortion of GFAP immunoreactivity following fetal HI was not prevented by MSC treatment (data not shown). We evaluated whether fetal HI induced changes in intestinal neuronal synapses and signaling by staining for synaptophysin and 5-HT (serotonin), respectively. Global HI induced increased positive stained area of synaptophysin in the ganglia of myenteric plexus when compared to control animals (Figure 9) whereas no changes were found in the expression of synaptophysin in the remaining groups when compared to control (Figure 9C). The positive stained area of 5-HT in myenteric ganglia was increased 7 days after fetal HI (Figure 10D). Similarly, increased expression of 5-HT was found when animals were treated with MSCs after UCO when compared to control (Figure 10D). In addition, fetal $\mathrm{HI}$ increased the numbers of 5 - $\mathrm{HT}^{*}$ cells in the mucosa (Figure 10A-C) whereas no changes were detected in animals that were treated with MSCs, with or without UCO, when compared to control (Figure 10C). 

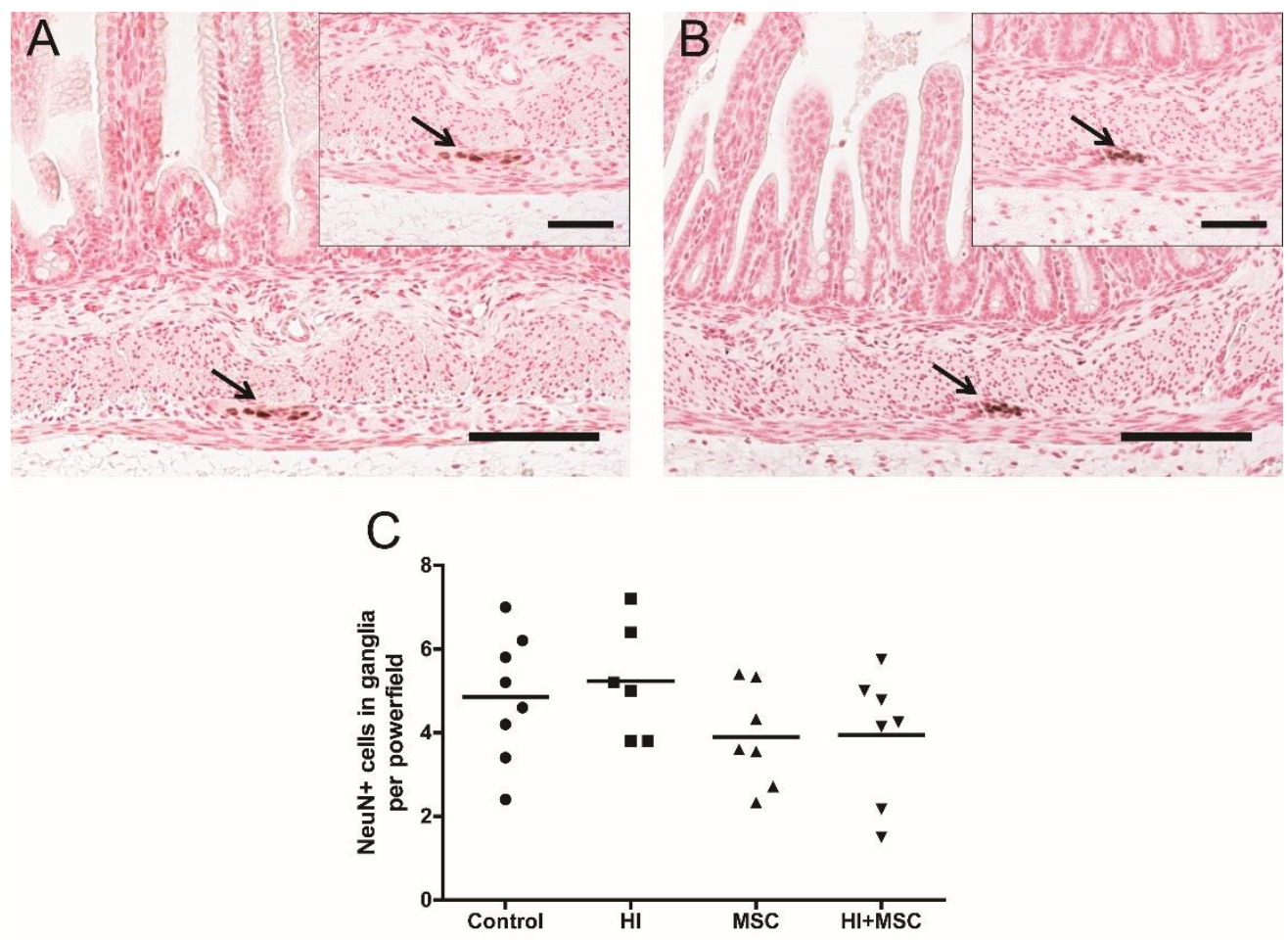

Figure 7: Number of $\mathrm{NeuN}^{+}$cells in myenteric plexus 7 days after HI. Representative gut sections of (A) control and (B) HI animals were stained by NeuN, a marker for neuronal nuclei. The number of $\mathrm{NeuN}^{+}$cells (arrows) in myenteric ganglia remained at baseline levels $(\mathrm{C})$. The scale bar in panels A and B represents $100 \mu \mathrm{m}$. The scale bar in insets represents $50 \mu \mathrm{m}$. 

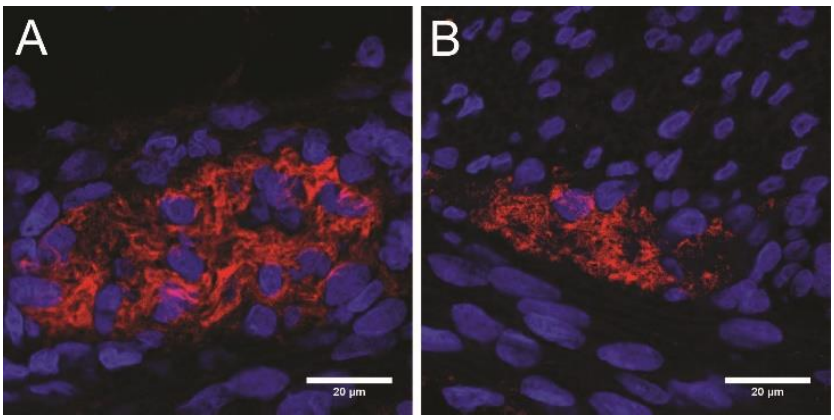

Figure 8: Distortion of enteric glial cells in myenteric plexus 7 days after HI. Representative sections of fetal ileum stained by immunofluorescence for GFAP (red), a marker for enteric glial cells and DAPI (blue), a marker for nuclei. Control animals appeared with normal perinuclear GFAP immunoreactivity and intact glial processes (A) whereas animals subjected to HI appeared with loss of GFAP immunoreactivity around the nuclei and aggregates of GFAP without clear enteric glial processes (B).
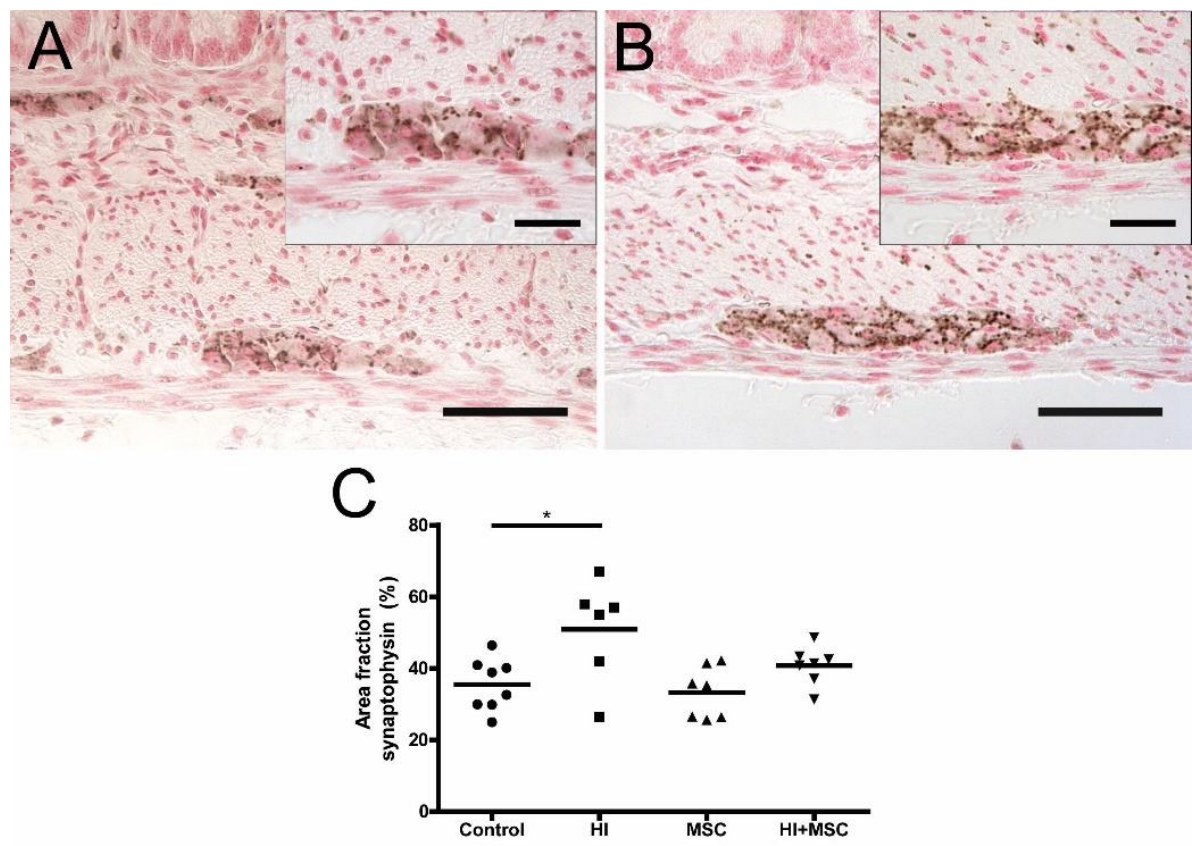

Figure 9: Increased expression of synaptophysin in myenteric ganglia 7 days after HI. Representative intestinal sections of (A) control and (B) HI animals were stained by immunohistochemistry for synaptophysin. For each experimental group, synaptophysin positive area in myenteric ganglia was measured and the mean area fraction (\%) per ganglion per animal is given $(\mathrm{C})$. The scale bar in panels A and B represents $50 \mu \mathrm{m}$. The scale bar in insets represents $20 \mu \mathrm{m} .{ }^{*} \mathrm{p}<0.05$. 

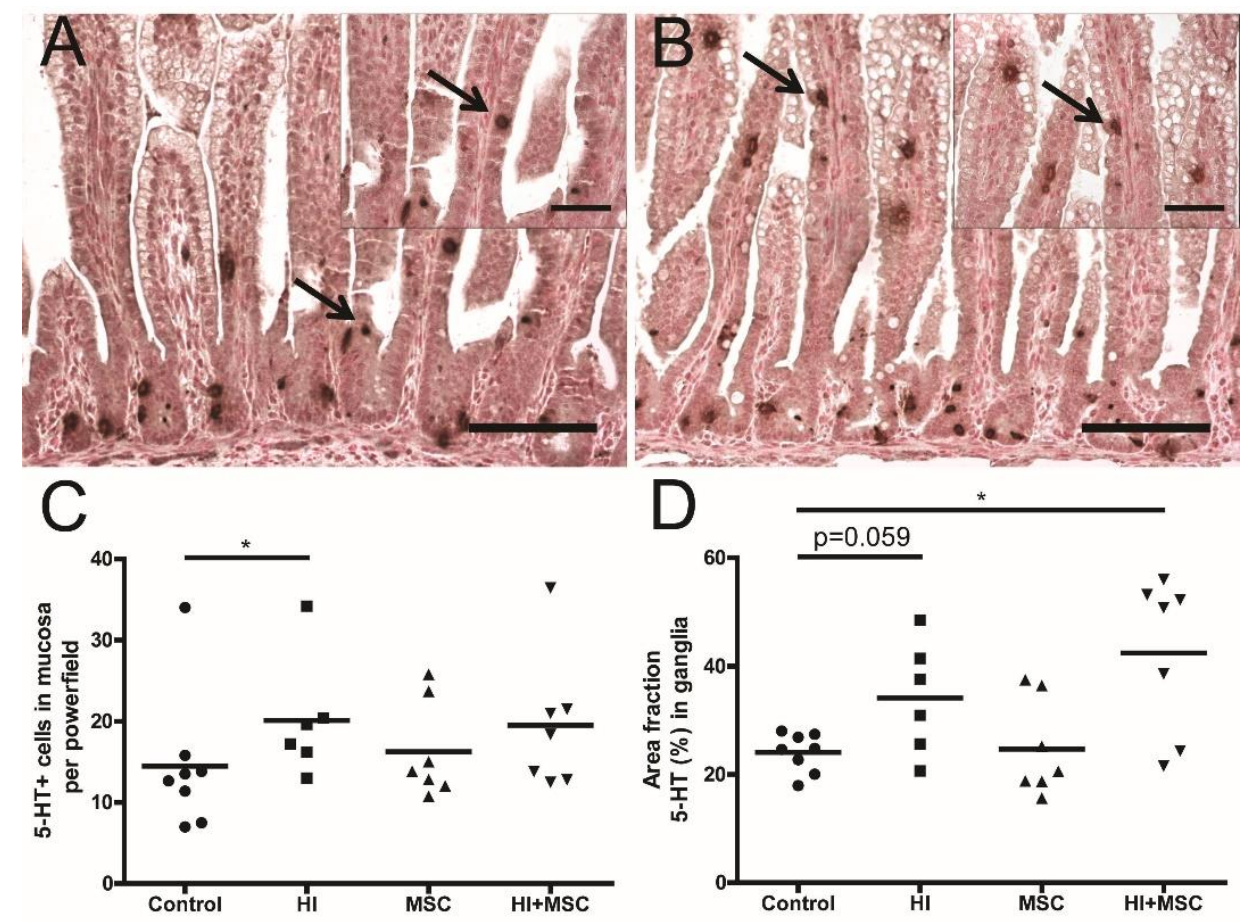

Figure 10: Increased 5-HT in fetal intestinal mucosa 7 days after HI. Representative intestinal sections of (A) control and (B) HI animals were stained by immunohistochemistry for 5-HT. For each experimental group, 5-HT cells (arrows) in mucosa (C) were counted and 5-HT positive area in myenteric ganglia (D) was measured. The mean cell counts in mucosa and area fraction (\%) per ganglion per animal are given. The scale bar in panels represents $100 \mu \mathrm{m}$. The scale bar in insets represents $50 \mu \mathrm{m} .{ }^{*} \mathrm{p}<0.05$. Significance between control and HI group in panel D was tested by ttest and $p$ value is given. 


\section{Discussion}

In the current study we used a preclinical ovine model to investigate the impact of fetal HI on the preterm gut and to assess the potential of intravenous administration of MSCs to improve the outcome of the post-ischemic intestine. Our data demonstrated that fetal global HI caused intestinal inflammation which was accompanied by thickening of the muscle layers, distortion of enteric glial cells and altered expression of mediators involved in neurotransmission in the preterm gut. These adverse intestinal outcomes induced by global HI were not attenuated by intravenous administration of MSCs.

Intestinal inflammation following fetal $\mathrm{HI}$ in our model was characterized by accumulation of neutrophils in the villus tips. Infiltration of neutrophils in the mucosa, as seen in the preterm fetal gut following global HI, has also been detected in adult rodent models of intestinal HI induced by transient superior mesenteric artery occlusion $(13,14,53)$. Interestingly, in the present study the influx of neutrophils was not associated with epithelial injury in villus tips, the first mucosal structures that are affected following intestinal HI $(17,54)$. This could be explained by the fact that damage to the enterocytes following intestinal $\mathrm{HI}$ in human and animal studies occurs acutely after the insult with sealing of the epithelial lining and re-epithelialization being documented within a few hours to a couple of days after the end of local intestinal HI (54-56). Our findings suggest that in the absence of epithelial injury, which most likely was resolved at 7 days after UCO, inflammatory processes in the intestinal mucosa persisted and might be responsible for some of the adverse intestinal effects in the lower layers of the gastrointestinal wall (57) as discussed below.

Intestinal immune activation below the submucosa was characterized by invasion of $\mathrm{T}$ lymphocytes into the circular muscle layer following fetal HI which is consistent with previous findings $(56,58)$. The invasion of $\mathrm{T}$ cells into the circular muscle (but not into longitudinal) at 7 days after fetal HI could be explained by the different anatomical positions of the two muscle layers within the intestinal wall. The circular muscle layer is closer to the mucosa/submucosa layer where an inflammatory 
response is initiated by resident immune cells upon a stressor stimulus (59). Moreover, previous studies have shown that adhesion of $\mathrm{T}$ lymphocytes was preferentially found in the submucosal and not in muscle venules of the post-ischemic intestine $(60,61)$. Therefore, the influx of T lymphocytes in the muscularis of the post-ischemic intestinal wall in our model is more likely to occur first in the circular muscle layer.

Intestinal inflammation in the mucosa and muscle layers following fetal HI was associated with thickening of the smooth muscle which has been previously described in rodent models of transient superior mesenteric artery occlusion (58). The inflammation-induced thickening of circular and longitudinal muscle layers could be explained by several mechanisms including hypertrophy and/or secretion of inflammatory cytokines which are considered to have mitogenic effects on muscle cells $(46,50,62)$. In line with these reports, muscle thickening after $\mathrm{HI}$ in our animal model was accompanied by increased cell numbers and cell proliferation within the muscle layers of the fetal intestine and elevated mRNA levels of IL-1 $\beta$ and IL-17, two proinflammatory cytokines which are known to promote intestinal muscle growth (50). Therefore, we speculate that the inflammatory cytokines IL-1 $\beta$ and IL-17 may contribute to the detected muscle hyperplasia at 7 days after UCO. Importantly, muscle thickening characterizes the inflamed gut of several gastrointestinal diseases and has been correlated with altered intestinal smooth muscle contractility $(57,63)$.

In addition to smooth muscle contractions, the enteric nervous system is essential for coordinated gastrointestinal motility $(52,64)$. In this regard, enteric glia cells are ideally positioned around enteric neurons to respond to and modulate neural activity by several mechanisms including terminating the actions of neurotransmitters from synapses and by generating neuroactive substances (44). The regulatory role of enteric glial cells in gastrointestinal function is further highlighted by experiments which have demonstrated that disruption of enteric glial cells altered the neurochemical phenotype of enteric neurons, reduced transmission to muscle and delayed gastrointestinal transit $(65,66)$. In the current study, global HI induced distortion of enteric glia cells in the ganglia of the myenteric plexus in a similar pattern found in 
animal models of HI-induced intestinal injury (67) and in neonates with NEC (31). Importantly, distortion of enteric glial cells upon gut HI has been correlated with loss of enteric neurons and impaired neuronal function with subsequent decreased gastrointestinal motility $(18,44,67,68)$. Gastrointestinal dysfunction might lead to vomiting with subsequent delay in tolerating enteral feeding postnatally, resulting in intestinal immaturity, as early initiation of enteral nutrition is crucial for normal gut development (69). Although the number of the enteric neurons remained unaltered following fetal HI in our model, overexpression of synaptophysin, a crucial regulator of neurotransmission (70), was detected in the ganglia of myenteric plexus of the fetal postischemic gut implying enhanced probability of neurotransmitter release (71) and/or abnormal intestinal motor function $(72,73)$. This finding is supported by the increased expression of serotonin in the myenteric ganglia following $\mathrm{HI}$, a neurotransmitter which regulates intestinal motility and its disrupted homeostasis has been correlated with several gastrointestinal inflammatory and motility disorders (74). In addition to the elevated expression of neuronal serotonin, global $\mathrm{HI}$ increased the number of serotonin positive cells along the intestinal mucosa. Such alterations in the mucosal-derived serotonin contribute to intestinal dysmotility (48) and have been associated with inflammatory bowel disease (75). Importantly, NEC has been associated with maternal use of selective serotonin reuptake inhibitor during pregnancy (76).

In the present study intravenous administration of MSCs did not ameliorate the adverse effects of fetal global HI on the preterm gut whereas this treatment was previously shown to protect the fetal brain from structural and functional impairment which was associated with T cell tolerance (32). Although MSCs have been proven beneficial when given intramucosally (77-79) or intra-peritoneally (i.p.) (80) to animal models of intestinal HI, in this study we deliberately chose to administer the MSCs intravenously since it was previously shown that intravenous MSC administration yielded better engraftment of MSCs to the fetal gut compared to i.p administration (23) and this route of administration could have beneficial effects not only in the gut but in multiple organs which are affected by global HI. In addition, the relative impact of 
global HI on the fetal gut is essentially lower compared to other vital organs such as HIinduced cerebral injury. Since MSCs have the tendency to migrate towards inflammatory tissues (81), it is conceivable that intravenous administration of MSCs following global HI would primarily lead to the engraftment of these stem cells in the inflamed organs that are most severely affected. Accordingly, we previously showed that at 7 days after i.v. administration, low numbers of MSCs were present in the fetal spleen, lung and occasionally in the brain (but not in the gut) which was accompanied by prevention of brain injury in our model (32). Therefore, the preferential distribution of MSCs following global HI might explain the lack of therapeutic effects on the fetal gut. Although the dosage of MSCs that was used in the current study was based on clinical trials of focal ischemia (28) and patients with inflammatory bowel disease (29, 30), it is conceivable that higher numbers of MSCs with repeated doses in subsequent time points might have increased the chance for MSC engraftment into the gut and potentially improved the intestinal outcome following global HI.

In summary, the preterm hypoxic-ischemic fetus and infant are especially vulnerable to functional gastrointestinal impairment during the first days of life. The intestinal clinical pathological characteristics of an HI neonate may include delayed gastrointestinal transit which frequently precedes abdominal distension, inflammation and edema of the intestine $(82,83)$. These factors not only predispose the preterm hypoxic-ischemic gut to feeding intolerance but also to NEC. In this study we showed that global HI in fetal sheep induced intestinal inflammation, muscle thickening, distortion of enteric glial cells and altered neurotransmission. Although we can only speculate about the postnatal consequences of these adverse intestinal outcomes, the detected gut inflammation and enteric nervous system abnormalities following HI, have been associated with neonatal gastrointestinal complications including loss of barrier integrity, delayed gastrointestinal motility and $\operatorname{NEC}(31,73,84)$. Future studies are warranted to investigate whether the detected pathological changes at 7 days after UCO will have long term adverse intestinal effects. In addition, MSC treatment did not protect the fetal gut against $\mathrm{HI}$-induced intestinal abnormalities but it prevented the $\mathrm{HI}$-induced 
cerebral injury. Since our data suggest selective organ protection after intravenous MSC treatment, future studies should focus on optimizing a MSC-based treatment regimen which will collectively protect the fetal brain and gut following global HI. 


\section{References}

1. Alonso-Spilsbury M, et al. Perinatal asphyxia pathophysiology in pig and human: a review. Anim Reprod Sci. 2005;90:1-30.

2. Tax N, et al. The influence of perinatal asphyxia on peripheral oxygenation and perfusion in neonates. Early Hum Dev. 2013;89:483-486.

3. Daripa M, et al. Perinatal asphyxia associated with early neonatal mortality: populational study of avoidable deaths. Rev Paul Pediatr. 2013;31:37-45.

4. Lawn JE, Kerber K, Enweronu-Laryea C, Cousens S. 3.6 million neonatal deaths--what is progressing and what is not? Semin Perinatol. 2010;34:371-386.

5. Hankins GD, et al. Neonatal organ system injury in acute birth asphyxia sufficient to result in neonatal encephalopathy. Obstet Gynecol. 2002;99:688-691.

6. Shah P, Riphagen S, Beyene J, Perlman M. Multiorgan dysfunction in infants with post-asphyxial hypoxic-ischaemic encephalopathy. Arch Dis Child Fetal Neonatal Ed. 2004;89:F152-155.

7. Berseth CL, McCoy HH. Birth asphyxia alters neonatal intestinal motility in term neonates. Pediatrics. 1992;90:669-673.

8. Fox TP, Godavitarne C. What really causes necrotising enterocolitis? ISRN Gastroenterol. 2012;2012:628317.

9. $\quad$ Neu J, Walker WA. Necrotizing enterocolitis. $N$ Engl J Med. 2011;364:255264.

10. Taylor CT, Cummins EP. The role of NF-kappaB in hypoxia-induced gene expression. Ann N Y Acad Sci. 2009;1177:178-184.

11. Eltzschig HK, Eckle T. Ischemia and reperfusion-from mechanism to translation. Nat Med. 2011;17:1391-1401.

12. Grenz A, Clambey E, Eltzschig HK. Hypoxia signaling during intestinal ischemia and inflammation. Curr Opin Crit Care. 2012;18:178-185.

13. Ozban M, et al. The effect of melatonin on bacterial translocation following ischemia/reperfusion injury in a rat model of superior mesenteric artery occlusion. BMC Surg. 2015;15:18.

14. Stefanutti G, Pierro A, Parkinson EJ, Smith VV, Eaton S. Moderate hypothermia as a rescue therapy against intestinal ischemia and reperfusion injury in the rat. Crit Care Med. 2008;36:1564-1572.

15. Kannan KB, et al. Hypoxia-inducible factor plays a gut-injurious role in intestinal ischemia reperfusion injury. Am J Physiol Gastrointest Liver Physiol. 2011;300:G853-861.

16. Pontell L, et al. Damaging effects of ischemia/reperfusion on intestinal muscle. Cell Tissue Res. 2011;343:411-419. 
17. Gonzalez LM, Moeser AJ, Blikslager AT. Animal models of ischemiareperfusion-induced intestinal injury: progress and promise for translational research. Am.J Physiol Gastrointest Liver Physiol. 2015;308:G63-75.

18. Mendes CE, et al. The Effect of Ischemia and Reperfusion on Enteric Glial Cells and Contractile Activity in the Ileum. Dig Dis Sci. 2015

19. Silva MA, de Meirelles LR, Bustorff-Silva JM. Changes in intestinal motility and in the myenteric plexus in a rat model of intestinal ischemia-reperfusion. $J$ Pediatr Surg. 2007;42:1062-1065.

20. Griffin MD, et al. Concise review: adult mesenchymal stromal cell therapy for inflammatory diseases: how well are we joining the dots? Stem Cells. 2013;31:20332041.

21. Martinez-Montiel Mdel P, Gomez-Gomez GJ, Flores AI. Therapy with stem cells in inflammatory bowel disease. World J Gastroenterol. 2014;20:1211-1227.

22. Nagaishi K, Arimura Y, Fujimiya M. Stem cell therapy for inflammatory bowel disease. J Gastroenterol. 2015;50:280-286.

23. Yang J, et al. Heparin-binding epidermal growth factor-like growth factor and mesenchymal stem cells act synergistically to prevent experimental necrotizing enterocolitis. J Am Coll Surg. 2012;215:534-545.

24. Jellema RK, et al. Cerebral inflammation and mobilization of the peripheral immune system following global hypoxia-ischemia in preterm sheep. $J$ Neuroinflammation. 2013;10:13.

25. Uccelli A, Moretta L, Pistoia V. Mesenchymal stem cells in health and disease. Nat Rev Immunol. 2008;8:726-736.

26. Ma S, et al. Immunobiology of mesenchymal stem cells. Cell Death Differ. 2014;21:216-225.

27. Parekkadan B, Milwid JM. Mesenchymal stem cells as therapeutics. Annu Rev Biomed Eng. 2010;12:87-117.

28. Bang OY, Lee JS, Lee PH, Lee G. Autologous mesenchymal stem cell transplantation in stroke patients. Ann Neurol. 2005;57:874-882.

29. Duijvestein M, et al. Autologous bone marrow-derived mesenchymal stromal cell treatment for refractory luminal Crohn's disease: results of a phase I study. Gut. 2010;59:1662-1669.

30. Dalal J, Gandy K, Domen J. Role of mesenchymal stem cell therapy in Crohn's disease. Pediatr Res. 2012;71:445-451.

31. Zhou Y, et al. Enteric nervous system abnormalities are present in human necrotizing enterocolitis: potential neurotransplantation therapy. Stem Cell Res Ther. 2013;4:157. 
32. Jellema RK, et al. Mesenchymal stem cells induce T-cell tolerance and protect the preterm brain after global hypoxia-ischemia. PLoS One. 2013;8:e73031.

33. Back SA, Riddle A, Dean J, Hohimer AR. The instrumented fetal sheep as a model of cerebral white matter injury in the premature infant. Neurotherapeutics. 2012;9:359-370.

34. Roelfsema V, et al. Window of opportunity of cerebral hypothermia for postischemic white matter injury in the near-term fetal sheep. J Cereb Blood Flow Metab. 2004;24:877-886.

35. Jellema RK, et al. Systemic G-CSF attenuates cerebral inflammation and hypomyelination but does not reduce seizure burden in preterm sheep exposed to global hypoxia-ischemia. Exp Neurol. 2013;250:293-303.

36. Bennet $\mathrm{L}$, et al. The effect of cerebral hypothermia on white and grey matter injury induced by severe hypoxia in preterm fetal sheep. J Physiol. 2007;578:491-506.

37. Wassink G, et al. The ontogeny of hemodynamic responses to prolonged umbilical cord occlusion in fetal sheep. J Appl Physiol (1985). 2007;103:1311-1317.

38. Bennet L, Quaedackers JS, Gunn AJ, Rossenrode S, Heineman E. The effect of asphyxia on superior mesenteric artery blood flow in the premature sheep fetus. $J$ Pediatr Surg. 2000;35:34-40.

39. Bennet $\mathrm{L}$, et al. Regulation of cytochrome oxidase redox state during umbilical cord occlusion in preterm fetal sheep. Am J Physiol Regul Integr Comp Physiol. 2007;292:R1569-1576.

40. Gunn AJ, Bennet L. Fetal hypoxia insults and patterns of brain injury: insights from animal models. Clin Perinatol. 2009;36:579-593.

41. Lear CA, et al. Subclinical decelerations during developing hypotension in preterm fetal sheep after acute on chronic lipopolysaccharide exposure. Sci Rep. 2015;5:16201.

42. Ryan M. McAdams DJL. Focal intestinal perforation in late preterm and term neonates with hypoxic ischemic encephalopathy. J Pediatr Surg Case Rep. 2015; 3:137139.

43. Sharma R, Hudak ML. A clinical perspective of necrotizing enterocolitis: past, present, and future. Clin Perinatol. 2013;40:27-51.

44. Gulbransen BD, Sharkey KA. Novel functional roles for enteric glia in the gastrointestinal tract. Nat Rev Gastroenterol Hepatol. 2012;9:625-632.

45. Nikiforou M, et al. Prophylactic Interleukin-2 Treatment Prevents Fetal Gut Inflammation and Injury in an Ovine Model of Chorioamnionitis. Inflamm Bowel Dis. 2015;21:2026-2038. 
46. Blennerhassett MG, Vignjevic P, Vermillion DL, Collins SM. Inflammation causes hyperplasia and hypertrophy in smooth muscle of rat small intestine. $\mathrm{Am} \mathrm{J}$ Physiol. 1992;262:G1041-1046.

47. Martin GR, et al. Endogenous cellular prion protein regulates contractility of the mouse ileum. Neurogastroenterol Motil. 2012;24:e412-424.

48. Crowell MD, Shetzline MA, Moses PL, Mawe GM, Talley NJ. Enterochromaffin cells and 5-HT signaling in the pathophysiology of disorders of gastrointestinal function. Curr Opin Investig Drugs. 2004;5:55-60.

49. Nikiforou M, et al. Selective IL-1alpha exposure to the fetal gut, lung, and chorioamnion/skin causes intestinal inflammatory and developmental changes in fetal sheep. Lab Invest. 2016;96:69-80.

50. Nair DG, Miller KG, Lourenssen SR, Blennerhassett MG. Inflammatory cytokines promote growth of intestinal smooth muscle cells by induced expression of PDGF-Rbeta. J Cell Mol Med. 2014;18:444-454.

51. Knowles $\mathrm{CH}$, et al. Deranged smooth muscle alpha-actin as a biomarker of intestinal pseudo-obstruction: a controlled multinational case series. Gut. 2004;53:1583-1589.

52. Furness JB. The enteric nervous system and neurogastroenterology. Nat Rev Gastroenterol Hepatol. 2012;9:286-294.

53. Guzman-De La Garza FJ, et al. Ketamine reduces intestinal injury and inflammatory cell infiltration after ischemia/reperfusion in rats. Surg Today. 2010;40:1055-1062.

54. Grootjans J, et al. Rapid lamina propria retraction and zipper-like constriction of the epithelium preserves the epithelial lining in human small intestine exposed to ischaemia-reperfusion. J Pathol. 2011;224:411-419.

55. Derikx JP, et al. Rapid reversal of human intestinal ischemia-reperfusion induced damage by shedding of injured enterocytes and reepithelialisation. PLOS One. 2008;3:e3428.

56. Pontell L, et al. Damaging effects of ischemia/reperfusion on intestinal muscle. Cell Tissue Res

2011;343:411-419.

57. Tanovic A, Fernandez E, Jimenez M. Alterations in intestinal contractility during inflammation are caused by both smooth muscle damage and specific receptormediated mechanisms. Croat MedJ. 2006;47:318-326.

58. Lindestrom LM, Ekblad E. Structural and neuronal changes in rat ileum after ischemia with reperfusion. Dig Dis Sci. 2004;49:1212-1222.

59. Maynard CL, Elson CO, Hatton RD, Weaver CT. Reciprocal interactions of the intestinal microbiota and immune system. Nature. 2012;489:231-241. 
60. Shigematsu T, Wolf RE, Granger DN. T-lymphocytes modulate the microvascular and inflammatory responses to intestinal ischemia-reperfusion. Microcirculation. 2002;9:99-109.

61. Beuk RJ, et al. Total warm ischemia and reperfusion impairs flow in all rat gut layers but increases leukocyte-vessel wall interactions in the submucosa only. Ann Surg. 2000;231:96-104.

62. Nair DG, Han TY, Lourenssen S, Blennerhassett MG. Proliferation modulates intestinal smooth muscle phenotype in vitro and in colitis in vivo. Am J Physiol Gastrointest Liver Physiol. 2011;300:G903-913.

63. Severi C, et al. Contribution of intestinal smooth muscle to Crohn's disease fibrogenesis. EurJ Histochem. 2014;58:2457.

64. Burns AJ, Roberts RR, Bornstein JC, Young HM. Development of the enteric nervous system and its role in intestinal motility during fetal and early postnatal stages. Semin Pediatr Surg. 2009;18:196-205.

65. Aube AC, et al. Changes in enteric neurone phenotype and intestinal functions in a transgenic mouse model of enteric glia disruption. Gut. 2006;55:630-637.

66. Sharkey KA. Emerging roles for enteric glia in gastrointestinal disorders. J Clin Invest. 2015;125:918-925.

67. Thacker M, Rivera LR, Cho HJ, Furness JB. The relationship between glial distortion and neuronal changes following intestinal ischemia and reperfusion. Neurogastroenterol Motil. 2011;23:e500-509.

68. Bassotti G, Villanacci V, Antonelli E, Morelli A, Salerni B. Enteric glial cells: new players in gastrointestinal motility? Lab Invest. 2007;87:628-632.

69. Strodtbeck $\mathrm{F}$. The role of early enteral nutrition in protecting premature infants from sepsis. Crit Care Nurs Clin North Am. 2003;15:79-87.

70. Kwon SE, Chapman ER. Synaptophysin regulates the kinetics of synaptic vesicle endocytosis in central neurons. Neuron. 2011;70:847-854.

71. Alder J, Kanki H, Valtorta F, Greengard P, Poo MM. Overexpression of synaptophysin enhances neurotransmitter secretion at Xenopus neuromuscular synapses. J Neurosci. 1995;15:511-519.

72. Dzienis-Koronkiewicz E, Debek W, Chyczewski L. Use of synaptophysin immunohistochemistry in intestinal motility disorders. EurJ Pediatr Surg. 2005;15:392398.

73. Geramizadeh B, Akbarzadeh E, Izadi B, Foroutan HR, Heidari T. Immunohistochemical study of enteric nervous system in hirschsprung's disease and intestinal neuronal dysplasia. Histol Histopathol. 2013;28:345-351.

74. Gershon MD. 5-Hydroxytryptamine (serotonin) in the gastrointestinal tract.

Curr Opin Endocrinol Diabetes Obes. 2013;20:14-21. 
75. Mawe GM, Hoffman JM. Serotonin signalling in the gut--functions, dysfunctions and therapeutic targets. Nat Rev Gastroenterol Hepatol. 2013;10:473-486. 76. Potts AL, Young KL, Carter BS, ShenaiJP. Necrotizing enterocolitis associated with in utero and breast milk exposure to the selective serotonin reuptake inhibitor, escitalopram. J Perinatol. 2007;27:120-122.

77. Shen ZY, Zhang J, Song HL, Zheng WP. Bone-marrow mesenchymal stem cells reduce rat intestinal ischemia-reperfusion injury, ZO-1 downregulation and tight junction disruption via a TNF-alpha-regulated mechanism. World J Gastroenterol. 2013;19:3583-3595.

78. Jiang $\mathrm{H}$, et al. Potential role of mesenchymal stem cells in alleviating intestinal ischemia/reperfusion impairment. PLoS One. 2013;8:e74468.

79. Jiang $\mathrm{H}$, et al. Bone marrow mesenchymal stem cells reduce intestinal ischemia/reperfusion injuries in rats. J Surg Res. 2011;168:127-134.

80. Watkins DJ, YangJ, Matthews MA, Besner GE. Synergistic effects of HB-EGF and mesenchymal stem cells in a murine model of intestinal ischemia/reperfusion injury. J Pediatr Surg. 2013;48:1323-1329.

81. Eggenhofer E, Luk F, Dahlke MH, Hoogduijn MJ. The life and fate of mesenchymal stem cells. Front Immunol. 2014;5:148.

82. Neu J. Gastrointestinal development and meeting the nutritional needs of premature infants. AmJ Clin Nutr. 2007;85:629S-634S.

83. Commare CE, Tappenden KA. Development of the infant intestine: implications for nutrition support. Nutr Clin Pract. 2007;22:159-173.

84. Khen N, et al. Fetal intestinal obstruction induces alteration of enteric nervous system development in human intestinal atresia. Pediatr Res. 2004;56:975-980. 


\section{Supplementary Material}
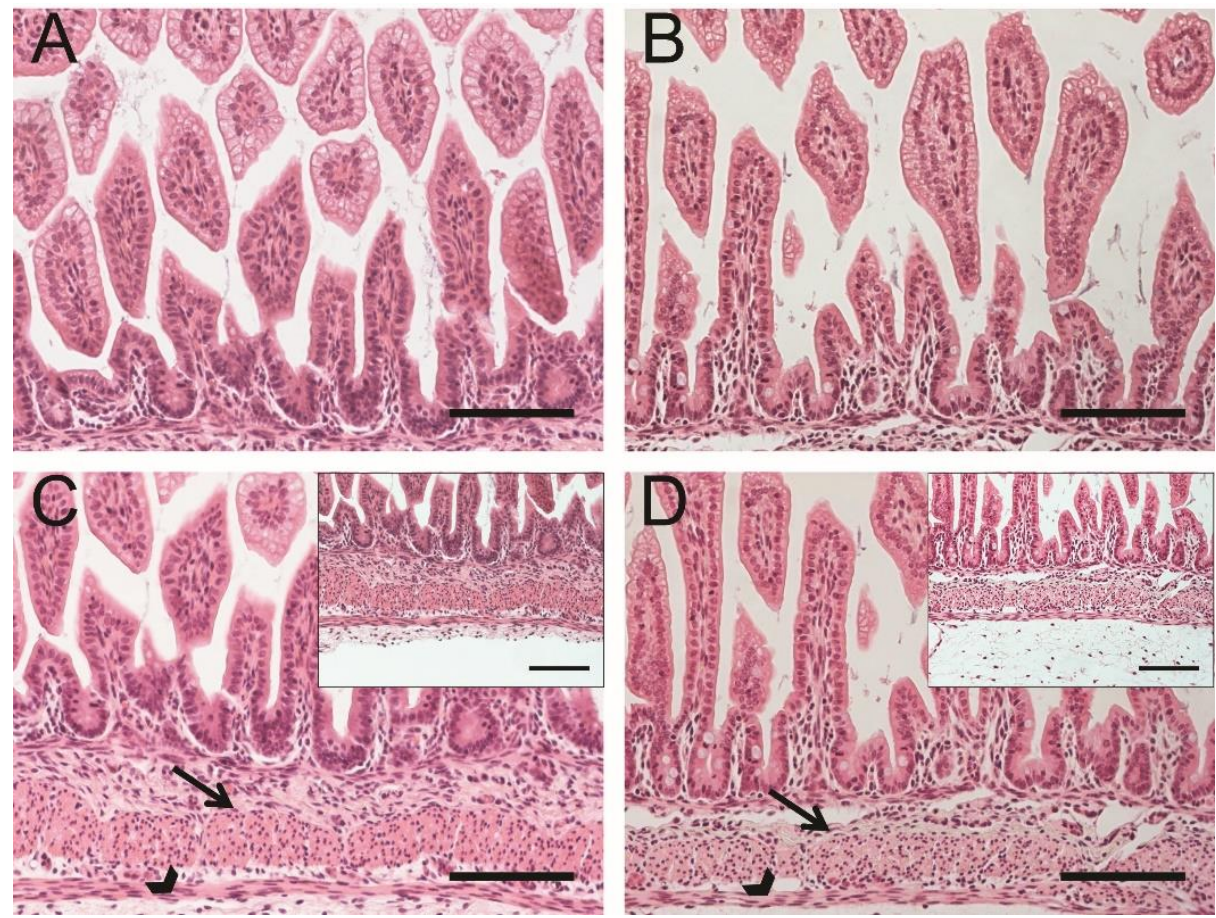

Supplementary Figure 1: Morphological examination of intestinal sections that were stained for hematoxylin and eosin. No epithelial injury was detected in (A) control and (B) HI animals. In addition, the thickness of both muscle layers circular (arrow) and longitudinal (arrow head) varied between the groups (C; control and D; HI). The scale bar in all panels represents $100 \mu \mathrm{m}$.

Supplementary Table 1: Primers used for qPCR.

\begin{tabular}{ccc}
\hline Primer & $\boldsymbol{F}_{\boldsymbol{W}}$ sequence & $\boldsymbol{R} \boldsymbol{\text { sequence }}$ \\
\hline ovRPS15 & CGAGATGGTGGGCAGCAT & GCTTGATTTCCACCTGGTTGA \\
\hline IL-1 $\beta$ & AGAATGAGCTGTTATTTGAGGTTGATG & GTGAGAAATCTGCAGCTGGATGT \\
\hline IL-17 & TGTGAGGGTCAACCTGAACAT & TGATAATCGGTGGGCCTTCTG \\
\hline
\end{tabular}

Fw: forward, IL: interleukin, qPCR: quantitative real time polymerase chain reaction, Rv: reverse. 
Fetal hypoxia-ischemia and adverse gut outcomes 



\section{Chapter 6}

\section{General Discussion}



Prenatal stress, such as chorioamnionitis and fetal hypoxia-ischemia (HI), is associated with pathological changes of several fetal organs including the intestines (1-8). The core element which is considered to be essential in the etiology of these pathophysiological states is inflammation. In this thesis, the intestinal inflammatory processes in conjunction with gut abnormalities after chorioamnionitis and fetal HI were investigated. In addition, we explored the potential of therapeutic interventions to protect the fetal gut against the detrimental intestinal effects induced by these two pathologies. For these purposes, we used our validated translational animal models of chorioamnionitis and fetal HI $(9,10)$.

\section{IL-1 $\alpha$ exposure to fetal mucosal surfaces and adverse intestinal effects}

Scientific evidence over the last decade has demonstrated that chorioamnionitis affects multiple fetal organs with time dependent inflammatory responses and structural changes after antenatal exposure $(11,12)$. Since organ crosstalk is important for fetal development, chorioamnionitis-induced inflammation in distinct organs can disrupt this interaction and impact the physiology of other remote organs. In line, we have previously shown that selective infusion of lipopolysaccharide (LPS) in the fetal lung induces intestinal inflammation and subsequent injury (13). Importantly, LPS-induced systemic, lung and gut inflammatory responses can be recapitulated by intra-amniotic (IA) exposure to IL-1 $\alpha$ (14-16). The significant role of IL-1-mediated signaling in the induction of adverse gut effects in the context of chorioamnionitis was further assessed by Wolfs et al. (17). In this latter study, the investigators blocked IL-1 signaling by IA administration of recombinant IL-1 receptor antagonist (IL-1RA), and demonstrated that intestinal inflammation, tight junctional loss and impaired gut development after IA exposure to Ureaplasma (UP) were ameliorated. In chapter 2, we further explored the contribution of IL-1 $\alpha$-mediated immune responses derived from the gut in comparison with extraintestinal IL-1 $\alpha$-mediated immune responses (derived from the lung or chorioamnion/skin) on adverse intestinal outcomes. We hypothesized that intestinal 
inflammation and injury induced by chorioamnionitis resulted not only from direct activation of IL-1 $\alpha$ signaling in the intestinal mucosa but also from selective IL-1 $\alpha$ driven signaling of the lung and chorioamnion/skin. We tested our hypothesis in our ovine model by selective administration of IL-1 $\alpha$ into the fetal gut, lung and amniotic cavity (chorioamnion/skin).

In agreement with our hypothesis, we demonstrated that intestinal inflammation was induced by both direct IL-1 $\alpha$ exposure to the intestinal mucosa and IL-1 $\alpha$-mediated immune responses driven by the lung and chorioamnion/skin. Nevertheless, the intestinal inflammatory response following selective infusion of IL- $1 \alpha$ to different fetal compartments had distinct features which were shown to be timedependent.

Our findings revealed that only direct IL-1 $\alpha$ infusion to the gut resulted in intestinal inflammation with concomitant injury as shown by increased CD $3^{+} \mathrm{T}$ cells and tight junctional loss in the fetal intestine. Similar results were previously obtained by selective LPS exposure to the fetal gut (13). Recognition and sensing of LPS by toll like receptor-4 (TLR-4) leads to activation of the nuclear factor $\mathrm{\kappa B}(\mathrm{NF}-\mathrm{kB})$ signaling pathway and subsequent production of several pro-inflammatory cytokines including IL-1 (18). Our data indicated that activation of IL-1 $\alpha$ signaling by intestinal epithelial cells and/or resident immune cells is absolutely required for the induction of paracellular barrier loss following chorioamnionitis. Future in vitro studies are needed to elucidate a causal link between the presence of IL-1 $\alpha$ in the gut lumen and the induction of IL-1 $\alpha$-driven inflammatory responses in the resident immune cells and/or intestinal epithelial cells with concomitant impaired wall integrity. Interestingly, IA administration of IL-RA in the aforementioned study was not sufficient to prevent epithelial injury and villus atrophy in UP-mediated chorioamnionitis (13). These previous results in conjunction with the findings in chapter 2 suggest that although IL-1 signaling plays a pivotal role in chorioamnionitis-induced intestinal inflammation and injury, additional inflammatory cascades are most likely involved in pathophysiological changes on the fetal gut caused by antenatal inflammation and need further exploration. 
Prolonged selective IL-1 $\alpha$ exposure to the gastrointestinal (GI) tract resulted in persistent immune activation and sustained impaired barrier integrity. Similar pronounced inflammatory responses and mucosal injury were previously detected after selective LPS exposure of the GI tract (13). Accordingly, our findings suggested that similar to acute responses, a single direct exposure of inflammatory stimuli such as LPS or IL-1 $\alpha$ to the gut can provoke long term detrimental effects in the fetal gut in the context of chorioamnionitis. Collectively, this knowledge contributes to better understanding of the intestinal pathology induced by chorioamnionitis and reveals new options for potential therapeutic interventions such as blockers for IL-1 signaling. IL1RA is a drug which is already in clinical use to treat rheumatoid arthritis, an autoimmune, inflammatory disease of the joints (19). In our ovine model of UPinduced chorioamnionitis, IA injection of IL-1RA prevented inflammation and villus atrophy whereas mucosal injury was still evident. As additional immune processes (apart from IL-1 signaling) seem to be involved in the detected mucosal injury after chorioamnionitis, further research is needed to identify these potential inflammatory molecules responsible for damage to gut epithelium after chorioamnionitis. These previous findings together with our results in chapter 2 suggest that infusion of IL-1RA directly into the GI in combination with other immunomodulatory agents might be a potential approach to protect the fetal gut in the context of chorioamnionitis.

Our data showed that direct IL-1 $\alpha$ infusion to the GI tract not only induced intestinal inflammation and loss of barrier integrity but also resulted in intestinal immaturity which was previously shown to be IL-1 dependent in our ovine model of UP-induced chorioamnionitis (17). These findings are clinically relevant as villus atrophy might predispose the fetus to postnatal complications such as malabsorption of nutrients and growth restriction (20). We speculated that impaired cell differentiation was responsible for the detected disturbed maturation of the fetal intestine after direct IL-1 $\alpha$ to the GI. As we did not elucidate the mechanisms underlying the observed impaired cell differentiation after selective IL-1 $\alpha$ infusion to the GI, further in vitro and ex vivo studies are needed to clarify the developmental molecular pathways and identify 
the cell types that are altered during antenatal inflammation. Possible candidates of molecular pathways that might be affected and re-programmed after antenatal inflammation include Wnt/ß-catenin (21), Notch (22) and hedgehog (Hh) developmental cascades $(23,24)$. Disruption of functional homeostasis of these pathways has been associated with a plethora of intestinal inflammatory diseases such as inflammatory bowel disease (IBD) (25-27).

The immune response of the gut after selective exposure of IL- $1 \alpha$ to the chorioamnion/skin was characterized by marginal inflammatory changes and absence of intestinal injury. In addition to gut inflammation, direct contact of IL-1 $\alpha$ to the fetal chorioamnion/skin provoked a systemic inflammatory response. This is in contrast to comparable experiments where the direct contact of LPS to the chorioamnion/skin, was not associated with intestinal inflammation despite induction of systemic inflammation $(13,28)$. Interestingly, relative low blood monocyte counts were found after selective IL-1 $\alpha$ exposure of the chorioamnion/skin when compared to LPS exposure and this was associated with increased gut macrophages. Based on these combined findings, we speculated that differential activation of monocytes/macrophages in the circulation might be responsible for the distinct intestinal inflammatory responses after exposure of chorioamnion/skin to IL-1 $\alpha$ compared with LPS. This hypothesis needs to be evaluated in future studies where trafficking of blood monocytes upon selective LPS and IL-1 $\alpha$ exposure to the fetal chorioamnion/skin can be monitored. In particular, monocyte chemoattractant protein-1 (MCP-1) is an essential chemokine that is involved in trafficking and tissue influx of monocytes/macrophage (29). Previous studies have revealed that LPS-induced chorioamnionitis leads to increased levels of MCP-1 in the fetal skin and to maturation of blood monocytes as shown by their competence to respond upon various inflammatory stimuli in vitro (30). However, the impact of IL$1 \alpha$-mediated chorioamnionitis on MCP-1 levels in the fetal skin and activation of blood monocytes remains unknown. In addition, maturation of blood monocytes after selective IL-1 $\alpha$ and LPS exposure to the fetal chorioamnion/skin has not been evaluated. Further in vitro and in vivo experiments are needed to explore the potential 
differences in activation of blood monocytes after selective IL-1 $\alpha$ and LPS exposure to the chorioamnion/skin which might explain the observed differences in the intestinal inflammatory responses following exposure to these inflammatory agonists.

An alternative explanation for the detected intestinal inflammation following IL-1 $\alpha$ (but not LPS) exposure to the chorioamnion/skin could be the specific response of the fetal skin. Clinical data have shown that the fetal skin of neonates diagnosed with chorioamnionitis is able to sense microbial products through the expression TLR-2 and TLR-4 receptors which are present in the keratinocytes, thereby causing fetal dermatitis (31). Experimentally, we previously showed that IA injection of LPS caused sustained inflammation and increased TLR-4 expression in the fetal ovine skin. These chorioamnionitis-induced changes in the fetal skin resulted from direct contact of keratinocytes to the inflammatory agonists present in the amniotic cavity and not by a systemically-driven immune response. Additional in vitro experiments showed that primary culture of sheep keratinocytes were able to acutely respond to LPS by producing inflammatory cytokines (32). In chapter 2, we neither assessed the inflammatory responses nor the histological injury of the skin after selective IL-1 $\alpha$ exposure to the chorioamnion/skin. Based on previous studies which have shown substantial differences in the response of fetal keratinocytes upon LPS compared to UP stimulation in vitro $(32,33)$, it is plausible that potential differences in TLR-4 and IL$1 \mathrm{R}$ expression and subsequent immune cell infiltrates in the fetal skin could contribute to the differential magnitude and nature of the systemic and/or intestinal inflammation.

Our findings demonstrated that selective IL-1 $\alpha$ infusion to the lung induces mild intestinal inflammatory changes which were not accompanied by mucosal injury. As previous studies showed that selective LPS administration to the fetal lung caused both intestinal inflammation and damage, we concluded that pulmonary-driven adverse effects on the fetal gut do not depend on activation of IL-1 $\alpha$ signaling. Nevertheless, consistent with previous results (28), selective IL-1 $\alpha$ infusion to the fetal lung induced systemic inflammation as shown by increased blood leukocytes which could be responsible for the detected accumulation of $\mathrm{T}$ cells in the gut. Additionally, the 
mediastinal lymph node might have played a role in the induction of intestinal inflammation after IL-1 $\alpha$ infusion to the lung, as the pulmonary and GI lymphatics communicate. This concept is supported by previous data which have revealed increased frequency of inflammatory cells in the mediastinal lymph node and node hypertrophy following IA infusion of IL-1 or LPS $(10,15)$. Further experiments are needed to unravel the mechanisms underlying pulmonary-induced intestinal inflammation.

Interestingly, IL-1 $\alpha$ exposure to any fetal compartment did not alter the number of intestinal Treg cells whereas IA exposure to IL-1 $\alpha$ was previously shown to result in acute depletion of these immunosuppressive cells in the fetal gut (14). These findings suggested that the reported depletion of intestinal Treg cells in the context of antenatal inflammation is not dependent on local gut-mediated immune activation but most likely results from a combined organ immune response to chorioamnionitis. In line, it has been shown that chorioamnionitis caused depletion of regulatory $\mathrm{T}$ cell (Treg) cells in the fetal thymus $(34,35)$ which disrupted $\mathrm{T}$ cell homeostasis and might cause a reduced Treg cell repertoire and function in the periphery postnatally $(36,37)$. These Treg cells are crucial to control the magnitude of inflammatory responses in several immune-related pathologies (38) and impaired Treg cell homeostasis has been associated with neonatal diseases including bronchopulmonary dysplasia (BPD) and necrotizing enterocolitis (NEC) $(39,40)$.

In conclusion, in chapter 2 we demonstrated that IL-1 $\alpha$-mediated immune responses from mucosal surfaces that interact with pro-inflammatory components from the amniotic fluid can provoke intestinal inflammatory processes. Nevertheless, intestinal immaturity and injury during antenatal inflammation required direct contact of the GI epithelium to IL-1 $\alpha$ (Figure 1). These findings support the concept that management of adverse intestinal effects induced by chorioamnionitis should focus on targeting both intestinal and extraintestinal immune responses. 


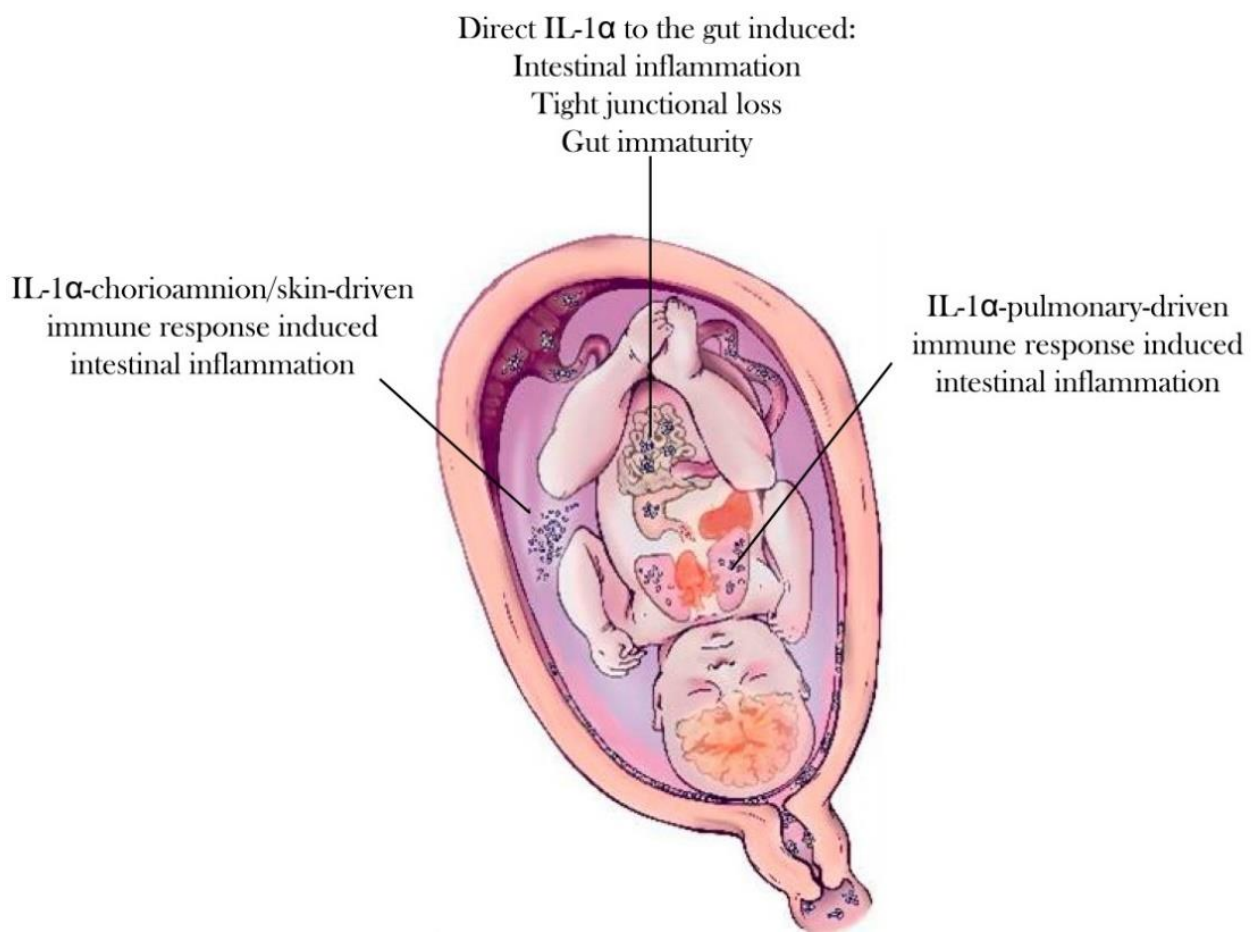

Figure 1. Effects of IL-1 $\alpha$-mediated immune responses on the fetal gut derived from IL-1 $\alpha$ exposure of the fetal gut, lung or chorioamnion/skin. Adapted from Gantert et al (11).

\section{Intestinal Treg/Teff cell balance: a key player in chorioamnionitis}

Based on earlier reports $(14,17)$ and the data described in chapter 2, we evaluated whether prophylactic administration of IL-2 would be protective against antenatal inflammation-induced intestinal injury by preferential expansion of Treg cells. The experiments in chapter 3 showed that intravenous IL-2 administration increased the intestinal Treg cells and restored the regulatory/effector T (Treg/Teff) cell balance which was followed by inhibition of intestinal inflammation and mucosal damage after chorioamnionitis.

Treg cells can suppress Teff cells by several mechanisms of action such as suppression by: i) secretion of inhibitory cytokines (such as IL-10, TGF- $\beta$ ), ii) cytolysis, 
iii) metabolic disruption and iv) modulation of dendritic-cell (DC) maturation or function $(41,42)$. However, it is generally assumed that the wide spectrum of Tregmediated suppression most likely results from the combined action of suppressive mechanisms rather than a single mechanism alone. We found increased IL-10 mRNA levels in the fetal gut after IL-2 administration which suggested that IL-10 is involved in the postulated Treg-mediated immunosuppression. In addition, the increased Treg/Teff cell ratio after prophylactic IL-2 treatment was associated with decreased IL17 mRNA levels. Experiments in a rhesus macaque model of chorioamnionitis have shown that IA exposure to inflammatory agonists altered the Treg/Th17 balance. Whether Th17 cells were responsible for the detected acute increase of IL-17 mRNA levels in the fetal gut and whether Treg cells suppressed this $\mathrm{T}$ cell subset in our model remain to be elucidated.

Targeting Treg cells might be a clinically relevant approach to prevent the adverse outcomes of organs following chorioamnionitis as it has been experimentally shown that IA exposure to inflammatory stimuli provoked a Treg/Teff cell imbalance in several fetal organs including the thymus, spleen, lung and intestine (12). Clinical data from infants diagnosed with chorioamnionitis have shown similar impaired Treg/Teff cell ratio indicated by decreased numbers and/or function of cord blood derived Treg cells $(36,37)$. Furthermore, a decreased Treg/Teff cell ratio has been found in clinical studies where neonates were diagnosed with NEC and BPD postnatally (39, 40).

Besides an increased Treg/Teff cell balance, the data described in chapter 3 suggest that prophylactic IL-2 administration might have prevented intestinal inflammation and injury by additional mechanisms: first, IL-2 can downregulate the expression of the IL-6 receptor and IL-6 signaling (43). IL-6 is associated with epithelial injury and impaired barrier integrity (44). Elevated IL-6 levels might be of clinical importance since increased levels of IL-6 have been detected in gastric aspirates of infants with chorioamnionitis and NEC $(45,46)$. Secondly, IL-2 could have a direct effect on intestinal epithelial cells (47) and third, IL-2 administration might have created an anti-inflammatory environment as evidenced by elevated IL-4 and IL-10 mRNA 
levels in the fetal gut. All these aspects should be further elucidated by several experimental approaches such as an in vitro culture system where the direct effects of IL-2 on fetal intestinal epithelial cells under physiological and/or inflammatory conditions could be assessed. Similarly, a co-culture system of mucosal immune cells of interest and epithelial cells could elucidate whether IL-2 induced an anti-inflammatory response derived from the local mucosal immune cells and whether this antiinflammatory environment was responsible for the preserved epithelial barrier after LPS exposure.

In this study, we were unable to identify the origin of the detected Treg cells in the fetal gut after IL-2 administration. We speculated that IL-2 administration could have resulted in Treg cell activation and migration from circulation, peripheral lymphatic organs and gut-associated lymphoid tissues which could be responsible for the detected Treg cell accumulation in the fetal gut. Therefore, we investigated the Treg cell numbers in the spleen and mesenteric lymph node (MLN). In the MLN, Treg cells can be generated, exert their immunosuppressive properties and travel to the gut lamina propria (48). We found increased Treg cell numbers in the MLN directly at the end of IL-2 administration and increased gut Treg cells at 2 days after IL-2 administration suggesting that MLN might have contributed to Treg homing in the fetal gut. In addition to lymphoid organs, we postulated that Treg cells might have derived from the circulation and/or local expansion of resident Treg cells or differentiation of naïve CD4 $\mathrm{T}$ cells in the fetal gut upon IL-2 administration. These important aspects need to be addressed in future studies by monitoring Treg cells over time with $\mathrm{T}$ cell labeling and trafficking experiments and/or markers to characterize the origin of Treg cells. Additionally, it still remains unknown whether chorioamnionitis-induced Treg/Teff cell imbalance in the fetal gut involves natural Treg (nTreg) or induced Treg (iTreg) cells or both subsets (49). Previous studies in our model revealed that chorioamnionitis induced thymic involution and decreased Treg cells in the thymus, where the nTreg cells are developed. It is tempting to postulate that lower thymic output in the course of chorioamnionitis could have contributed to the detected lower Treg cell numbers in the 
fetal gut $(35,50)$. Therefore, identification of the distinct Treg cell populations and the origin of their low frequency and/or function would provide more insight in the pathophysiology of chorioamnionitis and enable the development of novel $\mathrm{T}$ cell directed therapeutic strategies.

In conclusion, in chapter 3 we showed in a proof of concept study that prophylactic IL-2 treatment preferentially induced Treg cells, which was accompanied by prevention of intestinal inflammation and mucosal injury after IA exposure to LPS (Figure 2). Our findings indicate that expanding Treg cells and improving the intestinal Treg/Teff cell balance could be beneficial in the context of antenatal inflammation.

\section{Intestinal C.albicans invasion and inflammation induced by $C$.albicans-mediated chorioamnionitis}

The most frequently isolated microorganisms from the amniotic cavity of chorioamnionitis affected pregnancies involve bacteria, especially UP species (51). However, IA fungal infection and Calbicans in particular, has been recently identified in clinical cases of chorioamnionitis and is considered highly detrimental for fetal development if left untreated $(52,53)$. In chapter 4 , we evaluated the impact of C.albicans infection during pregnancy on fetal gut physiology. In addition, we tested the potential of in utero fluconazole treatment to ameliorate adverse intestinal effects caused by IA C.albicans infection.

Our findings showed that IA exposure to Calbicans for 3 days resulted in penetration of $C$ albicans hyphae into the gut tissue which was associated with mucosal injury. The time dependent interaction between Calbicans and epithelial cells include adherence, invasion and subsequent epithelial injury (54). Yeasts of C.albicans adhere to epithelial cells and this interaction triggers hyphae formation. Although C.albicans yeasts can be recognized by receptors present at intestinal epithelial cells, they are unable to induce an immune response and cause injury (54). In contrast, C.albicans hyphae as seen in our gut tissue segments are essential for active penetration into or 


\section{Chorioamnionitis \\ Disturbed intestinal $\mathrm{T}$ cell homeostasis}

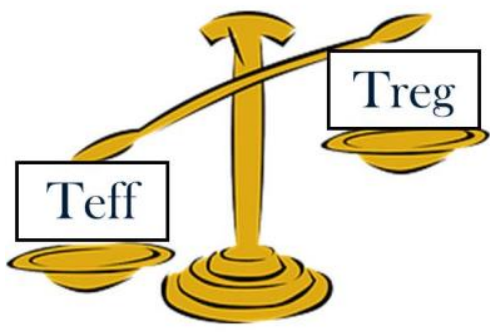

Intestinal inflammation

Mucosal Injury

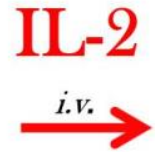

Restored immune homeostasis Prevention of intestinal damage

Figure 2. Schematic representation of the protective effects of intravenous IL-2 administration on the fetal gut against chorioamnionitis-induced intestinal inflammation and injury as discussed in this thesis.

between cells and this invasion is a prerequisite for induction of mucosal injury (55). In addition, our data suggested that penetration of C.albicans could have occurred via M cells as evidenced by the presence of hyphae $C$.albicans within and/or adjacent to Peyer Patches (56). These data provide important clinical insight since Calbicans was able to invade the fetal gut within a short timeframe, thereby provoking severe epithelial injury emphasizing the need for immediate diagnosis and appropriate therapeutic regime in case of C.albicans-mediated chorioamnionitis.

The invasion of C.albicans into the fetal gut after IA C.albicans infection was paralleled by C.albicans dissemination to the fetal bloodstream. This finding has clinical importance since Candidemia caused by intestinal Candidiasis, as in our study, is associated with NEC and in severe cases can lead to neonatal sepsis (57). Nevertheless, we cannot exclude the possibility that Calbicans dissemination to the bloodstream in our model could have resulted through other mucosal surfaces such as the lung. Future in vivo experiments are needed to explore the relative contribution of individual 
epithelial surfaces to fetal candidemia.

Penetration of the fetal intestine by C.albicans at 3 days after fungal exposure was accompanied by increased levels of the pro-inflammatory cytokines TNF- $\alpha$ and IL17. Although we did not identify the exact cell types that were responsible for the increased levels of these cytokines, macrophages and Th17 cells are considered to mediate immune responses against C.albicans infection (54). Detection of increased IL17 levels following C.albicans infection is a double edged sword. On one hand, IL-17 is considered to induce the production of $\beta$-defensins by epithelial cells which provide antifungal activity (58) and on the other hand, elevated levels of IL-17 have been associated with aggravation of C.albicans-induced inflammation and tissue injury (59). Future experiments are needed to unravel the exact role of Th17 pathway in fetal mucosal immunity against IA Calbicans infection.

In this study, we further explored the potential of in utero fluconazole treatment to attenuate the adverse intestinal effects induced by IA C.albicans infection. Intrauterine fluconazole treatment appears to be clinically relevant in chorioamnionitis, as fluconazole treatment reduced the number of fetal deaths (60), prevented systemic inflammation (61) and ameliorated intestinal injury. The latter is causally linked to NEC pathology emphasizing our previous findings which associate antenatal inflammation and postnatal NEC development (3). In addition, although fluconazole treatment was unable to completely eliminate C.albicans infection, C.albicans colonization, epithelial injury and bloodstream infection were attenuated after administration of fluconazole. These findings suggested that alleviation of mucosal injury following fluconazole treatment most likely contributed to the lower rate of Calbicans dissemination to the fetal bloodstream.

In conclusion, in chapter 4 we showed that IA C.albicans infection resulted in gut inflammation and injury. These adverse intestinal effects were accompanied by systemic inflammation and candidemia. Intra-amniotic fluconazole treatment in the same animal model was previously shown to be insufficient to diminish C.albicans from the amniotic fluid and only able to temporarily decrease lung and skin inflammation 
(60). These previous data and the findings described in chapter 4 indicated that fluconazole holds therapeutic promise, but alternative therapeutic strategies should be explored to achieve the maximum therapeutic potential of fluconazole in the context of C.albicans-induced chorioamnionitis.

\section{The impact of fetal hypoxia-ischemia on the fetal gut}

Perinatal HI is a risk factor for intestinal complications due to mesenteric hypoperfusion. The most common GI clinical features associated with perinatal HI include vomiting, altered gut motility, intestinal perforation (62) and NEC (5). Currently, there is limited experimental evidence available to explain the histopathological features of the fetal gut and the postnatal intestinal negative sequelae induced by global HI. In chapter 5, we evaluated the effects of global HI, induced by umbilical cord occlusion (UCO), on the fetal gut. In addition, we assessed the protective effects of intravenous administration of MSCs against HI-induced intestinal injury.

At 7 days after UCO, influx of neutrophils was not accompanied by signs of epithelial injury, which is considered to occur rapidly after intestinal HI (63). We concluded that although the fetal gut was able to recover from epithelial damage within 7 days after umbilical cord occlusion (UCO), the ongoing inflammatory processes most likely contributed to the pathological changes detected after UCO and described in chapter 5. Future studies are needed to establish the exact time-line and dynamics of fetal gut injury and recovery after global HI. Nevertheless, these findings have clinical relevance as the overt infiltration of neutrophils in conjunction with the increased levels of pro-inflammatory cytokines at 7 days after global HI might contribute to loss of paracellular barrier integrity facilitating bacteria translocation from the lumen to the gut tissue after birth (64). These results explain the current feeding guidelines in the clinic where enteral feeding is initiated approximately at 7 days after birth and is gradually advanced in asphyxiated newborns. In addition, the persistent inflammatory processes in combination with structural changes at 7 days after $\mathrm{HI}$ might explain the inability of 
the asphyxiated babies to tolerate full enteral feeds and the clinical experience of one week without enteral feedings.

In addition to mucosal changes, our data demonstrated that intestinal inflammation was associated with structural intestinal changes as shown by the overt muscle thickening after UCO. We speculated that gut inflammation contributed to muscle hyperplasia $(65,66)$. In addition to pro-inflammatory cytokines, secretion of growth factor could be responsible for the detected muscle thickness. In the present study we did not further explore the selective contribution of these factors (cytokines and/or growth factors) which will form the basis for further research. Although alteration of muscle thickness has been linked to several GI diseases in which muscle contractility is impaired, assessment of peristaltic movements of the fetal gut after HI would provide valuable information to better understand the current association between perinatal asphyxia and postnatal intestinal dysmotility.

In addition to muscle layers, intestinal function requires the contribution of the enteric nervous system. Our data demonstrated that global HI induces distortion of enteric glia cells. This finding has clinical importance as a similar pattern of structural changes in enteric glial cells has been observed in NEC infants (67). In addition to structural modifications, we also detected upregulation of synaptophysin and serotonin after HI. These alterations have been associated with intestinal inflammatory diseases and impaired GI motor function (68-70). Although these changes provide strong evidence of a dysregulated enteric network following HI, future studies are warranted to assess fetal intestinal motility after the insult. For this purpose, in vivo evaluation of intestinal motor function postnatally after global HI would link the current findings of gut histopathology with the clinical observations of food intolerance in neonates who suffered from perinatal asphyxia.

In chapter 5 we further tested the potential therapeutic effects of intravenous mesenchymal stem cell (MSC) administration following global HI. We chose to administer MSCs intravenously for the following reasons: first, it has been shown that intravenous administration yields better MSC engraftment in the fetal gut compared to 
intraperitoneal administration (71) and second, intravenous administration of MSCs could have provided beneficial effects in other organs affected by global HI such as the brain. Our results demonstrated that intravenous administration of MSCs did not alleviate the adverse intestinal effects induced by global HI. Interestingly, the same treatment regime was previously shown to protect the fetal ovine brain against global HI-induced structural changes and cerebral dysfunction (72).

In conclusion, in chapter 5 we provided evidence that global HI induces intestinal inflammation which was accompanied by muscle hyperplasia, structural distortion of enteric glial cells and altered neurotransmission. Further studies should optimize a cell-based treatment regime which would collectively protect the fetal brain and gut. Such an approach should consider the timing, dose, frequency and route of MSC administration. 


\section{Implications and future perspectives}

In this thesis we used our translational ovine models to study the mechanisms that underlie the pathological changes of the fetal gut after the onset of chorioamnionitis and fetal HI. In addition, we examined potential therapeutic interventions to prevent the detrimental intestinal effects induced by these pathologies. This acquired knowledge has provided valuable information for our understanding concerning fetal intestinal immune responses and induction of injury, which opens new avenues to treat and/or prevent the inflamed and compromised premature gut.

In this thesis, we demonstrated the protective effects of prophylactic administration of IL-2 against chorioamnionitis-induced adverse intestinal outcomes. The IA microbial infection was simulated by IA administration of E.coli-derived LPS. Although LPS is commonly used to facilitate an inflammatory response through TLR4 activation, does not mimic the variability and adaptability of living bacteria such as UP, which can activate TLR-1, 2 and 6, easily adapt to the environment and can invade the fetal tissues (73-76). Therefore, future research should focus on evaluating the protective effects of such an intervention when chorioamnionitis is induced by living bacteria including UP. In addition, future studies should consider multiple microorganisms in the induction of chorioamnionitis $(77,78)$. The differential interactions between the various microbiomes that colonize the uterine cavity in the course of chorioamnionitis can shape the amniotic environment thereby defining the magnitude of chorioamnionitis-induced adverse intestinal outcomes (79). Nevertheless, we provided evidence that targeting Treg cells can protect the fetal gut in the context of chorioamnionitis. In this study, we decided to augment intestinal Treg cells before the onset of antenatal inflammation. The therapeutic potential of Treg cell enrichment should be evaluated after chorioamnionitis, which more appropriately reflects the clinical scenario. In these experiments, alternative routes of increasing Treg cells should be explored which can include, but not limited to dietary interventions.

We revealed that within 3 days after IA exposure to C.albicans, the fungus invaded the fetal intestine, induced intestinal injury and resulted in blood infection. It 
is conceivable that the virulence of each individual microorganism in combination with duration and timing of fetal exposure to IA infection defines the final intestinal outcome after exposure to antenatal inflammation $(79,80)$. The rapid gut penetration of C.albicans in conjunction with mucosal injury emphasizes the need to discover new biomarkers for chorioamnionitis to enable interference on time, and limit the progression of IA infection. Culture and molecular techniques to identify potential microorganisms in the amniotic fluid during pregnancy would enable diagnosis of chorioamnionitis however, amniocentesis is generally avoided due to risk of abortion. Although there have been some attempts to detect biomarkers specific for chorioamnionitis in the maternal circulation, they have not been proven reliable to be translated into the clinic (81). Recent research, however, has identified increased DNA methylation levels in specific differentially methylated regions in cord blood of neonates that were diagnosed with chorioamnionitis (82). Future experiments are needed to investigate additional fetal epigenetic modifications induced by chorioamnionitis and assess whether these changes could potential be detected in the maternal circulation during pregnancy.

We showed that chorioamnionitis results in intestinal immaturity and mucosal injury, which are both risk factors for postnatal intestinal complications. The immature enterocyte might contain low numbers of nutrient transporters along the villus-crypts axis which can lead to decreased nutrient uptake postnatally (83). The uptake of macromolecules through the epithelial barrier such as immunoglobulins, growth factor and antigens is an essential process during fetal and neonatal intestinal development (83). In addition to impaired gut development, the detected epithelial injury and loss of paracellular integrity after chorioamnionitis might lead to bacterial translocation leading to neonatal sepsis and predisposing the fetus to NEC development $(84,85)$. Nevertheless, how the intestinal inflammatory response to chorioamnionitis contributes to NEC development remains the subject of ongoing research $(86,87)$. It should be stressed that NEC is a multifactorial disease with limited understanding on its etiology (87). Currently, the interaction between nutrition, gut ecology and the intestinal 
inflammatory response to gut microbiota are some factors that are considered to contribute to NEC development $(88,89)$. Future studies are needed to provide mechanistic explanations concerning the relationship between chorioamnionitisinduced intestinal pathological changes in utero and postnatal functional intestinal impairments and/or NEC development. In this experimental setting, tests for intestinal motility and permeability should be implemented to evaluate gut function in premature animals. In addition, stressful stimuli that the preterm neonate is exposed to should be considered. These exposures include antenatal treatments such as maternal corticosteroids, which are commonly given to women who are at high risk to deliver preterm and postnatal exposures such as mechanical ventilation and antibiotics which can influence the fetal inflammatory response to chorioamnionitis $(80,90,91)$.

In conclusion, by using our preclinical animal models of chorioamnionitis and global HI we demonstrated that these prenatal events induce intestinal inflammation in conjunction with mucosal injury and impaired gut and ENS development which can adversely affect the fetal gut postnatally. We have provided evidence of potential interventions to protect the fetal gut against the detrimental intestinal effects associated with antenatal inflammation. The results presented in this thesis facilitate the design of future studies where therapeutic strategies for gut-associated complications after chorioamnionitis and fetal $\mathrm{HI}$ will be tested. This translational research can offer a great opportunity towards improving and/or preventing neonatal morbidity following chorioamnionitis and fetal HI. 


\section{References}

1. Galinsky R, Polglase GR, Hooper SB, Black MJ, Moss TJ. The consequences of chorioamnionitis: preterm birth and effects on development. J Pregnancy. 2013;2013:412831.

2. Cordeiro CN, Tsimis M, Burd I. Infections and Brain Development. Obstet Gynecol Surv. 2015;70:644-655.

3. Been JV, Lievense S, Zimmermann LJ, Kramer BW, Wolfs TG. Chorioamnionitis as a risk factor for necrotizing enterocolitis: a systematic review and meta-analysis. J Pediatr. 2013;162:236-242 e232.

4. Kim CJ, et al. Acute chorioamnionitis and funisitis: definition, pathologic features, and clinical significance. AmJ Obstet Gynecol. 2015;213:S29-52.

5. Watkins DJ, Besner GE. The role of the intestinal microcirculation in necrotizing enterocolitis. Semin Pediatr Surg. 2013;22:83-87.

6. van Schie PE, et al. Long-term motor and behavioral outcome after perinatal hypoxic-ischemic encephalopathy. EurJ Paediatr Neurol. 2015;19:354-359.

7. Massaro AN, et al. Impaired cerebral autoregulation and brain injury in newborns with hypoxic-ischemic encephalopathy treated with hypothermia. $J$ Neurophysiol. 2015;114:818-824.

8. Chhavi N, Zutshi K, Singh NK, Awasthi A, Goel A. Serum liver enzyme pattern in birth asphyxia associated liver injury. Pediatr Gastroenterol Hepatol Nutr. 2014;17:162-169.

9. Jellema RK, et al. Cerebral inflammation and mobilization of the peripheral immune system following global hypoxia-ischemia in preterm sheep. $J$ Neuroinflammation. 2013;10:13.

10. Kramer BW, et al. Modulation of fetal inflammatory response on exposure to lipopolysaccharide by chorioamnion, lung, or gut in sheep. Am J Obstet Gynecol. 2010;202:77 e71-79.

11. Gantert M, et al. Chorioamnionitis: a multiorgan disease of the fetus? $J$ Perinatol. 2010;30 Suppl:S21-30.

12. Kallapur SG, Presicce P, Rueda CM, Jobe AH, Chougnet CA. Fetal immune response to chorioamnionitis. Semin Reprod Med. 2014;32:56-67.

13. Wolfs TG, et al. Chorioamnionitis-induced fetal gut injury is mediated by direct gut exposure of inflammatory mediators or by lung inflammation. Am J Physiol Gastrointest Liver Physiol. 2014;306:G382-393.

14. Wolfs TG, et al. IL-1alpha mediated chorioamnionitis induces depletion of FoxP3+ cells and ileal inflammation in the ovine fetal gut. PLoS One. 2011;6:e18355. 
15. Kallapur SG, et al. Pulmonary and systemic inflammatory responses to intraamniotic IL-1alpha in fetal sheep. AmJ Physiol Lung Cell Mol Physiol. 2011;301:L285295.

16. Berry CA, et al. Interleukin-1 in lipopolysaccharide induced chorioamnionitis in the fetal sheep. Reprod Sci. 2011;18:1092-1102.

17. Wolfs TG, et al. Antenatal ureaplasma infection impairs development of the fetal ovine gut in an IL-1-dependent manner. Mucosal Immunol. 2013;6:547-556.

18. O'Neill LA, Golenbock D, Bowie AG. The history of Toll-like receptors redefining innate immunity. Nat Rev Immunol. 2013;13:453-460.

19. Dinarello CA, Simon A, van der Meer JW. Treating inflammation by blocking interleukin-1 in a broad spectrum of diseases. Nat Rev Drug Discov. 2012;11:633-652. 20. Rodriguez L, Cervantes E, Ortiz R. Malnutrition and gastrointestinal and respiratory infections in children: a public health problem. Int J Environ Res Public Health. 2011;8:1174-1205.

21. Haegebarth A, Clevers H. Wnt signaling, lgr5, and stem cells in the intestine and skin. AmJ Pathol. 2009;174:715-721.

22. Greenow K, Clarke AR. Controlling the stem cell compartment and regeneration in vivo: the role of pluripotency pathways. Physiol Rev. 2012;92:75-99.

23. Kinzel B, et al. Functional roles of Lgr4 and Lgr5 in embryonic gut, kidney and skin development in mice. Dev Biol. 2014;390:181-190.

24. Garcia MI, et al. LGR5 deficiency deregulates Wnt signaling and leads to precocious Paneth cell differentiation in the fetal intestine. Dev Biol. 2009;331:58-67.

25. Jeon MK, Klaus C, Kaemmerer E, Gassler N. Intestinal barrier: Molecular pathways and modifiers. World J Gastrointest Pathophysiol. 2013;4:94-99.

26. Serafino A, et al. WNT-pathway components as predictive markers useful for diagnosis, prevention and therapy in inflammatory bowel disease and sporadic colorectal cancer. Oncotarget. 2014;5:978-992.

27. Buller NV, Rosekrans SL, Westerlund J, van den Brink GR. Hedgehog signaling and maintenance of homeostasis in the intestinal epithelium. Physiology. 2012;27:148-155.

28. Kemp MW, et al. Selective exposure of the fetal lung and skin/amnion (but not gastro-intestinal tract) to LPS elicits acute systemic inflammation in fetal sheep. PLoS One. 2013;8:e63355.

29. Deshmane SL, Kremlev S, Amini S, Sawaya BE. Monocyte chemoattractant protein-1 (MCP-1): an overview. J Interferon Cytokine Res. 2009;29:313-326.

30. Kramer BW, et al. Intra-amniotic LPS modulation of TLR signaling in lung and blood monocytes of fetal sheep. Innate Immun. 2009;15:101-107. 
31. Kim YM, et al. Dermatitis as a component of the fetal inflammatory response syndrome is associated with activation of Toll-like receptors in epidermal keratinocytes. Histopathology. 2006;49:506-514.

32. Kemp MW, et al. Exposure to in utero lipopolysaccharide induces inflammation in the fetal ovine skin. Reprod Sci. 2011;18:88-98.

33. Kemp MW, et al. Inflammation of the fetal ovine skin following in utero exposure to Ureaplasma parvum. Reprod Sci. 2011;18:1128-1137.

34. Kuypers E, et al. Intraamniotic lipopolysaccharide exposure changes cell populations and structure of the ovine fetal thymus. Reprod Sci. 2013;20:946-956.

35. Kuypers E, et al. Ovine fetal thymus response to lipopolysaccharide-induced chorioamnionitis and antenatal corticosteroids. PLoS One. 2012;7:e38257.

36. Luciano AA, et al. Alterations in regulatory $\mathrm{T}$ cell subpopulations seen in preterm infants. PLoS One. 2014;9:e95867.

37. Rueda CM, et al. Effect of chorioamnionitis on regulatory $\mathrm{T}$ cells in moderate/late preterm neonates. Hum Immunol. 2015;76:65-73.

38. Sakaguchi S, Yamaguchi T, Nomura T, Ono M. Regulatory T cells and immune tolerance. Cell. 2008;133:775-787.

39. Weitkamp JH, et al. Necrotising enterocolitis is characterised by disrupted immune regulation and diminished mucosal regulatory (FOXP3)/effector (CD4, CD8) T cell ratios. Gut. 2013;62:73-82.

40. Misra RS, et al. Preterm cord blood CD4(+) T cells exhibit increased IL-6 production in chorioamnionitis and decreased $\mathrm{CD} 4(+) \mathrm{T}$ cells in bronchopulmonary dysplasia. Hum Immunol. 2015;76:329-338.

41. Vignali DA, Collison LW, Workman CJ. How regulatory T cells work. Nat Rev Immunol. 2008;8:523-532.

42. Miyara M, Sakaguchi S. Natural regulatory T cells: mechanisms of suppression. Trends Mol Med. 2007;13:108-116.

43. Zheng SG, Wang J, Horwitz DA. Cutting edge: Foxp3+CD4+CD25+ regulatory $\mathrm{T}$ cells induced by IL-2 and TGF-beta are resistant to Th17 conversion by IL-6. J Immunol. 2008;180:7112-7116.

44. Al-Sadi R, et al. Interleukin-6 modulation of intestinal epithelial tight junction permeability is mediated by JNK pathway activation of claudin-2 gene. PLoS One. 2014;9:e85345.

45. Kim YD, Hyun WY, Cha HJ. Funisitis and raised interleukin 6 concentrations in gastric aspirates at birth. Arch Dis Child Fetal Neonatal Ed. 2005;90:F349-350.

46. Maheshwari A, et al. Cytokines associated with necrotizing enterocolitis in extremely-low-birth-weight infants. Pediatr Res. 2014;76:100-108. 
47. Okazawa A, et al. Human intestinal epithelial cell-derived interleukin (IL)-18, along with IL-2, IL-7 and IL-15, is a potent synergistic factor for the proliferation of intraepithelial lymphocytes. Clin Exp Immunol. 2004;136:269-276.

48. Pabst $\mathrm{O}$. Trafficking of regulatory $\mathrm{T}$ cells in the intestinal immune system. Int Immunol. 2013;25:139-143.

49. Lin $\mathrm{X}$, et al. Advances in distinguishing natural from induced Foxp3(+) regulatory T cells. Int J Clin Exp Pathol. 2013;6:116-123.

50. Kunzmann S, et al. Thymic changes after chorioamnionitis induced by intraamniotic lipopolysaccharide in fetal sheep. Am.J Obstet Gynecol. 2010;202:476 e471-479.

51. Czikk MJ, McCarthy FP, Murphy KE. Chorioamnionitis: from pathogenesis to treatment. Clin Microbiol Infect. 2011;17:1304-1311.

52. Meizoso T, et al. Intrauterine candidiasis: report of four cases. Arch Gynecol Obstet. 2008;278:173-176.

53. Bean LM, Jackson JR, Dobak WJ, Beiswenger TR, Thorp JA. Intra-amniotic fluconazole therapy for Candida albicans intra-amniotic infection. Obstet Gynecol. 2013;121:452-454.

54. Naglik JR, Moyes DL, Wachtler B, Hube B. Candida albicans interactions with epithelial cells and mucosal immunity. Microbes Infect. 2011;13:963-976.

55. Zhu W, Filler SG. Interactions of Candida albicans with epithelial cells. Cell Microbiol. 2010;12:273-282.

56. Albac S, et al. Candida albicans is able to use $\mathrm{M}$ cells as a portal of entry across the intestinal barrier in vitro. Cell Microbiol. 2015

57. Parra-Herran CE, Pelaez L, Sola JE, Urbiztondo AK, Rodriguez MM. Intestinal candidiasis: an uncommon cause of necrotizing enterocolitis (NEC) in neonates. Fetal Pediatr Pathol. 2010;29:172-180.

58. Netea MG, Joosten LA, van der Meer JW, Kullberg BJ, van de Veerdonk FL. Immune defence against Candida fungal infections. Nat Rev Immunol. 2015;15:630642 .

59. Conti HR, Gaffen SL. Host responses to Candida albicans: Th17 cells and mucosal candidiasis. Microbes Infect. 2010;12:518-527.

60. Maneenil G, et al. Fluconazole treatment of intrauterine Candida albicans infection in fetal sheep. Pediatr Res. 2015;77:740-748.

61. Ophelders DR, et al. Neuroinflammation and structural injury of the fetal ovine brain following intra-amniotic Candida albicans exposure. $J$ Neuroinflammation. 2016;13:29. 
62. Nishizaki N, Maiguma A, Obinata K, Okazaki T, Shimizu T. Localized intestinal perforations as a potential complication of brain hypothermic therapy for perinatal asphyxia. J Matern Fetal Neonatal Med. 2015:1-3.

63. Grootjans J, et al. Rapid lamina propria retraction and zipper-like constriction of the epithelium preserves the epithelial lining in human small intestine exposed to ischaemia-reperfusion. J Pathol. 2011;224:411-419.

64. Derikx JP, Luyer MD, Heineman E, Buurman WA. Non-invasive markers of gut wall integrity in health and disease. World J Gastroenterol. 2010;16:5272-5279.

65. Lindestrom LM, Ekblad E. Structural and neuronal changes in rat ileum after ischemia with reperfusion. Dig Dis Sci. 2004;49:1212-1222.

66. Blennerhassett MG, Vignjevic P, Vermillion DL, Collins SM. Inflammation causes hyperplasia and hypertrophy in smooth muscle of rat small intestine. Am J Physiol. 1992;262:G1041-1046.

67. Zhou Y, et al. Enteric nervous system abnormalities are present in human necrotizing enterocolitis: potential neurotransplantation therapy. Stem Cell Res Ther. 2013;4:157.

68. Crowell MD, Shetzline MA, Moses PL, Mawe GM, Talley NJ. Enterochromaffin cells and 5-HT signaling in the pathophysiology of disorders of gastrointestinal function. Curr Opin Investig Drugs. 2004;5:55-60.

69. Dzienis-Koronkiewicz E, Debek W, Chyczewski L. Use of synaptophysin immunohistochemistry in intestinal motility disorders. EurJ Pediatr Surg. 2005;15:392398.

70. Mawe GM, Hoffman JM. Serotonin signalling in the gut--functions, dysfunctions and therapeutic targets. Nat Rev Gastroenterol Hepatol. 2013;10:473-486. 71. Yang J, et al. Heparin-binding epidermal growth factor-like growth factor and mesenchymal stem cells act synergistically to prevent experimental necrotizing enterocolitis. J Am Coll Surg. 2012;215:534-545.

72. Jellema RK, et al. Mesenchymal stem cells induce T-cell tolerance and protect the preterm brain after global hypoxia-ischemia. PLoS One. 2013;8:e73031.

73. Knox CL, et al. The severity of chorioamnionitis in pregnant sheep is associated with in vivo variation of the surface-exposed multiple-banded antigen/gene of Ureaplasma parvum. Biol Reprod. 2010;83:415-426.

74. Dando SJ, et al. The role of the multiple banded antigen of Ureaplasma parvum in intra-amniotic infection: major virulence factor or decoy? PLoS One. 2012;7:e29856.

75. Shimizu T, Kida Y, Kuwano K. Ureaplasma parvum lipoproteins, including MB antigen, activate NF-\{kappa\}B through TLR1, TLR2 and TLR6. Microbiology. 2008;154:1318-1325. 
76. Viscardi RM, et al. Incidence of invasive ureaplasma in VLBW infants: relationship to severe intraventricular hemorrhage. J Perinatol. 2008;28:759-765.

77. DiGiulio DB, et al. Prevalence and diversity of microbes in the amniotic fluid, the fetal inflammatory response, and pregnancy outcome in women with preterm prelabor rupture of membranes. Am J Reprod Immunol. 2010;64:38-57.

78. Jones HE, et al. Differing prevalence and diversity of bacterial species in fetal membranes from very preterm and term labor. PLoS One. 2009;4:e8205.

79. Kemp MW. Preterm birth, intrauterine infection, and fetal inflammation. Front Immunol. 2014;5:574.

80. Jobe AH. Effects of chorioamnionitis on the fetal lung. Clin Perinatol. 2012;39:441-457.

81. Menon R, Taylor RN, Fortunato SJ. Chorioamnionitis--a complex pathophysiologic syndrome. Placenta. 2010;31:113-120.

82. Liu Y, et al. DNA methylation at imprint regulatory regions in preterm birth and infection. AmJ Obstet Gynecol. 2013;208:395 e391-397.

83. Drozdowski LA, Clandinin T, Thomson AB. Ontogeny, growth and development of the small intestine: Understanding pediatric gastroenterology. World J Gastroenterol. 2010;16:787-799.

84. Collado MC, et al. Factors influencing gastrointestinal tract and microbiota immune interaction in preterm infants. Pediatr Res. 2015;77:726-731.

85. Cilieborg MS, Boye M, Sangild PT. Bacterial colonization and gut development in preterm neonates. Early Hum Dev. 2012;88 Suppl 1:S41-49.

86. Derikx JP, Kramer BW, Wolfs TG. Are EGF and TLR-4 crucial to understanding the link between milk and NEC? Mucosal Immunol. 2015;8:979-981.

87. Gephart SM, McGrath JM, Effken JA, Halpern MD. Necrotizing enterocolitis risk: state of the science. Adv Neonatal Care. 2012;12:77-87; quiz 88-79.

88. Neu J. Preterm infant nutrition, gut bacteria, and necrotizing enterocolitis. Curr Opin Clin Nutr Metab Care. 2015;18:285-288.

89. Neu J. Necrotizing enterocolitis: the mystery goes on. Neonatology. 2014;106:289-295.

90. Goldenberg RL, et al. The Alabama preterm birth study: corticosteroids and neonatal outcomes in 23- to 32-week newborns with various markers of intrauterine infection. AmJ Obstet Gynecol. 2006;195:1020-1024.

91. Been JV, Degraeuwe PL, Kramer BW, Zimmermann LJ. Antenatal steroids and neonatal outcome after chorioamnionitis: a meta-analysis. Bjog. 2011;118:113-122. 
General Discussion 



\section{Chapter 7}

\section{Summary - Samenvatting}





\section{Summary}

Chorioamnionitis and fetal hypoxia-ischemia (HI) are two antenatal pathological conditions which are associated with increased risk of postnatal intestinal morbidity. Inflammation is considered as an essential component in the induction of organ injury after chorioamnionitis and fetal HI. Therefore, the studies described in this dissertation aimed to provide insight in the inflammatory responses and subsequent developmental processes in the fetal gut induced by chorioamnionitis or fetal HI. In addition, we focused on exploring potential therapeutic interventions in utero to prevent intestinal inflammation and injury associated with these two pathological conditions. For these purposes, we used the well characterized translational ovine models as the development of the fetal ovine intestine is comparable to human.

In Chapter 2, the relative contribution of selective IL-1 $\alpha$ exposure to fetal mucosal surfaces (i.e. lung, gut and chorioamnion/skin) in the induction of intestinal inflammation and injury were investigated. Previous studies in an ovine model of chorioamnionitis have shown that inhibition of IL-1 signaling largely prevents chorioamnionitis-induced gut inflammation and damage. Nevertheless, the impact of IL-1 $\alpha$-driven immune activation of the gut or extraintestinal tissues on the outcome of the fetal intestine has not been investigated. For this purpose, IL-1 $\alpha$ was selectively infused to different isolated fetal compartments (gut, lung and chorioamnion/skin) and intestinal histological changes were assessed. Our findings showed that intestinal inflammation was provoked by both direct IL-1 $\alpha$ exposure to the intestinal mucosa and indirect IL-1 $\alpha$-mediated immune responses driven by the lung and chorioamnion/skin. In addition, mucosal damage and altered maturation of the fetal gut were exclusively provoked by direct IL- $1 \alpha$ exposure. These results suggest that the local IL-1 $\alpha$-driven intestinal inflammatory response is fundamentally involved in the pathological features of the fetal gut in the context of chorioamnionitis. Since inflammatory changes in the fetal intestine can also be induced upon IL-1 $\alpha$ exposure of the fetal lung and chorioamnion/skin, future therapeutic strategies should focus on targeting both 
intestinal and extraintestinal immune responses to reduce gut morbidity after chorioamnionitis.

In Chapter 3, the potential therapeutic value of intestinal regulatory $\mathrm{T}$ (Treg) cell expansion with the cytokine IL-2 in the context of experimental chorioamnionitis was evaluated. Treg cells are crucial mediators of immune homeostasis in different organs including the intestine. Previous studies have shown that chorioamnionitis decreased the Treg/T effector (Teff) cell balance in the gut, which was accompanied by intestinal inflammation and mucosal injury. Therefore, in chapter 3 it was hypothesized that preferential expansion of Treg cells in the fetal gut by prophylactic IL-2 treatment would prevent the fetus from adverse intestinal outcomes in the course of chorioamnionitis. To test this hypothesis, fetal sheep were intra-amniotically exposed to lipopolysaccharide, with or without prophylactic intravenous IL-2 treatment. We found that systemic IL-2 administration resulted in an improved Treg/Teff cell ratio in the fetal gut. Importantly, when animals received prophylactic IL-2 treatment, chorioamnionitis-induced intestinal inflammation and mucosal damage were prevented. These findings indicate that boosting fetal Treg cells could be beneficial in case of chorioamnionitis-related intestinal complications.

In Chapter 4, the pathological intestinal changes as a consequence of Candida albicans (C.albicans)-mediated chorioamnionitis were studied. Although chorioamnionitis is commonly caused by bacterial infection of the amniotic cavity, fungi including C.albicans are also linked with intrauterine infection. In chapter 4 we also evaluated whether the antifungal drug fluconazole protected the fetal gut after C.albicans-induced chorioamnionitis. To address these issues, intra-amniotic (IA) injections with C.albicans were given to pregnant sheep before preterm delivery. In addition, in utero fluconazole treatment was given 2 days after the IA C.albicans infection. We found that IA C.albicans infection caused intestinal colonization and mucosal invasion with concomitant epithelial damage and inflammation of the fetal gut. Although fluconazole treatment decreased intestinal C.albicans colonization and mucosal injury, anti-fungal treatment did not attenuate intestinal inflammation. These 
data imply that although in utero fluconazole treatment may be a therapeutic strategy in case of Calbicans-mediated chorioamnionitis, more comprehensive treatment strategies which can completely prevent C.albicans-induced intestinal inflammation and injury should be investigated.

In Chapter 5, the pathological changes that occur in the fetal gut after global HI were examined. Similar to chorioamnionitis, global fetal HI is associated with detrimental postnatal intestinal outcomes, with inflammation being a key component involved in the underlying pathology. Since mesenchymal stem cells (MSCs) have been previously used to prevent HI-induced intestinal damage of the adult intestine, we administered MSCs as a potential approach to attenuate the adverse effects on the fetal intestine as a consequence of global HI. To address our aims, fetal sheep were subjected to umbilical cord occlusion (UCO), with or without intravenous MSC treatment. Global $\mathrm{HI}$ induced by UCO, resulted in intestinal inflammation, muscle thickening, distortion of enteric glial cells and altered neurotransmission. A single dose of intravenous MSC treatment at 1 hour after UCO did not ameliorate these HI-induced adverse intestinal consequences. Since the chosen MSC treatment regimen failed to ameliorate these detrimental intestinal effects, future research is needed to reveal a comprehensive cellbased therapy to protect the fetal gut after global HI.

In conclusion, in this dissertation evidence is provided that chorioamnionitis and global fetal $\mathrm{HI}$ induce intestinal inflammation which was associated with epithelial injury and impaired development of the gut and enteric nervous system (ENS). Although in this dissertation the postnatal consequences of these prenatal events were not explored, the reported pathological changes in the fetal gut are linked with neonatal pathologies including necrotizing enterocolitis (NEC). In addition, this thesis tested novel strategies for protecting the fetal gut against the detrimental intestinal consequences associated with antenatal inflammation and global HI. The findings obtained during this $\mathrm{PhD}$ contribute to the development of more comprehensive therapeutic strategies to treat and/or prevent gut-related complications following chorioamnionitis and fetal HI. 


\section{Samenvatting}

Vruchtwater infectie (Chorioamnionitis) en zuurstof tekort (hypoxie-ischemie, HI) rondom de geboorte) zijn twee pathologische condities die geassocieerd zijn met een verhoogd risico op darm ziekten. Bij beide aandoeningen speelt ontsteking een essentiële rol in het veroorzaken van orgaanschade. De studies beschreven in dit proefschrift hebben als doel inzicht te verkrijgen in de inflammatoire en ontwikkelingsreacties van de foetale darm na chorioamnionitis of HI. Daarnaast focust het onderzoek in dit proefschrift op het ontwikkelen van nieuwe therapieën rondom de zwangerschap om deze inflammatie/ontsteking en schade in de darm te voorkomen. Voor dit onderzoek hebben we gebruik gemaakt van een goed gekarakteriseerd translationeel schapenmodel omdat de ontwikkeling van de foetale darm van het schaap zeer vergelijkbaar is met die van de mens.

In hoofdstuk 2, hebben wij de relatieve bijdrage van selectieve IL-1 $\alpha$ blootstelling aan verschillende mucosale foetale weefsels (long, darm en chorionamnion/huid) in relatie tot de inductie van intestinale inflammatie en schade bestudeerd. Eerder onderzoek heeft laten zien dat het remmen van IL-1 grotendeels de nadelige veranderingen in de darm als gevolg van chorioamnionitis voorkomt. Echter, de gevolgen van IL- $1 \alpha$-gemedieerde immuun-activatie van mucosale organen, waaronder de darm, long en huid, voor van de foetale darm was nog nooit eerder onderzocht. Om dit te onderzoeken hebben we verschillende mucosale oppervlakten selectief blootgesteld aan IL-1 $\alpha$ en veranderingen in de darm histologisch geëvalueerd. Onze bevindingen tonen aan dat zowel directe IL-1 $\alpha$ blootstelling, als ook indirecte IL$1 \alpha$ blootstelling via de long en chorionamnion/huid, inflammatie in de darm induceert. Echter, mucosale schade en een verstoorde ontwikkeling van de foetale darm werd alleen waargenomen na directe IL-1 $\alpha$ blootstelling. Deze resultaten suggereren dat de lokale IL-1 $\alpha$ gemedieerde inflammatoire respons fundamenteel betrokken is bij de pathologische veranderingen in de foetale darm in het kader van chorioamnionitis. Gezien het feit dat ontsteking in de foetale darm ook geïnduceerd kan worden via IL- 
$1 \alpha$ blootstelling aan de long en chorioamnion/huid zullen toekomstige therapeutische strategieën zich moeten richten op zowel de intestinale als extra-intestinale immuun reacties om darm-gerelateerde morbiditeit na chorioamnionitis te voorkomen.

In hoofdstuk 3, hebben we in het kader van chorioamnionitis, de therapeutische potentie van het verhogen van het aantal regulatoire $\mathrm{T}$ (Treg) cellen door IL-2 in de foetale darm bestudeerd. Treg cellen zijn belangrijk in het reguleren van immuun homeostase in verschillende organen waaronder de darm. Eerder onderzoek heeft aangetoond dat chorioamnionitis de Treg/T effector (Teff) cel balans in de darm verlaagde, hetgeen gepaard ging met darmontsteking en darmschade. In dit hoofdstuk hebben we onderzocht of verhoging van de Treg/Teff cel balans door het profylactisch toedienen van IL-2 de chorioamnionitis-geïnduceerde pathologische veranderingen in de foetale darm kan voorkomen. In dit onderzoek werd IL-2 (of een zoutoplossing voor controle dieren) intraveneus toegediend aan foetale schapen. Vervolgens werd een intra-uteriene ontstekingsreactie opgewekt door lipopolysaccharide aan het vruchtwater toe te dienen. Intraveneuze IL-2 toediening resulteerde conform onze hypothese in een verbeterde Treg/Teff cel ratio in de foetale darm. De toename van deze Treg/Teff cel ratio ging gepaard met een remming van de ontstekingsreactie in de darm en het remmen/voorkomen van darm schade in chorioamnionitis dieren. Deze bevindingen tonen aan dat het boosten van de foetale Treg cellen therapeutisch zeer interessant is in het kader van chorioamnionitis-geinduceerde darmziekten.

In hoofdstuk 4, hebben we de veranderingen in de foetale darm als gevolg van Calbicans-geïnduceerde chorioamnionitis bestudeerd. Hoewel chorioamnionitis meestal veroorzaakt wordt door een bacteriële infectie van de amnionholte, worden schimmels zoals C.albicans ook geassocieerd met intra-uteriene infecties. Ook hebben we onderzocht of het gebruik van het antimycotisch middel Fluconazol de foetale darm beschermt na C.albicans-geïnduceerde chorioamnionitis. Hiervoor hebben zwangere schapen intra-amniotische injecties met Calbicans gekregen in de aan of afwezigheid van een eenmalige intra-amniotische Fluconazol injectie. Een intra-amniotische C.albicans infectie resulteerde in kolonisatie van deze schimel in de darm die gepaard 
ging met mucosale invasie door Calbicans met epitheliale schade en ontsteking. Dit onderzoek toont aan dat fluconazol behandeling de C.albicans kolonisatie en mucosale schade verminderde, maar intestinale schade werd niet voorkomen. Deze data impliceert dat hoewel in utero fluconazol behandeling een goede behandeling is in het geval van C.albicans-gemedieerde chorioamnionitis. Uitgebreider onderzoek nodig is naar behandelingen die ook de C.albicans-geinduceerde inflammatie en schade van de foetale darm voorkomt.

In hoofdstuk 5, hebben we de pathologische veranderingen die optreden in de foetale darm na globale HI onderzocht. HI wordt net als chorioamnionitis geassocieerd met schadelijke postnatale intestinale gevolgen en ook hier is inflammatie essentieel in de onderliggende pathologische veranderingen. Gelet op het feit dat mesenchymale stam cellen (MSCs) de HI-geïnduceerde darmschade van de volwassen darm voorkomen, hebben we MSCs als mogelijke behandelingsregime gekozen om de nadelige gevolgen van globale $\mathrm{HI}$ op de foetale darm te voorkomen. In dit onderzoek werden foetale schapen blootgesteld aan een tijdelijke navelstrengcompressie en werden de dieren al dan niet behandeld door een intraveneuze toediening van MSCs. Globale HI veroorzaakt door navelstrengcompressie veroorzaakt intestinale inflammatie, verdikking van de spierlagen in de darm, verstoring van enterale gliale cellen en veranderdingen in neurotransmissie. Een eenmalige intraveneuze gift van MSCs 1 uur na navelstrengcompressie had geen effect op deze HI-geïnduceerde nadelige intestinale gevolgen. Gelet op het gebrek aan farmacologische effecten van de MSC behandeling in dit model is er verder onderzoek naar nieuwe (cell-based) behandelingen om de foetale darm te beschermen na globale HI.

Samengevat, in dit proefschrift wordt bewijs geleverd dat chorioamnionitis en globale foetale HI intestinale inflammatie veroorzaken, welke geassocieerd is met epitheliale schade en een verstoorde ontwikkeling van de darm. Hoewel in dit proefschrift de postnatale gevolgen van deze prenatale gebeurtenissen niet werden onderzocht, worden de gerapporteerde pathologische veranderingen in de foetale darm geassocieerd met neonatale aandoeningen zoals necrotizerende enterocolitis (NEC). 
Daarnaast worden nieuwe behandelingsstrategieën getest die de foetale darm beschermen tegen de schadelijke gevolgen ten gevolge van antenatale inflammatie of globale HI. De bevindingen verkregen gedurende dit promotietraject dragen bij aan de ontwikkeling van nieuwe behandelingsstrategieën voor het behandelen en/of voorkomen van darm-gerelateerde complicaties na chorioamnionitis en/of foetale HI. 



\section{Chapter 8}

\section{Valorization}





\section{Valorization}

Preterm birth is the most important cause of neonatal morbidity and mortality in the developed world (1). The WHO estimates that each year, 15 million babies are born premature and approximately one million children die due to complications of prematurity $(1,2)$. For a large proportion of the surviving preterm neonates, there will be a lifetime of adverse health outcomes including respiratory problems, poor nutritional uptake, intestinal dysmotility, learning disabilities, motor and visual impairments (3-5). This indicates an enormous economic and social burden. Medical care costs have reversed relationship with the neonate's gestational age (6). Recently, a report by the Institute of Medicine in the US estimated that the economic burden related to preterm birth was approximately 26.2 billion USD in 2005 ( 51,600 USD per neonate born premature) (7). Around 33,000 USD per preterm neonate were utilized for medical care services, with more than $85 \%$ of those provided between 0 - 5 years of age (7). In Europe, recent evidence from a study in Finland has shown that the standard costs for surviving preterm $(<1000 \mathrm{~g})$ neonates are 100,000 EUR within 2 years whereas for term neonates are $\sim 3,000$ EUR (7). Besides the costs for hospitalization and associated neonatal intensive care for preterm babies, premature birth and related complications constitute additional costs including expenses for special education or costs due to travelling, accommodation, neonatal care (parental time and related lower income from parents' perspective) $(6,7)$. In addition to financial considerations, the birth of a premature infant can affect physical, emotional and social status of the parents and relatives $(6,7)$. In particular, mothers who have given birth to a preterm infant are at high risk of psychological distress, anxiety and depression and thus, they are in need for social support $(7,8)$.

The adverse health effects of a preterm birth can be further intensified by chorioamnionitis and perinatal asphyxia, which constitute independent risk factors for postnatal pathologies $(9,10)$. Chorioamnionitis, defined as inflammation of the fetal membranes, is the most frequent cause of preterm labor. It is estimated that approximately $25 \%$ of the premature infants are born by a mother with 
chorioamnionitis $(11,12)$. This percentage is even higher in lower gestational ages where approximately $60 \%$ of extremely premature ( $<25$ weeks of gestations) births are associated with chorioamnionitis $(13,14)$. Similar to chorioamnionitis, perinatal asphyxia causes fetal inflammation and is a frequent fetal/neonatal medical complication accounting for approximately one million deaths each year $(15,16)$ with an equal amount of survivors who are at high risk to develop lifelong physical and neurological disabilities. Both perinatal pathological conditions affect multiple fetal organs including the gut. The most serious, life threatening postnatal intestinal disease associated with chorioamnionitis is $\operatorname{NEC}(17,18)$. In addition to chorioamnionitis, prematurity is an independent risk factor for NEC as it has been shown that NEC is inversely correlated with gestational age $(19,20)$. Increased incidence of NEC has also been linked to perinatal asphyxia (21). Given the impact of chorioamnionitis and perinatal asphyxia on intestinal functioning, it is crucial to unravel the underlying mechanisms which may explain the correlation between chorioamnionitis/perinatal asphyxia and intestinal pathologies. Therefore, the studies described in this dissertation aimed at characterizing the intestinal pathological changes induced by chorioamnionitis and fetal HI. In addition, we investigated the potential of antenatal therapeutic interventions to prevent intestinal injury caused by these pathological conditions.

The findings in chapter 2 extended our previous knowledge in respect to first, the fundamental role of IL-1 $\alpha$ signaling in chorioamnionitis-induced adverse intestinal effects and second, the relative contribution of selective IL-1 $\alpha$ exposure to fetal mucosal surfaces (i.e. lung, gut and chorioamnion/skin) in the induction of intestinal inflammation and injury in the context of experimental chorioamnionitis. We provided mechanistic evidence that chorioamnionitis-driven intestinal pathological changes primarily require direct IL- $1 \alpha$-mediated intestinal activation. However, extraintestinal IL-1 $\alpha$-driven immune responses (i.e. lung and chorioamnion/skin) also contributed to intestinal inflammation. This increased insight is essential for the design of future immunomodulatory therapeutic strategies where both intestinal and extraintestinal IL$1 \alpha$-driven immune responses will be targeted to protect the fetal gut after antenatal 
inflammation.

Using our preclinical ovine model, we explored the therapeutic potential of systemic administration of IL-2 to prevent chorioamnionitis-induced adverse intestinal outcomes. In chapter 3 , the principal concept was to use the immunomodulatory properties of IL-2 to preferentially expand the Treg cell population which is necessary to control the intestinal immune responses under physiological and pathophysiological conditions. We revealed that IL-2, a drug that is already in clinical use, can be used to prevent chorioamnionitis-driven adverse intestinal outcomes. The application of IL-2 to protect the fetal gut in the context of experimental chorioamnionitis has been filed as a patent in January 2015 (22). This innovative in utero approach to prevent gastrointestinal diseases associated with chorioamnionitis has the potential to be beneficial in numerous neonates who are born with chorioamnionitis each year worldwide. Importantly, in this study prophylactic administration of IL-2 was not correlated with adverse health outcomes of the fetus including immunosuppression and vascular leak syndrome. Considering the current beneficial effects of IL-2 on the fetal gut, additional studies are needed to explore the therapeutic efficiency of IL-2 after the onset of chorioamnionitis.

Before prophylactic IL-2 administration can be translated into the clinic, there are several aspects that should be considered. The results need to be tested and validated under the scope of regulatory affairs. Toxicology testing of IL-2 on fetal tissues should be conducted. All products need to be prepared in good clinical practice (GCP) and standard operating procedures (SOP) need to be developed. The investigational medical product dossier (IMPD) needs to be written and the permission of ethics committee on research involving human subjects needs to be approved. The idea of using IL-2 to prevent gastrointestinal disease caused by chorioamnionitis can be further commercialized by companies which can support and provide services for clinical implementation.

Besides bacteria, fungi including C.albicans have been associated with chorioamnionitis. Therefore, in this dissertation (Chapter 4) we investigated the adverse 
intestinal effects of C.albicans-mediated chorioamnionitis in a translational ovine model. In addition we tested the therapeutic effects of the antifungal fluconazole to protect the fetal gut after C.albicans-induced chorioamnionitis. Our results demonstrated that intra-amniotic C.albicans infection causes intestinal infection, injury and inflammation within a short period of time ( 3 days). These intestinal pathological features were associated with systemic inflammation and candidemia. These findings imply that in case of C.albicans-mediated chorioamnionitis the progression of the infection is rapid indicating that it is of significant importance to early detect and immediately treat the IA fungal infection to reduce morbidity. In this study, the infected animals were treated with fluconazole at a single time point after IA C.albicans infection which although resulted in decreased mucosal injury and mortality, failed to ameliorate C.albicans-mediated mucosal inflammation. This indicates that the applied in utero therapeutic strategy needs to be optimized by considering several aspects including but not limited to the timing, frequency and dosing of the antifungal treatment.

In addition to chorioamnionitis, the present dissertation (Chapter 5) addressed the adverse intestinal outcomes as a consequence of fetal HI. We revealed that global $\mathrm{HI}$ in fetal sheep induced intestinal inflammation which was associated with structural changes and impaired development of the ENS. In addition, we used an innovative approach to test whether the adverse effects of global HI on the fetal gut would be ameliorated by intravenous administration of MSCs. Our findings showed that the detected pathological intestinal features as a consequence of global HI were not attenuated by the chosen therapeutic MSC-based therapeutic strategy. We chose to administer MSC systemically as this remedy was previously shown to protect the fetal brain from inflammation, structural and functional impairment which was associated with reduced mobilization and invasion of $\mathrm{T}$ cells in the preterm brain (23). As this therapeutic strategy provides selective organ protection, additional investigation should focus on a MSC-based therapy which will collectively protect the fetal brain and gut after global HI. These strategies should focus on timing, route and dose of MSC administration. 
The acquired knowledge from the translational studies described in this dissertation are of significant interest not only for researchers but also for clinicians including neonatologists, gynecologists, surgeons, perinatologists and pediatricians who are interested in understanding the basic mechanisms underlying gastrointestinal diseases in the newborn. In addition, this dissertation helps to raise parent's awareness of preterm neonates affected by chorioamnionitis and $\mathrm{HI}$ and their relationship (infantparent interaction). Moreover, the effects of the described innovative in utero therapeutic interventions can form the basis for scientists to investigate their therapeutic potential in depth and develop additional strategies which will collectively reduce fetal organ morbidity after chorioamnionitis and global HI.

In conclusion, the studies described in this dissertation contribute to our understanding concerning the effects of prenatal inflammatory stimuli (such chorioamnionitis and fetal HI) and intestinal complications. In addition, this dissertation presents potential interventions to protect the fetal gut in the context of chorioamnionitis. Nevertheless, additional research is required for clinical implementation and our translational model is suitable to test the efficacy and feasibility of more comprehensive therapeutic strategies to prevent and/or treat gastrointestinal complications after antenatal inflammation. 


\section{References}

1. Blencowe $\mathrm{H}$, Cousens $\mathrm{S}$. Addressing the challenge of neonatal mortality. Trop Med Int Health. 2013;18:303-312.

2. Blencowe $\mathrm{H}$, et al. National, regional, and worldwide estimates of preterm birth rates in the year 2010 with time trends since 1990 for selected countries: a systematic analysis and implications. Lancet. 2012;379:2162-2172.

3. Boyle EM, et al. Effects of gestational age at birth on health outcomes at 3 and 5 years of age: population based cohort study. BMJ. 2012;344:e896.

4. Lee AC, et al. Intrapartum-related neonatal encephalopathy incidence and impairment at regional and global levels for 2010 with trends from 1990. Pediatr Res. 2013;74 Suppl 1:50-72.

5. Moster D, Lie RT, Markestad T. Long-term medical and social consequences of preterm birth. N Engl J Med. 2008;359:262-273.

6. Zupancic JAF. Preterm Birth: Causes, Consequences, and Prevention. A Systematic Review of Costs Associated with Preterm Birth. Behrman RE BA, editor. Washington (DC): National Academies Press (US); 2007.

7. Hodek JM, von der Schulenburg JM, Mittendorf T. Measuring economic consequences of preterm birth - Methodological recommendations for the evaluation of personal burden on children and their caregivers. Health Econ Rev. 2011;1:6.

8. Eutrope J, et al. Emotional reactions of mothers facing premature births: study of 100 mother-infant dyads 32 gestational weeks. PLoS One. 2014;9:e104093.

9. Czikk MJ, McCarthy FP, Murphy KE. Chorioamnionitis: from pathogenesis to treatment. Clin Microbiol Infect. 2011;17:1304-1311.

10. Aslam HM, et al. "Risk factors of birth asphyxia". Ital J Pediatr. 2014;40:94.

11. Romero R, Dey SK, Fisher SJ. Preterm labor: one syndrome, many causes. Science. 2014;345:760-765.

12. Horvath B, Lakatos F, Toth C, Bodecs T, Bodis J. Silent chorioamnionitis and associated pregnancy outcomes: a review of clinical data gathered over a 16 -year period. J Perinat Med. 2014;42:441-447.

13. Romero R, Espinoza J, Chaiworapongsa T, Kalache K. Infection and prematurity and the role of preventive strategies. Semin Neonatol. 2002;7:259-274.

14. Goldenberg RL, Hauth JC, Andrews WW. Intrauterine infection and preterm delivery. N Engl J Med. 2000;342:1500-1507.

15. Black RE, et al. Global, regional, and national causes of child mortality in 2008: a systematic analysis. Lancet. 2010;375:1969-1987.

16. Lawn JE, Kerber K, Enweronu-Laryea C, Cousens S. 3.6 million neonatal deaths--what is progressing and what is not? Semin Perinatol. 2010;34:371-386. 
17. Been JV, Lievense S, Zimmermann LJ, Kramer BW, Wolfs TG. Chorioamnionitis as a risk factor for necrotizing enterocolitis: a systematic review and meta-analysis. J Pediatr. 2013;162:236-242 e232.

18. Coggins SA, Wynn JL, Weitkamp JH. Infectious causes of necrotizing enterocolitis. Clin Perinatol. 2015;42:133-154, ix.

19. Gephart SM, McGrath JM, Effken JA, Halpern MD. Necrotizing enterocolitis risk: state of the science. Adv Neonatal Care. 2012;12:77-87; quiz 88-79.

20. Derikx JP, Kramer BW, Wolfs TG. Are EGF and TLR-4 crucial to understanding the link between milk and NEC? Mucosal Immunol. 2015;8:979-981.

21. Thornton KM, Dai H, Septer S, Petrikin JE. Effects of whole body therapeutic hypothermia on gastrointestinal morbidity and feeding tolerance in infants with hypoxic ischemic encephalopathy. Int J Pediatr. 2014;2014:643689.

22. Tim Guillaume Anna Marie WOLFS BWWK, inventor Method for the treatment or prevention of gastrointestinal disease caused by chorioamnionitis. Universiteit Maastricht, Academisch Ziekenhuis Maastricht, Netherlands2015.

23. Jellema RK, et al. Mesenchymal stem cells induce T-cell tolerance and protect the preterm brain after global hypoxia-ischemia. PLoS One. 2013;8:e73031. 



\section{List of Abbreviations}





\section{Abbreviations}

ANOVA analysis of variance

APC antigen presenting cells

ATP adenosine triphosphate

BPD bronchopulmonary dysplasia

BSA bovine serum albumin

ELISA enzyme-linked immunosorbent assay

ER endoplasmic reticulum

C Celsius

C.albicans Candida Albicans

CCL25 Chemokine (C-C motif) ligand 25

CD cluster of differentiation

cDNA complementary DNA

CFU colony-forming unit

CNS central nervous system

d day (s)

DAMPs damage-associated molecular patterns

DAPI 4',6'-diamino-2-phenyl indole

DC dendritic-cell

DMSO dimethylsulfoxide

DNA deoxyribonucleic acid

ECG electrocardiography

E.coli escherichia coli

EEG electroencephalography

EGF epidermal growth factor

ENS enteric nervous system

EUR euro

FCS fetal calf serum

FIRS fetal inflammatory response syndrome

FITC fluorescein isothiocyanate

Fluc fluconazole

FoxP3 forkhead box P3

FSC forward scatter

Fw forward

GA gestational age

GFAP glial fibrillary acidic protein

GI gastrointestinal 
GCP good clinical practice

H\&E hematoxylin and eosin staining

HELLP Hemolysis, Elevated Liver enzymes, Low Platelet count

HI hypoxia-ischemia

HIE hypoxic-ischemic encephalopathy

HIF hypoxia inducible factor

$\mathrm{H}_{2} \mathrm{O}_{2} \quad$ hydrogen peroxide

Hrs hours

5-HT 5-hydroxytryptamine

IA intra-amniotic

IBD inflammatory bowel disease

I-FABP intestinal fatty acid-binding protein

IFN interferon

IGF insulin-like growth factor

IL interleukin

IL-1RA recombinant IL-1 receptor antagonist

IMPD investigational medical product dossier

Instrum. instrumentation

i.p. intra-peritoneal

IU international units

IUGR intrauterine growth restriction

i.v. intravenous

iTreg induced regulatory $\mathrm{T}$ cell

$\mathrm{kg} \quad$ kilogram

LPS lipopolysaccharide

$\mu \mathrm{g} \quad$ microgram

$\mathrm{mg} / \mathrm{kg} \quad$ milligram/kilogram

MCP monocyte chemoattractant protein

MFI mean fluorescence intensity

MLN mesenteric lymph node

$\mathrm{mL} \quad$ milliliter

MPO myeloperoxidase

mRNA messenger ribonucleic acid

MSCs mesenchymal stem cells

n number

$\mathrm{Na}^{+} / \mathrm{H}+\quad$ sodium/hydrogen

N.D. not detectable

NEC necrotizing enterocolitis 


\begin{tabular}{ll} 
NF-kB & nuclear factor $\kappa$ B \\
NiDAB & nickel sulfate-diaminobenzidine \\
nm & nanometer \\
nTreg & natural regulatory T cell \\
Ocln & snout occlusion \\
PAMPs & pathogen-associated molecular patterns \\
PAS & periodic acid Schiff \\
PBS & phosphate buffer saline \\
PCR & polymerase chain reaction \\
PE & phycoerythrin \\
PGE2 & prostaglandin E2 \\
PP & Peyer Patches \\
PPHN & persistent pulmonary hypertension of the newborn \\
PPROM & preterm premature rupture of the membranes \\
qPCR & quantitative real time polymerase chain reaction \\
RDS & respiratory distress syndrome \\
RNA & ribonucleic acid \\
ROS & reactive oxygen species \\
rRNA & ribosomal RNA \\
Rv & reverse \\
SD s & tandard deviation \\
SEM & standard error of the mean \\
SMA & superior mesenteric artery \\
SOP & standard operating procedure \\
SSC & side scatter \\
TBS & tris buffered saline \\
Teff & effector T cell \\
TGF & tumour growth factor \\
Th & helper T cell \\
TLRs & toll like receptors \\
TNF & tumour necrosis factor \\
Treg & regulatory T cell \\
Tris & tris(hydroxymethyl)aminomethane \\
UCO & umbilical cord occlusion \\
UP & Ureaplasma \\
USD & United States Dollar \\
VEGF & vascular endothelial growth factor \\
WA & Western Australia \\
\hline
\end{tabular}


Appendices

WHO World Health Organization

ZO-1 zonula occludens 1 



\section{Acknowledgements}





\section{Acknowledgements}

Last but certainly not least, I have the opportunity to thank all the people who contributed to the completion of this dissertation. This $\mathrm{PhD}$ thesis would have never been written and published without the support and help of several people who I would like to express my gratitude.

First of all, I would like to express my sincere gratitude to my supervision team Prof. Boris Kramer, Prof. Harry Steinbusch and Dr. Tim Wolfs. Dear Tim, thank you very much for your patience, motivation and criticism. With your continuous enthusiasm and support, I have learned that when you are determined you can overcome all the obstacles and challenges that a PhD project holds. I will always remember your way of creating a positive perspective not only in scientific research but also in daily routine lab/office aspects. I will never forget my broken shoe in Berlin and your problem-solving skills using the poster stickers@.). I know I never practice the Dutch language but Maria in de kantine zegt: ik vind het heel leuk dat je tijdens deze reis aan mijn zijde stond. Dear Boris, thank you very much for giving me the opportunity to start my $\mathrm{PhD}$ under your supervision. Your scientific combined with your clinical expertise helped me to understand what translational research means. You taught me that when you treat a patient you should consider the bigger picture, the complete clinical condition of this patient. This perspective helped me to evolve not only as a scientist but also as a person. Thank you!I would also like to thank Prof. Harry Steinbusch for giving me the opportunity to work at the School of Mental Health and Neuroscience. Dear Harry, I would like to thank you for your interest and trust in this project and for your support and guidance during my $\mathrm{PhD}$ project.

Moreover, I would like to thank the member of the assessment committee and corona, Prof. Dr. Marc H. V. de Baets, Prof. Dr. Paul H. M. Savelkoul, Prof. Dr. Marc E. A. Spaanderman, Prof. Dr. Mathias W. Hornef and Prof. Dr. Aletta D. Kraneveld for reading and evaluating my dissertation.

Of course a big thank you goes to all the people from the Department of Neuroscience for their constant support not only during my PhD but also during my 
Master internship. In particular, I would like to sincerely thank Dr. Danilo Gavilanes, Dr. Eveline Strackx and Dr. Evi Vlassaks for giving me the opportunity to perform my Master internship at their research group. Dear Danilo, thank you for your support and guidance during my master year. Dear Eveline, thank you very much for your enthusiasm, scientific input and enormous help in my first research steps. Dear Evi!!! Thank you sooo much for your guidance, help and advice during my Master. I am really glad that you were my supervisor and I really enjoyed working together even in the weekends $\odot$. I honestly appreciate your trust in me and how you always encouraged me to try things on my own. Your dedication in research inspired me to work hard, follow a $\mathrm{PhD}$ trajectory and try to achieve my goals. I will never forget the long lasting experiments at CPV and of course the night that the "expected" delivery never occurred...we all know why right?:- I am happy that we stayed in contact after all these years and I really hope that we will continue meeting each other in London/Maastricht/Genk/Athens and wherever our lives will take us . $^{\circ}$.

Manty thanks to the multicultural colleagues and friends from Neuroscience with whom I shared some funny moments at various stages of my $\mathrm{PhD}$. Tim, Jochen and Sven, thank you very much for all the support during my research. It was my pleasure to share the lab with you as well as the soccer field. Cheers to all the football evenings $(-)$. How can I forget the crazy travelers, Alejandro, Jo, Chiara and Gerard? $;$. Alejando, thank you so much for being so kind and willing to always help and support with all different kind of interesting "troubles":- I will never forget your positive energy and enthusiasm/eager to explore new places, taste new foods and try new things. It was a pleasure to meet you in this PhD journey. Hasta Luego $(-)$. Chiara, thank you sooo much for your help and advice on GPBP and western blotting, it was a nightmare : I really appreciate and admire your dedication and love on your research. I will always remember our trip to Morocco (including the other crazy travelers) and all funny (not only) moments we shared $\odot$. I love your Italian temperament. Stay tuned $\odot$. Jo, we both started as Master students at neuroscience, continued our PhDs and we almost finished together-). I always admired your independence and dedication to your research from 
this early stage. Thank you so much for all the nice moments we shared not only at work but also when travelling or climbing the volcanos in Sicily. Congratulations on your PhD, Dr. Jo Stevens $\odot$. Gerard, thank you very for your kindness and willingness to help and support me during this journey. It was a pleasure to have you on board:). Congratulations on your PhD, Dr. Gerard Bode-). A big thank you also goes to: Michelle, Kimberly, Annelies, Sara, Jana, Fabien, Pablo, Leonidas, Youssef, Kathleen, Rianne, Ali, Ehsan, Sarah, Ramona, João, Artemis, Sabien, Yara, Julie, Mathias, Ronald and many others who are not included in this list due to my weak memory $\odot$. I would also like to thank the technician's team (Hellen, Denise and Marjan) for their excellent assistance and willingness to always help and provide solutions even in cases of emergencies including broken devices, tubes stuck in centrifuge and stinky trizolcontaminated rooms.

I would like to sincerely thank all my colleagues and friends from the department of Pediatrics whose immense help and support are highly appreciated. The technician's team, Lilian, Nico and Leon thank you very much for your contribution, extreme enthusiasm and motivation on my research. You were always available to help (by any means) with urgent experiments and solve any issues arising in the lab. A huge thank you also for your patience, flexibility and collaboration during the long days at CPV. My roommates and colleagues during various stages of my PhD, Daan, Matthias, Ruth, Monique, Sizzle, Reint, Jennifer, Elke, Alex Jiep and Dennis. I am sincerely grateful that I shared this PhD journey with you. Thank you very much for all the good and bad times that we shared, your support and help in all levels. Reint, I am really grateful for introducing me to the FACS world, hand-made electrodes, the asphyxia animal model and much more-(). Alex, Jiep, Dennis, Jennifer and Elke thanks a lot for your guidance and help throughout my PhD. Monique, thank you so much for all the support and help in all levels! I am really glad that we still work together in a totally different environment and continue to share our daily experiences. Keep calm, your $\mathrm{PhD}$ thesis is almost done-(). Sizzle, congratulations on your $\mathrm{PhD}(-)$. Thank you very much for your inspiring words and optimism. Good luck with finding your next 
passion - . Matthias, Thank you sooo much for all the support and help during my $\mathrm{PhD}$. I could not imagine having better advisor at the LICU@.). It was a pleasure to work with you and I really appreciate your knowledge and expertise in neonatology that you shared during this PhD journey. I will never forget my very first intubation (thanks for teaching me) at the LICU. I truly appreciate your determination, team spirit and hardworking attitude. See you at the double PhD defense!!! Tschuss:-).

Many thanks to my paranymphs, Daan and Ruth!!! Thank you very much for your willingness to stand by me during this one hour of my $\mathrm{PhD}$ defense $\odot$. Daan, I am really grateful for your help, support and advice from my very first steps when I joined the Pediatrics group. I will always remember the first year that we spent at CPV when you introduced me to the sheep world and taught me all different surgical techniques and animal handling. I am really grateful for your team spirit, patience, support and kindness not only during the hard seasons of animal experiments but also throughout this $\mathrm{PhD}$ journey. Of course, I cannot forget the endless coffee breaks and conversations in the $4^{\text {th }}$ floor at $\mathrm{AzM}$, funny moments in the lab/office (it is always Maria's fault(-)) and your love for "Spanakopita". Good luck with finalizing your PhD. Looking forward to your Big Day-). Ruth, thank you sooo much for your willingness to stand next to me at my $\mathrm{PhD}$ defense. I really appreciate your help, team spirit and positive energy! Thank you very much for helping me with the Dutch summary and being there for all emergencies!!! I sincerely admire your determination, energy and craziness!!! Keep going, the $\mathrm{PhD}$ will be finished before you even realize it:). THANK YOU!

I am sincerely grateful to my students who not only supported my research and highly contributed to the publications of this $\mathrm{PhD}$ dissertation but also they taught me lots of interesting things: Anja, Caroline, Mandy, Ilse, Indira, Rick, Esmee and Stefan. THANK YOU@.

I would also like to express my gratitude to Sanne, Petra and Joyce from CPV for their enormous help with animal handling, their excellent assistance with all animal experiments and their patience throughout the long days that we had to spend at CPV 
during the sheep season:-). THANK YOU!

I would also like to thank all the co-authors and collaborators with whom I had the opportunity to share this PhD journey. A huge thank you goes to the colleagues from the Department of Internal Medicine and Transplantation Immunology, Birgit Senden, Dr. Tammy Oth, Dr. Wilfred Germeraad and Dr. Joris Vanderlocht. Dear Birgit and Tammy thank you so much for your help in the FACS experiments. Dear Wilfred and Joris thank you very much for your scientific input, guidance and support. I am also grateful to Dr. Valeria Lima Passos for her enormous help on statistics and to Dr. Monique Engel for her support and guidance.

I am also grateful to the secretaries of Pediatrics, Natascha Vrijhoven, Peggy van den Heuvel, Tamara Cauberg and Anne de Bruijn for their help with all administration work and last moment arrangements. Thank you $(-)$.

Of course a special thank you goes to all my friends who made the $\mathrm{PhD}$ life in Maastricht an amazing experience. Raaaaffa (the copyright holder of Maaaria), Tsilla, Luis, Rita, Nuria and Mo, it was wonderful to have you in Maastricht and experience all these international dinners, birthday parties, carnival nights, trips, Christmas markets, weddings, kart racing and much more with you. Thank you guys, I am grateful to have known you. Bart, Barbara and Riccardo(a), thank you very much for all the funny moments inside and outside the Dutch classes in Lanaken. Bartekje, I truly appreciate your support and optimism. You always see the glass as half-full!!! Cheers to the next bike trip with Baska and the little monkeys@). Dziękuję!!!

A special thank you goes to my lovely Elias and Alexandra for their support and friendship all the years I have known them. I still remember the day I met you Kopelia in the second year of the master and the day you introduced me to Elias. Since then, the master and PhD life got a different flavor. How can I forget the early morning meetings in the railways to go to the University (obviously we were never on time), the countless coffees in almost all cafeterias in Maastricht, the delicious dinners of Elias, all the trips we have shared and much more that I cannot describe here. This PhD journey

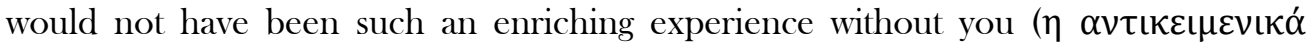




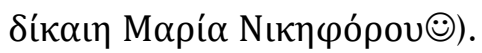

I would also like to thank my friends Eleni and Vasilis for their support and

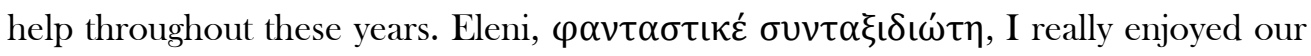
trip to Portugal and I am glad we managed to stay in touch after all these years. Since the $\mathrm{PhD}$ has come to an end, I am finally able to share your crazy travelling schedule $\odot$. Looking forward to the next destination $\odot$. Vasili, I am deeply grateful for your constant help and support since I have known you. I will never forget my first visit in Maastricht (March 2009) when we attended the "Open Dag" at Maastricht University and I had the opportunity to interact with the Master tutors. Your drive, dedication, determination and passion for music certainly inspired me to attain my goals. Looking forward to the next presentatie met Limburgse vlaai! Beste wensen. A!

I am sincerely grateful to my family who supported me during all these years. Without the constant support and guidance of my parents, Elias and Nikoletta, my sister and brother, Dimitra and George, this achievement would not have been possible. I am deeply thankful for their unconditional love and for the values that they instilled in me. I am also blessed for having Aggeliki, Stathis and my little nephews Konstantinos, Elias and bebakos in my life, who supported me (with their unique way) to complete this PhD journey.

Finally, I would like to express my deepest gratitude to my Kostas. A HUGE thank you for your continuous encouragement, support and love. Certainly, there are no words to describe your impact on my life. To be continued...:

$\sum \alpha \varsigma \varepsilon \cup \chi \alpha \rho \iota \sigma \tau \omega ́ !$ 
Acknowledgements 



\section{List of Publications}





\section{Publications}

Intra-amniotic Candida albicans infection induces mucosal injury and inflammation in the ovine fetal intestine. Maria Nikiforou, Esmee M.R. Jacobs, Matthew W. Kemp, Mathias W. Hornef, Matthew S. Payne, Masatoshi Saito, John P. Newnham, Leon E.W. Janssen, Alan H. Jobe, Suhas G. Kallapur, Boris W. Kramer and Tim G.A.M Wolfs.

Sci Rep. 2016Jul 14;6:29806.

Global hypoxia-ischemia induced inflammation and structural changes in the preterm ovine gut which were not ameliorated by mesenchymal stem cell treatment. Maria Nikiforou, Carolin Willburger, Anja E. de Jong, Nico Kloosterboer, Reint K. Jellema, Daan R.M.G. Ophelders, Harry W.M. Steinbusch, Boris W. Kramer and Tim G.A.M. Wolfs.

Mol Med. 2016 Apr 14;22.

Selective IL-1 $\alpha$ exposure to the fetal gut, lung and chorioamnion/skin causes intestinal inflammatory and developmental changes in fetal sheep. Maria Nikiforou, Matthew W. Kemp, Rick H. van Gorp, Saito Masatoshi, John P. Newnham, Niki L. Reynaert, Leon E.W. Janssen, Alan H. Jobe, Suhas G. Kallapur, Boris W. Kramer and Tim G.A.M. Wolfs.

Lab Invest. 2016 Jan;96(1):69-80.

Prophylactic interleukin-2 treatment induces preferential regulatory $\mathbf{T}$ cell expansion and prevents fetal gut inflammation and injury in an ovine model of chorioamnionitis. Maria Nikiforou', Joris Vanderlocht', Claire A. Chougnet, Reint K. Jellema, Daan R.M.G. Ophelders, Mandy Joosten, Nico Kloosterboer, Birgit L.M.G. SendenGijsbers, Wilfred T.V. Germeraad, Boris W. Kramer and Tim G.A.M. Wolfs. Inflamm Bowel Dis. 2015 Sep;21(9):2026-38. "equal contribution. 
Preconditioning by oxygen-glucose deprivation preserves cell proliferation and reduces cytotoxicity in primary astrocyte cultures. Maria Nikiforou ${ }^{*}$, Evi Vlassaks", Eveline Strackx, Boris W. Kramer, Johan S.H. Vles, Antonio W.D. Gavilanes.

CNS Neurol Disord Drug Targets. 2015;14(1):61-7. * equal contribution.

Systemic interleukin-2 administration improves lung function and modulates chorioamnionitis-induced pulmonary inflammation in the ovine fetus. Monique G.M. Willems, Daan R.M.G. Ophelders, Maria Nikiforou, Markus Fehrholz, Steffen Kunzmann, Anke Butz, Leon Janssen, Tammo Delhaas, Boris W. Kramer, Tim G.A.M. Wolfs.

AmJ Physiol Lung Cell Mol Physiol. 2016 Jan 1;310(1):L1-7.

Multipotent adult progenitor cells for hypoxic-ischemic injury in the preterm brain. Reint K. Jellema, Daan R.M.G Ophelders, Alex Zwanenburg, Maria Nikiforou, Tammo Delhaas, Peter Andriessen, Robert W. Mays, Robert Deans, Wilfred T.V. Germeraad, Tim G.A.M. Wolfs, Boris W. Kramer.

J Neuroinflammation. 2015 Dec 23;12:241.

Acute and chronic immunomodulatory changes in rat liver after fetal and perinatal asphyxia. Vlassaks $\mathrm{E}^{*}$, Nikiforou $\boldsymbol{M}^{*}$, Strackx E, Hütten M, Bekers O, Gazzolo D, Li Volti G, Martinez-Martinez P, Kramer BW, Gavilanes AW.

J Dev Orig Health Dis. 2014 Apr;5(2):98-108. *equal contribution.

Nebulization of Poractant alfa via a vibrating membrane nebulizer in spontaneously breathing preterm lambs with binasal continuous positive pressure ventilation. Hutten Matthias, Kuypers Elke, Ophelders Daan, Nikiforou Maria, Jellema RK, Niemarkt H, Fuchs C, Tservistas M, Razetti R, Bianco F, Kramer BW.

Pediatr Res. 2015 Dec;78(6):664-9. 
Fully automated predictive intelligent control of oxygenation (PRICO) in resuscitation and ventilation of preterm lambs. Matthias Hütten, Tom G Goos, Daan Ophelders, Maria Nikiforou, Elke Kuypers, Monique Willems, Hendrik Niemarkt, Jenny Dankelman, Peter Andriessen, Thilo Mohns, Irwin K Reiss, Boris W Kramer. Pediatr Res. 2015 Dec;78(6):657-63.

Effects of less-invasive surfactant administration on oxygenation, pulmonary surfactant distribution, and lung compliance in spontaneously breathing preterm lambs. Niemarkt HJ, Kuypers E, Jellema R, Ophelders D, Hütten M, Nikiforou M, Kribs A, Kramer BW. Pediatr Res. 2014 Aug;76(2):166-70.

Effects of intra-amniotic lipopolysaccharide and maternal betamethasone on brain inflammation in fetal sheep. Kuypers E, Jellema RK, Ophelders DR, Dudink J, Nikiforou M, Wolfs TG, Nitsos I, Pillow JJ, Polglase GR, Kemp MW, Saito M, Newnham JP, Jobe AH, Kallapur SG, Kramer BW.

PLoS One. 2013 Dec 17;8(12):e81644.

Systemic G-CSF attenuates cerebral inflammation and hypomyelination but does not reduce seizure burden in preterm sheep exposed to global hypoxia-ischemia. Jellema RK, Lima Passos V, Ophelders DR, Wolfs TG, Zwanenburg A, De Munter S,

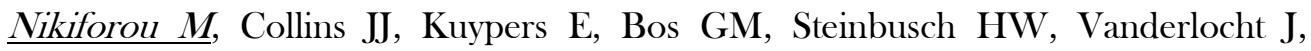
Andriessen P, Germeraad WT, Kramer BW.

Exp Neurol. 2013 Dec;250:293-303.

Fetal asphyxia induces acute and persisting changes in the ceramide metabolism in rat brain. Vlassaks E, Mencarelli C, Nikiforou M, Strackx E, Ferraz MJ, Aerts JM, De Baets MH, Martinez-Martinez P, Gavilanes AW.

J Lipid Res. 2013 Jul;54(7):1825-33. 
Fetal asphyctic preconditioning modulates the acute cytokine response thereby protecting against perinatal asphyxia in neonatal rats. Vlassaks E, Strackx E, Vles JSh, Nikiforou M, Martinez-Martinez P, Kramer BW, Gavilanes AW.

J Neuroinflammation. 2013 Jan 26;10:14.

Massive bleeding treated with fresh frozen plasma and fibrinogen concentrate: a prospective randomized intervention trial. Lance M, D., Ninivaggi M, Schols S E M, Feijge M.A.H., Oehrl S K, Kuiper G J A J M, Nikiforou M, Marcus M A E, Hamulyak K, Cate ten H, Heemskerk J W M.

Vox Sang. 2012 Jul;103(1):25-34.

Short term effects of endotracheally vs. intravenously administered nano-encapsuled, water-soluble vitamin A in preterm lambs: H. B. Wahl, M. C. Hütten, D. Monz, E.Tutdibi, D. R.M.G. Ophelders, M. Nikiforou, L. T. Tschernig, L. Gortner, D. Nohr, H-K. Biesalski, B.W. Kramer.

Submitted. 



\section{Curriculum Vitae}





\section{Curriculum Vitae}

Maria Nikiforou was born on April 24 $4^{\text {th }}, 1985$ in Athens, Greece. In 2003, she started her studies in Biology at the National and Kapodistrian University of Athens. After completion of her Bachelor's degree in 2009, she moved to Maastricht, the Netherlands to pursue a Master's degree in Clinical Molecular Life Sciences. During her senior internship at the School of Mental Health and Neuroscience (MHeNS) and the Department of Pediatrics, she actively worked on two projects entitled "The acute and chronic effects of inflammation in fetal asphyctic preconditioning" and "Preconditioning by oxygen-glucose deprivation preserves cell proliferation and reduces cytotoxicity in primary astrocyte cultures" under the supervision of Dr. Danilo Gavilanes. Her dedication and active involvement on these projects resulted in two first authorships and several co-authorships. In 2011, she graduated as a Master in Clinical Molecular Life Sciences and started to work as research assistant under the supervision of Dr. Tim Wolfs and Prof. Boris W. Kramer at the Department of Pediatrics at Maastricht University. During this year, she was involved in experiments with translational animal models of chorioamnionitis and fetal hypoxia-ischemia. This work and her interest in pre-clinical research resulted in a PhD project which started in 2012 at the MHeNS and the Department of Pediatrics at Maastricht University under the supervision of Dr. Tim Wolfs, Prof. Harry Steinbusch and Prof. Boris W. Kramer. In her $\mathrm{PhD}$ project, she investigated the pathological changes that are provoked by chorioamnionitis and global hypoxia-ischemia on the fetal intestine. In addition, she tested potential new therapeutic strategies to protect the fetal gut against these two prenatal pathological insults. The results obtained during her $\mathrm{PhD}$ project are presented in this dissertation. Since March 2016, she has been working as a Project Coordinator at Medpace Medical Device B.V. in Vaals, the Netherlands. 
